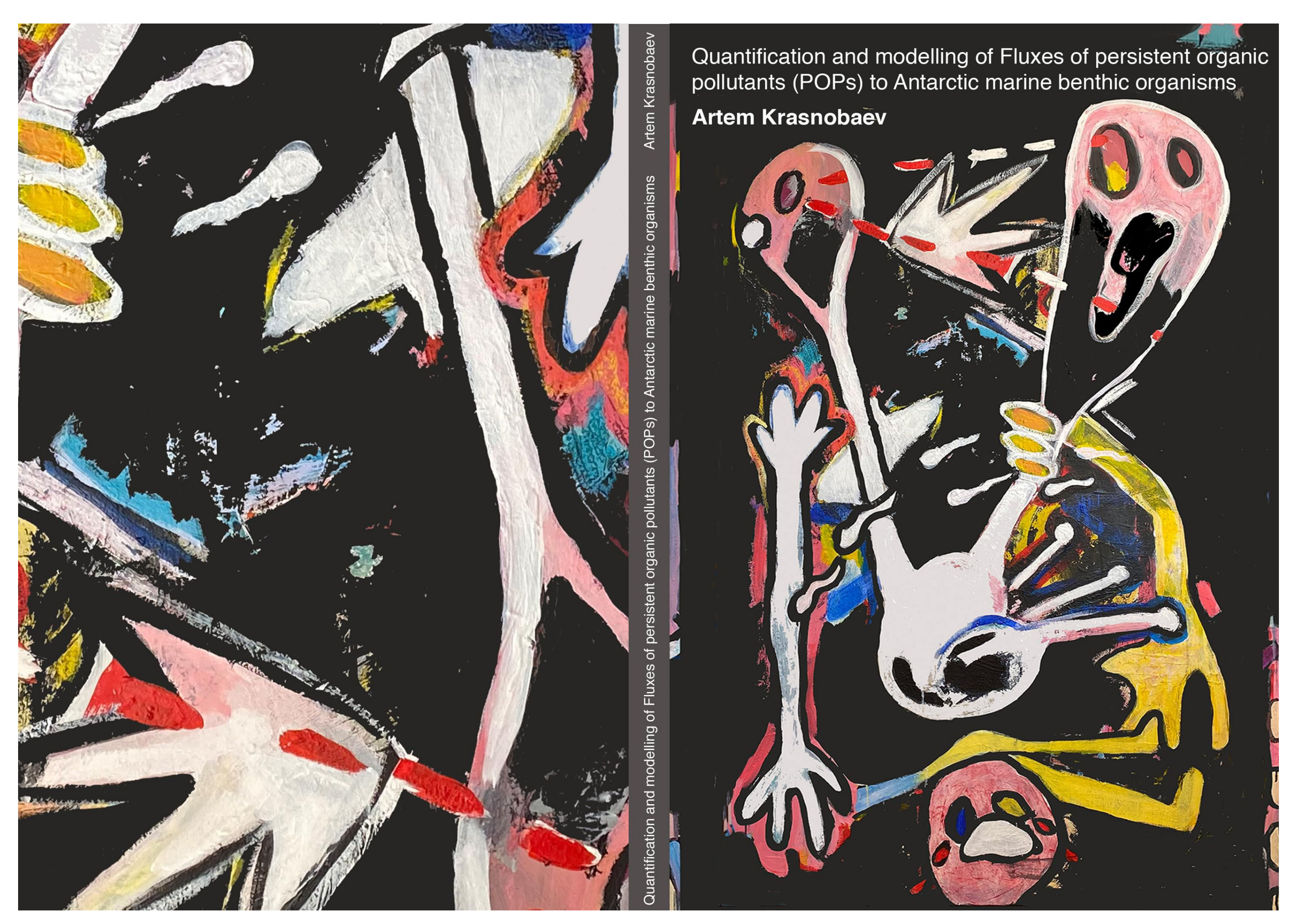




\section{Propositions}

1. Ecotoxicological risks of persistent organic pollutants for the Antarctic marine benthic ecosystems are limited.

(this thesis)

2. Seasonality is an essential factor when establishing long-term temporal trends of concentrations of Persistent Organic Pollutants in the Antarctic ecosystems. (this thesis)

3. Environmental omics must be an integral part of education in environmental sciences.

4. In-silico models should be built based on empirical knowledge and not compete with it.

5. Neither panic nor ignorance, but awareness will help fighting COVID-19.

6. Higher taxing of airplane fuel is essential for controlling climate change.

Propositions belonging to the thesis, entitled

"Quantification and modelling of Fluxes of persistent organic pollutants (POPs) to Antarctic marine benthic organisms (FluxPOPs)".

Artem Krasnobaev

Wageningen, 12 March 2020 


\section{Quantification and modelling of Fluxes of persistent organic pollutants (POPs) to Antarctic marine benthic organisms}




\section{Thesis committee}

\section{Promotor}

Prof. Dr Ivonne M.C.M. Rietjens

Professor of Toxicology

Wageningen University \& Research

\section{Co-promotor}

Dr Nico W. van den Brink

Associate professor, Toxicology

Wageningen University \& Research

\section{Other members}

Prof. Dr Albertinka J. Murk, Wageningen University \& Research

Prof. Dr Jan Hendriks, Radboud University Nijmegen

Prof. Dr Jaco de Boer, Vrije Universiteit Amsterdam

Dr Jan A. van Franeker, Wageningen University \& Research

This research was conducted under the auspices of the Graduate School for Socio-Economic and Natural Sciences of the Environment (SENSE) 


\title{
Quantification and modelling of Fluxes of persistent organic pollutants (POPs) to Antarctic marine benthic organisms
}

\author{
Artem Krasnobaev
}

\section{Thesis}

submitted in fulfilment of the requirements for the degree of doctor

at Wageningen University

by the authority of the Rector Magnificus

Prof. Dr A.P.J. Mol,

in the presence of the

Thesis Committee appointed by the Academic Board

to be defended in public

on Tuesday 16 June 2020

at 4 p.m. in the Aula. 


\section{Artem Krasnobaev}

Quantification and modelling of Fluxes of persistent organic pollutants (POPs) to Antarctic marine benthic organisms,

160 pages.

PhD thesis, Wageningen University, Wageningen, the Netherlands (2020)

With references, with summary in English

ISBN: 978-94-6395-359-7

DOI: https://doi.org/10.18174/518300 


\section{Contents}

$\begin{array}{lll}\text { Chapter } 1 & \text { General introduction } & 7\end{array}$

Chapter 2 Persistent Organic Pollutants in two species of Antarctic migratory flying predatory birds from the Rothera Point

Chapter 3 Seasonal variability in concentrations of Persistent Organic Pollutants in the particulate phase of marine water near Rothera Point, Western Antarctic Peninsula

Chapter 4 Legacy and emerging Persistent Organic Pollutants in Antarctic benthic invertebrates near Rothera Point, Western Antarctic Peninsula

Chapter 5 Effects of exposure of the Antarctic limpet Nacella concinna to Polychlorinated Biphenyls (PCBs)

Chapter 6 General discussion 


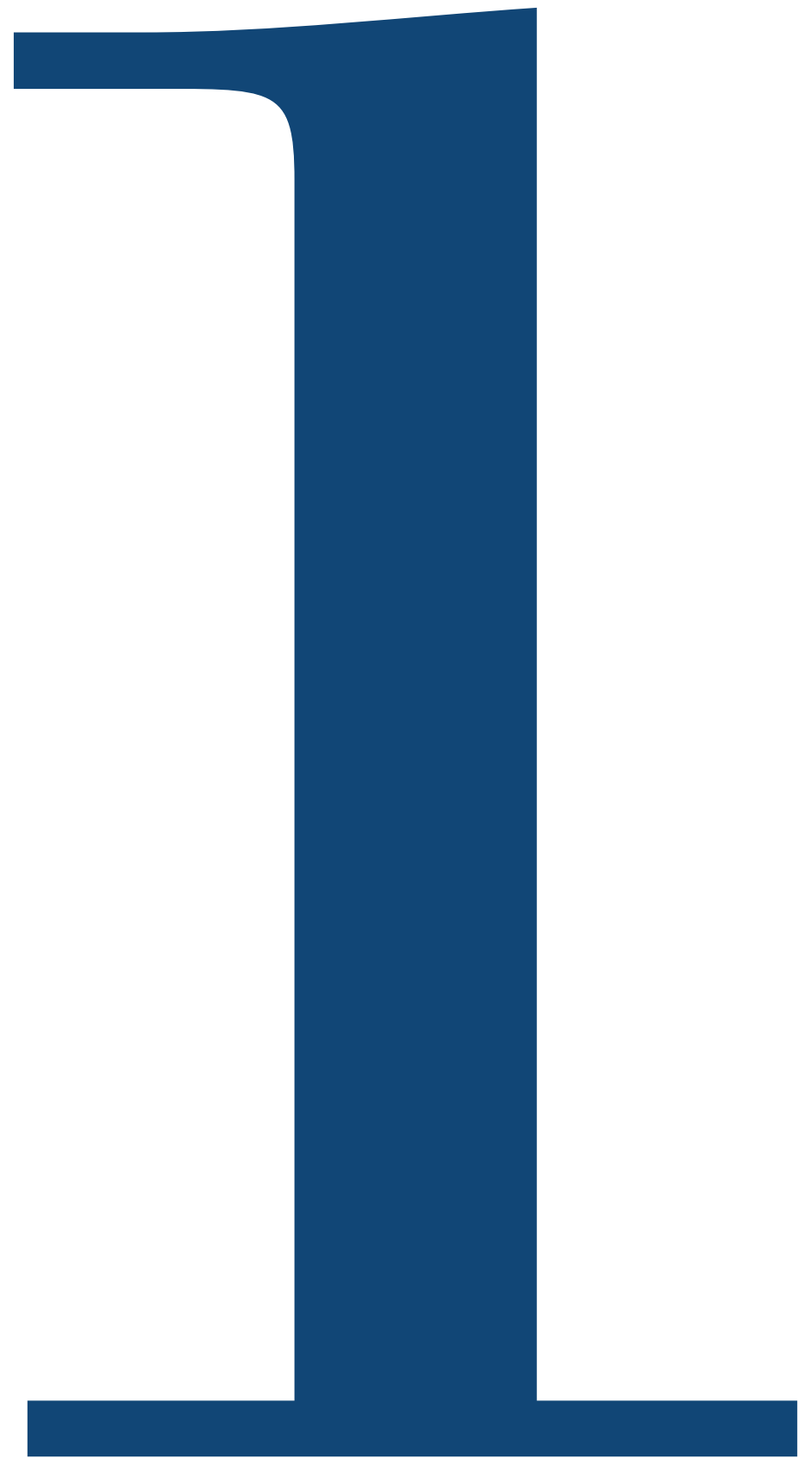




\section{Chapter 1}

General introduction 


\section{GENERAL INTRODUCTION}

Antarctica is the coldest, the driest and the most remote place on the planet. Having been separated from other landmasses for more than 30 million years $^{1}$, it was discovered by humans only in the $18^{\text {th }}$ century ${ }^{2}$. Antarctica boasts no state-like entities, no permanent settlements and the first human birth there happened only in $1978^{2}$. The total population of Antarctica, composed of scientists and tourists, reaches up to 5000 people in summer and even less in winter, making its population density 0.0035 people per square kilometre, which is 140000 times lower than the population density of the Netherlands ${ }^{3}$. Nevertheless, Antarctica experiences an anthropogenic burden, which may endanger its unique pristine ecosystems ${ }^{4}$.

One way of manifestation of this anthropogenic burden is contamination of Antarctic ecosystems with Persistent Organic Pollutants (POPs). POPs are a big group of contaminates, which includes substances like polychlorinated biphenyls (PCBs), polybrominated diphenyl ethers (PBDEs) and organochlorine pesticides (OCPs) ${ }^{5}$. These substances are able to cause considerable harm to reproductive, developmental, behavioural, neurologic, endocrine, and immunologic systems of animals and humans ${ }^{6}$.

Contamination of Antarctica with POPs concerns every type of local ecosystems : terrestrial ${ }^{7}$, pelagic marine ${ }^{8}$ and benthic marine ${ }^{9}$.The reason for contamination by POPs being so extensive lies in their physico-chemical properties. The chemical structure of POPs makes the majority of them remarkably stable, highly non-polar and lipophilic ${ }^{10,11}$. They thus exhibit a high potential for bioaccumulation in organisms and biomagnification in food webs, creating potential risks for animal life ${ }^{12}$. In polar ecosystems the rates of these processes are especially high, because of the constantly high energy demands of local species $^{13}$. For example, polar zooplankton accumulates PCBs on average 10 times more potent than its counterpart from temperate waters ${ }^{14}$.

\section{Transport of POPs to Antarctica}

There are 2 pathways via which POPs can enter the Antarctic environment. The most straightforward one is via direct contamination through navigational, shipping or tourist activities, or activities at research stations ${ }^{4,15-17}$. Some cases of local contamination, such as the pollution of McMurdo sound by logistical actions and waste dumping, caused unprecedented concentrations of POPs in all compartments of the local Antarctic marine ecosystem (e.g. $550 \mathrm{ng} / \mathrm{g}$ lipid weight (lw) in benthic urchin and $1800 \mathrm{ng} / \mathrm{g} \mathrm{lw}$ in pelagic cod $)^{18,19}$. Since then, better understanding and implementation of new protocols and guidelines have led to a successful mitigation of risks associated with direct contamination ${ }^{15,20}$, albeit such events may still occur as results of accidents ${ }^{15,21}$. 
However, a by far more important pathway is the secondary contamination of Antarctic by Long Range Atmospheric Transport (LRAT) of POPs, which occurs due to a biogeochemical process, known as "global distillation" or "grasshopper effect"22,23.

The core concept of this process is that after the initial release of POPs in temperate and tropical regions, the more volatile POPs may enter the gas phase by volatizing from soils, vegetation and bodies of water into the atmosphere. Due to their chemical stability they persist in the atmosphere and may travel long distances with the global atmospheric currents before being re-deposited. This re-deposition happens more at colder locations due to reduced vapor pressure and Henry's law constant when reduction in temperature become large enough. This results in a directed transport of the chemicals from warmer to cooler climates ("cold trap effect"23). Thus, Antarctic air masses serve as excellent enhancers of such re-deposition. Because global distillation is a relatively slow process that relies on successive cycles of evaporation and condensation cycles, it only effects persistent volatile chemicals, normally ones with $\log$ partition coefficients for air/water $>-2$ and octanol/air $<7-$ such as POPs $^{22,23,25,26}$.

Just as all marine ecosystems, the polar ones have been associated with high risks for contamination with POPs ${ }^{27,28}$. Such ecosystems become a sink for POPs firstly due to a lot of precipitation and thus LRAT inputs occurring at the coastal regions of the continent ${ }^{29}$. Secondly this happens due to local biogeochemical processes that enhance the fluxes of POPs in water ${ }^{30}$. Indeed, while dry and wet deposition of POPs with precipitation occurs in other parts of the world, the unique sea-ice regime creates very specific accumulation dynamics of these chemicals. At the beginning POPs become trapped in the forming ice around the continent. Their concentrations are then magnified by their further influx with snow, which deposits over the ice during winter. The melting of the ice in spring leads to a dramatic temporary increase in concentrations of POP. Then subsequent large phytoplankton blooms occur, which are theorised to drive fluxes of POPs towards the bottom of the coastal seas (i.e. benthic parts of the ecosystems). Because concentrations of POPs in the marine ecosystems reflect the prevailing seasonal dynamics of the Antarctic, they are recognised as an important indicator of the general state of environmental burden in the region, and require close research and monitoring ${ }^{31}$.

\section{Temporal trends of POPs in Antaretica}

Generally, the overall trends in POPs contamination of the Antarctic pelagic ecosystems by LRAT mirrors the history of usage and regulation of these chemicals worldwide $e^{4,932,33}$. Having been discovered in 1940s, PCBs and OCPs saw a major increase in production after the second world war. At this time these POPs were started to be universally applied on a large scale mainly in agriculture (pest control) and as industrial mixes (flame retardants, conductors $)^{34,35}$. The first reports of POPs in Antarctic marine ecosystems date back to 
the early 1960s, when DDE was discovered in penguins (93 ng/g lipid weight (lw)) and seals $(20 \mathrm{ng} / \mathrm{g} \mathrm{lw})^{36}$. The first PCBs were discovered there a bit later in 1970, but in higher concentrations ( $373 \mathrm{ng} / \mathrm{g}$ lw in snow petrels $)^{37}$. At the same time, the probable importance of the LRAT was acknowledged and the first concerns over possible future contamination scenarios and their consequences were raised ${ }^{38}$.

After this initial discovery, multiple reports have been conducted over the following decades looking at the POPs contamination in various parts of the polar marine environment, such as fish (notothenia, $200 \mathrm{ng} / \mathrm{g}$ lw of PCB in 1972) ${ }^{39}$, flying birds (giant petrel blubber, 150 $\mathrm{ng} / \mathrm{g}$ lw of DDE in 1974 $4^{40}$ ) and seals (grey seal blubber, $6000 \mathrm{ng} / \mathrm{g} \mathrm{lw}$ of DDT in 1967) (1) $^{41}$ efforts to continuously monitor the contamination. Public attention led to introduction of strict regulations and selective bans on production of POPs, for example the 1972 US ban on DDT production ${ }^{42}$ and the 1979 US ban on PCB production ${ }^{43}$. This started to occur worldwide first on the national (late 1970s) and then on the international levels $\mathrm{s}^{35,44}$. These efforts pinnacled in 2001 by signing the Stockholm convention by the majority of the UN members, which prohibited usage of the most dangerous POPs- the so called "dirty dozen", mainly comprised of PCBs and OCPs, while other POPs (e.g. PBDEs) were added later $\mathrm{on}^{45}$.

Around the 1980s the concentrations of PCBs and OCPs saw their maximum. The highest values discovered for PCBs were $5150 \mathrm{ng} / \mathrm{g} \mathrm{lw}$ in chinstrap penguins in $1978^{46}$, for DDE $468 \mathrm{ng} / \mathrm{g} \mathrm{lw}$ in adelie penguins in $1983^{47}$, and for HCB - $547 \mathrm{ng} / \mathrm{g} \mathrm{lw}$ in adelie penguins in $1983^{47}$. Afterwards, likely due to successful implementation of the regulations, the gradual decline of these compounds started, reaching $21 \mathrm{ng} / \mathrm{g}$ lw for PCBs in chinstrap penguins in 2003/2004 ${ }^{9}$, for DDE - $62 \mathrm{ng} / \mathrm{g} \mathrm{lw}$ in adelie penguins in 2003/2004 ${ }^{9}$ and for HCB - 153 $\mathrm{ng} / \mathrm{g} \mathrm{lw}$ in adelie penguins in 2003/2004'. Similarly the concentrations of POPs in the air declined over the same time period, demonstrating lower LRAT inputs ${ }^{48}$.

Unlike PCBs and OCPs, PBDEs are considered to be a relatively new POPs ${ }^{49}$. They first were detected in the environment in 2000, but their concentration trends even in the Antarctic biota remain uncertain, although they are theorised to follow the ones of PCBs and $\mathrm{OCPs}^{50}$. Such uncertainty and the very fact of their presence in Antarctica signify the necessity of establishing concentrations of existing POPs in Antarctica in light of possibly new emerging chemicals.

However, these trends were observed only for samples collected from organisms feeding on diet items from the pelagic part of the Antarctic marine ecosystems, while the trends in the benthic marine ecosystem remained less straightforward ${ }^{9,51}$. Benthic marine ecosystems are effectively considered to be ultimate sinks of POPs and thus may present an important compartment in characterization of global cycles of pollutants ${ }^{9,31}$. Studies 
indicate that benthic species can be used as indicators of the general environmental health of ecosystems due to their high trophic diversity, relatively long life-span, and sedentary lifestyles of the species ${ }^{52}$. A such, benthic species are wildly employed in polar and subpolar ecosystems as bioindicator of contamination with POPs, both in terms of establishing absolute concentrations of these chemical compounds and in investigation of toxicological stresses ${ }^{53-56}$.

\section{POPs in benthic ecosystems of Antarctica: the unknown}

The benthic ecosystems of Antarctica are extraordinary not only because of their isolation, but also because these Antarctic species often occupy a unique physiological and ecological position, created by the extreme conditions of the continent ${ }^{57,58}$. However, while existing systematic studies on POP levels in benthic ecosystems in the Artic currently report increasing concentrations 59,60 , such trends have not been properly established in the Antartic 9 , as the characterization of POPs in benthic ecosystems in Antarctica has been unsystematic and showing conflicting results ${ }^{31}$.

Researching benthic ecosystems for POPs in Antarctica has always been a very challenging task. The multiple logistical constrains brought by the remoteness and lack of infrastructure increase the costs and practical challenges associated with the field work. The difficult and rapidly changing weather conditions make systematic sampling highly difficult ${ }^{31}$. Moreover, because the concentrations of POPs are quite low in comparison to those found in routinely performed studies in industry and the matrix of samples may have a specific (lipid) composition ${ }^{61}$, analysis of samples becomes a major challenge and requires tailoredmade solutions. Yet, because data are sparse, it is crucial to clearly report all the employed techniques and related measures of quality assurance and control in order to allow for future data comparability ${ }^{31,62,63}$. These difficulties leave a certain number of research questions regarding POPs in benthic ecosystems still unanswered.

First and foremost, it is essential to gain knowledge of major environmental processes that control distribution of POPs, their kinetics and their dependence on the physicochemical properties of these compounds. This is essential to improve the understanding of the mechanisms leading to different time trends in the pelagic and benthic systems of the Antarctic marine environment. The biogeochemical drivers involved in the environmental fate of POPs in Antarctica are complex and very specific for the region ${ }^{64,65}$. First, the atmospheric distribution of POPs is quite special due to extremely cold air masses, which control deposition of POPs with LRAT and thus initial inputs to pelagic and thus benthic ecosystems $s^{48,66}$. Second, the functioning of these marine ecosystems in general is highly unique due to a number of unparalleled environmental features, such as long periods of sea ice cover, high intensity of plankton blooms and a large biomass of benthic ecosystems and characteristics of local biota (e.g. rapid changes in metabolism and lipid content) ${ }^{30,67-69}$. 
Together with more abiotic processes, such as atmosphere-sea water exchange (including sea ice-trapping of contaminants) $)^{70-73}$ and snow amplification ${ }^{74,75}$, they create a complex functioning system of fluxes of POPs. Currently this is less understood and modelled than in temperate climate zones, but even the available information on Antarctica deals chiefly with the pelagic ecosystems ${ }^{31,76}$.

Transparent and high-quality reports on POP concentrations are essential to enhance understanding of global cycles of POPs that can be confidently used in future studies ${ }^{31}$. Moreover, data are needed on a long-term perspective to establish a proposed comprehensive monitoring system. Its purpose would be the discovery of more detailed insights in the local kinetics and environmental fate of POPs, creating compressive time profiles of these compounds. Although such monitoring has been successfully implemented on national and international levels $s^{77,78}$, creating it in Antarctica is a difficult task, not only because of the practical challenges, but also because it would require a major international input. Because the time trends in the concentrations of POPs in pelagic and benthic ecosystems differ, it is crucial to estimate concentrations of POPs in each of them both separately, and as an interconnected environmental entity. In addition, sound estimation of POP levels in the benthic ecosystems would allow for a comprehensive estimation of effectiveness of international protocols ${ }^{77,79}$.

Another research question relates to the lack of knowledge about the possible toxicological effects of POPs specifically on the Antarctic marine life ${ }^{31,67}$. It has been theorized that Antarctic species may be exceptionally vulnerable to POPs because they may be lacking detoxification mechanisms similar to those of temperate and tropical counterparts ${ }^{80}$ and are very susceptible to small variations of surrounding environmental conditions ${ }^{69,81}$. However, till this date toxicological studies on Antarctic (benthic) marine animals have been chiefly limited to the exposure to heavy metals $s^{82-84}$, and only one series of studies was conducted on exposure to POPs, in particular of krill to DDE ${ }^{85-88}$. These studies indicated a slow rate of bioconcentration of DDE and a potential sensitivity of krill to this POP, especially to chronic exposure ${ }^{87,88}$. However, the toxicological response of the short-term exposure was comparable to the one of similar temperate species: Antarctic krill larvae demonstrated an $\mathrm{LC} 100$ of $11 \mathrm{mmol} / \mathrm{kg} \mathrm{lw}^{88}$ with the reference LC100 values for temperate species being $4-40 \mathrm{mmol} / \mathrm{kg} \mathrm{lw}^{89,90}$. Because there have been no further studies on other (benthic) invertebrates or other POPs, toxicological assessment of these compounds in Antarctica gains major importance.

Last but not the least, the effects of the climate change onto the local distribution of POPs in the Antarctic marine ecosystems remain relatively unknown ${ }^{31}$. However, because Antarctica is the region of the world, which experiences climate change the most ${ }^{91}$, climate change will most certainly directly or indirectly affect POPs and their fluxes in the local 
benthic ecosystems ${ }^{92-94}$. Firstly, it may lead to an additional re-release of POPs from melting glaciers $^{95}$, although this is debatable ${ }^{96}$. Secondly, it may alter the biogeochemical processes and thus influence distribution of POPs on a local or even global scale. While the exact effects of the climate change on sea ice dynamics, algal blooms and primary productivity and thus the carbon cycle in the Southern Ocean are not understood completely ${ }^{94}$, it has been theorised that the resulting surge in organic carbon will lead to higher fluxes from the pelagic ecosystems to the benthic ones ${ }^{97}$. Thirdly, increased temperatures in the temperate and tropical areas, where the initial release of POPs takes place, will promote their accessibility to LRAT $^{97}$ and thus intensify their input to Antarctic environment. Likewise, increased temperatures may result in an intensified scavenging of POPs from the atmospheric phase, although this may be balanced by the increased rates of degradation of these compounds ${ }^{98}$. Finally, the increased temperature stresses are likely to lower the toxicological resilience of local species to $\mathrm{POPs}^{94}$, which would endanger existing food webs and ecosystems ${ }^{99}$. All in all, climate change becomes an additional dimension, which increases the complexity of the previously stated research questions.

All in all, we hypothesize that, although low, the concentrations of PCBs, OCPs and PBDEs in the Antarctic benthic ecosystems are increasing, which is in contrast to the Antarctic pelagic ecosystems where concentrations of these compounds experience a decline. Therefore, the aim of this thesis was to establish and to characterize concentrations of multiple POPs (PCBs, OCPs and PBDEs) in the related elements of the pelagic and benthic compartments of Antarctic marine ecosystems and understand the biogeochemical processes that control distribution of POPs over these compartments. As an integral part of this research, toxicological risks on a benthic invertebrate species were investigated through an exposure experiment on living local animals, the first one concerning Antarctic benthic invertebrates. The field phase of the project was conducted at the Rothera research station of the British Antarctic Survey, located on the Adelaide Island near the coast of the Western Antarctic Peninsula (Lat. 67³5'8”S, Long. 68 $7^{\circ}$ '59”W).

\section{Outline of the thesis}

Background information, main hypothesis and an outline of this thesis are provided in the present Chapter 1.

The examination of concentrations of POPs in 2 species of Antarctic birds migrating to the Latin America mainland is described in Chapter 2. The data in this chapter are compared to previous studies estimating POPs in these species and are presented in the light of their ecology. Tthe study adds and compares data to a large (for Antarctic standards) available pool of measurements from previous articles. Based on this, spatio-temporal aspects of the distribution of POPs can be linked to their local dynamics in the Antarctic marine ecosystem. 
The concentrations of POPs in the particle matter of the water of the coastal Antarctic ecosystems is described in chapter 3. While such reports are very scarce in general, this is the first attempt to do so over the course of the whole austral spring and summer. Thus, the seasonal variation of the POP concentrations is closely examined for the first time. Another novelty of this chapter is that the water has been sampled not just at the surface, but also at the depth of 20 meters. The data are put into the context of the long-term oceanographic monitoring programme around Rothera (RATS). This allows for a deeper understanding of the drivers of the seasonal dynamics of POPs in the water, which can be used to forecast potential future trends related to climate change

Chapter $\mathbf{4}$ boasts the first compressive characterization of POPs in Antarctic marine invertebrates. Because invertebrates are considered to be good bioindicators of pollution by POPs, it provides a sound indication of the environmental burden of the Antarctic marine ecosystems. The chapter uses various statistical methods for investigation of synergy between traits (e.g. diets and dermis) of the animals and physico-chemical characteristics of POPs in order to facilitate understanding of patterns in POP concentrations. Additionally, this chapter evaluates possible contamination of the ecosystem by a local source - Rothera research station.

Toxicological effects of PCBs on an Antarctic invertebrate species are examined in chapter 5. This toxicological experiment was conducted with limpets in order to discover if they can be possible markers for exposure to PCBs of the Antarctic marine ecosystems. Both relatively simple analytical approaches (bioassays) and more complex ones (NMR) were employed. The chapter deals with these novel challenges and roadmaps future toxicological research in Antarctica.

Chapter 6 discusses the results of the previous chapters, while also providing future research perspectives. The final chapter, chapter 7 , provides a concluding summary of the results delivered in this thesis. 


\section{REFERENCES}

1. Veevers, J. J. \& McElhinny, M. W. The separation of Australia from other continents. Earth-Science Rev. 12, 139-143 (1976).

2. Martin, S. A history of Antarctica. (Rosenberg Publishing, 2013).

3. 2020 World Population by Country. Available at: http://worldpopulationreview.com/. (Accessed: 15th January 2020)

4. Corsolini, S. Industrial contaminants in Antarctic biota. J. Chromatogr. A 1216, 598-612 (2009).

5. Vallack, H. W. et al. Controlling persistent organic pollutants-what next? Environ. Toxicol. Pharmacol. 6, 143-175 (1998).

6. Noyes, P. D. et al. The toxicology of climate change: Environmental contaminants in a warming world. Environ. Int. 35, 971-986 (2009).

7. Corsolini, S., Baroni, D., Martellini, T., Pala, N. \& Cincinelli, A. PBDEs and PCBs in terrestrial ecosystems of the Victoria Land, Antarctica. Chemosphere 231, 233-239 (2019).

8. Weber, K. \& Goerke, H. Persistent organic pollutants (POPs) in antarctic fish: levels, patterns, changes. Chemosphere 53, 667-678 (2003).

9. van den Brink, N. W., Riddle, M. J., van den Heuvel-Greve, M. \& van Franeker, J. A. Contrasting time trends of organic contaminants in Antarctic pelagic and benthic food webs. Mar. Pollut. Bull. 62, 128-132 (2011).

10. Jones, K. C. \& de Voogt, P. Persistent organic pollutants (POPs): state of the science. Environ. Pollut. 100, 209-221 (1999).

11. Xu, W., Wang, X. \& Cai, Z. Analytical chemistry of the persistent organic pollutants identified in the Stockholm Convention: A review. Anal. Chim. Acta 790, 1-13 (2013).

12. Kelly, B. C., Ikonomou, M. G., Blair, J. D., Morin, A. E. \& Gobas, F. A. P. C. Food Web-Specific Biomagnification of Persistent Organic Pollutants. Science (80-. ). 317, 236-239 (2007).

13. Aaron T. Fisk, ${ }^{*}, \dagger$, Keith A. Hobson, $\ddagger, \$$ and $\&$ Norstrom, R. J. Influence of Chemical and Biological Factors on Trophic Transfer of Persistent Organic Pollutants in the Northwater Polynya Marine Food Web. (2001). doi:10.1021/ES001459W

14. Sobek, A. et al. A comparison of PCB bioaccumulation factors between an arctic and a temperate marine food web. Sci. Total Environ. 408, 2753-2760 (2010).

15. Wild, S. et al. An Antarctic Research Station as a Source of Brominated and Perfluorinated Persistent Organic Pollutants to the Local Environment. Environ. Sci. Technol. 49, 103-112 (2015).

16. Wang, P. et al. PCBs and PBDEs in environmental samples from King George Island and Ardley Island, Antarctica. RSC Adv. 2, 1350-1355 (2012).

17. Enzenbacher, D. J. Antarctic Tourism and Environmental Concerns. Marine Pollution Bulletin 25, (1992).

18. Kennicutt, II, M. C. et al. Human Contamination of the Marine Environment-Arthur Harbor and McMurdo Sound, Antarctica. Environ. Sci. Technol. 29, 1279-1287 (1995).

19. Hale, R. C. et al. Antarctic research bases: Local sources of polybrominated diphenyl ether (PBDE) flame retardants. Environ. Sci. Technol. 42, 1452-1457 (2008).

20. Gröndahl, F., Sidenmark, J. \& Thomsen1, A. Survey of waste water disposal practices at Antarctic research stations. Polar Res. 28, 298-306 (2009).

21. Colabuono, F. I. et al. Persistent organic pollutants and polycyclic aromatic hydrocarbons in mosses after fire at the Brazilian Antarctic Station. Mar. Pollut. Bull. 93, 266-269 (2015).

22. Simonich, S. L. \& Hites, R. A. Global distribution of persistent organochlorine compounds. Science 269, 1851-4 (1995).

23. Schenker, S., Scheringer, M. \& Hungerbühler, K. Do Persistent Organic Pollutants Reach a Thermodynamic Equilibrium in the Global Environment? Environ. Sci. Technol. 48, 5017-5024 (2014).

24. Pechan, P. \& de Vries, G. E. Living with Water. in Living with Water 1-30 (Springer New York, 2013). doi:10.1007/978-1-4614-3752-9_1 
25. Gouin, T., Mackay, D., Jones, K. C., Harner, T. \& Meijer, S. N. Evidence for the "grasshopper" effect and fractionation during long-range atmospheric transport of organic contaminants. Environ. Pollut. 128, 139-148 (2004).

26. Van den Brink, N. W. Directed transport of volatile organochlorine pollutants to polar regions: the effect on the contamination pattern of Antarctic seabirds. Sci. Total Environ. 198, 43-50 (1997).

27. Mckinney, M. A. et al. A review of ecological impacts of global climate change on persistent organic pollutant and mercury pathways and exposures in arctic marine ecosystems. Curr. Zool. 61, 617628 (2015).

28. Dietz, R. et al. Comparison of contaminants from different trophic levels and ecosystems. Sci. Total Environ. 245, 221-231 (2000).

29. Bromwich, D. H. et al. An Assessment of Precipitation Changes over Antarctica and the Southern Ocean since 1989 in Contemporary Global Reanalyses. J. Clim. 24, 4189-4209 (2011).

30. Cropp, R., Kerr, G., Bengtson-Nash, S. \& Hawker, D. A dynamic biophysical fugacity model of the movement of a persistent organic pollutant in Antarctic marine food webs. Environ. Chem. 8, 263 (2011).

31. Bengtson Nash, S. Persistent organic pollutants in Antarctica: current and future research priorities. J. Environ. Monit. 13, 497 (2011).

32. Breivik, K., Sweetman, A., Pacyna, J. M. \& Jones, K. C. Towards a global historical emission inventory for selected PCB congeners--a mass balance approach. 1. Global production and consumption. Sci. Total Environ. 290, 181-98 (2002).

33. de Wit, C. A., Herzke, D. \& Vorkamp, K. Brominated flame retardants in the Arctic environment — trends and new candidates. Sci. Total Environ. 408, 2885-2918 (2010).

34. Listing of POPs in the Stockholm Convention. Available at: http://chm.pops.int/TheConvention/ ThePOPs/AllPOPs/tabid/2509/Default.aspx. (Accessed: 21st December 2017)

35. Porta, M. \& Zumeta, E. Implementing the Stockholm Treaty on Persistent Organic Pollutants. Occup. Environ. Med. 59, 651-2 (2002).

36. SLADEN, W. J. L., MENZIE, C. M. \& REICHEL, W. L. DDT Residues in Adelie Penguins and A Crabeater Seal from Antarctica. Nature 210, 670-673 (1966).

37. Risebrough, R.W., Carmignani, G. M. Chlorinated hydrocarbons in Antarctic birds. Parker, B.C. (Ed.), Proceedings of the colloquium, conservation problems in Antarctica. (1970).

38. Risebrough, R. W., Rieche, P., Peakalll, D. B., Herman, S. G. \& Kirven, M. N. Polychlorinated Biphenyls in the Global Ecosystem. Nature 220, 1098-1102 (1968).

39. Monod, J.-L., Arnaud, P. M. \& Arnoux, A. The level of pollution of Kerguelen islands biota by organochlorine compounds during the seventies. Mar. Pollut. Bull. 24, 626-629 (1992).

40. Conroy, J. W. H. \& French, M. C. Organochlorine levels in two species of Antarctic birds. (1974).

41. HOLDEN, A. V. \& MARSDEN, K. Organochlorine Pesticides in Seals and Porpoises. Nature 216, 1274-1276 (1967).

42. US Center for Disease Control and Prevention. Dichlorodiphenyltrichloroethane (DDT) Factsheet | National Biomonitoring Program | CDC. Available at: https://www.cdc.gov/biomonitoring/ DDT_FactSheet.html. (Accessed: 11th February 2020)

43. US EPA, OA,OEAEE, O. EPA Bans PCB Manufacture.

44. US EPA, O. Persistent Organic Pollutants: A Global Issue, A Global Response.

45. Stockholm Convention \&gt; The Convention \&gt; Overview \&gt; History \&gt; Overview. Available at: http://www.pops.int/TheConvention/Overview/History/Overview/tabid/3549/Default.aspx. (Accessed: 15th January 2020)

46. Lukowski, A., Karolewski, M., Gorski, T. Polychlorinated biphenyls in the tissues of Antarctic marine migratory birds and penguins from the breeding colony on King George Island (South Shetland Islands). Polish Pol. Res. 179-187 (1987).

47. Schneider, R., Steinhagen-Schneider, G. \& Drescher, H. E. Organochlorines and Heavy Metals in Seals and Birds from the Weddell Sea. in Antarctic Nutrient Cycles and Food Webs 652-655 (Springer Berlin Heidelberg, 1985). doi:10.1007/978-3-642-82275-9_90 
48. Pozo, K. et al. Persistent organic pollutants (POPs) in the atmosphere of coastal areas of the Ross Sea, Antarctica: Indications for long-term downward trends. Chemosphere 178, 458-465 (2017).

49. Siddiqi, M. A., Laessig, R. H. \& Reed, K. D. Polybrominated diphenyl ethers (PBDEs): new pollutants-old diseases. Clin. Med. Res. 1, 281-90 (2003).

50. Markham, E. et al. Time Trends of Polybrominated Diphenyl Ethers (PBDEs) in Antarctic Biota. ACS omega 3, 6595-6604 (2018).

51. Goerke, H., Weber, K., Bornemann, H., Ramdohr, S. \& Plötz, J. Increasing levels and biomagnification of persistent organic pollutants (POPs) in Antarctic biota. Mar. Pollut. Bull. 48, 295-302 (2004).

52. Renaud, P. E., Morata, N., Carroll, M. L., Denisenko, S. G. \& Reigstad, M. Pelagic-benthic coupling in the western Barents Sea: Processes and time scales. Deep Sea Res. Part II Top. Stud. Oceanogr. 55, 2372-2380 (2008).

53. Szczybelski, A. S. et al. Bioaccumulation of polycyclic aromatic hydrocarbons, polychlorinated biphenyls and hexachlorobenzene by three Arctic benthic species from Kongsfjorden (Svalbard, Norway). Mar. Pollut. Bull. 112, 65-74 (2016).

54. Camus, L., Birkely, S., Jones, M., ... J. B.-S. of the total \& 2003, undefined. Biomarker responses and PAH uptake in Mya truncata following exposure to oil-contaminated sediment in an Arctic ford (Svalbard). Elsevier

55. Olsen, G., Smit, M., Carroll, J., ... I. J.-M. environmental \& 2011, undefined. Arctic versus temperate comparison of risk assessment metrics for 2-methyl-naphthalene. Elsevier

56. Markert, B. et al. The use of bioindicators for monitoring the heavy-metal status of the environment. J. Radioanal. Nucl. Chem. 240, 425-429 (1999).

57. Clarke, A. Benthic marine habitats in Antarctica. in 123-133 (American Geophysical Union (AGU), 1996). doi:10.1029/AR070p0123

58. Szopińska, M., Namieśnik, J. \& Polkowska, Ż. How Important Is Research on Pollution Levels in Antarctica? Historical Approach, Difficulties and Current Trends. in Reviews of environmental contamination and toxicology 239, 79-156 (2016).

59. Evenset, A. et al. Seasonal variation in accumulation of persistent organic pollutants in an Arctic marine benthic food web. Sci. Total Environ. 542, 108-120 (2016).

60. West, J. E., O'Neill, S. M. \& Ylitalo, G. M. Time Trends of Persistent Organic Pollutants in Benthic and Pelagic Indicator Fishes from Puget Sound, Washington, USA. Arch. Environ. Contam. Toxicol. 73, 207-229 (2017).

61. Perosnal communication with the employees of Wageningen Food Safety Research. (2020).

62. Magi, E. \& Tanwar, S. 'Extreme Mass Spectrometry': the role of mass spectrometry in the study of the Antarctic Environment. J. Mass Spectrom. 49, 1071-1085 (2014).

63. Environmental chemistry in Antarctica: The quest for accuracy. Environ. Contam. Antarct. 1-32 (2001). doi:10.1016/B978-008043199-4/50002-2

64. Cavan, E. L. et al. The importance of Antarctic krill in biogeochemical cycles. Nat. Commun. 10, $4742(2019)$.

65. Henley, S. F. et al. Variability and change in the west Antarctic Peninsula marine system: Research priorities and opportunities. Prog. Oceanogr. 173, 208-237 (2019).

66. Bengtson Nash, S. M. et al. Persistent Organic Pollutants in the East Antarctic Atmosphere: InterAnnual Observations from 2010 to 2015 Using High-Flow-Through Passive Sampling. Environ. Sci. Technol. 51, 13929-13937 (2017).

67. Bargagli, R. Environmental contamination in Antarctic ecosystems. Sci. Total Environ. 400, 212 226 (2008).

68. Bates, M. L., Bengtson Nash, S. M., Hawker, D. W., Shaw, E. C. \& Cropp, R. A. The distribution of persistent organic pollutants in a trophically complex Antarctic ecosystem model. J. Mar. Syst. 170, 103-114 (2017).

69. Peck, L. Antarctic marine biodiversity: adaptations, environments and responses to change. Oceanogr. Mar. Biol. An Annu. Rev. 56, (2018). 
70. Bigot, M. et al. Air-Seawater Exchange of Organochlorine Pesticides in the Southern Ocean between Australia and Antarctica. Environ. Sci. Technol. 50, 8001-8009 (2016).

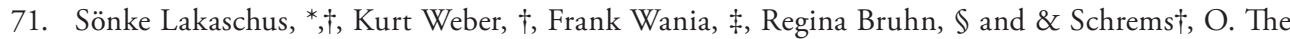
Air-Sea Equilibrium and Time Trend of Hexachlorocyclohexanes in the Atlantic Ocean between the Arctic and Antarctica. (2001). doi:10.1021/ES010211J

72. Wang, P. et al. Three-year monitoring of atmospheric PCBs and PBDEs at the Chinese Great Wall Station, West Antarctica: Levels, chiral signature, environmental behaviors and source implication. Atmos. Environ. 150, 407-416 (2017).

73. Cao, S. et al. Fate and deposition of polycyclic aromatic hydrocarbons in the Bransfield Strait, Antarctica. Mar. Pollut. Bull. (2018). doi:10.1016/j.marpolbul.2018.10.045

74. Casal, P. et al. Snow Amplification of Persistent Organic Pollutants at Coastal Antarctica. Environ. Sci. Technol. acs.est.9b03006 (2019). doi:10.1021/acs.est.9b03006

75. Bigot, M. et al. Spring Melt and the Redistribution of Organochlorine Pesticides in the Sea-Ice Environment: A Comparative Study between Arctic and Antarctic Regions. Environ. Sci. Technol. 51, 8944-8952 (2017).

76. Bates, M. L. et al. On the formulation of environmental fugacity models and their numerical solutions. Environ. Toxicol. Chem. 35, 2182-2191 (2016).

77. Overview - Global Monitoring Plan. Available at: http://www.pops.int/Implementation/ GlobalMonitoringPlan/Overview/tabid/83/Default.aspx. (Accessed: 15th January 2020)

78. Environmental country reviews - OECD. Available at: http://www.oecd.org/env/country-reviews/. (Accessed: 15th January 2020)

79. Kallenborn, R. et al. Long-term monitoring of persistent organic pollutants (POPs) at the Norwegian Troll station in Dronning Maud Land, Antarctica. Atmos. Chem. Phys. 13, 6983-6992 (2013).

80. Renzi, M. Perfluorinated Organic Compounds and Polybrominated Diphenyl Ethers Compounds - Levels and Toxicity in Aquatic Environments: A Review. in Organic Pollutants - Monitoring, Risk and Treatment (InTech, 2013). doi:10.5772/53835

81. Fraser, K., Clarke, A. \& Peck, L. Feast and famine in Antarctica: seasonal physiology in the limpet Nacella concinna. Mar. Ecol. Prog. Ser. 242, 169-177 (2002).

82. Duquesne, Riddle, Schulz \& Liess. Effects of contaminants in the Antarctic environment - potential of the gammarid amphipod crustacean Paramorea walkeri as a biological indicator for Antarctic ecosystems based on toxicity and bioacccumulation of copper and cadmium. Aquat. Toxicol. 49, 131-143 (2000).

83. Chapman, P. M. \& Riddle, M. J. Toxic Effects of Contaminants in Polar Marine Environments. Environ. Sci. Technol. 39, 200A-206A (2005).

84. King, C. \& Riddle, M. Effects of metal contaminants on the development of the common Antarctic sea urchin Sterechinus neumayeri and comparisons of sensitivity with tropical and temperate echinoids. Mar. Ecol. Prog. Ser. 215, 143-154 (2001).

85. Poulsen, A. H., Kawaguchi, S., King, C. K., King, R. A. \& Bengtson Nash, S. M. Behavioural sensitivity of a key Southern Ocean species (Antarctic krill, Euphausia superba) to p,p'-DDE exposure. Ecotoxicol. Environ. Saf. 75, 163-170 (2012).

86. Poulsen, A. H., Kawaguchi, S., Kukkonen, J. V. K., Leppänen, M. T. \& Bengtson Nash, S. M. Aqueous uptake and sublethal toxicity of p,p'-DDE in non-feeding larval stages of Antarctic krill (Euphausia superba). Environ. Pollut. 160, 185-191 (2012).

87. Poulsen, A. H., Kawaguchi, S., Leppänen, M. T., Kukkonen, J. V. K. \& Bengtson Nash, S. M. Altered developmental timing in early life stages of Antarctic krill (Euphausia superba) exposed to p,p'-DDE. Sci. Total Environ. 409, 5268-5276 (2011).

88. Poulsen, A. H., Landrum, P. F., Kawaguchi, S. \& Bengtson Nash, S. M. Dietary exposure of Antarctic krill to p,p'-DDE: Uptake kinetics and toxicological sensitivity in a key polar species. Environ. Pollut. 175, 92-99 (2013).

89. McCarty, L. S. \& Mackay, D. Enhancing ecotoxicological modeling and assessment. Body Residues and Modes Of Toxic Action. Environ. Sci. Technol. 27, 1718-1728 (1993). 
90. Wezel, A. P. van \& Opperhuizen, A. Narcosis Due to Environmental Pollutants in Aquatic Organisms: Residue-Based Toxicity, Mechanisms, and Membrane Burdens. Crit. Rev. Toxicol. 25, 255-279 (1995).

91. Rogers, A. D. et al. Antarctic Futures: An Assessment of Climate-Driven Changes in Ecosystem Structure, Function, and Service Provisioning in the Southern Ocean. Ann. Rev. Mar. Sci. 12, 87-120 (2020).

92. Sahade, R. et al. Climate change and glacier retreat drive shifts in an Antarctic benthic ecosystem. Sci. Adv. 1, e1500050 (2015).

93. Ingels, J. et al. Possible effects of global environmental changes on Antarctic benthos: a synthesis across five major taxa. Ecol. Evol. 2, 453-85 (2012).

94. Barnes, D., Griffiths, H. \& Kaiser, S. Geographic range shift responses to climate change by Antarctic benthos: where we should look. Mar. Ecol. Prog. Ser. 393, 13-26 (2009).

95. Geisz, H. N., Dickhut, R. M., Cochran, M. A., Fraser, W. R. \& Ducklow, H. W. Melting Glaciers: A Probable Source of DDT to the Antarctic Marine Ecosystem. Environ. Sci. Technol. 42, 39583962 (2008).

96. Brink, N. van den et al. Correspondence on Geisz et al. Melting Glaciers: A Probable Source of DDT to the Antarctic Marine Ecosystem. Environ. Sci. Technol. 43, 3976-3977 (2009).

97. Dalla Valle, M., Codato, E. \& Marcomini, A. Climate change influence on POPs distribution and fate: A case study. Chemosphere 67, 1287-1295 (2007).

98. Frank Wania, *, $\dagger$, Donald Mackay, $\ddagger$ and \& HoffS, J. T. The Importance of Snow Scavenging of Polychlorinated Biphenyl and Polycyclic Aromatic Hydrocarbon Vapors. (1998). doi:10.1021/ ES980806N

99. Post, E. et al. Ecological dynamics across the Arctic associated with recent climate change. Science 325, 1355-8 (2009). 


$$
2
$$




\title{
Chapter 2
}

\section{Persistent Organic Pollutants in two species of Antarctic migratory flying predatory birds from the Rothera Point}

Artem Krasnobaev, Guillaume ten Dam, Stefan P.J. van Leeuwen, Lloyd S. Peck, Nico W. van den Brink.

\author{
Published in:
}

Mar Pollut Bull. 2018 Dec;137:113-118 


\section{ABSTRACT}

Carcasses of South polar skuas (Catharacta maccormicki) and kelp gulls (Larus dominicanus) were opportunistically collected in the vicinity of Rothera Research station $\left(67^{\circ} 35^{\prime} 8^{\prime \prime} \mathrm{S}\right.$ and $68^{\circ} 7^{\prime} 59^{\prime \prime W}$ ) during the 2016/2017 austral summer. Samples of their tissues (muscle, liver and subcutaneous fat) were analysed for persistent organic pollutants (POPs) to assess their current burden in the two species. Organochlorine pesticides (OCPs) showed the highest concentrations, notably for pp'-DDE (2-62 $\mu \mathrm{g} / \mathrm{g} \mathrm{lw})$ and $\mathrm{HCB}(0.1-3.2 \mu \mathrm{g} / \mathrm{g} / \mathrm{w})$. The Polychlorinated biphenyls (PCBs)-profiles demonstrated a clear dominance of hexa- and hepta-CBs, while concentrations of polybrominated diphenyl ethers (PBDEs) remained relatively low. The levels of some POPs (e.g. HCB) were lower than in past studies on similar species, however others were within the previous range (PCBs) or even higher than previous reported values (DDE, $\mathrm{HCH})$. This may imply continuous accumulation of the latter in the Antarctic and South American environments. Although no major interspecific differences in the absolute levels of POPs were detected, their profiles varied, being likely related to specific feeding and migration patterns of each species. The current study provides important baseline data for future monitoring of POPs in Antarctica. 


\section{INTRODUCTION}

Persistent Organic Pollutants (POPs) encompass a group of contaminates including polychlorinated biphenyls (PCBs), polybrominated diphenyl ethers (PBDEs) and organochlorine pesticides (OCPs) ${ }^{1}$. POPs have been demonstrated to potentially affect reproductive, developmental, neurologic, endocrine, and immunologic systems of animals and humans ${ }^{2}$. Despite these risks being known since the 1960s, only in 2001 international agreement was achieved on the ban, restricted use or reduction of hazardous POPs by the Stockholm convention ${ }^{3,4}$. POPs are known to accumulate in multiple compartments of ecosystems all around the world ${ }^{1,4}$. Even the remote continent of Antarctica has been established as an environmental sink for POPs ${ }^{5,6}$. Because of a unique combination of relative volatility and environmental persistence some POPs are able to reach the Antarctic continent via long-range atmospheric transport process and the cold condenser effect ${ }^{7}$. Therefore more volatile POPs can reach high concentrations in Antarctic apex predators, including marine birds ${ }^{8}$. In addition, the birds also migrating North of the Antarctic convergence are exposed to relatively higher amounts of other POPs in their wintering grounds ${ }^{9-11}$. In this manner birds that migrate into and out of Antarctica may be exposed to a wide spectrum of POPs, with both Antarctic as well as more Northerly signatures ${ }^{12}$. This has been shown for Skua (Stercorarius maccormicki) ${ }^{8,13-17}$ However, little information is available on the exposure of related migrating species, one of them being the Kelp gull (Larus dominicanus).

South polar skuas (Catharacta maccormicki) and kelp gulls (Larus dominicanus) are two species of migratory seabirds that nest around the whole Antarctic continent, including the Western Antarctic Peninsula during austral summer. The south polar skua (widely hybridised with the brown skua - Stercorarius antarcticus ${ }^{18}$ ) may be found almost everywhere around Antarctica, but in the same time can commence a trans-equatorial migration when foraging ${ }^{19,20}$. The exact patterns of its migration have been investigated in detail ${ }^{21}$. Kelp gulls are less inclined towards very long haul migration than skuas, but can move all around the Sub-Antarctic islands and South America ${ }^{22,23}$. These reports indicate that Skuas and kelp gulls demonstrate consistent migration patterns on both populational and individual scales ${ }^{24}$. They have both been shown to be highly affected by global climate change ${ }^{25}$, and established migration routes are therefore likely to change, or even cease to exist $^{26}$. Skuas and kelp gulls are predominantly opportunistic omnivore avian predators and scavengers in the marine food chain of the Southern Ocean. Their diet composition may shift dramatically when travelling from Antarctica to South America: as they move north the amount of krill and marine fish and invertebrates gradually decreases, being substituted with terrestrial insects and even garbage ${ }^{27,23}$. Skuas also very often predate on other bird species $^{27,28}$, while kelp gulls may forage on live whales ${ }^{29}$ and seal pups $^{30}$ in Antarctica and on rodents in South America ${ }^{31}$. Both species may also exhibit cannibalistic behaviour towards both chicks and adults ${ }^{27,32}$. 
The first research on POPs concentrations in migratory birds in the Antarctic dates back to the $1960 \mathrm{~s}^{33}$, however the data is often incomplete or sporadic (see Appendix Table 1 for details). For permanent Antarctic species, concentrations of POPs have been shown to be declining over the last decade, but it remains unknown whether this also applies to migratory species reaching Antarctica ${ }^{34}$. Since the 1990s explicit studies were performed to compare POPs in the migratory Antarctic birds to the native Antarctic non-flying birds (mainly Adélie penguins) ${ }^{35-37}$. These studies reported that levels of POPs in the former are almost 2 times higher than in the latter. However, direct comparisons between birds of different migratory routes are lacking. Skuas and Giant Petrels continue to be the most well-researched species among the Antarctic marine predators on the topic of POPs contamination $^{13,15,17,35,36,38-40}$, while information on others is more limited ${ }^{8,41,42}$.

In the current study we report a wide range of POPs in different tissues of opportunistically obtained skua and kelp gull specimen. To our best knowledge this is the first article to do so in various tissues of kelp gulls. The data will provide important insights to the task of monitoring of POPs in Antarctic birds.

\section{MATERIAL AND METHODS}

\section{Sample collection and preparation}

Three corpses of (Catharacta maccormicki) and kelp gulls (Larus dominicanus) were opportunistically collected on Rothera Point $\left(67^{\circ} 35^{\prime} 8^{\prime \prime}\right.$ 'S, 68 $8^{\circ} 7^{\prime} 59^{\prime \prime}$ W, fig. 1) and nearby islands in Ryder Bay during the austral summer of 2016-2017. Only adult birds found dead were collected, with the main cause of death determined to be collisions with masts or buildings. The corpses were stored and transported at $-20^{\circ} \mathrm{C}$ until further analysis in the laboratory in the Netherlands. During necropsies, samples of liver, muscle and subcutaneous fat were collected where possible, and stored in hexane pre-cleaned $60 \mathrm{ml}$ amber glass vials. Due to scavengers, birds were found in different physical states, and therefore, it was not possible to sample all the targeted organs in each specimen.

\section{Chemical analysis}

The whole procedure is based on the EN 15741:2009 ${ }^{43}$ method with some adjustments during the extraction step (details in Appendix 2A). In short, the procedure was as follows: After homogenization, 2 to $6 \mathrm{~g}$ of sample was transferred into hexane pre-cleaned $60 \mathrm{ml}$ amber glass tubes, and spiked with ${ }^{13} \mathrm{C}_{12}$ standards. MiliQ water was added until the total sample volume was $13 \mathrm{ml}$. After this $10 \mathrm{ml}$ of ethyl acetate was added, and the mixture was vigorously shaken in an overhead shaker for at least 10 minutes. This was followed by the addition of a mix of $2 \mathrm{~g}$ of sodium chloride and $4 \mathrm{~g}$ of magnesium sulphate. The samples were then centrifuged for at least 10 minutes at $350 \mathrm{G}$. The ethyl acetate supernatant was 


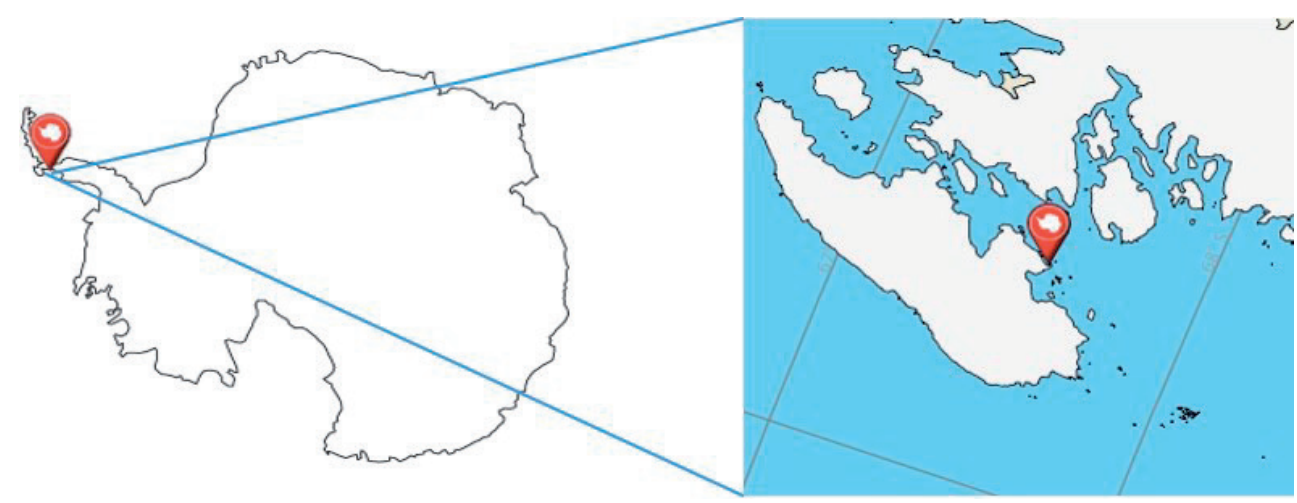

Figure 1. Location of Rothera research station on the Antarctic continent (left) and on Adelaide Island (right).

then transferred into a Turbovap ${ }^{\odot}$ tube, and the procedure was repeated 2 times, starting from the addition of $10 \mathrm{ml}$ of ethyl acetate, so that the total extract volume at the end of the process was $30 \mathrm{ml}$. The samples were then concentrated to $1 \mathrm{ml}$, and carefully transferred to new pre-cleaned $60 \mathrm{ml}$ amber glass tubes. $27 \mathrm{ml}$ of hexane and $10 \mathrm{~g}$ of $40 \%$ acidic silica were added to each sample and left overnight. The hexane fraction was then transferred to a hexane pre-cleaned Turbovap ${ }^{\oplus}$ tube, and evaporated to $1 \mathrm{ml}$, after which the sample was passed through a clean-up column which consisted of $1 \mathrm{~g}$ of activated silica and $8 \mathrm{~g}$ of $40 \%$ acidic silica. The sample was eluted with $25 \mathrm{ml}$ of hexane and subsequently by a mixture of $18 \mathrm{ml}$ hexane and $12 \mathrm{ml}$ dichloromethane. The resulting solvent mixture was evaporated in a Turbovap ${ }^{\oplus}$ to $1 \mathrm{ml}$, and a solvent exchange to iso-octane was performed. The resulting $1 \mathrm{ml}$ of extract in iso-octane was then stored at $-20^{\circ} \mathrm{C}$ until measurements of PCBs, PBDEs and OCPs were made.

Table 1 presents the full list of POPs analysed in this study.

PCBs and PBDES were quantified by a Magnetic Sector Autospec GC-HRMS from Waters (Manchester, UK) equipped with an Agilent 6890 GC (Santa Clara, USA). Because of practical constraints OCPs were measured by an Agilent 7010B Triple Quadrupole coupled with an Agilent 7890 GC (Santa Clara, USA). A DB-5MS 60m $\times 0.25 \mathrm{~mm} \times 0.25 \mu \mathrm{m}$ fused silica capillary column (Agilent J\&W, Folson, USA) was used for PCB analysis, while a CL-Pesticide $30 \mathrm{~m}$ x $0.25 \mathrm{~mm}$ x $0.25 \mu \mathrm{m}$ column (Restek, Bellefonte, USA) was fitted for the analysis of PBDEs and OCPs. The measurements were conducted at RIKILT laboratories in Wageningen, the Netherlands. For further details on the GC-methods see Appendix 2B. Limits of quantification (LOQ) were set for each individual compound as the lowest quantifiable standard, while the limit of detection (LOD) was calculated as 3 times the concentration of the compound in the extract of the corresponding blank sample. Concentrations in samples were not adjusted for blanks nor corrected for recovery 
Table 1. Chemical compounds analysed in the current study.

\begin{tabular}{|c|c|c|}
\hline PCBs & PBDEs & OCPs \\
\hline PCB 28 & BDE-47 & $\mathrm{HCB}$ \\
\hline РCB 52 & BDE-66 & $\mathrm{HCH}-\alpha$ \\
\hline PCB 101 & BDE- 85 & $\mathrm{HCH}-\gamma$ \\
\hline PCB 105 & BDE-99 & $\mathrm{HCH}-\beta$ \\
\hline PCB 114 & BDE-100 & $\mathrm{HCH}-\delta$ \\
\hline PCB 118 & BDE-138 & Heptachlor \\
\hline PCB 123 & BDE-153 & op'-DDE \\
\hline PCB 138 & BDE-154 & trans-Chlordane \\
\hline PCB 153 & BDE-183 & cis-Chlordane \\
\hline PCB 156 & & pp'-DDE \\
\hline PCB 157 & & Endosulfan- $\alpha$ \\
\hline PCB 167 & & op'-DDD \\
\hline PCB 180 & & op'-DDT \\
\hline PCB 189 & & $\begin{array}{l}\text { pp'-TDE(DDD) } \\
\text { pp'-DDT }\end{array}$ \\
\hline
\end{tabular}

rates, however all values are reported in Appendix 2C. The lipid content was determined gravimetrically on a fraction of each sample after extraction.

\section{QA/QC}

Each measurement batch contained 7 tissue samples, a procedural blank and sample of a certified reference material (SRM 1947, National Institute of Standards and Technology). The samples were considered valid if the recoveries of all internal standards were $50 \%$ $150 \%$ and the difference between measured and estimated SRM concentrations was $<50 \%$. The detailed QA data is shown in Appendix 3.

\section{Data treatment}

The low number (1-3 per specific tissues per specimen) of samples did not allow for a comprehensive interpretation of results based on statistical tests. Therefore, further analysis and discussion chiefly refer to the obtained values mostly in a descriptive manner. The only exception are the samples of muscles, where 3 samples were collected for both skuas and gulls, allowed a Mann-Whitney-Wilcoxon (MWW) test to be conducted on them using the Real Statistics $@$ package in Microsoft Excel. The results of the test are presented in Appendix 4.

The mean values were calculated in cases when more than one sample was available per specific tissue in a species. The standard deviation (SD) values were calculated only for instances with 3 samples present. 

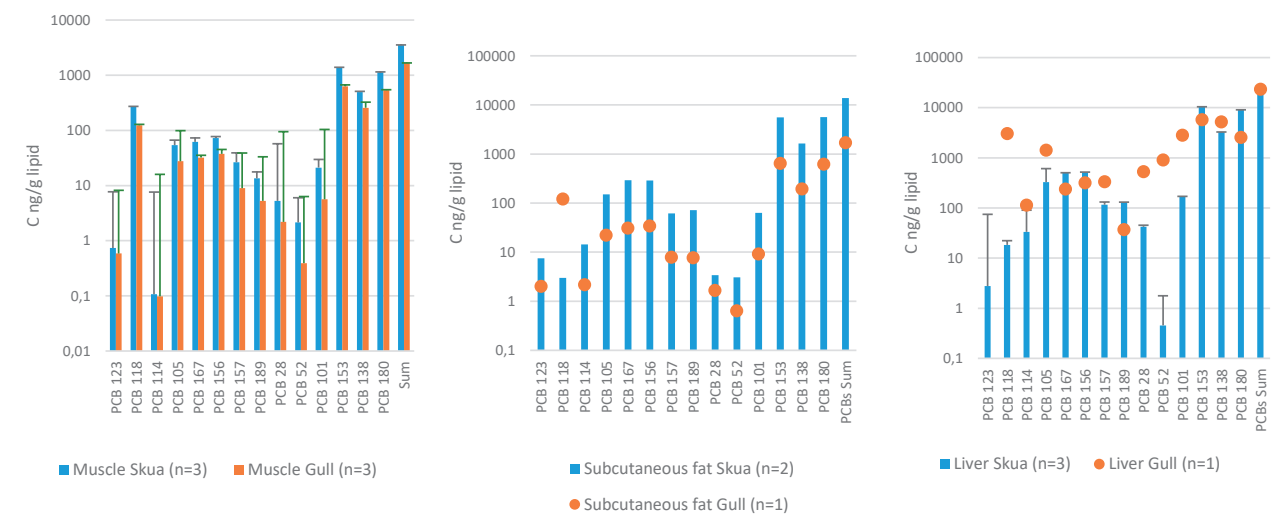

Figure 2. Concentrations (mean and standard deviations back-transformed from log-transformed data) of PCBs in muscles, livers and subcutaneous fat of skuas (blue bars) and kelp gulls (orange bars and dots (in cases where only 1 sample was available)). Note that $\log$ scale is used ubiquitously.

\section{RESULTS AND DISCUSSION}

Concentrations of POPs across different tissues in a single organism may be similar due to lipid-mediated exchange of contaminants between tissues. In the current study there were higher concentrations of PCBs and OCPs in muscles and livers of skuas than in fat ${ }^{44}$. Although similar patterns were reported for non-Antarctic birds ${ }^{45,46}$, the most probable explanations are that the bird specimens were found in different stages of decomposition and natural variability ${ }^{14}$.

\section{PCBs}

Concentrations of PCBs (fig.2) are generally higher in subcutaneous fat and livers than in muscles for both species. The patterns of individual congeners, nevertheless, appear quite similar with a predominance of hexa- and hepta-CBs, i.e. PCB 153, PCB 180 and PCB 138. Among tri-, tetra- and hepta-CBs the highest concentrations are attributed to $\mathrm{PCB}$ 118. The predominance of hexa- and hepta-CBs in both skuas and gulls agrees with many preceding studies for various Antarctic marine birds (including skuas) ${ }^{13,15,17,47}$, although this may not observed for penguins ${ }^{8}$. This outcome may arise from characteristics of the metabolism of PCBs by avian species, which allows them to eliminate lower chlorinated $\mathrm{PCB}$ faster than the higher chlorinated ones ${ }^{36,48}$.

Although PCB concentrations in this study are higher than those reported recently for Antarctic seabirds ${ }^{13,15,17,35,38,41,42}$ and are comparable to the ones from 15-20 years ago ${ }^{8,36}$, Antarctic birds are known to demonstrate high individual variability in their PCB 
contents $^{17}$, which also varies with their seasonal breeding activities ${ }^{49}$. From the current samples, no indications of their reproductive condition could be acquired, so it was not feasible to account for such seasonal variability. Neither was it possible to find significant differences between concentrations of PCBs in skuas and kelp gulls. Therefore, although PCBs levels in the current study may indicate that concentrations may be stable over time, more detailed information is needed to account for different factors affecting the uncertainty when comparing between studies.

\section{OCPs}

OCPs are arbitrary the most abundant group of POPs among the individual compounds and congeners analysed (fig. 3), possibly due to their application method which involves their dispersion over large areas and therefore an increased tendency for the long-range atmospheric transfer ${ }^{42}$. In addition, recent reports ${ }^{50-53}$ indicate that despite multiple legislative restrictions, several OCPs (e.g. HCB) are still being produced and/or sold (sometimes as by-products) in South America, which facilitates their continuous intake into environments which the collected birds were very likely to have visited ${ }^{9}$.

The profile of OCPs is quite similar among species: the highest concentrations measured were for $\mathrm{p}, \mathrm{p}$ '-DDE, followed by HCB, p,p'-DDT, p,p'-DDD, oxychlordane and HCB- $\beta$. Concentrations of other pesticides are low.

The overall burden of total DDTs (DDTs, DDEs and DDDs) is higher than reported in recent studies for skua eggs, but is similar to an earlier report for different tissues of adult skuas $^{8}$. Furthermore, the DDT and especially the DDE concentrations in the both species of the current study are higher than found in penguins ${ }^{54-56}$. This may demonstrate that exposure to DDT is a continuing issue for the former during their winter migrations. Blood samples of giant petrels and skuas were yet reported to have lower DDT concentrations, and this may result from their different migration patterns and/or site-specific variations ${ }^{13,35,57}$.

$\mathrm{HCB}$ is the second most abundant OCP. The concentrations of HCB were higher in this study than for eggs of Antarctic flying birds (including skuas) recently reported (possibly due to the absence of potential for HCB to accumulate in eggs) ${ }^{17}$, but are yet consistent with reported values for blood of giant petrels ${ }^{39}$. Compared to Antarctic non-flying birds, HCB levels reported here were similar for kelp gulls, and were higher for skuas ${ }^{13,49}$.

The chlordane group (Oxychlordane, trans-Chlordane, cis-Chlordane, Heptachlor and Heptachlor epoxide) is mainly represented by Oxychlordane, a metabolite of other chlordanes $^{58}$, while their concentrations are higher than those found in other studies ${ }^{35,39,42}$. The $\mathrm{HCH}$ group is chiefly represented by $\beta$ - and $\gamma$ - stereoisomers, which are the mostly used isomers ${ }^{59}$. 


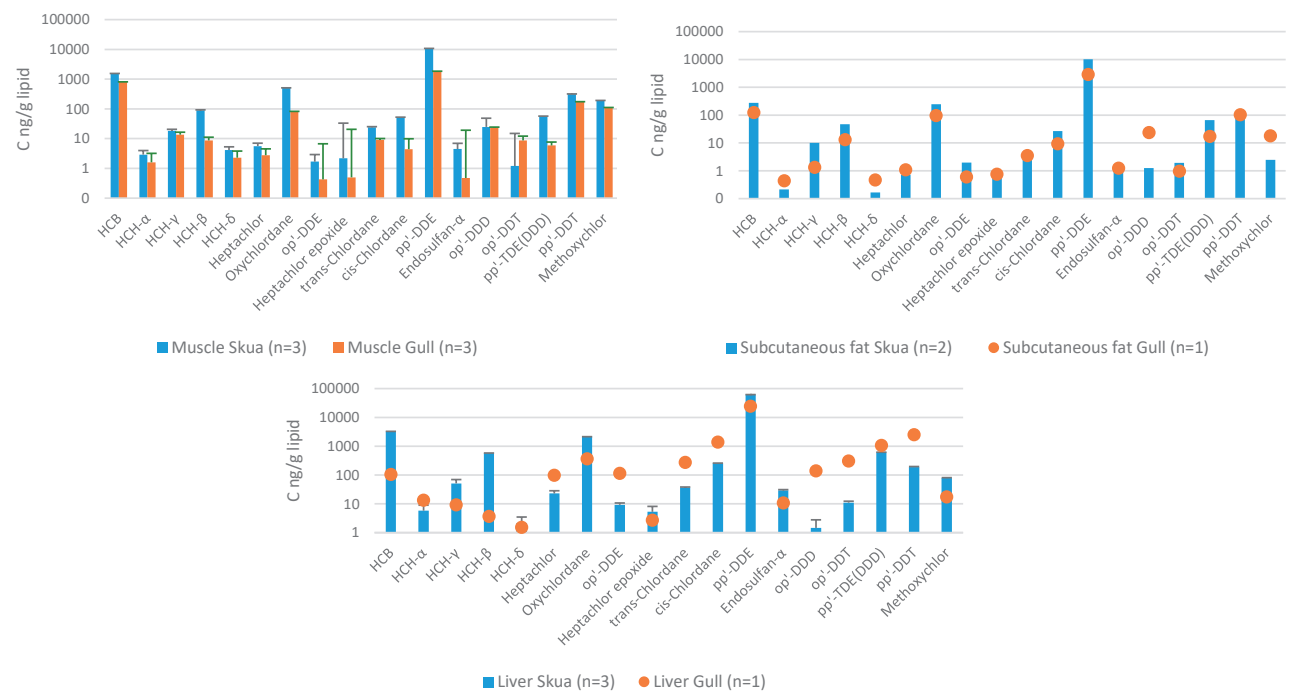

Figure 3. Concentrations (mean and standard deviations back-transformed from log-transformed data) of OCPs in muscles, livers and subcutaneous fat of skuas (blue bars) and kelp gulls (orange bars and dots (in cases where only 1 sample was available)). Note that $\log$ scale is used ubiquitously.

There were no significant differences between concentrations of OCPs in skuas and kelp gulls.

\section{PBDEs}

The concentrations of PBDEs (fig. 4) are low compared to other POPs. They are comparable, however, to previous studies for eggs of skuas ${ }^{17,38}$, but lower than the ones reported in blood of giant petrels and prions. This can be explained by the different migration behaviour ${ }^{17}-$ petrels and prions tend to travel less further North and therefore are less directly exposed to industrial chemcials ${ }^{13,42}$. Composition of congeners is similar in all tissues of both species: the highest values are attributed to BDE-47 followed by BDE-153, BDE-154, BDE-99, and BDE-100. While levels of other congeners are minimal, they exhibit high variability as seen in their large standard deviations. The presence of PBDE-183 in quantifiable concentrations has been suggested to occur due to direct exposure to decaBDEs in Antarctica, and may be an indicator of emerging pollution of local seas by microplastics ${ }^{42}$.

The MWW test demonstrated significant differences between PBDE concentrations in muscles of skuas and kelp gulls, which was the only instance when significant differences were found in this study. Because skuas tend to travel longer distances than gulls ${ }^{21,23,24}$, concentrations of PBDEs in the former can be expected to be higher.

The second explanation may arise from different feeding habits of the two birds species during their stay in South America. Skuas are more likely to forage on landfills and therefore 


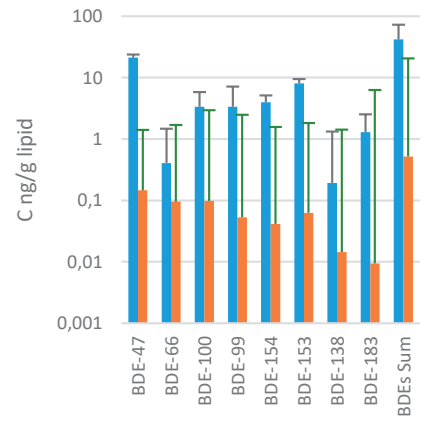

- Muscle Skua $(\mathrm{n}=3)$ Muscle Gull $(\mathrm{n}=3)$

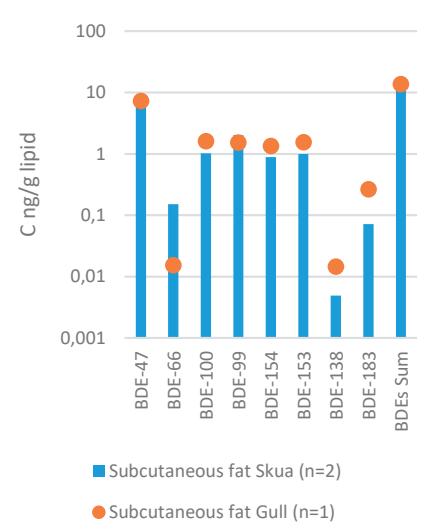

Figure 4. Concentrations (mean and standard deviations back-transformed from log-transformed data) of PBDEs in muscles, livers and subcutaneous fat of skuas (blue bars) and kelp gulls (orange bars and dots (in cases where only 1 sample was available)). Note that log scale is used ubiquitously.

to be exposed to industrial chemicals (such as PBDEs), while kelp gulls prefer to forage in agricultural areas $23,27,60,61$

However, due to low concentrations of PBDEs in the muscles of the gulls their comparison to the ones of skuas should be regarded with caution.

\section{CONCLUSIONS}

Despite limitations imposed by the low number and heterogeneity of the samples collected, the present study provides an important baseline for any future evaluation of trends of POPs in Antarctic marine avian predators, near the Antarctic Peninsula and the Southern regions of South America. The concentrations of PCBs, OCPs and PBDEs were generally in good agreement with similar earlier reports. This study confirms that skuas and kelp gulls are still subjected to direct exposure to POPs, whose concentration patterns are linked not only to environmental levels in the areas the birds are visiting, but also to the characteristic ecological traits of each species. 


\section{REFERENCES}

1. Vallack, H. W. et al. Controlling persistent organic pollutants-what next? Environ. Toxicol. Pharmacol. 6, 143-175 (1998).

2. Noyes, P. D. et al. The toxicology of climate change: Environmental contaminants in a warming world. Environ. Int. 35, 971-986 (2009).

3. Listing of POPs in the Stockholm Convention. Available at: http://chm.pops.int/TheConvention/ ThePOPs/AllPOPs/tabid/2509/Default.aspx. (Accessed: 21st December 2017)

4. Gavrilescu, M. Fate of Pesticides in the Environment and its Bioremediation. Eng. Life Sci. 5, 497526 (2005).

5. Wania, F. Assessing the Potential of Persistent Organic Chemicals for Long-Range Transport and Accumulation in Polar Regions. Environ. Sci. Technol. 37, 1344-1351 (2003).

6. Bargagli, R. Environmental contamination in Antarctic ecosystems. Sci. Total Environ. 400, 212 226 (2008).

7. Schenker, S., Scheringer, M. \& Hungerbühler, K. Do Persistent Organic Pollutants Reach a Thermodynamic Equilibrium in the Global Environment? Environ. Sci. Technol. 48, 5017-5024 (2014).

8. Van den Brink, N. W. Directed transport of volatile organochlorine pollutants to polar regions: the effect on the contamination pattern of Antarctic seabirds. Sci. Total Environ. 198, 43-50 (1997).

9. Martínez-López, E. et al. Contaminants in the southern tip of South America: Analysis of organochlorine compounds in feathers of avian scavengers from Argentinean Patagonia. Ecotoxicol. Environ. Saf. 115, 83-92 (2015).

10. Bourgeon, S. et al. Individual variation in biomarkers of health: Influence of persistent organic pollutants in Great skuas (Stercorarius skua) breeding at different geographical locations. Environ. Res. 118, 31-39 (2012).

11. Pozo, K. et al. Levels of Persistent Organic Pollutants (POPs) in sediments from Lenga estuary, central Chile. Mar. Pollut. Bull. 79, 338-341 (2014).

12. Battaglia, B. (Bruno), Valencia, J. (José) \& Walton, D. W. H. Antarctic communities : species, structure and survival. (CAMBRIDGE UNIVERSITY PRESS, NEW YORK, NY (USA), 1997).

13. Roscales, J. L., González-Solís, J., Zango, L., Ryan, P. G. \& Jiménez, B. Latitudinal exposure to DDTs, HCB, PCBs, PBDEs and DP in giant petrels (Macronectes spp.) across the Southern Ocean. Environ. Res. 148, 285-294 (2016).

14. Carravieri, A. et al. From Antarctica to the subtropics: Contrasted geographical concentrations of selenium, mercury, and persistent organic pollutants in skua chicks (Catharacta spp.). Environ. Pollut. 228, 464-473 (2017).

15. Corsolini, S., Borghesi, N., Ademollo, N. \& Focardi, S. Chlorinated biphenyls and pesticides in migrating and resident seabirds from East and West Antarctica. Environ. Int. 37, 1329-1335 (2011).

16. Focardi, S. et al. Mixed function oxidase activity and chlorinated hydrocarbon residues in antarctic sea birds: South polar skua (Catharacta maccormicki) and adélie penguin (Pygoscelis adeliae). Mar. Environ. Res. 34, 201-205 (1992).

17. Mello, F. V. et al. Relationship between legacy and emerging organic pollutants in Antarctic seabirds and their foraging ecology as shown by $\delta 13 \mathrm{C}$ and $\delta 15$ N. Sci. Total Environ. 573, 1380-1389 (2016).

18. Ritz, M. S., Hahn, S., Janicke, T. \& Peter, H.-U. Hybridisation between South polar skua (Catharacta maccormicki) and Brown skua (C. antarctica lonnbergi) in the Antarctic Peninsula region. Polar Biol. 29, 153-159 (2006).

19. Trillmich, F. Feeding Territories and Breeding Success of South Polar Skuas. Auk 95, 23-33 (1978).

20. Hahn, S. \& Bauer, S. Dominance in feeding territories relates to foraging success and offspring growth in brown skuas Catharacta antarctica lonnbergi. Behav. Ecol. Sociobiol. 62, 1149-1157 (2008). 
21. Kopp, M. et al. South polar skuas from a single breeding population overwinter in different oceans though show similar migration patterns. Mar. Ecol. Prog. Ser. 435, 263-267 (2011).

22. Harrison, P. Seabirds : an indentification guide. (Houghton Mifflin, 1991).

23. Bertellotti, M. \& Yorio, P. Spatial and Temporal Patterns in the Diet of the Kelp Gull in Patagonia. Condor 101, 790-798 (1999).

24. Krietsch, J. et al. Consistent variation in individual migration strategies of brown skuas. Mar. Ecol. Prog. Ser. 578, 213-225 (2017).

25. Micol, T. \& Jouventin, P. Long-term population trends in seven Antarctic seabirds at Pointe Géologie (Terre Adélie). Polar Biol. 24, 175-185 (2001).

26. Constable, A. J. et al. Climate change and Southern Ocean ecosystems I: how changes in physical habitats directly affect marine biota. Glob. Chang. Biol. 20, 3004-3025 (2014).

27. REINHARDT, K., HAHN, S., PETER, H.-U. \& WEMHOFF, H. A review of the diets of the Southern Hemisphere skuas. Mar. Ornithol. 28, 7-19 (1988).

28. Furness, R. W. \& Hislop, J. R. G. Diets and feeding ecology of Great skuas Catharacta skua during the. J. Zool. 195, 1-23 (2009).

29. Rowntree, V. J. et al. INCREASED HARASSMENT OF RIGHT WHALES (EUBALAENA AUSTRALIS) BY KELP GULLS (LARUS DOMINICANUS) AT PENINSULA VALDES, ARGENTINA. Mar. Mammal Sci. 14, 99-115 (1998).

30. Seguel, M. et al. Kelp and dolphin gulls cause perineal wounds in South American fur seal pups ( Arctocephalus australis) at Guafo Island, Chilean Patagonia. R. Soc. Open Sci. 4, 170638 (2017).

31. Ruiz, J. \& Simeone, A. Feeding by Kelp Gulls on Rodents during a Mouse Outbreak at an Inland Area in Southern Chile. Waterbirds Int. J. Waterbird Biol. 24, 118 (2001).

32. Coulson, R. \& Coulson, G. Diets of the Pacific Gull Larus pacificus and the Kelp Gull Larus dominicanus in Tasmania. Emu - Austral Ornithol. 93, 50-53 (1993).

33. Risebrough, R. W., RIECHE, P., PEAKAlL, D. B., HERMAN, S. G. \& KIRVEN, M. N. Polychlorinated Biphenyls in the Global Ecosystem. Nature 220, 1098-1102 (1968).

34. van den Brink, N. W., Riddle, M. J., van den Heuvel-Greve, M. \& van Franeker, J. A. Contrasting time trends of organic contaminants in Antarctic pelagic and benthic food webs. Mar. Pollut. Bull. 62, 128-132 (2011).

35. Kim, J.-T. et al. Occurrence of Legacy and New Persistent Organic Pollutants in Avian Tissues from King George Island, Antarctica. Environ. Sci. Technol. 49, 13628-13638 (2015).

36. Court, G. S. et al. Chlorinated hydrocarbons in the tissues of South Polar Skuas (Catharacta maccormicki) and Adélie Penguins (Pygoscelis adeliea) from Ross Sea, Antarctica. Environ. Pollut. 97, 295-301 (1997).

37. Wolschke, H., Meng, X.-Z., Xie, Z., Ebinghaus, R. \& Cai, M. Novel flame retardants (N-FRs), polybrominated diphenyl ethers (PBDEs) and dioxin-like polychlorinated biphenyls (DL-PCBs) in fish, penguin, and skua from King George Island, Antarctica. Mar. Pollut. Bull. 96, 513-518 (2015).

38. Yogui, G. T. \& Sericano, J. L. Levels and pattern of polybrominated diphenyl ethers in eggs of Antarctic seabirds: Endemic versus migratory species. Environ. Pollut. 157, 975-980 (2009).

39. Colabuono, F. I. et al. Persistent organic pollutants in blood samples of Southern Giant Petrels ( Macronectes giganteus ) from the South Shetland Islands, Antarctica. Environ. Pollut. 216, 38-45 (2016).

40. Norheim, G., Sømme, L. \& Holt, G. Mercury and persistent chlorinated hydrocarbons in antarctic birds from bouvetøya and dronning maud land. Environ. Pollut. Ser. A, Ecol. Biol. 28, 233-240 (1982).

41. Cipro, C. V. Z., Colabuono, F. I., Taniguchi, S. \& Montone, R. C. Persistent organic pollutants in bird, fish and invertebrate samples from King George Island, Antarctica. Antarct. Sci. 25, 545-552 (2013). 
42. Fromant, A. et al. Wide range of metallic and organic contaminants in various tissues of the Antarctic prion, a planktonophagous seabird from the Southern Ocean. Sci. Total Environ. 544, 754-764 (2016).

43. European Committee for Standardization CEN/TC 327. EN 16215:2012. Animal feeding stuffs - Determination of dioxins and dioxin-like PCBs by GC/HRMS and of indicator PCBs by GC/ HRMS. (2012).

44. Haddad, S., Poulin, P. \& Krishnan, K. Relative lipid content as the sole mechanistic determinant of the adipose tissue:blood partition coefficients of highly lipophilic organic chemicals. Chemosphere 40, 839-843 (2000).

45. Zheng, S. et al. Tissue distribution and maternal transfer of persistent organic pollutants in Kentish Plovers (Charadrius alexandrines) from Cangzhou Wetland, Bohai Bay, China. Sci. Total Environ. 612, 1105-1113 (2018).

46. Jaspers, V. L. B. et al. Brominated flame retardants and organochlorine pollutants in aquatic and terrestrial predatory birds of Belgium: levels, patterns, tissue distribution and condition factors. Environ. Pollut. 139, 340-352 (2006).

47. Corsolini, S. et al. Legacy persistent organic pollutants including PBDEs in the trophic web of the Ross Sea (Antarctica). Chemosphere 185, 699-708 (2017).

48. Maervoet, J. et al. Accumulation and tissue distribution of selected polychlorinated biphenyl congeners in chickens. Chemosphere 57, 61-66 (2004).

49. van den Brink, N. W., van Franeker, J. A. \& de Ruiter-Dijkman, E. M. Fluctuating concentrations of organochlorine pollutants during a breeding season in two Antarctic seabirds: Adelie penguin and southern fulmar. Environ. Toxicol. Chem. 17, 702-709 (1998).

50. Hjorth, K. et al. Pesticide residues in fruits and vegetables from South America - A Nordic project. Food Control 22, 1701-1706 (2011).

51. Joyce, S. Growing pains in South America. Environ. Health Perspect. 105, 794-9 (1997).

52. Carvalho, F. P. Pesticides, environment, and food safety. Food Energy Secur. 6, 48-60 (2017).

53. Brisbois, B. W. Epidemiology and 'developing countries': Writing pesticides, poverty and political engagement in Latin America. Soc. Stud. Sci. 44, 600-624 (2014).

54. Montone, R. C. et al. Persistent organic pollutants and polycyclic aromatic hydrocarbons in penguins of the genus Pygoscelis in Admiralty Bay - An Antarctic specially managed area. Mar. Pollut. Bull. 106, 377-382 (2016).

55. Kumar, K. S. et al. Polychlorinated dibenzo-p-dioxins, dibenzofurans and polychlorinated biphenyls in polar bear, penguin and south polar skua. Environ. Pollut. 119, 151-161 (2002).

56. Weichbrodt, M., Vetter, W., Scholza, E., Luckas, B. \& Reinhardt, K. Determination of Organochlorine Levels in Antarctic Skua and Penguin Eggs by Application of Combined Focused Open-Vessel Microwave-Assisted Extraction, Gel-Permeation Chromatography, Adsorption Chromatography, and GC/ECD. Int. J. Environ. Anal. Chem. 73, 309-328 (1999).

57. Colabuono, F. I., Taniguchi, S., Petry, M. V. \& Montone, R. C. Organochlorine contaminants and polybrominated diphenyl ethers in eggs and embryos of Antarctic birds. Antarct. Sci. 27, 355-361 (2015).

58. Eisler, R. Chlordane Hazards to Fish, Wildlife, and Invertebrates: A Synoptic Review. Contam. Hazard Rev. (1990).

59. Kristine L. Willett, Elin M. Ulrich, and \& Hites*, R. A. Differential Toxicity and Environmental Fates of Hexachlorocyclohexane Isomers. (1998). doi:10.1021/ES9708530

60. Votier, S. C., Bearhop, S., MacCormick, A., Ratcliffe, N. \& Furness, R. W. Assessing the diet of great skuas, Catharacta skua, using five different techniques. Polar Biol. 26, 20-26

61. Hahn, S. \& Peter, H.-U. Feeding territoriality and the reproductive consequences in brown skuas Catharacta antarctica lonnbergi. Polar Biol. 26, 552-559 (2003). 


\section{SUPPLEMENTARY INFORMATION}

All supplementary information is available online at DOI: 10.1016/j.marpolbul.2018.10.008 


$$
3
$$




\section{Chapter 3}

\section{Seasonal variability in concentrations of Persistent Organic Pollutants in the particulate phase of marine water near Rothera Point, Western Antarctic Peninsula}

Artem Krasnobaev, Guillaume ten Dam, Rita Boerrigter-Eenling, Stefan P.J. van Leeuwen, Simon A. Morley, Lloyd S. Peck, Nico W. van den Brink. 


\section{ABstraCT}

Concentrations of different Persistent Organic Pollutants (POPs) - polychlorinated biphenyls (PCBs), organochloride pesticides (OCPs) and polybrominated diphenyl ethers (PBDEs) were measured in particulate matter $<2.7 \mu \mathrm{m}$ present in marine water collected in Rothera Bay (Western Antarctic Peninsula) at 15 timepoints during the austral summer of 2016-2017. For all compounds the maximum concentrations were found at the start of the summer season after ice melt and during the phytoplankton bloom. Afterwards, the concentrations gradually decreased following the mixing of the water column and sedimentation of the particulate organic matter. Total concentrations of PCBs and OCPs were similar to those previously reported for Antarctica. PBDEs were detected for the first time in Antarctic waters and their concentrations were higher than in previous studies in the Arctic. The most abundant PCB congener was PCB-28, while the most abundant OCP was $\mathrm{HCH}$-alpha. Unlike PCBs, the major PBDEs present were heavier congeners. Overall, the dynamics of POPs in the water column of Ryder Bay are driven mostly by melting of sea ice and snow early in the season, and by primary production and related sedimentation later in the season. The physico-chemical properties of compounds shape their individual responses to these drivers. 


\section{INTRODUCTION}

Persistent organic pollutants (POPs) are a group of chemicals which among others include polychlorinated biphenyls (PCBs), polybrominated diphenyl ethers (PBDEs) and organochloride pesticides (OCPs) $)^{1}$. These compounds are resistant to environmental degradation and may be transported via the atmosphere into remote areas of the world, such as the Western Antarctic Peninsula (WAP) $)^{2}$. Characterization and quantification of POPs in these remote areas is of major importance for estimation of risks related to global pollution by these compounds and the potential effect of climate change on their global distribution ${ }^{2,3}$.

Coastal marine ecosystems play a pivotal role in the assessment of the possible consequences of POP levels in Antarctica, as these ecosystems support high levels of endemic species, while being a potential sink for environmental contaminants ${ }^{2,4}$. Yet, comprehensive data on concentrations of POPs in the lower trophic levels of such ecosystems is still lacking. The main reasons for that are the logistical difficulties of sampling large amounts of water in very remote locations and subsequent chemical analysis of the samples, which normally have extremely low concentrations of $\mathrm{POPs}^{6}$.

The first detection of POPs in Antarctic marine water dates back to 1981 when OCPs and PCBs were measured around the coast of Showa station (Queen Maud Land) 7 . Since then a number of studies have been conducted in East ${ }^{8-11}$ and in West ${ }^{5,12-17}$ Antarctica, that have reported overall declining trends of concentrations of POPs in pelagic waters, although the sparsity of data reduces confidence in this conclusion ${ }^{2}$.

On the other hand, only a few studies have focused on POPs in the particulate phase of Antarctic marine water ${ }^{5,18,19}$, despite its importance as a first step in the biomagnification chain of POPs in trophic webs and therefore crucial role in the environmental fate and associated modelling of $\mathrm{POPs}^{4,20,21}$. All studies showed a high variability of concentrations and highlighted a strong need for further research, with the aim of establishing the drivers of behaviour and fluctuations of concentrations of POPs in the particulate phase. Unfortunately, the studies were often done with a disregard for seasonal variation and little concern for other local environmental parameters (e.g. algae blooms), which may likely affect POP concentrations ${ }^{22}$. Besides natural drivers, Antarctic research stations can be a local source of POPs pollution ${ }^{23}$, which are likely to impact local concentrations of POPs in the coastal seas ${ }^{23,24}$.

To gain more insights in the dynamics of concentrations of POPs in the coastal Antarctic ecosystems, the current study was designed to identify trends during an initial spring plankton bloom and an austral summer in concentrations of various POPs in the particulate phase 
collected from local water by filtration, to quantify the influence of local environmental biological, physical and chemical factors and to assess potential contamination due to local research activities.

The study was conducted at Rothera research station of the British Antarctic Survey, which brings benefits from the Rothera Time Series (RaTS) ${ }^{25}$ - a long term programme recording local oceanographic and biological data, when interpreting the data. This allowed for the inclusion of oceanographic parameters potentially driving time dependent changes in concentrations of POPs in the Antarctic inshore marine environment.

\section{MATERIALS AND METHODS}

\section{Field sampling}

The samples of water and phytoplankton were collected between January and April of 2017 (the 2017 austral summer) in Ryder Bay near Rothera research station (67⒊ $36^{\prime \prime}$ 'S $68^{\circ} 07^{\prime} 33^{\prime \prime W}$ ), Adelaide Island (fig. 1, left). This season was characterized by 2 conspicuous abnormalities at its start: the exceptionally late, but rapid melting of the sea ice (around the 3rd of January) and a large algae bloom (3rd of January till 10th of January). The rest of the season was relatively uneventful. The autumn sea-ice formation did not happen until the end of sampling. The main sampling site $\left(67^{\circ} 31^{\prime} \mathrm{S} 68^{\circ} 15^{\prime} \mathrm{W}\right)$ was located in the close proximity of the Sheldon Glacier (fig. 1, right), while an auxiliary site, which was used during bad weather conditions was located approximately $2.5 \mathrm{~km}$ further east, closer to Rothera. Both sites were in the direct proximity of the RaTS station (67 $\left.31^{\prime} \mathrm{S} 68^{\circ} 14^{\prime} \mathrm{W}\right)$. Due to clockwise water currents in the Ryder Bay, the sampling area was perceived not to be affected by downstream local sources of POPs, such as the research station and transportation activities. Overall, 15 samples were taken at $1 \mathrm{~m}$ depth and 7 at $20 \mathrm{~m}$ depth. To investigate the influence of the station on local contaminant patterns, 3 additional samples were collected from the station water supply system, which uses local marine water from the South Cove (sampling site 3)(fig. 1).

Our sampling system, designed and built by the Technical Development Studio of Wageningen University, used a sucking pump to filter water from specific depths through glass fibre (GF) General Electric Whatman ${ }^{\text {TM }}$ GFD and GFF $(0.7 \mu \mathrm{m}) 142 \mathrm{~mm}$ filters via 3 separate channels. Various measures were undertaken to minimise background levels during sampling. The system was built only from high-grade steel and Teflon', it was thoroughly cleaned with water and hexane before and after sampling, and the system was designed so that water flowed through the filters before going through the pump. The GF filters were per-ashed at $450^{\circ} \mathrm{C}$ for 12 hours immediately prior to the on-site sampling. After sampling the filters were packed into aluminium foil (which had been pre-ashed at $450^{\circ} \mathrm{C}$ 


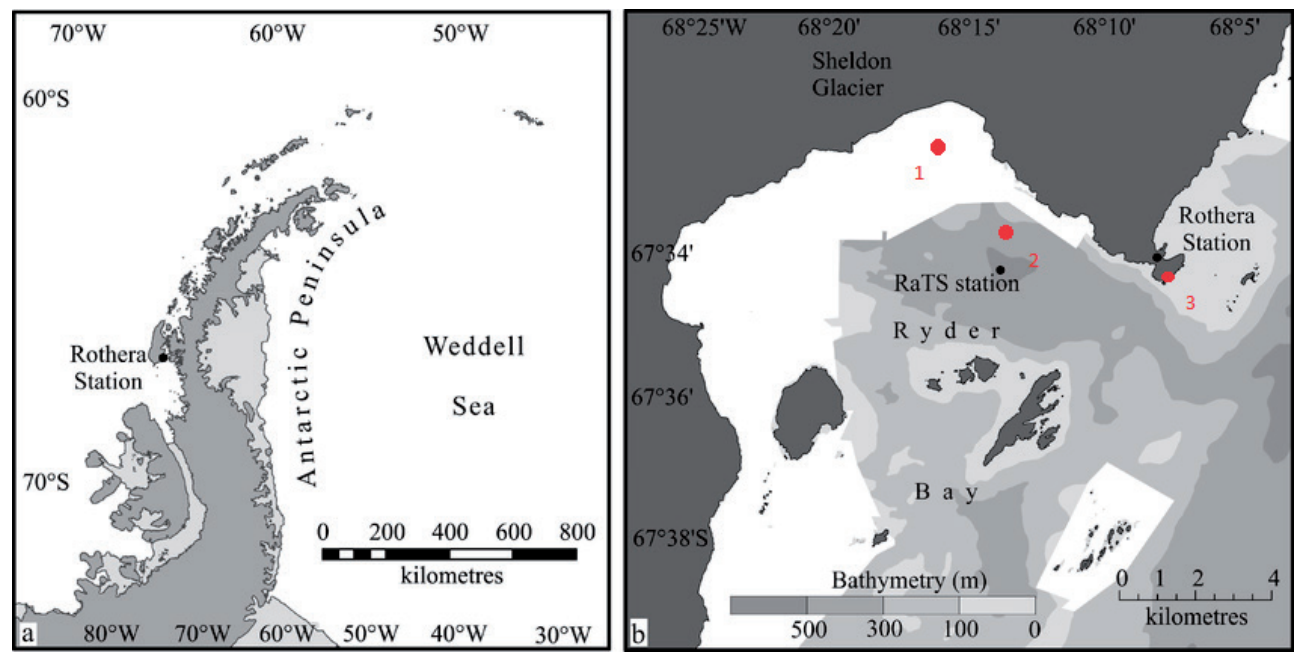

Figure 1. Location of the Rothera Station on the Western Antarctic Peninsula (left) and locations of the sampling sites in the Ryder Bay (1 - main sampling site, 2 - auxiliary sampling site, 3 - station sampling site).

for 18 hours and then cleaned with hexane), and then promptly stored at $-20^{\circ} \mathrm{C}$ and shipped to the Netherlands.

To account for background levels, field blanks $(n=4)$ were created at different time points during the season. A field blank would undergo exactly the same routine as a regular sample except for not being subjected to water flow during the on-site sampling.

\section{Chemical analysis}

A detailed description of analytical procedures can be found in Appendix 1. All solvents and other chemicals used in the current study were of the highest analytical grade. Glassware and metal hardware used in the analysis were thoroughly pre-cleaned with acetone and twice with hexane. Extractions were performed on a Dionex 350 Automated Solvent Extractor (ASE) machine. Four to eight individual filters (respective GFD and GFF) were pooled into a single sample (per time point and location) to analyse the chemicals filtered from a total volume of at least $450 \mathrm{~L}$ sea water. Samples were placed into a $100 \mathrm{ml}$ ASE steel cell and spiked with ${ }^{13} \mathrm{C}$ standards for each analysed compound. The extraction consisted of 1 cycle of $100 \%$ acetone, 1 cycle of $75 \%$ acetone and $25 \%$ hexane and 3 cycles of $50 \%$ acetone and $50 \%$ hexane. The duration of each cycle was 150 minutes at $100^{\circ} \mathrm{C}$ and at $10 \mathrm{MPa}$. Then a liquid-liquid extraction with hexane was conducted twice for the extracts from the first 2 cycles. Afterwards, the combined extracts were concentrated to $1 \mathrm{ml}$ in a Turbovap ${ }^{\oplus}$ apparatus, and $0.1 \mathrm{ml}$ of this material was used for quantification of extractable matter. The rest of the sample was then transported onto a clean-up column, which was packed with $2.5 \mathrm{~g}$ of activated silica and some glass wool, which were twice pre-eluted 
with $10 \mathrm{ml}$ and $15 \mathrm{ml}$ of hexane respectively. After the sample was added the column was eluted consecutively with $18 \mathrm{ml}$ hexane and $12 \mathrm{ml}$ dichloromethane. The resulting solvent mixture was evaporated in a Turbovap to $0.5 \mathrm{ml}$, and a solvent exchange to iso-octane was performed. The final $0.5 \mathrm{ml}$ of extract in iso-octane was stored at $-20^{\circ} \mathrm{C}$ until analysis.

PCBs and PBDEs were quantified using a Magnetic Sector Autospec GC-HRMS from Waters (Manchester, UK) equipped with an Agilent 6890 GC (Santa Clara, USA). OCPs were measured by an Agilent 7010B Triple Quadrupole coupled with an Agilent 7890 GC (Santa Clara, USA). DB-5MS $60 \mathrm{~m} \times 0.25 \mathrm{~mm} \times 0.25 \mu \mathrm{m}$ fused silica capillary column from Agilent J\&W (Folson, USA) was used for PCB analysis, while CL-Pesticide $30 \mathrm{~m} \times 0.25 \mathrm{~mm}$ $\mathrm{x} 0.25 \mu \mathrm{m}$ from Restek (Bellefonte, USA) was applied for the analysis of PBDEs and OCPs. Measurements were conducted at WFSR laboratories in Wageningen, the Netherlands. For further details on the GC-methods see Appendix 1.

Limits of quantification (LOQ) were calculated as 2 times the concentration of the compound in the extract of the corresponding blank sample. The content of extractable matter (predominantly lipid content) of each sample was determined gravimetrically.

For quality assurance (QA) and quality control (QC), procedural and field blanks were analysed for at least every 10 actual samples. Furthermore, each analysed ${ }^{12} \mathrm{C}$ compound had a corresponding ${ }^{13} \mathrm{C}$ compound as an internal standard for concentration correction.

Further data on LOQs and QA/QC can be found in the Appendix 2.

\section{Data Analysis}

The concentrations in the samples were corrected for the field blanks and for recovery rates of the ${ }^{13} \mathrm{C}$ standards. Results are expressed on a pg/L basis. The reason for not expressing them on an extractible matter (lipid basis) was the high variance of the obtained lipid values. Most likely, this was due to random presence of other organisms (e.g. copepods). For comparison with other studies, the values were adjusted by the lipid content reported in the literature or, in case of their absence, by the mean extractable matter values from the current study.

The RaTS data included measurements of mixed layer depth (MLD), water temperature, density, salinity, chlorophyll content and photosynthetically active radiation (PAR) at the depths of $1 \mathrm{~m}$ and $20 \mathrm{~m}$. If the RaTS data were not available for the day of POPs sampling, the data from the previous or the following day were used. 
Because of the time-dependency of the data, the values (both POPs and RATS) presented in this article were calculated as rolling (moving) averages with the window of 2 observations. Exceptions are specifically stressed. The first value of the rolling average was assumed to be equal to the first observation.

\section{RESULTS AND DISCUSSION}

Detailed information on concentrations of POPs in individual samples can be found in Appendix 3.

Concentrations of POPs in the samples from the station saltwater supply system, which originated from $1 \mathrm{~m}$ depth of South Cove (fig 1, location 3) were not different from the concentrations in the samples collected farther away from the station in the Ryder Bay (fig1, locations 1 and 2). Therefore, all samples were combined in the further discussions on POP concentrations at 1 meter depth.

The austral season of 2016/2017 was a fairly usual season in terms oceanographic dynamics, except for a very late (first days of January) melting of the sea-ice cover. The season experienced 2 algae blooms. While the later one from the end-January was present on the RATS data (fig. 2), it was not possible to characterise the earlier one (before the $5^{\text {th }}$ of January) due to unnavigable sea condition $\mathbf{s}^{25,26}$.

\section{PCBs}

PCB concentrations showed high variability during the season. Figure 2 demonstrates the rolling average of the sum of concentration of PCBs and chlorophyll at $1 \mathrm{~m}$ depth.

The highest concentrations of approximately $100 \mathrm{pg} / \mathrm{L}$ of PCBs were detected at the start of the sampling season when the sea ice showed a very rapid melt (around the $5^{\text {th }}$ of January) and an algae bloom started to occur. The melting sea ice created a stratification of the water column which can be traced from the salinity gradients (Fig. 3), keeping the released PCBs in the top layer of the water column, which was heavily affected by the melt and runoff water. This stratification disappeared over time, increasing the mixed layer depth and diluting the PCBs originating from the melted sea ice. The decrease of PCB concentrations was also enhanced by their removal by the sedimentation with organic matter (biological pump $)^{27}$.Then the PCB concentrations stabilised until the $25^{\text {th }}$ of January.

As from the $17^{\text {th }}$ of January another algal bloom started to develop, reaching peak around the $30^{\text {th }}$ of January and declining again after the $4^{\text {th }}$ of February ${ }^{25}$. During the build of this bloom and further on, PCB concentrations remained declining till the end of the season. 


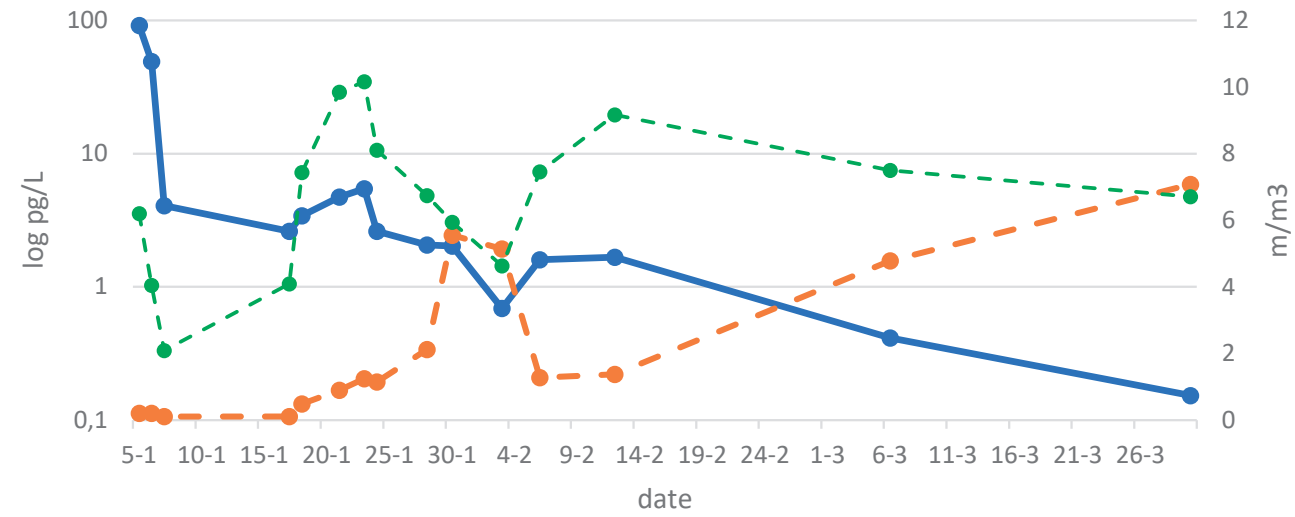

Figure 2. Rolling average of sum of concentrations of PCB congeners (blue line) (log scale) in pg/L and chlorophyll in $\mathrm{mg} / \mathrm{m}^{3}$ (dashed orange line) at $1 \mathrm{~m}$ depth, and chlorophyll in $\mathrm{mg} / \mathrm{m}^{3}$ (dashed green line) at $20 \mathrm{~m}$ depth

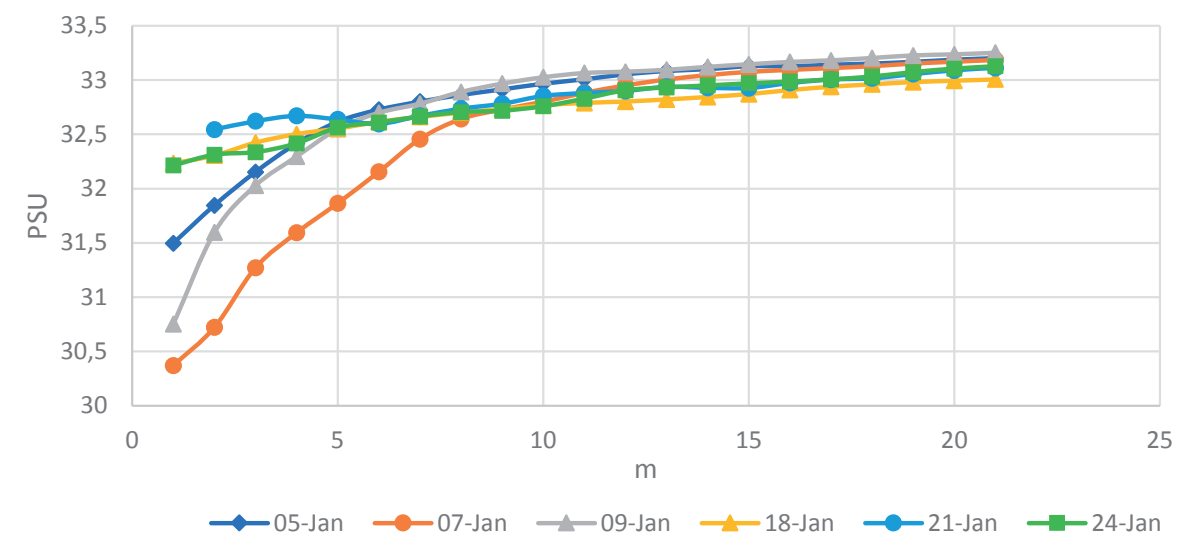

Figure 3. Density of water in PSU at different depths as a proxy for the estimation of water column stratification.

This decline can be caused by the elimination of PCBs from the upper water layer, namely by sedimentation with the algae, as well as by gradual dilution and dispersion over time. The elimination happened because of the build-up of the biomass and the adsorption of the PCBs to this biomass, while the air-water exchange was not able to compensate the mass balance through atmospheric inputs ${ }^{27}$. However, this decline in concentrations of PCBs during the second bloom was not as rapid as the initial one, because no surplus PCBs were available for sedimentation this time, as had been previously from the ice and snow melt. Thus, the current data suggest that the biological processes (i.e. algae bloom) had lesser effect on the dynamics of POPs in the particulate phase of water, than the abiotic ones (i.e. ice and snow melting, and mixing), which is in agreement with a previous study on seasonal POPs dynamics in the Baltic Sea ${ }^{28}$. 


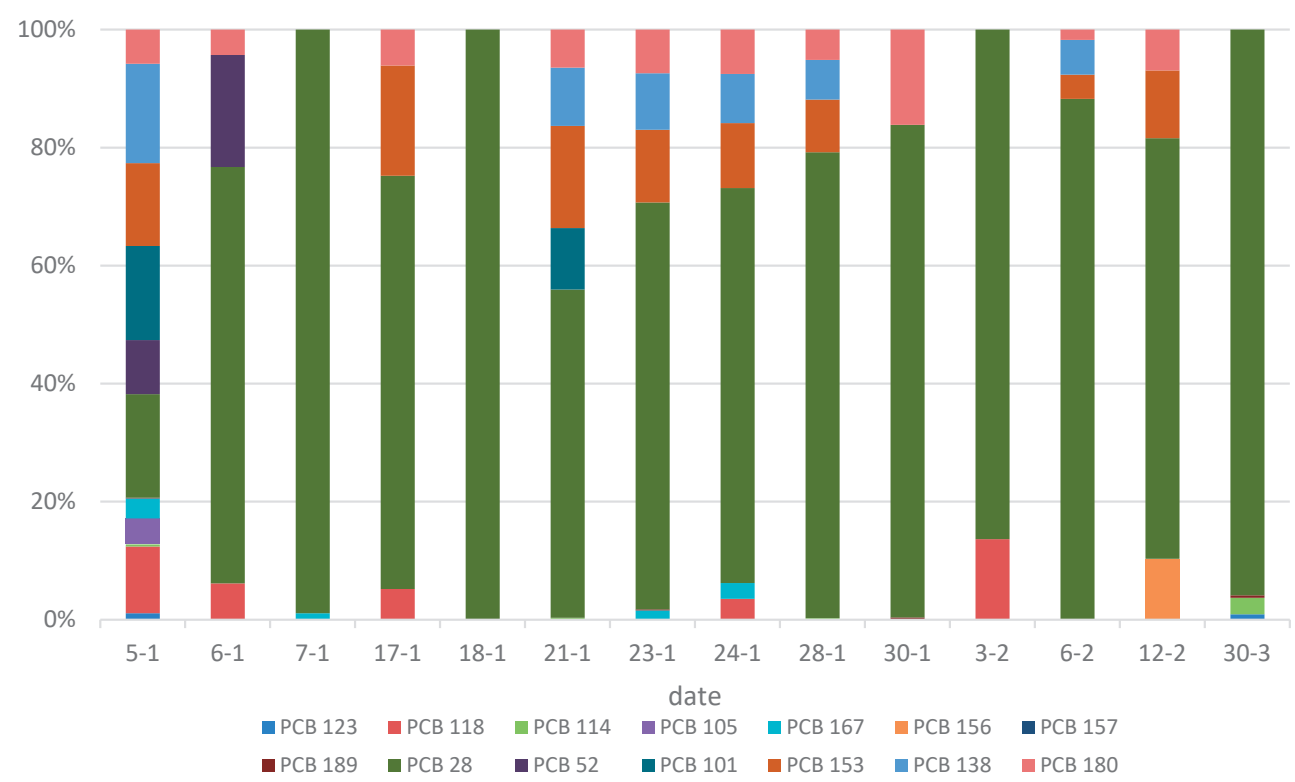

Figure 4. Contributions of different PCB congeners (\%) to the overall sum of concentrations of PCBs at $1 \mathrm{~m}$ depth.

The absolute concentrations of PCBs in the current study were approximately 10 times higher than in the Indian sector of the Sothern ocean in $1991^{19}$. Yet, they were similar to the concentrations detected around the WAP in 2008 both in terms of absolute values and in the decreasing trend towards the end of the season 5 . However, in the current study the PCB concentrations associated with the beginning of the season were almost 10 times higher than those reported in the 2008 article 5 , which may arise from a longer duration of the ice coverage, more intensive sedimentation in the current study ${ }^{29}$ or simply because the previous study might have missed the peak concentrations immediately after the ice melt. The relative concentrations of PCB congeners at $1 \mathrm{~m}$ depth are presented in figure 4 .

With a notable exception of the very first sample, the profile of PCB congeners remained relatively similar throughout the season. The most abundant congener was PCB-28, which contributed $58-100 \%$ to the overall concentrations, which is explained by the relative low hydrophobicity of this congener. It was followed by PCB-153 (0-20\%), PCB-138, PCB-180 and PCB-118 (0-10\%), with occasional inputs of other congeners. The change in composition at the start of the season may be related to the higher hydrophobicity of the heavier PCB congeners, which promotes their faster adsorption to organic matter and consecutive sedimentation. 


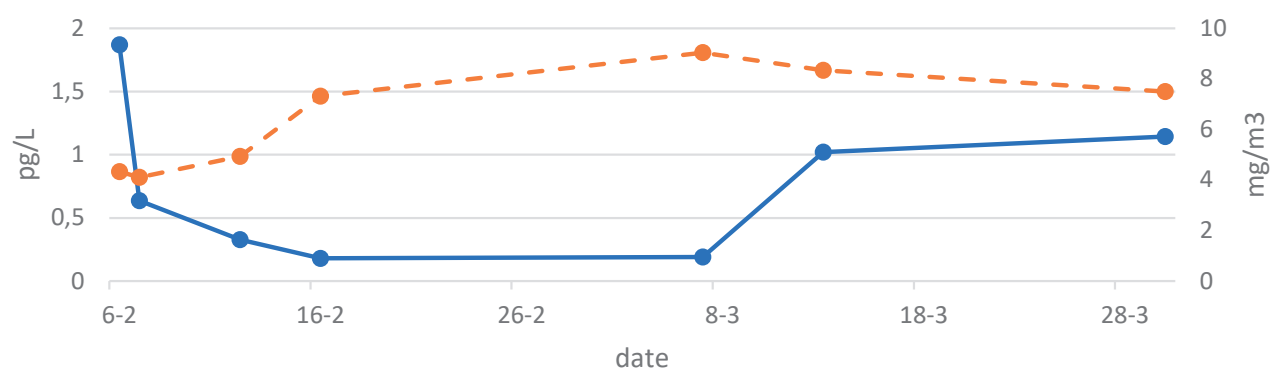

Figure 5. Rolling average of sum of concentrations of PCB congeners (blue line) in pg/L (log scale) and chlorophyll in $\mathrm{mg} / \mathrm{m}^{3}$ (dashed red line) at $20 \mathrm{~m}$ depth. Note that the timeframe is different to figure 4 .

These results were in contrast to the earlier research from 1991, where only heavy PCB congeners were detected ${ }^{19}$, while they were in a very good agreement with a more recent study from 2013, conducted around WAP5. Note that the latter study also indicated presence of some heavier PCBs (e.g. PCB-187), not analysed in the current study5.

Concentrations of PCBs at $20 \mathrm{~m}$ depth did not change much over the period from the $6^{\text {th }}$ of February to the $30^{\text {th }}$ of March, with a minimum from the $7^{\text {th }}$ of February until the $7^{\text {th }}$ of March. This was in good agreement with previous modelling studies ${ }^{30}$, which predicted relatively stable concentrations of POPs (figure 5) in particular matter at $20 \mathrm{~m}$ depth. The slightly increased PCB concentrations around the $6^{\text {th }}$ of February and from the beginning of March onwards may be attributed to increased downward vertical fluxes of PCBs with settling organic matter related to the algal bloom ${ }^{31}$.

The relative concentrations of PCBs at $20 \mathrm{~m}$ depth are shown in figure 6. Their profile resembles the relative concentrations at $1 \mathrm{~m}$, with $\mathrm{PCB}-28$ still being the most prevalent congener. A previous study in the Artic ${ }^{32}$ found a shift towards heavier PCBs at $500 \mathrm{~m}$ depth, which, however, was not observed at $20 \mathrm{~m}$ depth in the current study (the MLD was located at depth of $2-13 \mathrm{~m}$ for all data points).

Over almost the whole season the absolute PCB concentrations at $1 \mathrm{~m}$ depth were significantly higher than those at $20 \mathrm{~m}$, as they only reached similar values at the point of the last measurement on the $30^{\text {th }}$ of March. Because of the MLD depth, the water layer at $1 \mathrm{~m}$ served as the initial recipient compartment where the PCB inputs from the atmosphere (including ice and snow) start coagulation before settling down, while the $20 \mathrm{~m}$ depth layer represents a transient medium, through which particles pass on their way to the seafloor ${ }^{33}$. 


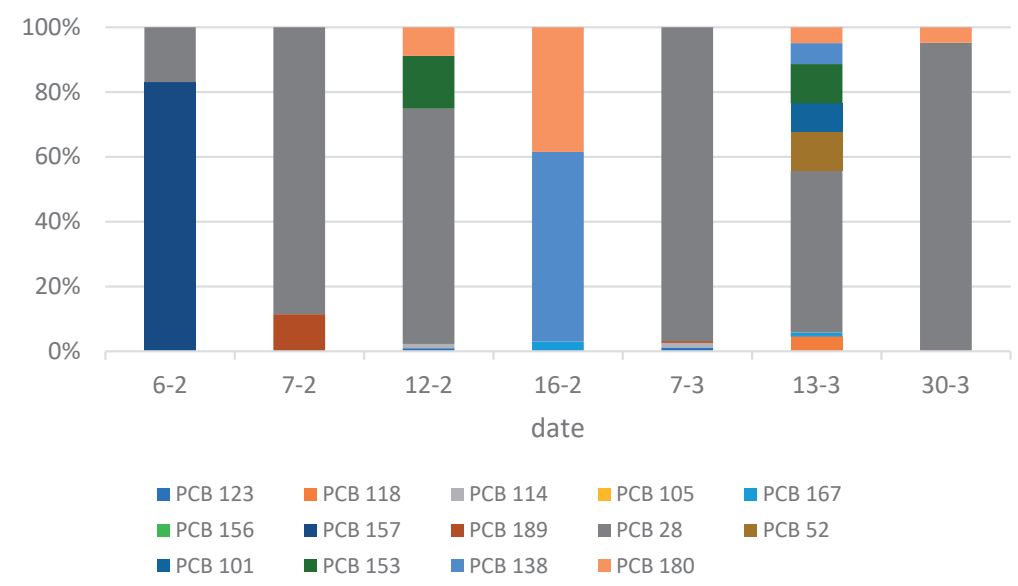

Figure 6. Contributions of different PCB congeners (\%) to the overall sum of concentrations of PCBs at $20 \mathrm{~m}$ depth.

\section{OCPs}

The most abundant OCP (and furthermore, POP) was HCH-alpha (Appendix 3), which was, relatively to other POPs, present at high levels $(50-100 \mathrm{pg} / \mathrm{L})$ at the depth of $1 \mathrm{~m}$ at the beginning of the season (the $5^{\text {th }}$ of January till the $10^{\text {th }}$ January).

Previous studies demonstrated the presence of $\mathrm{HCH}$-alpha in Antarctic phytoplankton around the WAP in 2004 ${ }^{18}$ and $2013^{5}$ but in 10-100 times lower concentrations. On the other hand, $\mathrm{HCH}$-alpha concentrations in this study were lower than both the historical and recent reports for the Artic ${ }^{34,35}$. The most likely reason for these rather high in comparison to other OCPs concentrations of $\mathrm{HCH}$-alpha was the relatively low Kow value of the compound (Appendix 4) which would make it likely to partition to the water phase and thus be less prone to sedimentation with organic matter (biological pump ${ }^{27}$ ). The sharp decline in concentrations after the $10^{\text {th }}$ of January may have been related to the earlier mixing of the surface water. More complexity may have also been brought by microbial activity - an important driver of $\mathrm{HCH}$-alpha kinetics in the environment ${ }^{36,37}$, although this may be of less importance in the colder conditions of the Antarctic.

Among other detected OCPs were heptachlor, HCB, trans-Chlordane, Aldrin and ppDDE (Appendix 3). Their concentrations (0-4 pg/L) were much lower than of $\mathrm{HCH}$-alpha, and they steadily declined towards the end of the season. The absence of HCH-gamma in contrast to relative high $\mathrm{HCH}$-alpha concentrations can be explained by the high activity of the biological pump during the algae bloom, which depleted $\mathrm{HCH}$-gamma more intensively than $\mathrm{HCH}$-alpha due to a slightly higher hydrophobicity of the former ${ }^{27}$. 
When compared to the previous research, the OCP concentrations in the current study, including $\mathrm{HCH}$-alpha, were 10-20 times lower than those reported in 1991 from sites around Dronning Maud land ${ }^{19}$, but $\mathrm{HCH}$-gamma concentrations in particular were similar to the ones measured around Anvers Island (Palmer station) and the WAP in 2006 and 2013 respectively ${ }^{5,18}$. Generally, the concentrations of OCPs followed the same trend as the concentrations of PCBs. Because the majority of OCPs are less hydrophobic than PCBs, the decrease in the concentrations after the bloom may be expected to have been less rapid. However, apart from $\mathrm{HCH}$-alpha, the concentrations of OCPs were lower than of PCBs, which may be related to lower atmospheric inputs of OPCs when compared to PCBs.

Most observations of concentrations of the OCPs at the depth of 20m were below detection limits (Appendix 3), which confirmed the previously established low potential of OCPs to be transported down the water column, related to their relatively low Kow ${ }^{27}$.

Because sampling in this study was conducted in the vicinity of a melting glacier (the Sheldon Glacier), the almost complete absence of DDT-group congeners, indicating influx of non-degraded DDTs, strikingly contradicts the previous theory that glaciers are an important secondary source of DDTs into the Antarctic environment ${ }^{38,39}$.

\section{PBDEs}

Figure 7 presents, to the best knowledge of the authors, the first report of PBDEs identified in Antarctic waters. The concentrations were relatively low and dropped down to the detection limits by the end of the season.

Over the season concentrations of PBDEs followed a pattern similar to PCBs and OCPs, having the highest values $(10 \mathrm{pg} / \mathrm{L})$ after the melting of the sea ice and then gradually declining. As the Kow values of the majority of PBDEs are higher than of PCBs and OCPs, their sedimentation occurred faster, and the values of around $0.1 \mathrm{pg} / \mathrm{L}$ were already reached in the end of January. At the $20 \mathrm{~m}$ depth PBDEs were detected only sporadically in the samples at concentrations of around $0.1 \mathrm{pg} / \mathrm{L}$ (Appendix 3).

A study in 2011 from the Artic conducted at the end of summer ${ }^{40}$ showed PBDE concentrations similar to the ones found at the end of the season in the current study, although concentrations of PBDEs in Antarctic pelagic biota are generally known to be lower than in the Artic ${ }^{41}$.

Figure 8 illustrates relative concentrations of PBDEs.

While the exact PBDE congener composition varied between samples, overall there was a dominance of heavier PBDEs (BDE-85, BDE-99, BDE-119, BDE-154). This was generally 


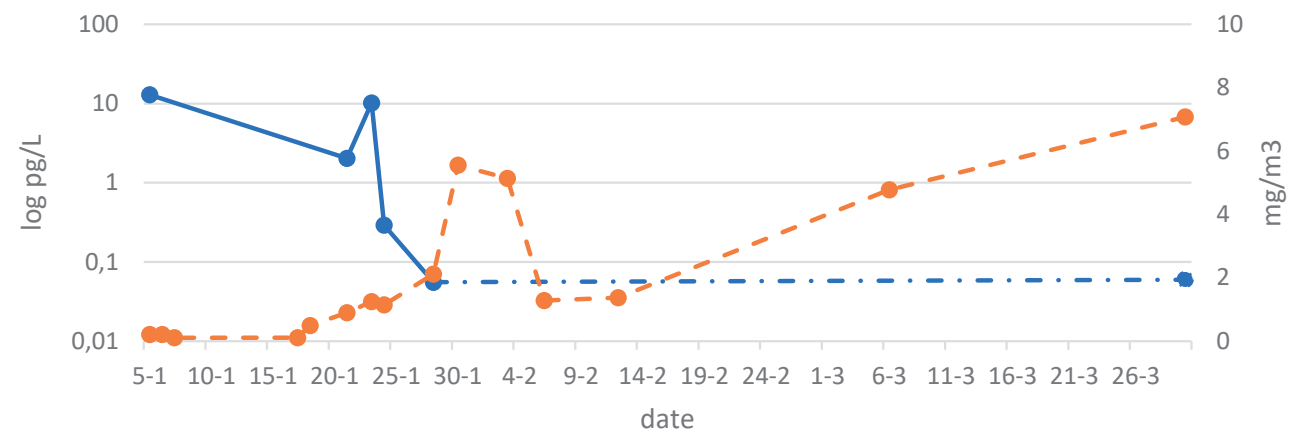

Figure 7. Rolling average of sum of concentrations of PBDE congeners (blue line) (log scale) in pg/L and chlorophyll in $\mathrm{mg} / \mathrm{m}^{3}$ (dashed red line) at $1 \mathrm{~m}$ depth (only including samples with concentrations of PBDEs above LOD).

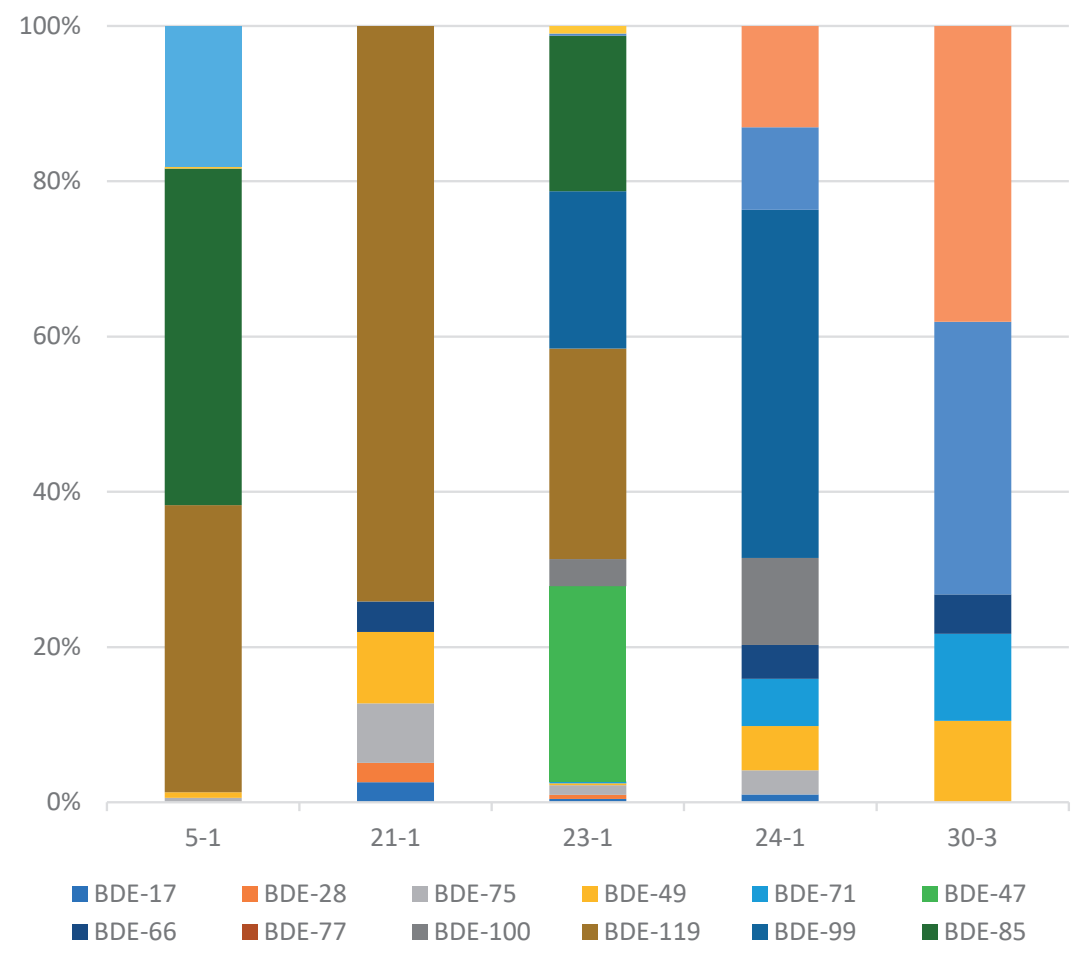

Figure 8. Contributions of different PBDE congeners (\%) to the overall sum of PBDEs at $1 \mathrm{~m}$ depth (only including samples with concentrations of PBDEs above LOD).

in a good agreement with previous research from the Artic ${ }^{40}$, with a notable exception of presence of BDE-119 in the current study. However, these patterns differ from the ones of PCBs in the current study, which showed a predominance of lighter congeners. Presence of BDE-99 and BDE1-54 can be likely explained by their abundancy in technical mixtures of PBDEs ${ }^{42}$. BDE-119 and BDE-85 may originate from degradation of BDE-20943,44, and 
thus may provide an indirect evidence of presence of BDE-209 in the Southern Ocean. At the same time, the absence of lighter PBDEs can be explained by their high (relative to PCBs) hydrophobicity (Appendix 5) and therefore higher chance of being removed from the upper layers of water by the biological pump ${ }^{27}$.

The current study for the first time comprehensively examined the seasonal change in concentrations of POPs in the Antarctic coastal marine environment. Due to their depletion at the beginning of the season following oceanographic (chiefly abiotic) and algae dynamics, the concentrations demonstrated considerable fluctuation when compared to the similar research in the polar marine ecosystems around $\mathrm{Erope}^{28}$. It was shown that POPs were received by the upper layers of the Antarctic marine waters from the melting sea ice. After this POPs with relatively high Kow were effectively transported to deeper layers with algae towards the benthic ecosystem. This would indicate that the Antarctic pelagic marine ecosystem is a transient compartment for POPs, while the benthic ecosystem is likely the final sink.

The variable kinetics make interpretation of long-term data difficult, and thus suggest that other environmental endpoints (e.g. birds or benthic animals) should be included in considerations for this task. Additionally, it creates difficulties with comparisons with historic data sets as these may be collected at different times of year and therefore under different phases within the seasonal oceanographic cycle. However, investigation of the concentrations of POPs in the particulate phase of seawater is absolutely essential for modelling of environmental transport and evaluation of the toxicological effects of these compounds. 


\section{ACKNOWLEDGEMENT}

The authors acknowledge help of the British Antarctic Survey (BAS) with infrastructure and coordination. The BAS boating officers, especially Adam Burke, are acknowledged for their support in sampling. We express our gratitude towards the Technical Development Studio of WUR for designing and constructing the pump. We thank Willie Hijman and Guido van der Weg for their help with measurements of PCBs. We express our gratitude towards the Netherlands Organisation for Scientific Research (NWO) (grant 866.14.104) for financing this project. 


\section{REFERENCES}

1. Morris, A. D.; Muir, D. C. G.; Solomon, K. R.; Letcher, R. J.; McKinney, M. A.; Fisk, A. T.; McMeans, B. C.; Tomy, G. T.; Teixeira, C.; Wang, X.; et al. Current-Use Pesticides in Seawater and Their Bioaccumulation in Polar Bear-Ringed Seal Food Chains of the Canadian Arctic. Environ. Toxicol. Chem. 2016, 35 (7), 1695-1707. https://doi.org/10.1002/etc.3427.

2. Bengtson Nash, S. Persistent Organic Pollutants in Antarctica: Current and Future Research Priorities. J. Environ. Monit. 2011, 13 (3), 497. https://doi.org/10.1039/c0em00230e.

3. Jones, K. C.; de Voogt, P. Persistent Organic Pollutants (POPs): State of the Science. Environ. Pollut. 1999, 100 (1-3), 209-221. https://doi.org/10.1016/S0269-7491(99)00098-6.

4. Bates, M. L.; Bengtson Nash, S. M.; Hawker, D. W.; Shaw, E. C.; Cropp, R. A. The Distribution of Persistent Organic Pollutants in a Trophically Complex Antarctic Ecosystem Model. J. Mar. Syst. 2017, 170, 103-114. https://doi.org/10.1016/J.JMARSYS.2017.02.005.

5. Galbán-Malagón, C. J.; Del Vento, S.; Berrojalbiz, N.; Ojeda, M.-J.; Dachs, J. Polychlorinated Biphenyls, Hexachlorocyclohexanes and Hexachlorobenzene in Seawater and Phytoplankton from the Southern Ocean (Weddell, South Scotia, and Bellingshausen Seas). Environ. Sci. Technol. 2013, 47 (11), 5578-5587. https://doi.org/10.1021/es400030q.

6. Xu, W.; Wang, X.; Cai, Z. Analytical Chemistry of the Persistent Organic Pollutants Identified in the Stockholm Convention: A Review. Anal. Chim. Acta 2013, 790, 1-13. https://doi.org/10.1016/J. ACA.2013.04.026.

7. Tanabe, S.; Hidaka, H.; Tatsukawa, R. PCBs and Chlorinated Hydrocarbon Pesticides in Antarctic Atmosphere and Hydrosphere. Chemosphere 1983, 12 (2), 277-288. https://doi.org/10.1016/00456535(83)90171-6.

8. Xie, Z.; Koch, B. P.; Möller, A.; Sturm, R.; Ebinghaus, R. Transport and Fate of Hexachlorocyclohexanes in the Oceanic Air and Surface Seawater. Biogeosciences 2011, 8 (9), 2621-2633. https://doi.org/10.5194/bg-8-2621-2011.

9. Sönke Lakaschus, * $†$; Kurt Weber, †; Frank Wania, $\ddagger$; Regina Bruhn, $₫$ and; Schrems $\dagger$, O. The Air-Sea Equilibrium and Time Trend of Hexachlorocyclohexanes in the Atlantic Ocean between the Arctic and Antarctica. 2001. https://doi.org/10.1021/ES010211J.

10. Schreitmueller, J.; Ballschmiter, K. Air-Water Equilibrium of Hexachlorocyclohexanes and Chloromethoxybenzenes in the North and South Atlantic. Environ. Sci. Technol. 1995, 29 (1), 207215. https://doi.org/10.1021/es00001a027.

11. Sen Gupta, R.; Sarkar, A.; Kureishey, T. W. PCBs and Organochlorine Pesticides in Krill, Birds and Water from Antartica. Deep Sea Res. Part II Top. Stud. Oceanogr. 1996, 43 (1), 119-126. https://doi. org/10.1016/0967-0645(95)00086-0.

12. Rebecca M. Dickhut, *,; Alessandra Cincinelli, $\ddagger$; Michele Cochran, $\dagger$ and; Ducklow $\dagger$, H. W. Atmospheric Concentrations and Air-Water Flux of Organochlorine Pesticides along the Western Antarctic Peninsula. 2004. https://doi.org/10.1021/ES048648P.

13. Luek, J. L.; Dickhut, R. M.; Cochran, M. A.; Falconer, R. L.; Kylin, H. Persistent Organic Pollutants in the Atlantic and Southern Oceans and Oceanic Atmosphere. Sci. Total Environ. 2017, 583, 6471. https://doi.org/10.1016/j.scitotenv.2016.12.189.

14. Bigot, M.; Muir, D. C. G.; Hawker, D. W.; Cropp, R.; Dachs, J.; Teixeira, C. F.; Bengtson Nash, S. Air-Seawater Exchange of Organochlorine Pesticides in the Southern Ocean between Australia and Antarctica. Environ. Sci. Technol. 2016, 50 (15), 8001-8009. https://doi.org/10.1021/acs.est. $6 \mathrm{~b} 01970$.

15. Bigot, M.; Hawker, D. W.; Cropp, R.; Muir, D. C.; Jensen, B.; Bossi, R.; Bengtson Nash, S. M. Spring Melt and the Redistribution of Organochlorine Pesticides in the Sea-Ice Environment: A Comparative Study between Arctic and Antarctic Regions. Environ. Sci. Technol. 2017, 51 (16), 8944-8952. https://doi.org/10.1021/acs.est.7b02481. 
16. Fuoco, R.; Giannarelli, S.; Wei, Y.; Ceccarini, A.; Abete, C.; Francesconi, S.; Termine, M. Persistent Organic Pollutants (POPs) at Ross Sea (Antarctica). Microchem. J. 2009, 92 (1), 44-48. https://doi. org/10.1016/J.MICROC.2008.11.004.

17. Cincinelli, A.; Martellini, T.; Del Bubba, M.; Lepri, L.; Corsolini, S.; Borghesi, N.; King, M. D.; Dickhut, R. M. Organochlorine Pesticide Air-Water Exchange and Bioconcentration in Krill in the Ross Sea. Environ. Pollut. 2009, 157 (7), 2153-2158. https://doi.org/10.1016/J. ENVPOL.2009.02.010.

18. Amy L. Chiuchiolo; Rebecca M. Dickhut, *; Michele A. Cochran, and; Ducklow, H. W. Persistent Organic Pollutants at the Base of the Antarctic Marine Food Web. 2004. https://doi.org/10.1021/ ES0351793.

19. Joiris, C. R.; Overloop, W. PCBs and Organochlorine Pesticides in Phytoplankton and Zooplankton in the Indian Sector of the Southern Ocean. Antarct. Sci. 1991, 3 (4), 371-377. https:/doi. org/10.1017/S0954102091000470.

20. Bates, M. L.; Bigot, M.; Cropp, R. A.; Engwirda, D.; Friedman, C. L.; Hawker, D. W. On the Formulation of Environmental Fugacity Models and Their Numerical Solutions. Environ. Toxicol. Chem. 2016, 35 (9), 2182-2191. https://doi.org/10.1002/etc.3403.

21. Cropp, R.; Kerr, G.; Bengtson-Nash, S.; Hawker, D. A Dynamic Biophysical Fugacity Model of the Movement of a Persistent Organic Pollutant in Antarctic Marine Food Webs. Environ. Chem. 2011, 8 (3), 263. https://doi.org/10.1071/EN10108.

22. Harris, T.; Smith, V. Do Persistent Organic Pollutants Stimulate Cyanobacterial Blooms? Inl. Waters 2016, 6 (2), 124-130. https://doi.org/10.5268/IW-6.2.887.

23. Wild, S.; McLagan, D.; Schlabach, M.; Bossi, R.; Hawker, D.; Cropp, R.; King, C. K.; Stark, J. S.; Mondon, J.; Nash, S. B. An Antarctic Research Station as a Source of Brominated and Perfluorinated Persistent Organic Pollutants to the Local Environment. Environ. Sci. Technol. 2015, 49 (1), $103-$ 112. https://doi.org/10.1021/es5048232.

24. Gröndahl, F.; Sidenmark, J.; Thomsen1, A. Survey of Waste Water Disposal Practices at Antarctic Research Stations. Polar Res. 2009, 28 (2), 298-306. https://doi.org/10.1111/j.17518369.2008.00056.x.

25. Venables, H. A. B. P. H. M. M. Rothera Time Series - Project - British Antarctic Survey https:// www.bas.ac.uk/project/rats/\#about (accessed May 9, 2019).

26. Personal Communication with Rothera Marine Research Support Stuff. 2017.

27. Galbán-Malagón, C.; Berrojalbiz, N.; Ojeda, M.-J.; Dachs, J. The Oceanic Biological Pump Modulates the Atmospheric Transport of Persistent Organic Pollutants to the Arctic. Nat. Commun. 2012, 3 (1), 862. https://doi.org/10.1038/ncomms1858.

28. Bruhn, R.; McLachlan, M. S. Seasonal Variation of Polychlorinated Biphenyl Concentrations in the Southern Part of the Baltic Sea. Mar. Pollut. Bull. 2002, 44 (2), 156-163. https://doi.org/10.1016/ S0025-326X(01)00198-9.

29. Fitzgerald, S. A.; Steuer, J. J. Association of Polychlorinated Biphenyls (PCBs) with Live Algae and Total Lipids in Rivers—a Field-Based Approach. Sci. Total Environ. 2006, 354 (1), 60-74. https:// doi.org/10.1016/J.SCITOTENV.2004.11.025.

30. Jurado, E.; Zaldívar, J.-M.; Marinov, D.; Dachs, J. Fate of Persistent Organic Pollutants in the Water Column: Does Turbulent Mixing Matter? Mar. Pollut. Bull. 2007, 54 (4), 441-451. https:/doi. org/10.1016/J.MARPOLBUL.2006.11.028.

31. PECK, L. S.; BARNES, D. K. A.; COOK, A. J.; FLEMING, A. H.; ClARKE, A. Negative Feedback in the Cold: Ice Retreat Produces New Carbon Sinks in Antarctica. Glob. Chang. Biol. 2010, 16 (9), 2614-2623. https://doi.org/10.1111/j.1365-2486.2009.02071.x. 
32. Ma, Y.; Adelman, D. A.; Bauerfeind, E.; Cabrerizo, A.; McDonough, C. A.; Muir, D.; Soltwedel, T.; Sun, C.; Wagner, C. C.; Sunderland, E. M.; et al. Concentrations and Water Mass Transport of Legacy POPs in the Arctic Ocean. Geophys. Res. Lett. 2018, 45 (23), 12,972-12,981. https://doi. org/10.1029/2018GL078759.

33. Jurado, E.; Lohmann, R.; Meijer, S.; Jones, K. C.; Dachs, J. Latitudinal and Seasonal Capacity of the Surface Oceans as a Reservoir of Polychlorinated Biphenyls. Environ. Pollut. 2004, 128 (1-2), $149-162$.

34. Wang, X.; Wang, C.; Zhu, T.; Gong, P.; Fu, J.; Cong, Z. Persistent Organic Pollutants in the Polar Regions and the Tibetan Plateau: A Review of Current Knowledge and Future Prospects. Environ. Pollut. 2019, 248, 191-208. https://doi.org/10.1016/J.ENVPOL.2019.01.093.

35. Li, Y. .; Macdonald, R. .; Ma, J. .; Hung, H.; Venkatesh, S. Historical $\alpha-\mathrm{HCH}$ Budget in the Arctic Ocean: The Arctic Mass Balance Box Model (AMBBM). Sci. Total Environ. 2004, 324 (1-3), 115-139. https://doi.org/10.1016/J.SCITOTENV.2003.10.022.

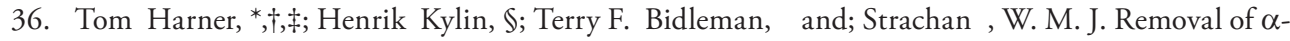
and $\gamma$-Hexachlorocyclohexane and Enantiomers of $\alpha$-Hexachlorocyclohexane in the Eastern Arctic Ocean. 1999. https://doi.org/10.1021/ES980898G.

37. Pućko, M.; Stern, G. A.; Macdonald, R. W.; Barber, D. G.; Rosenberg, B. When Will $\alpha-\mathrm{HCH}$ Disappear from the Western Arctic Ocean? J. Mar. Syst. 2013, 127, 88-100. https://doi.org/10.1016/J. JMARSYS.2011.09.007.

38. Brink, N. van den; Riddle, M.; Heuvel-Greve, M. van den; Allison, I.; Snape, I.; van Franeker, J. A. Correspondence on Geisz et Al. Melting Glaciers: A Probable Source of DDT to the Antarctic Marine Ecosystem. Environ. Sci. Technol. 2009, 43 (10), 3976-3977. https://doi.org/10.1021/ es8034494.

39. Geisz, H. N.; Dickhut, R. M.; Cochran, M. A.; Fraser, W. R.; Ducklow, H. W. Melting Glaciers: A Probable Source of DDT to the Antarctic Marine Ecosystem. Environ. Sci. Technol. 2008, 42 (11), 3958-3962. https://doi.org/10.1021/es702919n.

40. Möller, A.; Xie, Z.; Sturm, R.; Ebinghaus, R. Polybrominated Diphenyl Ethers (PBDEs) and Alternative Brominated Flame Retardants in Air and Seawater of the European Arctic. Environ. Pollut. 2011, 159 (6), 1577-1583. https://doi.org/10.1016/J.ENVPOL.2011.02.054.

41. Markham, E.; Brault, E. K.; Khairy, M.; Robuck, A. R.; Goebel, M. E.; Cantwell, M. G.; Dickhut, R. M.; Lohmann, R. Time Trends of Polybrominated Diphenyl Ethers (PBDEs) in Antarctic Biota. ACS omega 2018, 3 (6), 6595-6604. https://doi.org/10.1021/acsomega.8b00440.

42. Mark J. La Guardia, *; Robert C. Hale, and; Harvey, E. Detailed Polybrominated Diphenyl Ether (PBDE) Congener Composition of the Widely Used Penta-, Octa-, and Deca-PBDE Technical Flame-Retardant Mixtures. 2006. https://doi.org/10.1021/ES060630M.

43. Chen, J.; Luo, J.; Luo, Q.; Pang, Z.; Group, C. E. P. Wastewater Treatment: Application of New Functional Materials.

44. Zeng, X.; Simonich, S. L. M.; Robrock, K. R.; Korytár, P.; Alvarez-Cohen, L.; Barofsky, D. F. Development and Validation of a Congener-specific Photodegradation Model for Polybrominated Diphenyl Ethers. Environ. Toxicol. Chem. 2008, 27 (12), 2427-2435. https://doi.org/10.1897/07570.1 . 


\section{SUPPLEMENTARY INFORMATION}

\section{Table of contents}

Appendix 1. Chemical analysis

Appendix 2. Quality analysis/quality control

Appendix 3. Concentration of POPs in individual samples

Appendix 4. Physico-chemical properties of measured POPs. 


\section{APPENDIX 1. CHEMICAL ANALYSIS}

\section{Appendix 1A. Complete extraction and clean-up procedure.}

1. Weigh 3 gram $\pm 1 \mathrm{mg}$ of sample in a $60 \mathrm{ml}$ glass tube.

2. Add internal standards.

3. Add as much NanoQ water as needed to reach the total volume of $13 \mathrm{ml}$ (= $13-0.8^{*}$ weight of the sample).

4. Vortex or shake vigorously to mix the water and the sample.

5. Add $10 \mathrm{ml}$ Ethyl Acetate, vortex and mix head-over-head for 10 minutes.

6. Add a homogenised mixture of 2 gram Sodium chloride and 4 gram Magnesium sulphate, and shake vigorously for at least 2 minutes. If no liquid phase is visible, add $1 \mathrm{ml}$ of methanol.

7. Centrifuge for 10 minutes at $1500 \mathrm{rpm}$.

8. Repeat steps 5-7 two times.

9. Transfer the Ethyl Acetate phase to a pre-cleaned Turbovap ${ }^{\oplus}$ glass tube, evaporate in a Turbovap ${ }^{\oplus}$ Evaporator at $40^{\circ} \mathrm{C}$ and 0.8 Bar to the volume of $1 \mathrm{ml}$.

10. Take a fraction of the sample $(0.1$ or $0.2 \mathrm{ml})$ for lipid analysis.

11. Add $3 \mathrm{ml}$ of hexane.

12. Transfer the Hexane/Ethyl Acetate mixture to a pre-rinsed $60 \mathrm{ml}$ brown glass tube.

13. Rinse the Turbovap ${ }^{\oplus}$ glass tube three more times with $9 \mathrm{ml}$ of Hexane and transfer the solvent to the $60 \mathrm{ml}$ brown glass tube.

14. Mix in a pre-rinsed Erlenmeyer flask 60 gram activated silica with 40 gram of concentrated Sulphuric acid (i.e. to get $40 \% \mathrm{H}_{2} \mathrm{SO}_{4}$ ).

15. Add 10 gram of the $40 \%$ acid silica to the $60 \mathrm{ml}$ tube and mix, repeat mixing 3 times with intervals of 10 minutes.

16. Leave the samples stand overnight.

17. Centrifuge for 10 minutes at $1500 \mathrm{rpm}$.

18. Transfer the Hexane into a pre-cleaned Turbovap ${ }^{\oplus}$ tube.

19. Add $10 \mathrm{ml}$ of Hexane to the $60 \mathrm{ml}$ tube (with the solid phase of the sample in it) and mix.

20. Repeat steps $17-19$ two times.

21. Evaporate Hexane phase of the sample in the Turbovap ${ }^{\oplus}$ at $40^{\circ} \mathrm{C}$ and $0.8 \mathrm{Bar}$ to the volume of $1 \mathrm{ml}$.

22. Prepare a clean-up column by filling a glass column with glass wool stopper, 1 gram conditioned silica and 8 grams of $40 \%$ acid silica (prepared in the step 14).

23. Elute the column firstly with $10 \mathrm{ml}$ of Hexane, wait 5 minutes, and add another 15 $\mathrm{ml}$ of Hexane.

24. Discard these Hexane fractions.

25. Place a clean Turbovap ${ }^{\oplus}$ tube under the column and add the $1 \mathrm{ml}$ extract of the sample onto the column. 
26. Rinse the initial Turbovap ${ }^{\oplus}$ tube two times with $1 \mathrm{ml}$ of Hexane and add these fractions onto the column.

27. Leave the column for 15 minutes.

28. Eluate first with $18 \mathrm{ml}$ of Hexane and then with $12 \mathrm{ml}$ Dichloromethane.

29. Evaporate Hexane/Dichloromethane mix in Turbovap ${ }^{\oplus}$ at $40^{\circ} \mathrm{C}$ and $0.8 \mathrm{Bar}$ to the volume of $1 \mathrm{ml}$.

30. Rinse the walls of the Turbovap ${ }^{\oplus}$ tube twice carefully with $0.5 \mathrm{ml}$ of lso-Octane and thoroughly mix.

31. Evaporate again in the Turbovap ${ }^{\oplus}$ at $40^{\circ} \mathrm{C}$ and 0.8 Bar to a volume of $1 \mathrm{ml}$.

32. Store the sample in an amber glass vial at $-20^{\circ} \mathrm{C}$. 


\section{Appendix 1B. Instrumental settings for analysis of POPs}

\section{PCBs}

The GC method for PCB analysis was adapted without changes from:

Guillaume ten Dam, Pussente I.C., Scholl G., Eppe G., Schaechtele A., van Leeuwen S. The performance of atmospheric pressure gas chromatography-tandem mass spectrometry compared to gas chromatography-high resolution mass spectrometry for the analysis of polychlorinated dioxins and polychlorinated biphenyls in food and feed samples. Journal of Chromatography A. Volume 1477, Pages 76-90.

\section{PBDEs}

The GC method for PBDE analysis was designed at RIKILT specifically for usage on an HRMS system.

The PBDEs included in this study are BDE-47, -66, -85, -99, -100, -138, -153, -154, and 183. PBDEs were quantified by a magnetic sector Autospec high resolution mass spectrometer (HRMS) from Waters (Manchester, UK) equipped with an Agilent 6890 gas chromatograph (GC) (Santa Clara, USA). The GC was equipped with a programmed temperature vaporiser (PTV injector, Gerstel, Mülheim an der Ruhr, Germany) which allowed injection of 10 $\mu \mathrm{l}$ extract. A CL-Pesticide $30 \mathrm{~m} \times 0.25 \mathrm{~mm}$ i.d. $\times 0.25 \mu \mathrm{m}$ film thickness analytical column (Restek, Bellefonte, USA) was fitted for the separation. The HRMS is operated in the EI+ mode, at $35 \mathrm{eV}$. The source temperature is $260^{\circ} \mathrm{C}$. Resolution is set at $10000 \pm 1000$ at $10 \%$ peak height. The photomultiplier gain is set at $350 \mathrm{~V}$. The ions monitored and GC-settings are specified in below tables. 
Table 1. Settings GC for PBDE analysis.

\begin{tabular}{|c|c|}
\hline Parameter & Setting Unit \\
\hline Mode & Solvent vent \\
\hline initial injection temperature & $20^{\circ} \mathrm{C}$ \\
\hline Rate 1 & $6^{\circ} \mathrm{C}$ \\
\hline Final temperature 1 & $90^{\circ} \mathrm{C} / \mathrm{s}$ \\
\hline Hold 1 & $0.1 \mathrm{~min}$ \\
\hline Rate 2 & $10^{\circ} \mathrm{C} / \mathrm{s}$ \\
\hline Final temperature 2 & $280^{\circ} \mathrm{C}$ \\
\hline Hold 2 & $50 \mathrm{~min}$ \\
\hline Injection volume & $10 \bigotimes l$ \\
\hline Vent flow & $200 \mathrm{ml} / \mathrm{min}$ \\
\hline Vent pressure & $3 \mathrm{kPa}$ \\
\hline Carrier & Helium \\
\hline Injection pressure mode & Constant flow \\
\hline Column flow & $2 \mathrm{ml} / \mathrm{min}$ \\
\hline Initial oven temperature & $120^{\circ} \mathrm{C}$ \\
\hline Time at initial oven temperature & $2 \min$ \\
\hline Gradient & $7^{\circ} \mathrm{C} / \mathrm{min}$ \\
\hline Final temperature & $300^{\circ} \mathrm{C}$ \\
\hline Time at final temperature & $25 \mathrm{~min}$ \\
\hline
\end{tabular}


Chapter 3

Table 2. Data acquisition methods for the HRMS for PBDE analysis.

Group 1 (TBDE) BDE-47, -66

\begin{tabular}{|c|c|c|c|}
\hline Window & $15.5-19 \mathrm{~min}$ & & \\
\hline Mass & Time (ms) & Delay (ms) & $L M$ \\
\hline 483.7131 & 80 & 20 & \\
\hline 485.7111 & 80 & 10 & \\
\hline 492.9696 & 80 & 10 & V \\
\hline 495.7533 & 80 & 10 & \\
\hline 497.7513 & 80 & 10 & \\
\hline
\end{tabular}

Group 2 (PeBDE) BDE-85, -99, -100

\begin{tabular}{|c|c|c|c|}
\hline Window & $19-21.3 \mathrm{~min}$ & & \\
\hline Mass & Time (ms) & Delay (ms) & $L M$ \\
\hline 563.6215 & 80 & 20 & \\
\hline 565.6195 & 80 & 10 & \\
\hline 566.9664 & 80 & 10 & V \\
\hline 575.6618 & 80 & 10 & \\
\hline 577.6598 & 80 & 10 & \\
\hline
\end{tabular}

Group 3 (HxBDE) BDE-138, 153, 154

\begin{tabular}{llll}
\hline Window & $21.3-23.7 \mathrm{~min}$ & & \\
\hline Mass & Time $(\mathrm{ms})$ & Delay $(\mathrm{ms})$ & $L M$ \\
\hline 641.5320 & 80 & 20 & 10 \\
\hline 643.5300 & 80 & 10 & 10
\end{tabular}

Group 4 (HpBDE) BDE-183

\begin{tabular}{|c|c|c|c|}
\hline Window & $24.2-26.5 \mathrm{~min}$ & & \\
\hline Mass & Time (ms) & Delay (ms) & $L M$ \\
\hline 721.4405 & 80 & 20 & \\
\hline 723.4385 & 80 & 10 & \\
\hline 730.9537 & 80 & 10 & V \\
\hline 733.4808 & 80 & 10 & \\
\hline 735.4788 & 80 & 10 & \\
\hline
\end{tabular}

*LM: Lock Mass 


\section{OCPs}

The OCPCB's were quantified with a triple quad mass spectrometer (Agilent 7010B) equipped with an Agilent 7890B gas chromatograph and an Agilent 7693 autosampler, all from Agilent technologies (Santa Clara, USA). The GC was equipped with a programmed temperature vaporizer (PTV injector) which allowed injection of $5 \mu$ l extract. A A CLPesticide $30 \mathrm{~m} \times 0.25 \mathrm{~mm}$ i.d. x $0.25 \mu \mathrm{m}$ film thickness analytical column (Restek, Bellefonte, USA) was fitted for the separation. The MS was operated in the EI+ mode. The source temperature is $250^{\circ} \mathrm{C}$, gainfactor $5 \mathrm{~V}$, with an signal limiter of $1.0 \mathrm{E} 08$. The ions monitored and GC-settings are specified below

Table 3. Settings GC for OCP analysis.

\begin{tabular}{|c|c|}
\hline Parameter & Setting Unit \\
\hline Mode & Solvent vent \\
\hline initial injection temperature & $70^{\circ} \mathrm{C}$ \\
\hline Initial time & $0.11 \mathrm{~min}$ \\
\hline Rate 1 & $750{ }^{\circ} \mathrm{C} / \mathrm{s}$ \\
\hline Final temperature 1 & $275^{\circ} \mathrm{C}$ \\
\hline Hold 1 & $1.5 \mathrm{~min}$ \\
\hline Rate 2 & $275^{\circ} \mathrm{C} / \mathrm{s}$ \\
\hline Final temperature 2 & $350{ }^{\circ} \mathrm{C}$ \\
\hline Hold 2 & $2 \min$ \\
\hline Injection volume & $5 \otimes l$ \\
\hline Vent flow & $75 \mathrm{ml} / \mathrm{min}$ \\
\hline Vent pressure & $2 \mathrm{psi}$ \\
\hline Carrier & Helium \\
\hline Injection pressure mode & Constant flow \\
\hline Column flow & $1,2 \mathrm{ml} / \mathrm{min}$ \\
\hline Initial oven temperature & $60^{\circ} \mathrm{C}$ \\
\hline Time at initial oven temperature & $2 \min$ \\
\hline Gradient & $20^{\circ} \mathrm{C} / \mathrm{min}$ \\
\hline $2^{\text {nd }}$ temperature & $150^{\circ} \mathrm{C}$ \\
\hline hold & $0 \min$ \\
\hline gradient & $10^{\circ} \mathrm{C} / \mathrm{min}$ \\
\hline $3^{\text {rd }}$ temperature & $280^{\circ} \mathrm{C}$ \\
\hline hold & $0 \min$ \\
\hline gradient & $25^{\circ} \mathrm{C} / \mathrm{min}$ \\
\hline Final temperature & $320^{\circ} \mathrm{C}$ \\
\hline Time at final temperature & $5 \mathrm{~min}$ \\
\hline
\end{tabular}




\section{APPENDIX 2. QUALITY ANALYSIS/QUALITY CONTROL}

\section{Appendix 2A. Limits of quantification}

\begin{tabular}{|c|c|}
\hline Compound & $\mathrm{ng} / \mathrm{ml}$ \\
\hline PCB 123 & 0.000 \\
\hline PCB 118 & 0.071 \\
\hline PCB 114 & 0.000 \\
\hline PCB 105 & 0.129 \\
\hline PCB 167 & 0.004 \\
\hline PCB 156 & 0.000 \\
\hline PCB 157 & 0.000 \\
\hline PCB 189 & 0.000 \\
\hline PCB 28 & 0.163 \\
\hline PCB 52 & 0.323 \\
\hline PCB 101 & 0.174 \\
\hline PCB 153 & 0.121 \\
\hline PCB 138 & 0.107 \\
\hline PCB 180 & 0.047 \\
\hline $\mathrm{HCB}$ & 0.247 \\
\hline $\mathrm{HCH}$ alpha & 8.558 \\
\hline $\mathrm{HCH}$ gamma & 0.220 \\
\hline Heptachlor & 0.198 \\
\hline Aldrin & 0.020 \\
\hline Oxychlordane & 0.117 \\
\hline DDE o,p' & 0.102 \\
\hline Chlordane trans- (gamma) & 0.076 \\
\hline DDE p,p' & 0.073 \\
\hline $\mathrm{BDE}-17$ & 0.000 \\
\hline BDE-28 & 0.008 \\
\hline $\mathrm{BDE}-75$ & 0.000 \\
\hline $\mathrm{BDE}-49$ & 0.000 \\
\hline BDE-71 & 0.000 \\
\hline $\mathrm{BDE}-47$ & 0.095 \\
\hline BDE-66 & 0.000 \\
\hline BDE-77 & 0.000 \\
\hline BDE-100 & 0.015 \\
\hline BDE-119 & 0.186 \\
\hline BDE-99 & 0.058 \\
\hline BDE-85 & 0.398 \\
\hline BDE-154 & 0.000 \\
\hline BDE-153 & 0.000 \\
\hline BDE-138 & 0.000 \\
\hline BDE-183 & 0.000 \\
\hline BDE-190 & 0.128 \\
\hline
\end{tabular}




\section{Appendix 2B. Average recovery rates of internal 13C standards}

\begin{tabular}{|c|c|}
\hline Compound & Median recovery rate \\
\hline 13C-PCB-123 & $95 \%$ \\
\hline 13C-PCB-118 & $95 \%$ \\
\hline 13C-PCB-114 & $95 \%$ \\
\hline 13C-PCB-105 & $94 \%$ \\
\hline 13C-PCB-167 & $94 \%$ \\
\hline $13 \mathrm{C}-\mathrm{PCB}-156$ & $94 \%$ \\
\hline 13C-PCB-157 & $58 \%$ \\
\hline 13C-PCB-189 & $75 \%$ \\
\hline 13C-PCB- 028 & $70 \%$ \\
\hline 13C-PCB-052 & $89 \%$ \\
\hline 13C-PCB-101 & $91 \%$ \\
\hline 13C-PCB-153 & $90 \%$ \\
\hline 13С-PCB-138 & $84 \%$ \\
\hline 13С-PCB-180 & $81 \%$ \\
\hline НCB 13C6 & $54 \%$ \\
\hline $\mathrm{HCH}$ alpha- $13 \mathrm{C} 6$ & $45 \%$ \\
\hline HCH gamma- 13C6 & $56 \%$ \\
\hline Heptachlor $13 \mathrm{C} 10$ & $79 \%$ \\
\hline Aldrin $13 \mathrm{C} 12$ & $53 \%$ \\
\hline Oxychlordane $13 \mathrm{C} 10$ & $101 \%$ \\
\hline $\mathrm{DDE}$ o,p'- $13 \mathrm{C} 12$ & $20 \%$ \\
\hline Chlordane trans- (gamma) 13C10 & $71 \%$ \\
\hline DDE $p, p^{\prime}-13 C 12$ & $74 \%$ \\
\hline 13C-BDE-17 & $65 \%$ \\
\hline 13C-BDE-28 & $65 \%$ \\
\hline 13C-BDE-75 & $52 \%$ \\
\hline 13C-BDE-49 & $52 \%$ \\
\hline 13C-BDE-71 & $52 \%$ \\
\hline $13 \mathrm{C}-\mathrm{BDE}-47$ & $52 \%$ \\
\hline $13 \mathrm{C}-\mathrm{BDE}-66$ & $52 \%$ \\
\hline 13C-BDE-77 & $40 \%$ \\
\hline $13 \mathrm{C}-\mathrm{BDE}-100$ & $32 \%$ \\
\hline 13C-BDE-119 & $32 \%$ \\
\hline 13C-BDE-99 & $33 \%$ \\
\hline $13 \mathrm{C}-\mathrm{BDE}-85$ & $33 \%$ \\
\hline 13C-BDE-154 & $28 \%$ \\
\hline 13C-BDE-153 & $34 \%$ \\
\hline 13C-BDE-138 & $32 \%$ \\
\hline 13C-BDE-183 & $33 \%$ \\
\hline 13C-BDE-190 & $33 \%$ \\
\hline
\end{tabular}




\section{APPENDIX 3. CONCENTRATION OF POPS IN INDIVIDUAL SAMPLES}

All data is presented in $\mathrm{pg} / \mathrm{L}$. Only samples with at least one measurement higher than LOQ are included. "AS" stands for a sample from the aquarium supply.

\subsection{A PCBs, lm depth}

\begin{tabular}{|c|c|c|c|c|c|c|c|}
\hline & & & & & & & S \\
\hline & $5 / 1$ & $6 / 1$ & $7 / 1$ & $17 / 1$ & $18 / 1$ & $21 / 1$ & $23 / 1$ \\
\hline PCB 123 & 1.01 & $<\mathrm{LOQ}$ & $<\mathrm{LOQ}$ & $<\mathrm{LOQ}$ & $<\mathrm{LOQ}$ & $<\mathrm{LOQ}$ & $<\mathrm{LOQ}$ \\
\hline PCB 118 & 10.4 & 0.411 & $<\mathrm{LOQ}$ & 0.199 & $<\mathrm{LOQ}$ & $<\mathrm{LOQ}$ & $<\mathrm{LOQ}$ \\
\hline PCB 114 & 0.33 & $<\mathrm{LOQ}$ & $<\mathrm{LOQ}$ & $<\mathrm{LOQ}$ & $<\mathrm{LOQ}$ & 0.020 & $<\mathrm{LOQ}$ \\
\hline PCB 105 & 4.03 & $<\mathrm{LOQ}$ & $<\mathrm{LOQ}$ & $<\mathrm{LOQ}$ & $<\mathrm{LOQ}$ & $<\mathrm{LOQ}$ & $<\mathrm{LOQ}$ \\
\hline PCB 167 & 3.10 & $<\mathrm{LOQ}$ & 0.016 & $<\mathrm{LOQ}$ & $<\mathrm{LOQ}$ & $<\mathrm{LOQ}$ & 0.071 \\
\hline PCB 156 & $<\mathrm{LOQ}$ & $<\mathrm{LOQ}$ & $<\mathrm{LOQ}$ & $<\mathrm{LOQ}$ & $<\mathrm{LOQ}$ & $<\mathrm{LOQ}$ & $<\mathrm{LOQ}$ \\
\hline PCB 157 & $<\mathrm{LOQ}$ & $<\mathrm{LOQ}$ & $<\mathrm{LOQ}$ & $<\mathrm{LOQ}$ & $<\mathrm{LOQ}$ & $<\mathrm{LOQ}$ & $<\mathrm{LOQ}$ \\
\hline РCB 189 & 0.08 & $<\mathrm{LOQ}$ & $<\mathrm{LOQ}$ & $<\mathrm{LOQ}$ & $<\mathrm{LOQ}$ & $<\mathrm{LOQ}$ & 0.009 \\
\hline PCB 28 & 16.05 & 4.73 & 1.40 & 2.67 & 3.02 & 3.59 & 3.10 \\
\hline PCB 52 & 8.41 & 1.27 & $<\mathrm{LOQ}$ & $<\mathrm{LOQ}$ & $<\mathrm{LOQ}$ & $<\mathrm{LOQ}$ & $<\mathrm{LOQ}$ \\
\hline РCB 101 & 14.58 & $<\mathrm{LOQ}$ & $<\mathrm{LOQ}$ & $<\mathrm{LOQ}$ & $<\mathrm{LOQ}$ & 0.67 & $<\mathrm{LOQ}$ \\
\hline РCB 153 & 12.86 & $<\mathrm{LOQ}$ & $<\mathrm{LOQ}$ & 0.711 & $<\mathrm{LOQ}$ & 1.12 & 0.554 \\
\hline РCB 138 & 15.38 & $<\mathrm{LOQ}$ & $<\mathrm{LOQ}$ & $<\mathrm{LOQ}$ & $<\mathrm{LOQ}$ & 0.633 & 0.430 \\
\hline PCB 180 & 5.32 & 0.290 & $<\mathrm{LOQ}$ & 0.234 & $<$ LOQ & 0.418 & 0.333 \\
\hline & AS & & & & & & AS \\
\hline & $24 / 1$ & $28 / 1$ & $30 / 1$ & $3 / 2$ & $6 / 2$ & $12 / 2$ & $30 / 3$ \\
\hline РCB 123 & $<\mathrm{LOQ}$ & $<\mathrm{LOQ}$ & $<\mathrm{LOQ}$ & $<\mathrm{LOQ}$ & $<\mathrm{LOQ}$ & $<\mathrm{LOQ}$ & 0.003 \\
\hline РCВ 118 & 0.027 & $<\mathrm{LOQ}$ & $<\mathrm{LOQ}$ & 0.095 & $<\mathrm{LOQ}$ & $<\mathrm{LOQ}$ & $<\mathrm{LOQ}$ \\
\hline РCB 114 & $<\mathrm{LOQ}$ & 0.009 & $<\mathrm{LOQ}$ & $<\mathrm{LOQ}$ & $<\mathrm{LOQ}$ & $<\mathrm{LOQ}$ & 0.009 \\
\hline PCB 105 & $<\mathrm{LOQ}$ & $<\mathrm{LOQ}$ & $<\mathrm{LOQ}$ & $<\mathrm{LOQ}$ & $<\mathrm{LOQ}$ & $<\mathrm{LOQ}$ & $<\mathrm{LOQ}$ \\
\hline PCB 167 & 0.020 & $<\mathrm{LOQ}$ & $<\mathrm{LOQ}$ & $<\mathrm{LOQ}$ & $<\mathrm{LOQ}$ & $<\mathrm{LOQ}$ & $<\mathrm{LOQ}$ \\
\hline РCB 156 & $<\mathrm{LOQ}$ & $<\mathrm{LOQ}$ & $<\mathrm{LOQ}$ & $<\mathrm{LOQ}$ & $<\mathrm{LOQ}$ & 0.086 & $<\mathrm{LOQ}$ \\
\hline РCB 157 & $<\mathrm{LOQ}$ & $<\mathrm{LOQ}$ & $<\mathrm{LOQ}$ & $<\mathrm{LOQ}$ & $<\mathrm{LOQ}$ & $<\mathrm{LOQ}$ & $<\mathrm{LOQ}$ \\
\hline PCB 189 & $<\mathrm{LOQ}$ & $<\mathrm{LOQ}$ & 0.003 & $<\mathrm{LOQ}$ & $<\mathrm{LOQ}$ & $<\mathrm{LOQ}$ & 0.001 \\
\hline PCB 28 & 0.501 & 2.67 & 0.573 & 0.598 & 2.21 & 0.591 & 0.294 \\
\hline PCB 52 & $<\mathrm{LOQ}$ & $<\mathrm{LOQ}$ & $<\mathrm{LOQ}$ & $<\mathrm{LOQ}$ & $<\mathrm{LOQ}$ & $<\mathrm{LOQ}$ & $<\mathrm{LOQ}$ \\
\hline РCB 101 & $<\mathrm{LOQ}$ & $<\mathrm{LOQ}$ & $<\mathrm{LOQ}$ & $<\mathrm{LOQ}$ & $<\mathrm{LOQ}$ & $<\mathrm{LOQ}$ & $<\mathrm{LOQ}$ \\
\hline РCB 153 & 0.082 & 0.301 & $<\mathrm{LOQ}$ & $<\mathrm{LOQ}$ & 0.102 & 0.096 & $<\mathrm{LOQ}$ \\
\hline PCB 138 & 0.062 & 0.228 & $<\mathrm{LOQ}$ & $<\mathrm{LOQ}$ & 0.148 & $<\mathrm{LOQ}$ & $<\mathrm{LOQ}$ \\
\hline PCB 180 & 0.056 & 0.173 & 0.111 & $<\mathrm{LOQ}$ & 0.044 & 0.057 & $<\mathrm{LOQ}$ \\
\hline
\end{tabular}


3.1B PCBs, 20m depth

\begin{tabular}{|c|c|c|c|c|c|c|c|}
\hline & $6 / 2$ & $7 / 2$ & $12 / 2$ & $16 / 2$ & $7 / 3$ & $13 / 3$ & $30 / 3$ \\
\hline PCB 123 & $<\mathrm{LOQ}$ & $<\mathrm{LOQ}$ & 0.006 & $<\mathrm{LOQ}$ & 0.008 & 0.008 & $<\mathrm{LOQ}$ \\
\hline PCB 118 & $<\mathrm{LOQ}$ & $<\mathrm{LOQ}$ & $<\mathrm{LOQ}$ & $<\mathrm{LOQ}$ & $<\mathrm{LOQ}$ & 0.149 & $<\mathrm{LOQ}$ \\
\hline PCB 114 & $<\mathrm{LOQ}$ & $<\mathrm{LOQ}$ & 0.008 & $<\mathrm{LOQ}$ & 0.010 & $<\mathrm{LOQ}$ & $<\mathrm{LOQ}$ \\
\hline PCB 105 & $<\mathrm{LOQ}$ & $<\mathrm{LOQ}$ & $<\mathrm{LOQ}$ & $<\mathrm{LOQ}$ & $<\mathrm{LOQ}$ & $<\mathrm{LOQ}$ & $<\mathrm{LOQ}$ \\
\hline PCB 167 & $<\mathrm{LOQ}$ & $<\mathrm{LOQ}$ & $<\mathrm{LOQ}$ & 0.003 & $<\mathrm{LOQ}$ & 0.041 & $<\mathrm{LOQ}$ \\
\hline PCB 156 & $<$ LOQ & $<\mathrm{LOQ}$ & $<\mathrm{LOQ}$ & $<\mathrm{LOQ}$ & $<\mathrm{LOQ}$ & $<$ LOQ & $<$ LOQ \\
\hline PCB 157 & 1.55 & $<\mathrm{LOQ}$ & $<\mathrm{LOQ}$ & $<\mathrm{LOQ}$ & $<\mathrm{LOQ}$ & $<\mathrm{LOQ}$ & $<\mathrm{LOQ}$ \\
\hline PCB 189 & $<\mathrm{LOQ}$ & 0.08 & $<\mathrm{LOQ}$ & $<\mathrm{LOQ}$ & 0.00 & $<\mathrm{LOQ}$ & 0.00 \\
\hline PCB 28 & 0.317 & 0.600 & 0.458 & $<\mathrm{LOQ}$ & 0.654 & 1.70 & 1.11 \\
\hline РСB 52 & $<\mathrm{LOQ}$ & $<\mathrm{LOQ}$ & $<\mathrm{LOQ}$ & $<\mathrm{LOQ}$ & $<\mathrm{LOQ}$ & 0.410 & $<\mathrm{LOQ}$ \\
\hline PCB 101 & $<\mathrm{LOQ}$ & $<\mathrm{LOQ}$ & $<\mathrm{LOQ}$ & $<\mathrm{LOQ}$ & $<\mathrm{LOQ}$ & 0.299 & $<\mathrm{LOQ}$ \\
\hline PCB 153 & $<\mathrm{LOQ}$ & $<\mathrm{LOQ}$ & 0.103 & $<\mathrm{LOQ}$ & $<\mathrm{LOQ}$ & 0.415 & $<\mathrm{LOQ}$ \\
\hline РCB 138 & $<\mathrm{LOQ}$ & $<\mathrm{LOQ}$ & $<\mathrm{LOQ}$ & 0.053 & $<\mathrm{LOQ}$ & 0.220 & $<\mathrm{LOQ}$ \\
\hline PCB 180 & $<\mathrm{LOQ}$ & $<\mathrm{LOQ}$ & 0.056 & 0.035 & $<\mathrm{LOQ}$ & 0.166 & 0.056 \\
\hline
\end{tabular}

3.2A OCPs, 1m depth

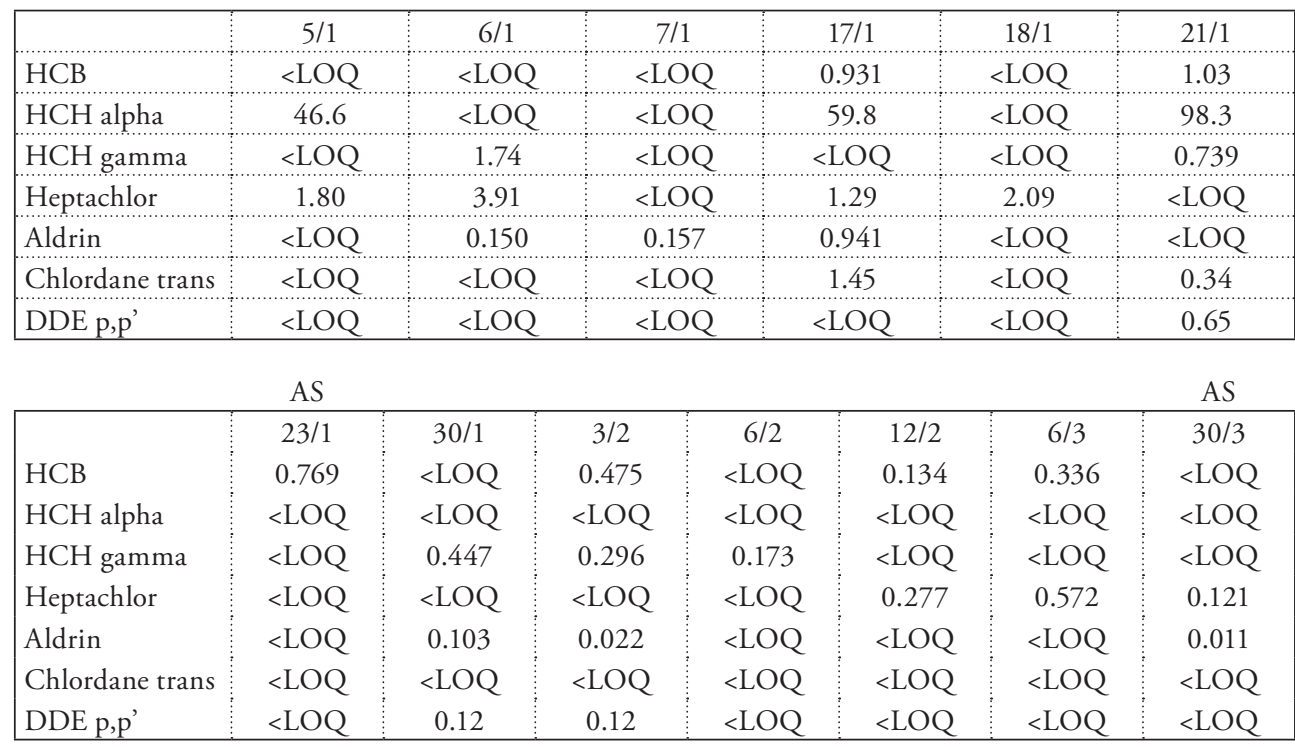




\subsection{B OCPs, 20m depth}

\begin{tabular}{|l|c|c|c|c|c|}
\hline & $3 / 2$ & $6 / 2$ & $12 / 2$ & $6 / 3$ & $30 / 4$ \\
\hline HCB & 0.475 & $<\mathrm{LOQ}$ & 0.134 & 0.336 & $<\mathrm{LOQ}$ \\
\hline HCH alpha & $<\mathrm{LOQ}$ & $<\mathrm{LOQ}$ & $<\mathrm{LOQ}$ & $<\mathrm{LOQ}$ & $<\mathrm{LOQ}$ \\
\hline $\mathrm{HCH}$ gamma & 0.296 & 0.173 & $<\mathrm{LOQ}$ & $<\mathrm{LOQ}$ & $<\mathrm{LOQ}$ \\
\hline Heptachlor & $<\mathrm{LOQ}$ & $<\mathrm{LOQ}$ & 0.277 & 0.572 & 0.121 \\
\hdashline Aldrin & 0.022 & $<\mathrm{LOQ}$ & $<\mathrm{LOQ}$ & $<\mathrm{LOQ}$ & 0.011 \\
\hdashline Oxychlordane & $<\mathrm{LOQ}$ & 0.119 & $<\mathrm{LOQ}$ & $<\mathrm{LOQ}$ & $<\mathrm{LOQ}$ \\
\hline DDE o,p' & $<\mathrm{LOQ}$ & $<\mathrm{LOQ}$ & $<\mathrm{LOQ}$ & $<\mathrm{LOQ}$ & $<\mathrm{LOQ}$ \\
\hdashline Chlordane trans & $<\mathrm{LOQ}$ & $<\mathrm{LOQ}$ & $<\mathrm{LOQ}$ & $<\mathrm{LOQ}$ & $<\mathrm{LOQ}$ \\
\hdashline DDE p,p & 0.119 & $<\mathrm{LOQ}$ & $<\mathrm{LOQ}$ & $<\mathrm{LOQ}$ & $<\mathrm{LOQ}$ \\
\hline
\end{tabular}

\subsection{A PBDEs, 1m depth}

\begin{tabular}{|c|c|c|c|c|c|c|}
\hline & $5 / 1$ & $21 / 1$ & $23 / 1$ & $24 / 1$ & $28 / 1$ & $30 / 3$ \\
\hline BDE-17 & $<\mathrm{LOQ}$ & 0.053 & 0.045 & 0.003 & $<\mathrm{LOQ}$ & $<\mathrm{LOQ}$ \\
\hline BDE-28 & $<\mathrm{LOQ}$ & 0.050 & 0.052 & $<\mathrm{LOQ}$ & $<\mathrm{LOQ}$ & $<\mathrm{LOQ}$ \\
\hline BDE-75 & 0.075 & 0.155 & 0.127 & 0.009 & 0.056 & $<\mathrm{LOQ}$ \\
\hline BDE-49 & 0.089 & 0.186 & 0.023 & 0.017 & $<\mathrm{LOQ}$ & 0.006 \\
\hline BDE-71 & $<\mathrm{LOQ}$ & $<\mathrm{LOQ}$ & 0.025 & 0.018 & $<\mathrm{LOQ}$ & 0.007 \\
\hline BDE-47 & $<\mathrm{LOQ}$ & $<\mathrm{LOQ}$ & 2.54 & $<\mathrm{LOQ}$ & $<\mathrm{LOQ}$ & $<\mathrm{LOQ}$ \\
\hline BDE-66 & $<\mathrm{LOQ}$ & 0.079 & $<\mathrm{LOQ}$ & 0.013 & $<\mathrm{LOQ}$ & 0.003 \\
\hline BDE-77 & $<\mathrm{LOQ}$ & $<\mathrm{LOQ}$ & $<\mathrm{LOQ}$ & $<\mathrm{LOQ}$ & $<\mathrm{LOQ}$ & $<\mathrm{LOQ}$ \\
\hline BDE-100 & $<\mathrm{LOQ}$ & $<\mathrm{LOQ}$ & 0.353 & 0.033 & $<\mathrm{LOQ}$ & $<\mathrm{LOQ}$ \\
\hline BDE-119 & 4.76 & 1.50 & 2.74 & $<\mathrm{LOQ}$ & $<\mathrm{LOQ}$ & $<\mathrm{LOQ}$ \\
\hline BDE-99 & $<\mathrm{LOQ}$ & $<\mathrm{LOQ}$ & 2.05 & 0.131 & $<\mathrm{LOQ}$ & $<\mathrm{LOQ}$ \\
\hline BDE-85 & 5.58 & $<\mathrm{LOQ}$ & 2.03 & $<\mathrm{LOQ}$ & $<\mathrm{LOQ}$ & $<\mathrm{LOQ}$ \\
\hline BDE-154 & $<\mathrm{LOQ}$ & $<\mathrm{LOQ}$ & 0.026 & 0.031 & $<\mathrm{LOQ}$ & 0.021 \\
\hline BDE-153 & $<\mathrm{LOQ}$ & $<\mathrm{LOQ}$ & $<\mathrm{LOQ}$ & 0.038 & $<\mathrm{LOQ}$ & 0.023 \\
\hline BDE-138 & $<\mathrm{LOQ}$ & $<\mathrm{LOQ}$ & $<\mathrm{LOQ}$ & $<\mathrm{LOQ}$ & $<\mathrm{LOQ}$ & $<\mathrm{LOQ}$ \\
\hline BDE-183 & 0.027 & $<\mathrm{LOQ}$ & 0.100 & $<\mathrm{LOQ}$ & $<\mathrm{LOQ}$ & $<\mathrm{LOQ}$ \\
\hline BDE-190 & 2.335 & $<$ LOQ & $<$ LOQ & $<$ LOQ & $<$ LOQ & $<\mathrm{LOQ}$ \\
\hline
\end{tabular}




\subsection{B PBDEs, 20m depth}

\begin{tabular}{|l|c|c|}
\hline & $13 / 3$ & $30 / 3$ \\
\hline BDE-17 & 0.012 & $<\mathrm{LOQ}$ \\
\hdashline BDE-28 & $<\mathrm{LOQ}$ & $<\mathrm{LOQ}$ \\
\hline BDE-75 & $<\mathrm{LOQ}$ & 0.006 \\
\hdashline BDE-49 & $<\mathrm{LOQ}$ & $<\mathrm{LOQ}$ \\
\hdashline BDE-71 & $<\mathrm{LOQ}$ & $<\mathrm{LOQ}$ \\
\hdashline BDE-47 & $<\mathrm{LOQ}$ & $<\mathrm{LOQ}$ \\
\hdashline BDE-66 & $<\mathrm{LOQ}$ & $<\mathrm{LOQ}$ \\
\hdashline BDE-77 & $<\mathrm{LOQ}$ & $<\mathrm{LOQ}$ \\
\hdashline BDE-100 & 0.082 & $<\mathrm{LOQ}$ \\
\hdashline BDE-119 & $<\mathrm{LOQ}$ & 0.612 \\
\hdashline BDE-99 & $<\mathrm{LOQ}$ & $<\mathrm{LOQ}$ \\
\hdashline BDE-85 & $<\mathrm{LOQ}$ & $<\mathrm{LOQ}$ \\
\hdashline BDE-154 & $<\mathrm{LOQ}$ & $<\mathrm{LOQ}$ \\
\hdashline BDE-153 & $<\mathrm{LOQ}$ & $<\mathrm{LOQ}$ \\
\hdashline BDE-138 & $<\mathrm{LOQ}$ & $<\mathrm{LOQ}$ \\
\hdashline BDE-183 & 0.044 & $<\mathrm{LOQ}$ \\
\hdashline BDE-190 & $<\mathrm{LOQ}$ & $<\mathrm{LOQ}$ \\
\hline
\end{tabular}




\section{APPENDIX 4. PHYSICO-CHEMICAL PROPERTIES OF MEASURED POPS}

All data is taken from EPI Web suit version 4.11

US EPA. [2019]. Estimation Programs Interface Suite ${ }^{\mathrm{TM}}$ for Microsoft ${ }^{\oplus}$ Windows, v $\left.^{4} .11\right]$. United States Environmental Protection Agency, Washington, DC, USA.

\subsection{PCBs}

\begin{tabular}{|c|c|c|c|c|c|}
\hline & kow & koa & $\begin{array}{r}\text { Water solubility } \\
(\mathrm{m} / \mathrm{gL})\end{array}$ & $\begin{array}{r}\text { Henry's Law constant } \\
(\text { atm } \mathrm{m} 3 / \mathrm{mol})\end{array}$ & Vapor pressure PA \\
\hline PCB28 & 5.6 & 8.4 & 0.3407000 & 0.000200 & 0.300000 \\
\hline РCB52 & 5.88 & 8.49 & 0.0860600 & 0.000200 & 0.010500 \\
\hline PCB101 & 6.32 & 9.28 & 0.0133700 & 0.000090 & 0.040800 \\
\hline PCB110 & 6.18 & 9.58 & 0.0418300 & 0.000190 & 0.003730 \\
\hline РCB77 & 6.29 & 9.92 & 0.0297600 & 0.000009 & 0.020000 \\
\hline PCB81 & 6.27 & 8.63 & 0.0531600 & 0.000223 & 0.010500 \\
\hline PCB123 & 6.60 & 9.40 & 0.0093940 & 0.003730 & 0.003730 \\
\hline PCB118 & 6.63 & 10.04 & 0.0071260 & 0.000288 & 0.014500 \\
\hline PCB114 & 6.72 & 9.40 & 0.0093940 & 0.000190 & 0.003730 \\
\hline PCB153 & 6.76 & 9.99 & 0.0012810 & 0.000023 & 0.007250 \\
\hline PCB105 & 6.60 & 10.20 & 0.0136400 & 0.000283 & 0.010600 \\
\hline PCB138 & 6.75 & 10.20 & 0.0023570 & 0.000021 & 0.008030 \\
\hline PCB126 & 6.93 & 10.66 & 0.0093940 & 0.000190 & 0.003730 \\
\hline PCB167 & 7.11 & 10.77 & 0.0020950 & 0.000162 & 0.001320 \\
\hline PCB156 & 7.25 & 10.87 & 0.0017210 & 0.000143 & 0.003400 \\
\hline PCB157 & 7.10 & 11.07 & 0.0017210 & 0.000162 & 0.001320 \\
\hline PCB180 & 7.28 & 10.72 & 0.0002842 & 0.000010 & 0.003050 \\
\hline PCB169 & 7.59 & 11.32 & 0.0025000 & 0.000162 & 0.001320 \\
\hline PCB189 & 7.77 & 11.54 & 0.0002842 & 0.000138 & 0.000461 \\
\hline
\end{tabular}




\begin{tabular}{|c|c|c|c|c|c|}
\hline & kow & koa & $\begin{array}{r}\text { Water solubility } \\
(\mathrm{m} / \mathrm{gL})\end{array}$ & $\begin{array}{r}\text { Henry's Law constant } \\
\text { (atm m3/mol) }\end{array}$ & Vapor pressure PA \\
\hline $\mathrm{HCB}$ & 5.50 & 7.38 & 0.1922000 & 0.001700 & 0.267000 \\
\hline $\mathrm{a}-\mathrm{HCH}$ & 3.81 & 7.61 & 4.0440000 & 0.000005 & 0.034400 \\
\hline $\mathrm{b}-\mathrm{HCH}$ & 3.80 & 8.88 & 4.0440000 & 0.000005 & 0.034400 \\
\hline $\mathrm{g}-\mathrm{HCH}$ & 3.70 & 7.85 & 4.0440000 & 0.000005 & 0.034400 \\
\hline $\mathrm{d}-\mathrm{HCH}$ & 4.14 & 8.84 & 4.0440000 & 0.000005 & 0.034400 \\
\hline Heptachlor & 5.27 & 7.64 & 0.0952600 & 0.000294 & 0.265000 \\
\hline Aldrin & 3.01 & 8.08 & 0.0141500 & 0.000044 & 2.150000 \\
\hline Oxychlordane & 5.48 & 8.39 & 0.0451200 & 0.000000 & 0.014900 \\
\hline trans-Chlordane & 6.00 & 8.87 & 0.0129900 & 0.000049 & 0.008410 \\
\hline Endosulfan 1 & 3.62 & 8.64 & 1.4870000 & 0.000065 & 0.000507 \\
\hline cis-Chlordane & 6.00 & 8.92 & 0.0129900 & 0.000049 & 0.008410 \\
\hline trans-Nonachlor & 6.35 & 9.29 & 0.0061200 & 0.000025 & 0.002200 \\
\hline p,p-DDE & 5.70 & 9.68 & 0.0265300 & 0.000042 & 0.003440 \\
\hline Endrin & 5.20 & 8.13 & 0.1455000 & 0.000010 & 0.038900 \\
\hline$p p-D D D$ & 5.50 & 10.10 & 0.0676400 & 0.000007 & 0.001230 \\
\hline cis-Nonachlor & 6.35 & 9.66 & 0.0061200 & 0.000025 & 0.002200 \\
\hline $\mathrm{o}, \mathrm{p}-\mathrm{DDT}$ & 6.79 & 9.45 & 0.0091710 & 0.000007 & 0.001680 \\
\hline $\mathrm{p}, \mathrm{p}-\mathrm{DDT}$ & 6.19 & 9.80 & 0.0073070 & 0.000008 & 0.000143 \\
\hline o,p-DDD & 5.87 & 9.35 & 0.0902400 & 0.000008 & 0.000845 \\
\hline
\end{tabular}


Chapter 3

\subsection{PBDEs}

\begin{tabular}{|c|c|c|c|c|c|}
\hline & kow & koa & $\begin{array}{r}\text { Water solubility } \\
(\mathrm{m} / \mathrm{gL})\end{array}$ & $\begin{array}{r}\text { Henry's Law constant } \\
\text { (atm m3/mol) }\end{array}$ & Vapor pressure PA \\
\hline BDE 3 & 4.94 & 7.66 & 1.4480000 & 0.000117 & 0.200000 \\
\hline BDE 15 & 5.83 & 8.64 & 0.0882600 & 0.000049 & 0.032000 \\
\hline BDE 17 & 5.74 & 9.30 & & & \\
\hline BDE 28 & 5.94 & 9.50 & 0.0264200 & 0.000020 & 0.001220 \\
\hline BDE 47 & 6.81 & 10.53 & 0.0014610 & 0.000008 & 0.000211 \\
\hline BDE 66 & 6.77 & 10.82 & 0.0014610 & 0.000008 & 0.000815 \\
\hline BDE 77 & 7.61 & 10.87 & 0.0002802 & 0.000008 & 0.000815 \\
\hline BDE 85 & 7.66 & 11.66 & 0.0000786 & 0.000004 & 0.000035 \\
\hline BDE 99 & 6.84 & 11.31 & 0.0003940 & 0.000004 & 0.000004 \\
\hline BDE 100 & 7.24 & 11.13 & & 0.000002 & \\
\hline BDE 138 & 8.55 & 13.27 & 0.0000041 & 0.000001 & 0.000019 \\
\hline BDE 153 & 7.90 & 11.82 & & 0.000007 & \\
\hline BDE 154 & 8.55 & 13.27 & 0.0000041 & 0.000001 & 0.000025 \\
\hline BDE 183 & 9.44 & 14.55 & 0.0000002 & 0.000001 & 0.000004 \\
\hline BDE 190 & 9.44 & 14.55 & 0.0000002 & 0.000001 & 0.000003 \\
\hline BDE 209 & 12.11 & 18.42 & 0.0000000 & 0.000000 & 0.000001 \\
\hline
\end{tabular}




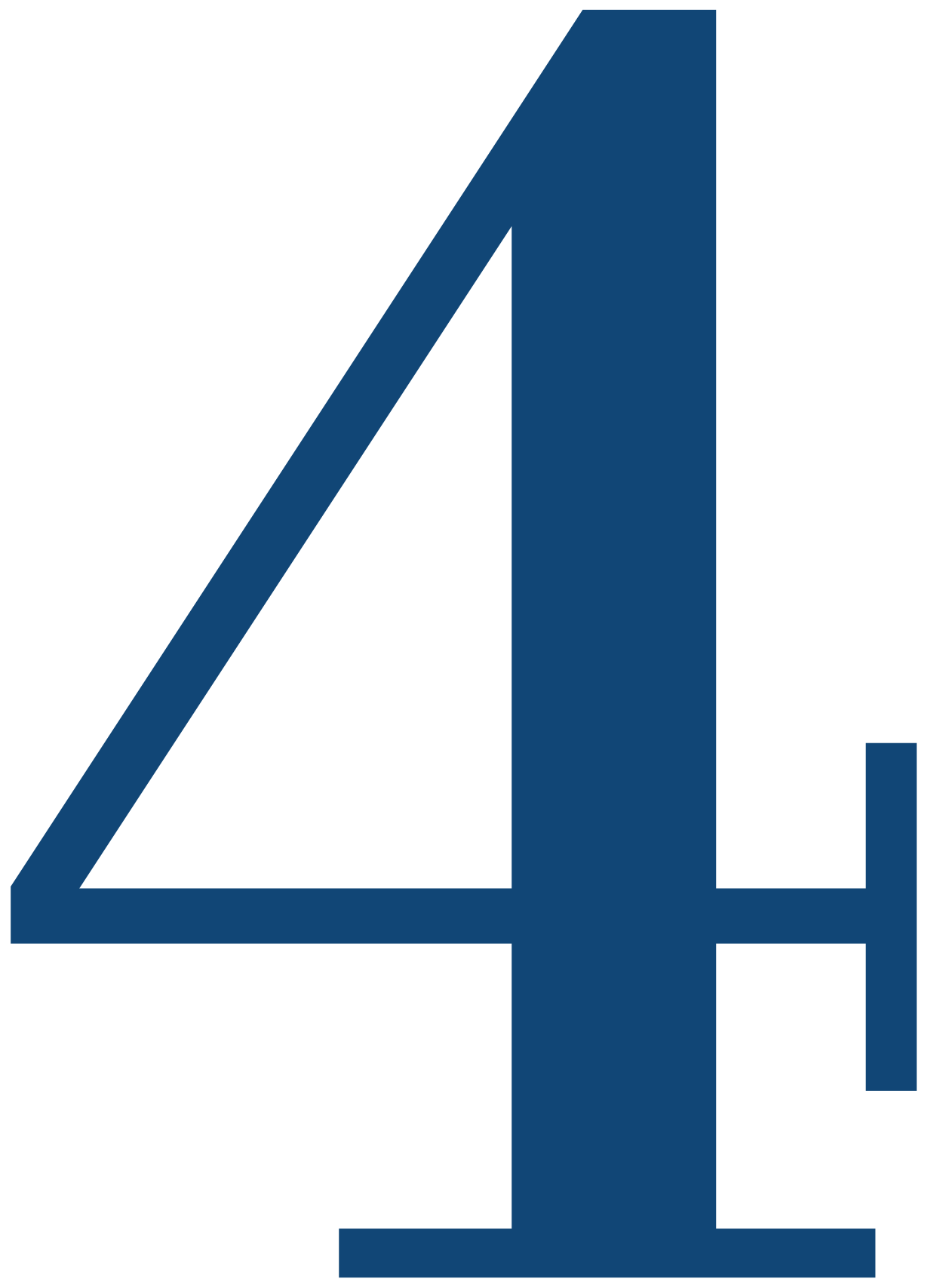




\section{Chapter 4}

\section{Legacy and emerging Persistent Organic Pollutants in Antarctic benthic invertebrates near Rothera Point, Western Antarctic Peninsula}

Artem Krasnobaev, Guillaume ten Dam, Rita Boerrigter-Eenling, Fang Peng, Stefan P.J. van Leeuwen, Simon A. Morley, Lloyd S. Peck, Nico W. van den Brink. 


\section{ABSTRACT}

Pollutant levels in polar regions are gaining progressively more attention from the science community. This is especially so for pollutants that persist in the environment and can reach polar latitudes via a wide range of routes, such as some persistent organic pollutants (POPs). In this study samples of Antarctic marine benthic organisms were analysed for legacy and emerging POPs (polychlorinated biphenyls, polybrominated diphenyl ethers and organochlorine pesticides) to comprehensively assess their current POP concentrations and infer the potential sources of the pollutants. Specimens of 5 benthic invertebrate species were collected at 2 distinct locations near Rothera research station on the Antarctic

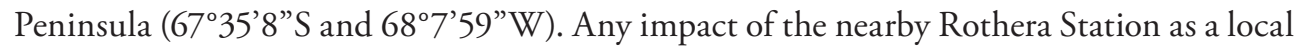
source of pollution appeared to be negligible. The most abundant chemicals detected were HCB and BDE-209. The highest concentrations detected were in limpets and sea urchins, followed by sea stars, ascidians and sea cucumbers. The relative congener patterns of PCBs and PBDEs were similar in all species. Some chemicals (e.g. Heptachlor, Oxychlordane and Mirex) were detected in the Antarctic invertebrates for the first time. Statistical analyses revealed that the distribution of the POPs was not only driven by the feeding traits of the species, but also by the physico-chemical properties of the specific compounds 


\section{INTRODUCTION}

Persistent Organic Pollutants (POPs) are a large group of contaminants characterized by long environmental half-lives and high potential for accumulation in food webs and organisms ${ }^{1}$. The more volatile POPs have the ability to be re-dispersed into the atmosphere after application ${ }^{2}$. Driven by Long Range Atmospheric Transport (LRAT) such more or less volatile POPs can travel away from the industrialised and inhabited regions of release and be deposited in remote areas, including the marine ecosystems of Antarctica ${ }^{3}{ }^{4}$.

Concentrations of POPs in Antarctic pelagic ecosystems have been studied well enough to create a comprehensive time series in different components of these ecosystems e.g. in birds $s^{5}$, mammals ${ }^{6}$, pelagic fish ${ }^{7,8}$ and water ${ }^{9}$.

Yet the concentrations and fluxes of POPs in Antarctic benthic marine ecosystems are still poorly described ${ }^{5,10,11}$ due to two major challenges Firstly, there are logistical problems associated with the remoteness of the locations and the resources needed for the collection of samples (often including ship cruises or SCUBA diving support). Secondly, chemical analysis of Antarctic benthic samples is often demanding as the concentrations of POPs are usually much lower than in temperate and tropical areas of the world ${ }^{12,13}$.

Invertebrates are by far the most dominant macrofauna of the Antarctic marine benthic ecosystems in terms of both species number and biomass ${ }^{14}$ and can serve as important bioindicators of POPs because of their trophic diversity, slow growth rates, long life spans and low mobility of adult animals ${ }^{14}$. Moreover, sessile benthic organisms may provide the potential to identify local sources of POPs, such as research stations $s^{15}$ and touristic ships ${ }^{16,17}$.

A few reports on POPs in various Antarctic benthic species exist, for instance around Dumont d'Urville station (Adelie Land) ${ }^{18}$, Davis station (Princess Elizabeth Land) ${ }^{19}$ and Zucchelli station (Terra Nova bay) ${ }^{20}$. Unfortunately, the contribution of invertebrate samples to these studies was small, the proximity to the research stations as a potential contamination source was not always taken into account, and all of these studies were conducted in the Eastern Antarctica ${ }^{21}$.

Because the Western Antarctic Peninsula (WAP) has experienced some of the fastest rates of climate change, the composition and abundance of species in benthic ecosystems is likely to alter ${ }^{22-27}$. Given their complexity and diversity, this could also lead to changes in biomagnification across the entire food web. Moreover, while temporal trends in the studies of pelagic ecosystems demonstrated a clear decline in concentrations of POPs, such trends are less clear in benthic ecosystems, which makes future predictions even more difficult ${ }^{8}$. 
For a better understanding of the accumulation patterns of POPs in benthic organisms and systems it is essential to analyse those accumulation patterns with information on species traits and properties of POPs together with details on the collection locations (proximity of nearby stations, shipping activities etc.). To gain such insights, a study was conducted with the aim of performing a comprehensive characterization of POPs in a range of benthic invertebrate species from the WAP, representing different trophic levels, collected from different locations around Rothera research station. Therefore this study not only quantifies current levels of POPs, but is also an important step in monitoring global chemical pollutant cycles $^{28}$.

\section{MATERIALS AND METHODS.}

\section{Sample collection}

Samples of various Antarctic benthic invertebrate species, selected on the basis of diversity in physiology and feeding traits (table 1, Appendix 1D), were collected in the beginning of February of 2017 at depths of 10-30 meters in the north-eastern part of Ryder Bay (fig. 1), next to the coast of Adelaide Island. Previous studies suggest that it is unlikely for an Antarctic station to serve as a source of POPs for areas located farther than $3 \mathrm{~km}$ distance ${ }^{15}$. Thus, 2 distinct collection sites were established: site "Islands" was identified as a rarely visited area of background contamination at least $5 \mathrm{~km}$ away from the station (i.e. with POPs intake exclusively from LRAT), while the site "Station" was the area near the station, with potential for POPs contamination from local sources,. All samples were collected by SCUBA divers, packed into aluminium foil (which was first furnaced at $450^{\circ} \mathrm{C}$ for 12 hours and then cleaned with hexane), and stored in an freezer at $-20^{\circ} \mathrm{C}$ until further analysis was carried out in the Netherlands.

\section{Chemical analysis}

All solvents and other chemicals used in the current study were of highest analytical grade. Glassware and metal hardware used were thoroughly pre-cleaned, twice with hexane and twice with ethyl acetate.

Individual specimens (3 to 5) of limpets, sea urchins and sea stars were pooled to ensure sufficient sample volumes for later analyses. Sea cucumbers and ascidians were large enough to be analysed individually. All samples were freeze-dried at $-50^{\circ} \mathrm{C}$ for at least 48 hours and homogenised into a fine powder.

All samples were analysed for polychlorinated biphenyls (PCBs; PCB 28, 52, 101, 105, $114,118,123,138,153,156,157,167,180,189)$, polybrominated diphenyl ethers (PBDEs; 
Table 1. Overview of collected samples after pooling. An "“-indicates that samples of the species were not collected at the location.

\begin{tabular}{|c|c|c|c|c|}
\hline Latin name & Common name & Predominant feeding behaviour & $\begin{array}{l}\text { Total } \\
\text { number at site } \\
\text { "Islands" }\end{array}$ & $\begin{array}{l}\text { Total } \\
\text { number at site } \\
\text { "Station" }\end{array}$ \\
\hline Heterocucumis steineni & Sea cucumber & Sediment/Suspension feeder ${ }^{29}$ & 12 & 16 \\
\hline $\begin{array}{l}\text { Cnemidocarpa } \\
\text { verrucosa }\end{array}$ & $\begin{array}{l}\text { Ascidian } \\
\text { (sea squirt) }\end{array}$ & Filter/ Suspension feeder ${ }^{30}$ & 15 & 14 \\
\hline Odontaster validus & Sea star & Carnivore $^{31}$ & 6 & 5 \\
\hline Nacella concinna & Limpet & Grazer $^{32}$ & - & 7 \\
\hline Sterechinus neumayeri & Sea urchin & Omnivore $^{33}$ & 5 & - \\
\hline
\end{tabular}

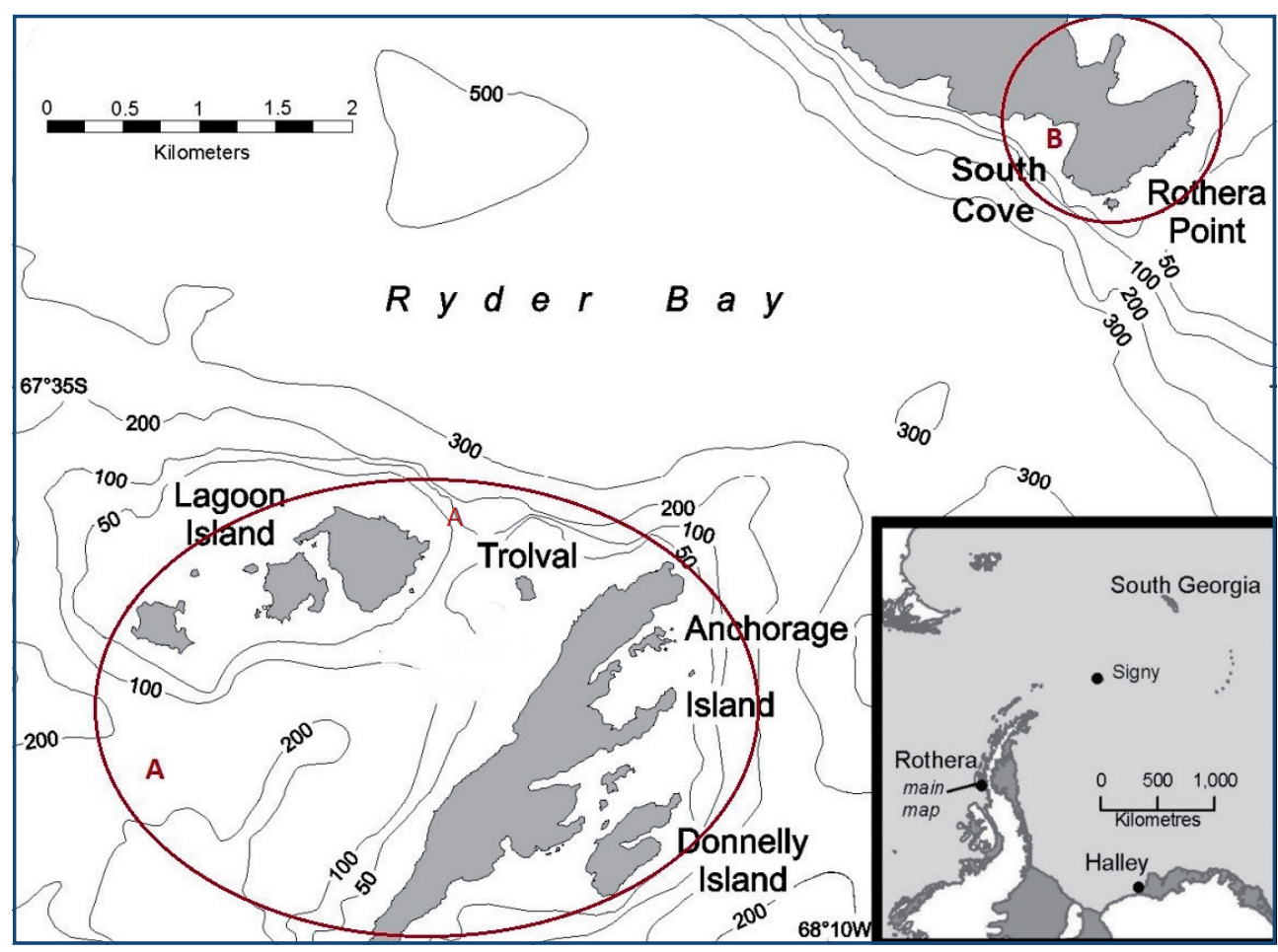

Figure 1. Map of north-eastern part of Ryder Bay with sampling locations. Site "Islands" (A) will principally only receive POPs by LRAT, while site "Station" (B) has potential for additional contamination from the research station and air and shipping activities.

PBDE 17, 28, 47, 49, 66, 71, 75, 77, 85, 99, 100,119, 138, 153, 154, 183, 190, 209) and organochlorine pesticides (OCPs; $\mathrm{HCB}, \mathrm{HCH}$-alpha, $\mathrm{HCH}$-beta, $\mathrm{HCH}$-gamma, $\mathrm{HCH}$ epsilon, Heptachlor, Oxychlordane, Heptachlor epoxide-alpha, heptachlor epoxide-beta, trans-Chlordane, cis-Chlordane, Endosulfan-alpha, Endosulfan-beta, o,p'-DDE, p,p'DDE, o,p'-DDD, p,p'-DDE, Mirex). 
The complete extraction and clean-up procedure is described step-by-step in the Appendix 1A. For extraction, $15 \mathrm{ml}$ (corresponding to $3-7 \mathrm{~g}$ dry weight) of homogenised and freezedried sample was transferred into $60 \mathrm{ml}$ amber glass tubes, and spiked with ${ }^{13} \mathrm{C} \mathrm{PCB}$ and ${ }^{13} \mathrm{C}$ PBDE138 standards obtained from LGC Standards (Teddington, UK). Distilled water was added until the total mass of the sample was $13 \mathrm{~g}$, and the sample was shaken for 3 minutes. These mass and volume values were essential to establish a balance between the sample intake and instrumental capacities of the extraction equipment. After this, $10 \mathrm{ml}$ of ethyl acetate was added and the mixture was vigorously shaken again in an overhead shaker for at least 10 minutes. This was followed by an addition of a mix of $2 \mathrm{~g}$ of sodium chloride and $4 \mathrm{~g}$ of magnesium sulphate. The samples were then centrifuged for at least 10 minutes at $350 \mathrm{~g}$. The ethyl acetate supernatant was transferred into a Turbovap tube and the procedure was repeated twice, starting from the addition of another $10 \mathrm{ml}$ of ethyl acetate. Therefore, the total volume of the extract obtained was approximately $30 \mathrm{ml}$. The samples were concentrated in a Turbovap apparatus to $1 \mathrm{ml}$, of which $0.1 \mathrm{ml}$ of was used for later lipid quantification, which was done gravimetrically. The rest of the extract was transferred quantitatively to a $60 \mathrm{ml}$ amber glass vial. Each tube was washed 3 times with $9 \mathrm{ml}$ of hexane each time, and this was combined with the extract in the $60 \mathrm{ml}$ vials. Ten $\mathrm{g}$ of $40 \%$ acidic silica was added to each sample and the sample was left overnight. After this, the hexane fraction of the sample was transferred to a new Turbovap tube, which was followed by 2 cycles of washing with $10 \mathrm{ml}$ of hexane, centrifugation for 10 minutes at $350 \mathrm{~g}$ and transferring the hexane phase to the Turbovap tube. The samples were concentrated down to $1 \mathrm{ml}$ in a Turbovap and brought onto a clean-up silica column, which was packed with $1 \mathrm{~g}$ of activated silica and $8 \mathrm{~g}$ of $40 \%$ acidic silica, which were twice pre-eluted with $10 \mathrm{ml}$ and $15 \mathrm{ml}$ of hexane respectively. The sample was eluted consecutively with $18 \mathrm{ml}$ hexane and $12 \mathrm{ml}$ dichloromethane. The resulting solvent mixture was evaporated in a Turbovap to $0.5 \mathrm{ml}$, and a solvent exchange to iso-octane was performed. The final $0.5 \mathrm{ml}$ of extract in iso-octane was stored at $-20^{\circ} \mathrm{C}$ until measurements were made. Some OCPs (e.g. dieldrin and endrin) degrade under acidic conditions (i.e. acidic silica) used in this clean-up approach and are therefore not reported in this study.

PCBs and PBDEs were quantified using a Magnetic Sector Autospec GC-HRMS from Waters (Manchester, UK) equipped with an Agilent 6890 GC (Santa Clara, USA). OCPs were measured by an Agilent 7010B Triple Quadrupole coupled with an Agilent 7890 GC (Santa Clara, USA). DB-5MS $60 \mathrm{~m} \times 0.25 \mathrm{~mm} \times 0.25 \mu \mathrm{m}$ fused silica capillary column from Agilent J\&W (Folson, USA) was used for PCB analysis, while CL-Pesticide $30 \mathrm{~m} \mathrm{x}$ $0.25 \mathrm{~mm} \times 0.25 \mu \mathrm{m}$ from Restek (Bellefonte, USA) was fitted for the analysis of PBDEs and OCPs. Measurements were conducted at the Wageningen Food Safety Research (WFSR) laboratories in Wageningen, the Netherlands. For further details on the GC-methods see Appendix 1B. 
For Quality Assurance/Quality Control (QA/QC) (Appendix 2), each measurement batch contained 10 samples, a procedural blank and a sample of a certified reference material (SRM 1947 Lake Michigan fish tissue, National Institute of Standards and Technology). For extra QC the samples were spiked with ${ }^{13} \mathrm{C}$-labeled $\mathrm{PCB}$ (all analysed congeners) and ${ }^{13} \mathrm{C}-\mathrm{PBDE}-138$.

Limits of quantification (LOQ) were calculated as 2 times the concentration of the compound in the extract of the corresponding blank sample. The concentrations in the samples were adjusted for blanks, while the recovery rates (Appendix 2) were used exclusively for QC (i.e. they were not used for adjustment).

\section{Data analysis}

All data analysis was completed using Jypiter Notebook with Python 3 and Canoco 5 software. The values below detection limits were not considered in the statistical analysis and set to zero when calculating total concentrations.

The detailed description of statistical methods is presented in the Appendix 3. MannWhitney-Wilcoxon (MWW) (another name - Mann-Whitney U) test was used to assess whether differences between samples were significant $(\alpha=0.05)$, which was Bonferonniadjusted when exploring site-specific differences (see Appendix 3 for rationale). Principal component analysis (PCA) and its derivative double constrained principal component analysis (dc-PCA) were used to investigate accumulation patterns among species and to identify which physico-chemical properties of POPs control their accumulation patterns ${ }^{34}$. The values of these physico-chemical properties of the different POPs values are presented in Appendix 5.

All results in the current study are expressed as picogram per gram lipid (pg/g Lw). For comparison with other studies, where concentrations were expressed on wet or dry weight basis, the data were adjusted to lipid weight basis using average lipid contents of the species determined gravimetrically in the current study.

\section{RESULTS AND DISCUSSION}

The results for concentrations of PCBs, PBDEs and OCPs in individual samples can be found in Appendices 4A, 4B and 4C respectively. The lipid content of the samples did not show any interspecific differences (Appendix 1). 


\section{Rothera station as a possible source of POPs pollution.}

There were no significant differences between samples collected near Rothera station (site "Station") and the islands in Ryder bay (site "Islands") (MWW test with Bonferonni correction; Appendix 3). This is in contrast to previous research in Antarctica around McMurdo station which identified differential PBDE and PCB congener patterns (linked to the composition of industrial mixtures such as Arochlor) as clear signs of local contamination $^{35}$. Results indicate that Rothera station and associated operations have not resulted in a significant release of the POPs studied. Since there were no statistically significant differences between the locations, all the datasets were merged and used together for further statistical analyses and discussion of species-specific accumulation patterns.

\section{Species specific concentrations}

\section{PCBs}

The total PCB concentrations in the different species are presented in figure 2

Overall, the results show that PCB concentrations vary significantly among species in the current study. Sea cucumbers had the lowest PCB concentrations, which were significantly lower than in all other species. The concentrations in ascidians were higher than in the sea cucumbers, but their variance was higher because of 3 noticeable outliers. Concentrations in the sea stars were similar to the ascidians, while limpets had significantly higher PCB concentrations than the sea stars. The concentrations in urchins were not significantly different from the limpets but had a larger variance.

The concentrations measured in the current study were all well below concentrations found in the same or similar species in previous studies in Antarctica: PCB concentrations in the limpets were up to 30 times lower than values reported in the same species from Princess Elizabeth Land in $2018^{19}$, and in urchins they were up to 30 or even 60 times lower than from Adélie Land ${ }^{18}$ in 2009 and Princess Elizabeth Land ${ }^{19}$ in 1995, respectively.

There may be several reasons for the consistently low PCB concentrations. First, the benthic invertebrates near Rothera may simply not have been exposed to PCBs as those from other studies. Second, concentrations in the other studies may have been influenced by unrecognized local inputs of PCBs. For example, an earlier report ${ }^{20}$ indicated an order of magnitude difference in PCB concentrations found in the same benthic invertebrate species, collected at the same sampling site, but at different timepoints during the season with the elevated concentrations corresponding to the periods of increased station activity.

Concentrations in the sea stars $O$. Validus of the current study were approximately 2 times lower than previously found in the sea stars Saliasterias brachiata from Adélie Land in 


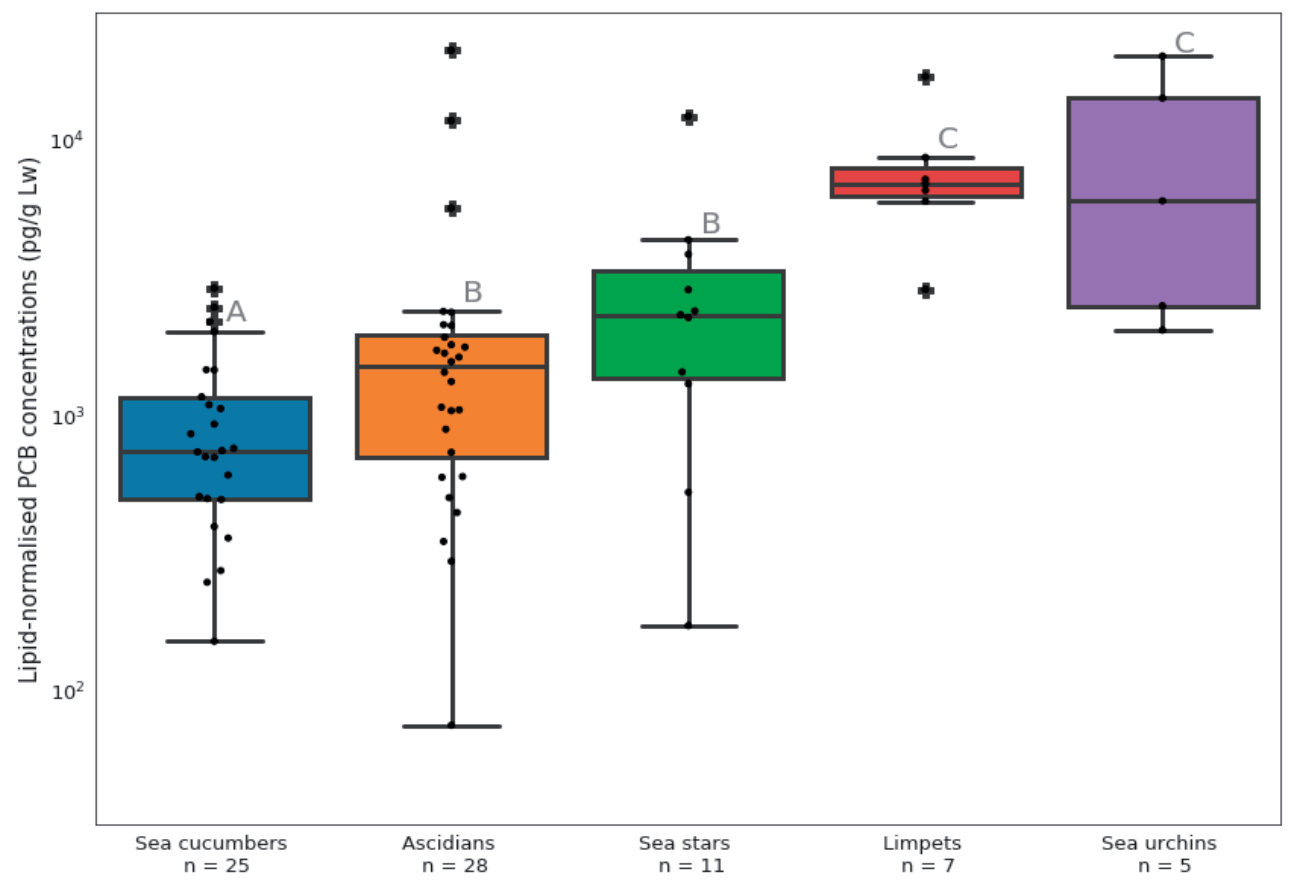

Figure 2. Boxplot of total concentrations of PCBs in $\mathrm{pg} / \mathrm{g}$ Lw. The " $\mathrm{n}$ " quoted above denotes the number of pooled samples analysed. The mid-line of each plot indicates the median value, the box the interquartile (25\%-75\%) range and the whiskers - the 95\% percentile. Black dots are the original data with black square crosses representing outliers. The plots with the same grey letter indicate no statistically significant differences.

$2013^{18}$. The most likely explanation lies in a different feeding behaviour: while the former is a carnivore, the latter is a necrophagous ${ }^{36}$

The relative concentrations of the individual PCB congeners were similar across the species (Appendix 4A). These outcomes followed previous findings ${ }^{20}$, which quantified penta- and hexa- $\mathrm{CBs}$ to account for approximately $60 \%$ of all $\mathrm{PCB}$ concentrations. However, there was a slight disagreement with a smaller study on sea stars and sea urchins ${ }^{18}$, which showed a predominance of penta-CBs.

\section{PBDEs}

Concentrations of PBDEs in limpets were significantly higher (Fig. 3) than in sea cucumbers, ascidians and sea stars, while he differences between sea urchins and all the other species were not significant, possibly due to the low number of samples $(n=3)$. This is different to the trends seen for PCBs (Fig. 1), which however, is in close agreement with recent experimental work on accumulation patterns of PCBs and PBDEs in invertebrates with different feeding behaviour, which found that concentrations of PCBs tended to increase more rapidly with increasing trophic level than $\mathrm{PBDEs}^{37}$. 


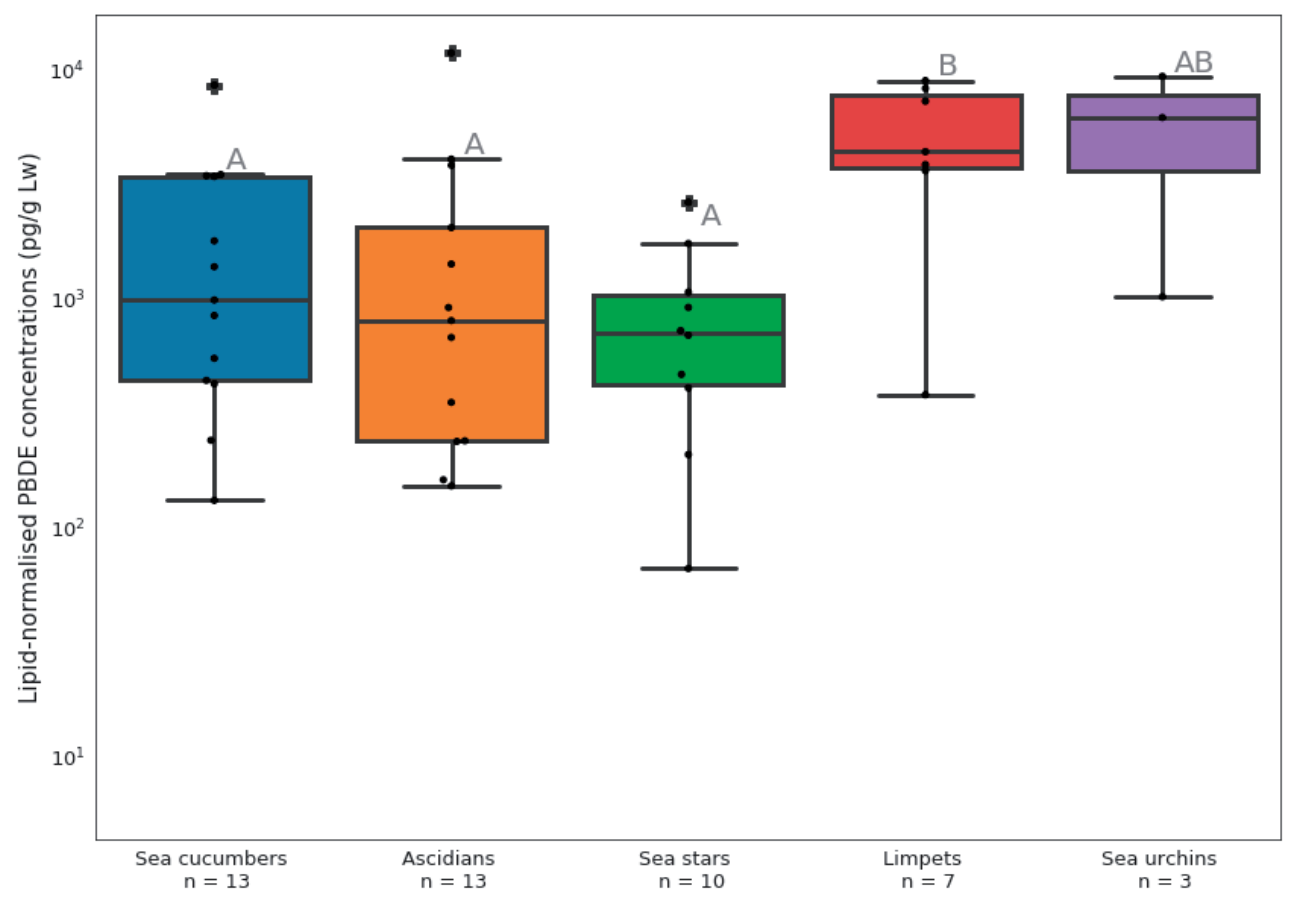

Figure 3. Boxplot of total concentrations of PBDEs in $\mathrm{pg} / \mathrm{g}$ Lw. The " $n$ " quoted above denotes the number of pooled samples analysed. The mid-line of each plot indicates the median value, the box the interquartile (25\%-75\%) range and the whiskers - the 95\% percentile. Black dots are the original data with black square crosses representing outliers. The plots with the same grey letter indicate no statistically significant differences.

BDE-209 accounted for more than 90\% of the total PBDE concentrations for all species (Appendix 4B). Although other PBDE congeners showed much lower concentrations, their accumulation pattern is similar to BDE-209 (Appendix 4B).

Because BDE-209 may dibrominate into more toxic congeners during LRAT and in the environment ${ }^{38,39}$, its accumulation in benthic animals deserves a closer attention. Overall, there is a lot of conflicting information about BDE-209 in the Antarctic environment. While some studies in biota were not able to detect it all ${ }^{40,41}$, it was the predominant congener in long-term air monitoring ${ }^{42}$. Historically, BDE-209 input in Antarctica was attributed to local activities ${ }^{35}$, however the fact that its high concentrations were currently found in an area with very little or no human activity (site "Islands") provides evidence that atmospheric inputs also play an important role in fluxes of BDE-209 in Antarctica. Such predominance of BDE-209 over other congeners in sea stars and urchins was also previously reported in Adélie Land in $2013^{18}$, and that showed similar total PBDEs concentrations. A study from McMurdo Sound in 2008 stressed the contribution of BDE-209 to the overall PBDE burden, but the total concentrations were up to 5 times higher ${ }^{35}$ than those here. Results 
from our and other studies indicate that BDE-209 may be released in the Antarctic marine system by atmospheric deposition, resulting from LRAT, without the need for local sources.

Previous efforts were dedicated to determining the general temporal trends of PBDEs in different parts of Antarctic ecosystems, which demonstrated that in constrast to decreasing trends in the Arctic, the PBDE concentrations in Antarctica are remaining constant ${ }^{41}$. However, not all of those articles reported BDE-209, therefore potentially missing the most important congener. The concentrations in the current study were comparable to those found 10 years before ${ }^{18}$, which would support the general consensus of the combined studies that, even when BDE-209 is accounted for, the total PBDE concentrations did not seem to change over time in the Antarctic system.

\section{OCPs}

In all the species studied the most prevalent OCP was HCB, which can be expected for the Antarctic biota due to its high atmospheric mobility and its preferential condensation in cold regions ${ }^{7,43}$. Moreover, HCB is known to accumulate in invertebrates ${ }^{44}$. The concentrations of HCB did not differ significantly among the species (Fig. 5). This is in good agreement with previous research, which indicated a lack of HCB biomagnification across marine species in different trophic levels from Antarctica ${ }^{45}$. Generally, the currently measured HCB concentrations were 10-30 times lower in comparison to HCB levels in invertebrates measured in 1993 at Terra Nova Bay ${ }^{46}$, which implies a decrease in HCB concentrations over time. On the other hand, a more recent study in Adélie Land from 2013 was not able to detect any HCB in invertebrates at all ${ }^{18}$. The explanation likely lies in the more frequent snowfalls around the $\mathrm{WAP}^{47-50}$ which could have amplified HCB in the current study ${ }^{51,52}$.

The second most abundant OCP was p,p'-DDE. There were no statistically significant differences in its concentrations among species except for the sea cucumbers, which contained significantly more p,p'-DDE than the other species (Fig. 5 and Appendix 3). The $\mathrm{p}, \mathrm{p}$-DDE concentrations were similar to those reported in a previous study from 1993 on bivalves in Terra Nova Bay ${ }^{46}$. p,p'-DDE concentrations measured in the Artic in 2000 were 10-20 higher in waved whelks ${ }^{53}$ than in the invertebrates in the current study. Interestingly, no p,p'-DDT could be detected in any of the current species, which may signify its complete transformation into p,p'-DDE. This would indicate no recent inputs of p,p'-DDT into the local marine environment of Ryder Bay. This may imply a very limited input of p,p'-DDT from glacial run-off ${ }^{54}$, as has been suggested as a contemporary source of OCPs into Antarctic ecosystems, although its actual extent is debated ${ }^{55}$ and thus supported by the current study.

HCB and p,p'-DDE were followed by the chlordane (mainly cis-chlordane) and $\mathrm{HCH}$ (mainly HCH-beta) groups, Heptachlor, Mirex and Endosulfan. It is the first time these 

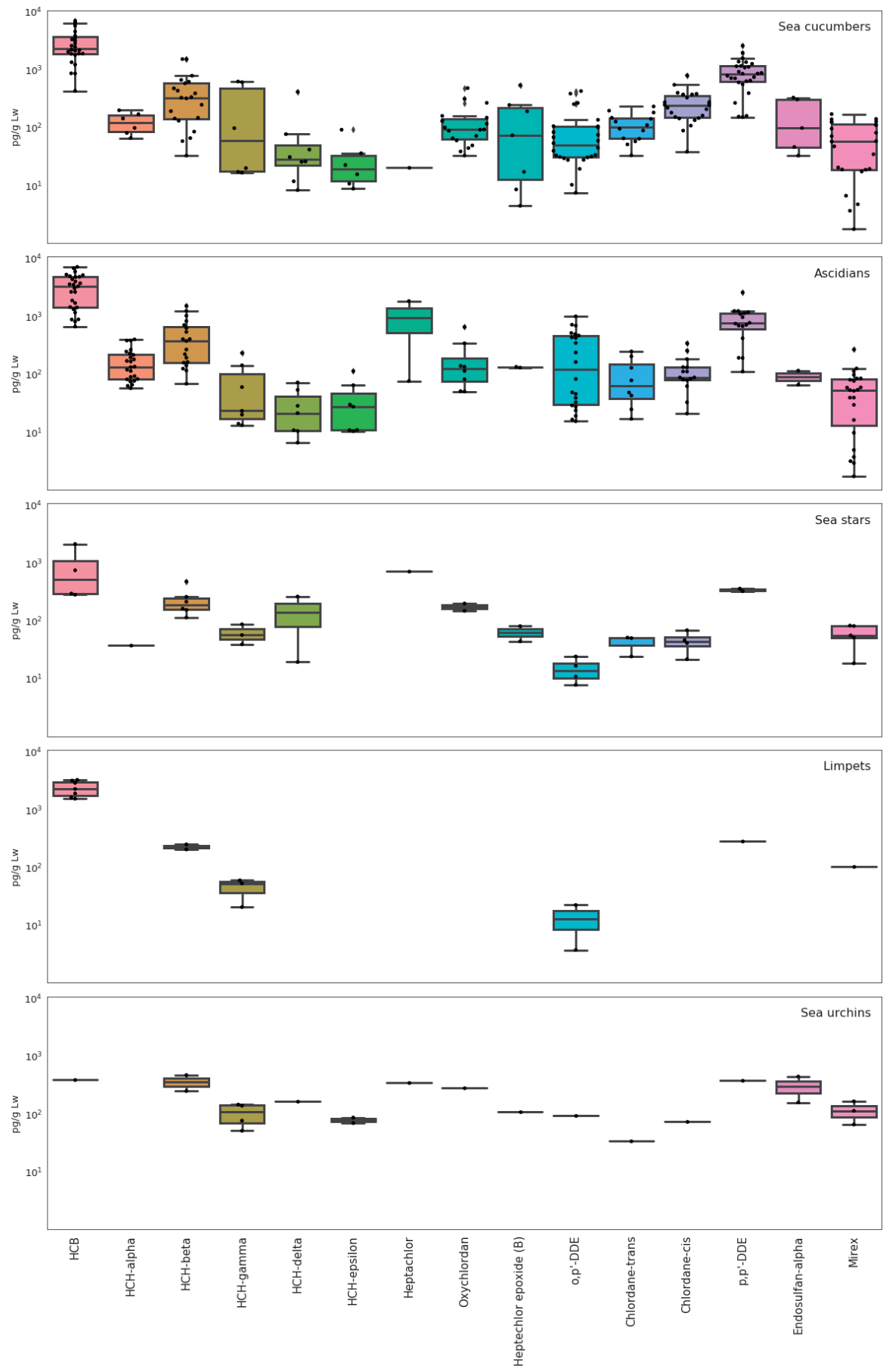

Figure 5. OCP concentrations in five antarctic benthic species in $\mathrm{pg} / \mathrm{g} \mathrm{Lw}$. The mid-line of each plot indicates the median value, the box shows the interquartile range and the whiskers are the $95 \%$ percentile range. The blank spaces indicate no data, as all measurements were below detection limit. 


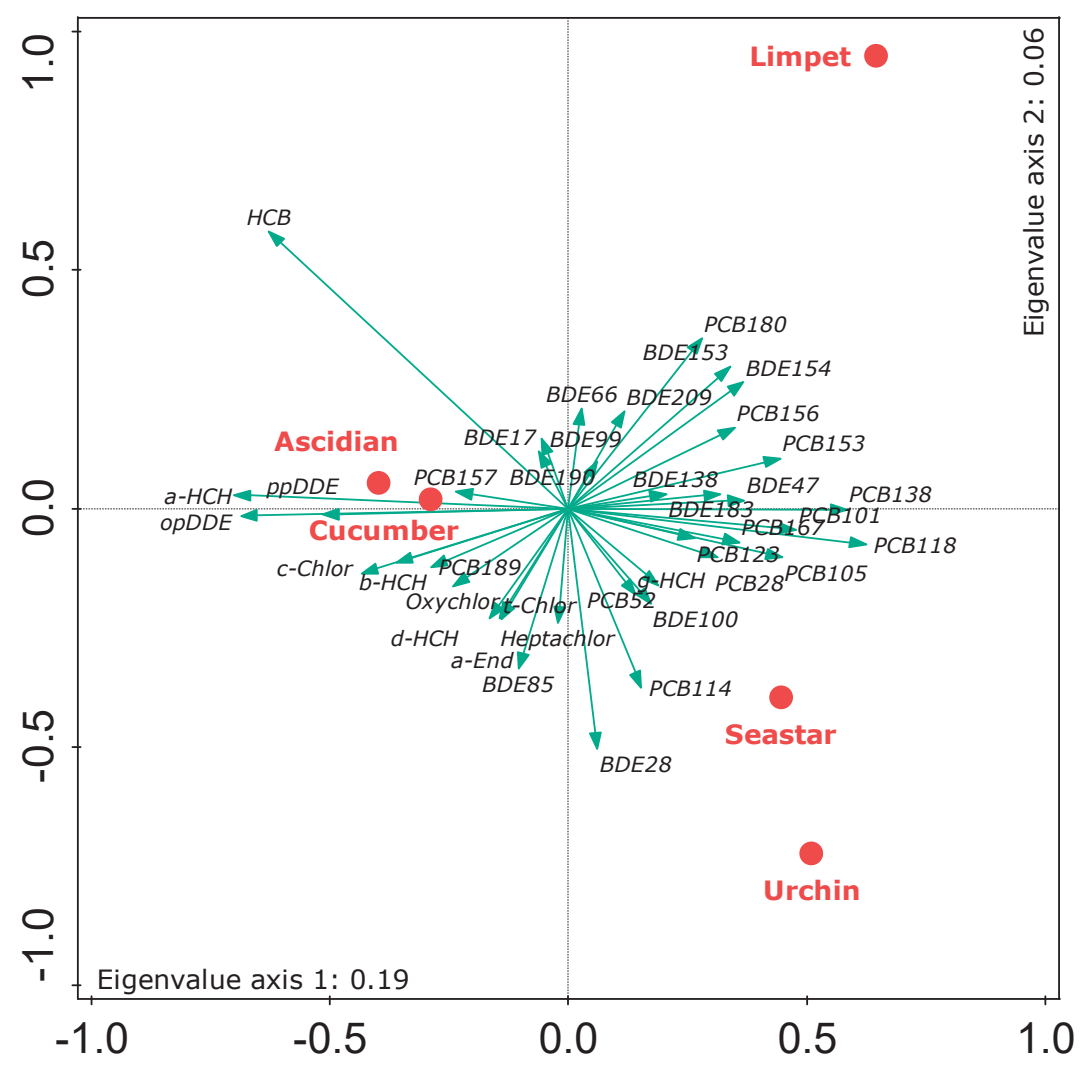

Figure 6. Bi-plot of dc-PCA relating concentrations of POPs (green arrows) and species (red dots) $(\lambda 1$ $=0.19$ and $\lambda 2=0.06)$.

compounds were measured in Antarctic invertebrates and their concentrations were lower than those reported in the $\mathrm{Artic}^{53}$. Overall, there were few interspecific differences in OCP concentrations (Appendix 3). A notable exception were heptachlor and oxychlordane, which were detected at significantly higher concentrations in sea cucumbers than in other species, which may result from them being suspension feeders.

\section{Drivers of species specific accumulation}

A dc-PCA was performed on the data on measured concentrations of POPs to extract insights of the interspecific accumulation patterns (Fig. 6) and to link them with the biological traits of the species and physico-chemical properties of the compounds (Fig. 8). The eigenvalue of axis 1 was 0.194 (Statistics pseudo $\mathrm{F}_{\text {prob }}: 3.1, \mathrm{p}=0.002$ ) and the one for axis 2 was 0.056 (statistics of combined axes: pseudo $\mathrm{F}_{\text {prob }}: 5.9, \mathrm{p}=0.002$ ). This dc-PCA indicates that limpets contained relatively high concentrations of higher halogenated PCBs and PBDEs, while ascidians and cucumbers accumulated more OCPs (especially HCB), with sea stars and urchins being in between. 


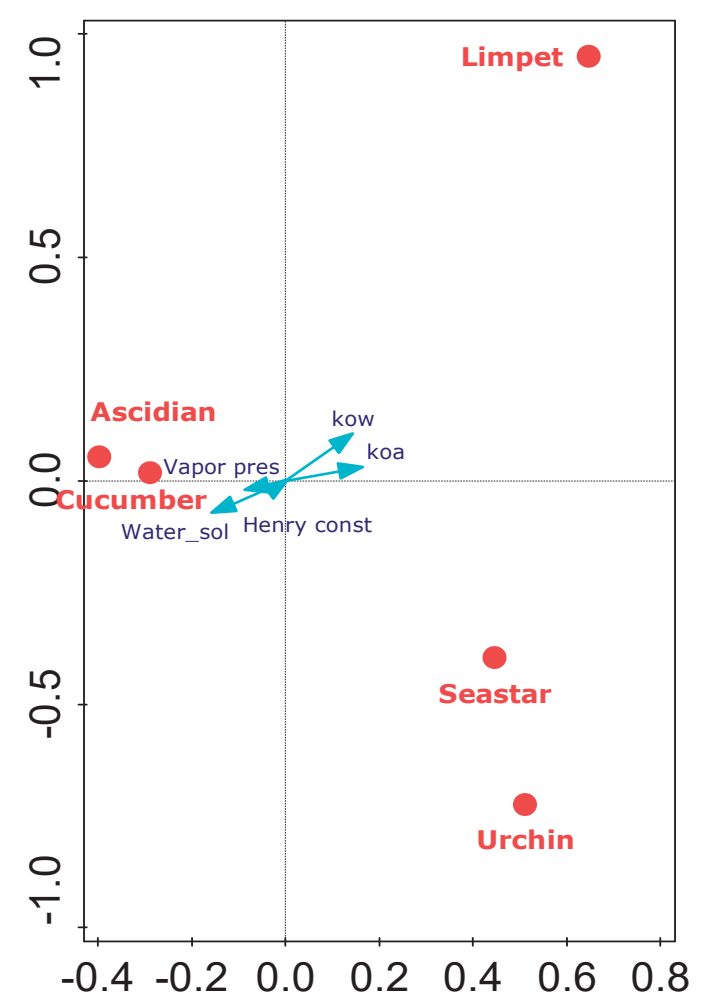

Figure 7. Bi-plot of dc-PCA relating species (red dots) and properties of POPs (blue arrows) $(\lambda 1=0.059$ and $\lambda 2=0.026$ ).

The dc-PCA on the data, constrained by physico-chemical properties of POPs (Kow, Koa, Henry's constant, water solubility and vapour pressure) (fig. 7) indicates that these properties were significantly related to the concentrations of POPs (pseudo $\mathrm{F}_{\text {prob }}: 2.7, \mathrm{p}=0.008$ ).

Limpets contained more POPs with higher Kow and Koa (Appendix 5), which was likely related to the grazing feeding behaviour of this species, as POPs with high Kow can be expected to accumulate in the lipophilic particles limpets feed on ${ }^{32}$. Furthermore, it may be related to the fact that limpets may have limited dermal exchange with the water because of their shell. This may limit the uptake of more water soluble POPs, i.e. the ones with lower Kow. Ascidians and sea cucumbers contained more compounds that were relatively water soluble, which corresponded to their greater surface area of exposed soft tissue and their respective filter and suspension feeding modes. Finally, sea stars and urchins occupied (again) somewhat a middle ground. This was possibly related to their respective predatory and omnivorous behaviour ${ }^{31,33}$, which includes diet items exposed to either foodborne POPs (with high Kow) or waterborne POPs (with low Kow). This mechanism is supported by previous attempts to explain differences in uptake between species ${ }^{45,51}$. The structure 
of dermis can be another factor controlling bioconcentration of POPs: the softer dermis of sea cucumbers ${ }^{56}$ and ascidian ${ }^{57}$ may lead to more intensive accumulation of POPs in these species, when compared to sea urchins, whose dermis is harder ${ }^{31,58,59}$.

Overall, specific feeding behaviour and the dermis of the species, and Kow and Koa of particular POPs influence the concentration of these compounds in examined animals. 


\section{ACKNOWLEDGMENTS}

The authors acknowledge help of the British Antarctic Survey (BAS) with infrastructure and coordination. The BAS divers are acknowledged for their support in sampling. We thank Willie Hijman and Guido van der Weg for their help with measurements with PCBs and PBDEs. We express our gratitude towards the Netherlands Organisation for Scientific Research (NWO) (grant 866.14.104) for financing this project. 


\section{REFERENCES}

1. Kelly, B. C.; Ikonomou, M. G.; Blair, J. D.; Morin, A. E.; Gobas, F. A. P. C. Food Web-Specific Biomagnification of Persistent Organic Pollutants. Science (80-. ). 2007, 317 (5835), 236-239. https://doi.org/10.1126/science.1138275.

2. Jones, K. C.; de Voogt, P. Persistent Organic Pollutants (POPs): State of the Science. Environ. Pollut. 1999, 100 (1-3), 209-221. https://doi.org/10.1016/S0269-7491(99)00098-6.

3. Andreas Beyer, †; Donald Mackay, *, †; Michael Matthies, †; Frank Wania, $₫$ and; Webster $\neq$, E. Assessing Long-Range Transport Potential of Persistent Organic Pollutants. 2000. https:/doi. org/10.1021/ES990207W.

4. Bargagli, R. Environmental Contamination in Antarctic Ecosystems. Sci. Total Environ. 2008, 400 (1-3), 212-226. https://doi.org/10.1016/j.scitotenv.2008.06.062.

5. Ellis, D. S.; Cipro, C. V. Z.; Ogletree, C. A.; Smith, K. E.; Aronson, R. B. A 50-Year Retrospective of Persistent Organic Pollutants in the Fat and Eggs of Penguins of the Southern Ocean. Environ. Pollut. 2018, 241, 155-163. https://doi.org/10.1016/J.ENVPOL.2018.05.003.

6. Trumble, S. J.; Robinson, E. M.; Noren, S. R.; Usenko, S.; Davis, J.; Kanatous, S. B. Assessment of Legacy and Emerging Persistent Organic Pollutants in Weddell Seal Tissue (Leptonychotes Weddellii) near McMurdo Sound, Antarctica. Sci. Total Environ. 2012, 439, 275-283. https://doi. org/10.1016/J.SCITOTENV.2012.09.018.

7. Goerke, H.; Weber, K.; Bornemann, H.; Ramdohr, S.; Plötz, J. Increasing Levels and Biomagnification of Persistent Organic Pollutants (POPs) in Antarctic Biota. Mar. Pollut. Bull. 2004, 48 (3-4), 295302. https://doi.org/10.1016/J.MARPOLBUL.2003.08.004.

8. van den Brink, N. W.; Riddle, M. J.; van den Heuvel-Greve, M.; van Franeker, J. A. Contrasting Time Trends of Organic Contaminants in Antarctic Pelagic and Benthic Food Webs. Mar. Pollut. Bull. 2011, 62 (1), 128-132. https://doi.org/10.1016/J.MARPOLBUL.2010.09.002.

9. Galbán-Malagón, C. J.; Del Vento, S.; Berrojalbiz, N.; Ojeda, M.-J.; Dachs, J. Polychlorinated Biphenyls, Hexachlorocyclohexanes and Hexachlorobenzene in Seawater and Phytoplankton from the Southern Ocean (Weddell, South Scotia, and Bellingshausen Seas). Environ. Sci. Technol. 2013, 47 (11), 5578-5587. https://doi.org/10.1021/es400030q.

10. Bates, M. L.; Bengtson Nash, S. M.; Hawker, D. W.; Shaw, E. C.; Cropp, R. A. The Distribution of Persistent Organic Pollutants in a Trophically Complex Antarctic Ecosystem Model. J. Mar. Syst. 2017, 170, 103-114. https://doi.org/10.1016/J.JMARSYS.2017.02.005.

11. Weber, K.; Goerke, H. Persistent Organic Pollutants (POPs) in Antarctic Fish: Levels, Patterns, Changes. Chemosphere 2003, 53 (6), 667-678. https://doi.org/10.1016/S0045-6535(03)00551-4.

12. R. Fuoco, G. Capodaglio, B. M. and M. R. (SCAR A. G. on E. C. in A. Persistent Organic Pollutants $(P O P s)$ in the Antarctic Environment: A Review of Findings; SCAR: Cambridge, 2017.

13. Bengtson Nash, S. Persistent Organic Pollutants in Antarctica: Current and Future Research Priorities. J. Environ. Monit. 2011, 13 (3), 497. https://doi.org/10.1039/c0em00230e.

14. Peck, L. Antarctic Marine Biodiversity: Adaptations, Environments and Responses to Change. Oceanogr. Mar. Biol. An Annu. Rev. 2018, 56, 105-236.

15. Wild, S.; McLagan, D.; Schlabach, M.; Bossi, R.; Hawker, D.; Cropp, R.; King, C. K.; Stark, J. S.; Mondon, J.; Nash, S. B. An Antarctic Research Station as a Source of Brominated and Perfluorinated Persistent Organic Pollutants to the Local Environment. Environ. Sci. Technol. 2015, 49 (1), $103-$ 112. https://doi.org/10.1021/es5048232.

16. Cressey, D. Polar Code Protects Ships and Species in Icy Waters. Nature 2014. https://doi. org/10.1038/nature.2014.16402.

17. Enzenbacher, D. J. Antarctic Tourism and Environmental Concerns; 1992; Vol. 25.

18. Goutte, A.; Chevreuil, M.; Alliot, F.; Chastel, O.; Cherel, Y.; Eléaume, M.; Massé, G. Persistent Organic Pollutants in Benthic and Pelagic Organisms off Adélie Land, Antarctica. Mar. Pollut. Bull. 2013, 77 (1-2), 82-89. https://doi.org/10.1016/j.marpolbul.2013.10.027. 
19. Ko, F.-C.; Pan, W.-L.; Cheng, J.-O.; Chen, T.-H.; Kuo, F.-W.; Kao, S.-J.; Chang, C.-W.; Ho, H.-C.; Wang, W.-H.; Fang, L.-S. Persistent Organic Pollutants in Antarctic Notothenioid Fish and Invertebrates Associated with Trophic Levels. PLoS One 2018, 13 (4), e0194147. https://doi. org/10.1371/journal.pone.0194147.

20. Grotti, M.; Pizzini, S.; Abelmoschi, M. L.; Cozzi, G.; Piazza, R.; Soggia, F. Retrospective Biomonitoring of Chemical Contamination in the Marine Coastal Environment of Terra Nova Bay (Ross Sea, Antarctica) by Environmental Specimen Banking. Chemosphere 2016, 165, 418-426. https://doi.org/10.1016/J.CHEMOSPHERE.2016.09.049.

21. Corsolini, S. Industrial Contaminants in Antarctic Biota. J. Chromatogr. A 2009, 1216 (3), 598612. https://doi.org/10.1016/J.CHROMA.2008.08.012.

22. Moreau, S.; Mostajir, B.; Bélanger, S.; Schloss, I. R.; Vancoppenolle, M.; Demers, S.; Ferreyra, G. A. Climate Change Enhances Primary Production in the Western Antarctic Peninsula. Glob. Chang. Biol. 2015, 21 (6), 2191-2205. https://doi.org/10.1111/gcb.12878.

23. Ashton, G. V.; Morley, S. A.; Barnes, D. K. A.; Clark, M. S.; Peck, L. S. Warming by $1^{\circ} \mathrm{C}$ Drives Species and Assemblage Level Responses in Antarctica's Marine Shallows. Curr. Biol. 2017, 27 (17), 2698-2705.e3. https://doi.org/10.1016/J.CUB.2017.07.048.

24. Barnes, D. K. A. Antarctic Sea Ice Losses Drive Gains in Benthic Carbon Drawdown. Curr. Biol. 2015, 25 (18), R789-R790. https://doi.org/10.1016/J.CUB.2015.07.042.

25. PECK, L. S.; BARNES, D. K. A.; COOK, A. J.; FLEMING, A. H.; ClARKE, A. Negative Feedback in the Cold: Ice Retreat Produces New Carbon Sinks in Antarctica. Glob. Chang. Biol. 2010, 16 (9), 2614-2623. https://doi.org/10.1111/j.1365-2486.2009.02071.x.

26. Kennicutt, M. C.; Bromwich, D.; Liggett, D.; Njåstad, B.; Peck, L.; Rintoul, S. R.; Ritz, C.; Siegert, M. J.; Aitken, A.; Brooks, C. M.; Cassano, S.; Chaturvedi, D.; Dodds, K.; Golledge, N.; Le Bohec, C; Murray, A; Raphael, M; Yang, H.; Chown, S.. Sustained Antarctic Research: A 21st Century Imperative. One Earth 2019, 1 (1), 95-113. https://doi.org/10.1016/j.oneear.2019.08.014.

27. Henley, S. F.; Schofield, O. M.; Hendry, K. R.; Schloss, I. R.; Steinberg, D. K.; Moffat, C.; Peck, L. S.; Costa, D. P.; Bakker, D. C. E.; Hughes, C.; Rozema, P; Ducklow, H. ; Abele, Doris , Stefels, J., van Leeuwe, M.; Brussaard, C; Buma, A; Kohut, J; Sahade, R; Friedlaender, A.; Stammerjohn, S; Venables, H; Meredith, P.. Variability and Change in the West Antarctic Peninsula Marine System: Research Priorities and Opportunities. Prog. Oceanogr. 2019, 173, 208-237. https://doi. org/10.1016/J.POCEAN.2019.03.003.

28. Teran, T.; Lamon, L.; Marcomini, A. Climate Change Effects on POPs' Environmental Behaviour: A Scientific Perspective for Future Regulatory Actions. Atmos. Pollut. Res. 2012, 3 (4), 466-476. https://doi.org/10.5094/APR.2012.054.

29. Sun, J.; Zhang, L.; Pan, Y.; Lin, C.; Wang, F.; Kan, R.; Yang, H. Feeding Behavior and Digestive Physiology in Sea Cucumber Apostichopus Japonicus. Physiol. Behav. 2015, 139, 336-343. https:// doi.org/10.1016/J.PHYSBEH.2014.11.051.

30. Tatián, M.; Sahade, R.; Kowalke, J.; Kivatinitz, S.; Esnal, G. Food Availability and Gut Contents in the Ascidian Cnemidocarpa Verrucosa at Potter Cove, Antarctica. Polar Biol. 2002, 25 (1), 58-64. https://doi.org/10.1007/s003000100311.

31. Peck, L. S.; Clark, M. S.; Dunn, N. I. Morphological Variation in Taxonomic Characters of the Antarctic Starfish Odontaster Validus. Polar Biol. 2018, 41 (10), 2159-2165. https://doi.org/10.1007/ s00300-018-2344-z.

32. Brêthes, J.-C.; Ferreyra, G.; de la Vega, S. Distribution, Growth and Reproduction of the Limpet Nacella (Patinigera) Concinna (Strebel 1908) in Relation to Potential Food Availability, in Esperanza Bay (Antarctic Peninsula). Polar Biol. 1994, 14 (3), 161-170. https://doi.org/10.1007/BF00240521.

33. S., B.; A., C.; A., C. Seasonality of Feeding and Nutritional Status during the Austral Winter in the Antarctic Sea Urchin Sterechinus Neumayeri. Mar. Biol. 2001, 139 (1), 127-138. https:/doi. org/10.1007/s002270100561.

34. Maaten, L. van der; Hinton, G. Visualizing Data Using T-SNE. J. Mach. Learn. Res. 2008, 9 (Nov), $2579-2605$. 
35. Hale, R. C.; Kim, S. L.; Harvey, E.; La Guardia, M. J.; Mainor, T. M.; Bush, E. O.; Jacobs, E. M. Antarctic Research Bases: Local Sources of Polybrominated Diphenyl Ether (PBDE) Flame Retardants. Environ. Sci. Technol. 2008, 42 (5), 1452-1457. https://doi.org/10.1021/es702547a.

36. Michel, L. N.; Danis, B.; Dubois, P.; Eleaume, M.; Fournier, J.; Gallut, C.; Jane, P.; Lepoint, G. Increased Sea Ice Cover Alters Food Web Structure in East Antarctica. Sci. Rep. 2019, 9 (1), 8062. https://doi.org/10.1038/s41598-019-44605-5.

37. Frouin, H.; Jackman, • P; Dangerfield, • N D; Ross, • P S. Effects of Feeding Strategy, Sediment Characteristics, and Chemical Properties on Polychlorinated Biphenyl and Polybrominated Diphenyl Ether Bioaccumulation from Marine Sediments in Two Invertebrates. https://doi.org/10.1007/ s00244-016-0361-x.

38. Zheng, B.; Zhao, X.; Ni, X.; Ben, Y.; Guo, R.; An, L. Bioaccumulation Characteristics of Polybrominated Diphenyl Ethers in the Marine Food Web of Bohai Bay. Chemosphere 2016, 150, 424-430. https://doi.org/10.1016/J.CHEMOSPHERE.2016.01.110.

39. Viganò, L.; Roscioli, C.; Guzzella, L. Decabromodiphenyl Ether (BDE-209) Enters the Food Web of the River Po and Is Metabolically Debrominated in Resident Cyprinid Fishes. Sci. Total Environ. 2011, 409 (23), 4966-4972. https://doi.org/10.1016/J.SCITOTENV.2011.07.062.

40. Wang, P.; Zhang, Q.; Wang, T.; Chen, W.; Ren, D.; Li, Y.; Jiang, G. PCBs and PBDEs in Environmental Samples from King George Island and Ardley Island, Antarctica. RSC Adv. 2012, 2 (4), 1350-1355. https://doi.org/10.1039/C1RA00462J.

41. Markham, E.; Brault, E. K.; Khairy, M.; Robuck, A. R.; Goebel, M. E.; Cantwell, M. G.; Dickhut, R. M.; Lohmann, R. Time Trends of Polybrominated Diphenyl Ethers (PBDEs) in Antarctic Biota. ACS Omega 2018, 3 (6), 6595-6604. https://doi.org/10.1021/acsomega.8b00440.

42. Wang, P.; Li, Y.; Zhang, Q.; Yang, Q.; Zhang, L.; Liu, F.; Fu, J.; Meng, W.; Wang, D.; Sun, H.. Three-Year Monitoring of Atmospheric PCBs and PBDEs at the Chinese Great Wall Station, West Antarctica: Levels, Chiral Signature, Environmental Behaviors and Source Implication. Atmos. Environ. 2017, 150, 407-416. https://doi.org/10.1016/J.ATMOSENV.2016.11.036.

43. Sönke Lakaschus, ${ }^{*} \dagger ;$ Kurt Weber, $†$; Frank Wania, $\ddagger$; Regina Bruhn, $\mathbb{S}$ and; Schrems $\dagger$, O. The Air-Sea Equilibrium and Time Trend of Hexachlorocyclohexanes in the Atlantic Ocean between the Arctic and Antarctica. 2001. https://doi.org/10.1021/ES010211J.

44. Moermond, C. T.; Verbruggen, E. M. An Evaluation of Bioaccumulation Data for Hexachlorobenzene to Derive Water Quality Standards According to the EU-WFD Methodology. Integr. Environ. Assess. Manag. 2013, 9 (1), 87-97. https://doi.org/10.1002/ieam.1351.

45. Corsolini, S.; Sarà, G. The Trophic Transfer of Persistent Pollutants (HCB, DDTs, PCBs) within Polar Marine Food Webs. Chemosphere 2017, 177, 189-199. https://doi.org/10.1016/J. CHEMOSPHERE.2017.02.116.

46. Focardi, S.; Bargagli, R.; Corsolini, S. Organochlorines in Antarctic Marine Food Chain at Terranova Bay (Ross Sea). 1993.

47. Bromwich, D. H.; Nicolas, J. P.; Monaghan, A. J.; Bromwich, D. H.; Nicolas, J. P.; Monaghan, A. J. An Assessment of Precipitation Changes over Antarctica and the Southern Ocean since 1989 in Contemporary Global Reanalyses. J. Clim. 2011, 24 (16), 4189-4209. https://doi. org/10.1175/2011JCLI4074.1.

48. Shanklin, J.; Moore, C.; Colwell, S. Meteorological Observing and Climate in the British Antarctic Territory and South Georgia: Part 2. Weather 2009, 64 (7), 171-177. https://doi.org/10.1002/ wea.398.

49. Bertler, N. A. N.; Conway, H.; Dahl-Jensen, D.; Emanuelsson, D. B.; Winstrup, M.; Vallelonga, P. T.; Lee, J. E.; Brook, E. J.; Severinghaus, J. P.; Fudge, T. J.. The Ross Sea Dipole - Temperature, Snow Accumulation and Sea Ice Variability in the Ross Sea Region, Antarctica, over the Past 2700 Years. Clim. Past 2018, 14 (2), 193-214. https://doi.org/10.5194/cp-14-193-2018.

50. Genthon, C.; Berne, A.; Grazioli, J.; Durán Alarcón, C.; Praz, C.; Boudevillain, B. Precipitation at Dumont d'Urville, Adélie Land, East Antarctica: The APRES3 Field Campaigns Dataset. Earth Syst. Sci. Data 2018, 10 (3), 1605-1612. https://doi.org/10.5194/essd-10-1605-2018. 
51. Galbán-Malagón, C.; Cabrerizo, A.; Caballero, G.; Dachs, J. Atmospheric Occurrence and Deposition of Hexachlorobenzene and Hexachlorocyclohexanes in the Southern Ocean and Antarctic Peninsula. Atmos. Environ. 2013, 80, 41-49. https://doi.org/10.1016/J.ATMOSENV.2013.07.061.

52. Casal, P.; Casas, G.; Vila-Costa, M.; Cabrerizo, A.; Pizarro, M.; Jiménez, B.; Dachs, J. Snow Amplification of Persistent Organic Pollutants at Coastal Antarctica. Environ. Sci. Technol. 2019, acs.est.9b03006. https://doi.org/10.1021/acs.est.9b03006.

53. Muir, D.; Savinova, T.; Savinov, V.; Alexeeva, L.; Potelov, V.; Svetochev, V. Bioaccumulation of PCBs and Chlorinated Pesticides in Seals, Fishes and Invertebrates from the White Sea, Russia. Sci. Total Environ. 2003, 306 (1-3), 111-131. https://doi.org/10.1016/S0048-9697(02)00488-6.

54. Geisz, H. N.; Dickhut, R. M.; Cochran, M. A.; Fraser, W. R.; Ducklow, H. W. Melting Glaciers: A Probable Source of DDT to the Antarctic Marine Ecosystem. Environ. Sci. Technol. 2008, 42 (11), 3958-3962. https://doi.org/10.1021/es702919n.

55. Brink, N. van den; Riddle, M.; Heuvel-Greve, M. van den; Allison, I.; Snape, I.; van Franeker, J. A. Correspondence on Geisz et Al. Melting Glaciers: A Probable Source of DDT to the Antarctic Marine Ecosystem. Environ. Sci. Technol. 2009, 43 (10), 3976-3977. https://doi.org/10.1021/ es8034494.

56. Thurmond, F.; Trotter, J. Morphology and Biomechanics of the Microfibrillar Network of Sea Cucumber Dermis. J. Exp. Biol. 1996, 199 (8).

57. McClintock, J. B.; Heine, J.; Slattery, M.; Weston, J. Biochemical and Energetic Composition, Population Biology, and Chemical Defense of the Antarctic Ascidian Cnemidocarpa Verrucosa Lesson. J. Exp. Mar. Bio. Ecol. 1991, 147 (2), 163-175. https://doi.org/10.1016/0022-0981(91) 90180-5.

58. Janosik, A. M.; Halanych, K. M. Unrecognized Antarctic Biodiversity: A Case Study of the Genus Odontaster (Odontasteridae; Asteroidea). Integr. Comp. Biol. 2010, 50 (6), 981-992. https:/doi. org/10.1093/icb/icq119.

59. Ruppert, E. E.; Fox, R. S.; Barnes, R. D. Invertebrate Zoology : A Functional Evolutionary Approach; Thomson-Brooks/Cole, 2004. 


\section{SUPPLEMENTARY INFORMATION}

All supplementary information is available online at DOI: 10.1021/acs.est.9b06622 


$$
5
$$




\section{Chapter 5}

\section{Effects of exposure of the Antarctic limpet}

Nacella concinna to Polychlorinated Biphenyls (PCBs)

Artem Krasnobaev, Guillaume ten Dam, Stefan P.J. van Leeuwen, Simon A. Morley, Lloyd S. Peck, Hans van den Berg, Jacques Vervoort, Nico W. van den Brink. 


\section{ABSTRACT}

A toxicodynamic experiment was conducted with Antarctic benthic invertebrate limpet (Nacella concinna) to establish potential biomarkers of exposure and effect and to assess current risks of Polychlorinated Biphenyls (PCBs) to this Antarctic benthic species. Animals were exposed to different water-borne concentrations of a mixture of PCBs during a period of 4 weeks. The results obtained revealed an accumulation of these compounds in the limpet tissue with increasing water-borne concentrations. Ethoxyresorufin-O-deethylase (EROD) analyses of the limpet hepatopancreas showed low enzyme activities in control animals, which decreased with increasing concentrations of PCBs. Nuclear magnetic resonance (NMR) measurements of endogenous lipid metabolites revealed negative associations between PCBs and major lipids in N. concinna,. Overall, this study for the first time established effects of exposure of an Antarctic marine benthic species to PCBs. 


\section{INTRODUCTION}

Polychlorinated biphenyls (PCBs) are a group of organochloride compounds, which was one of the earliest to be recognised as Persistent Organic Pollutants (POPs) because of the persistence and harmful effects of these chemicals on the environment ${ }^{1}$. In the 1970 s the presence of PCBs was even reported in Antarctica, a remote and perceived to be pristine area $^{2}$. Although over the last decades the concentrations of PCBs in the Antarctic pelagic ecosystems have decreased and are low in comparison to temperate areas, future trends in exposure and toxicological risks of these compounds to local marine (both pelagic and benthic) ecosystems are not fully understood ${ }^{3}$.

Because Antarctic organisms are highly endemic, often show extreme metabolic profiles and lipid composition ${ }^{4,5}$, and live under extreme conditions, it has been speculated that Antarctic marine animals may be more sensitive to POPs, including PCBs, when compared to species from temperate and tropical areas ${ }^{3}$. Invertebrate species have been recognised as bioindicators of PCBs in temperate ${ }^{6-8}$ and also Arctic ${ }^{9}$ regions due their high trophic diversity, relatively long lifespan and sedentary lifestyle with respect to benthic species ${ }^{10}$. To this date, only one series of studies was conducted on hazards of POPs for Antarctic invertebrates ${ }^{11-14}$. Effects of either food-born or water-boon DDE exposure on krill (Euphausia superba) and krill larvae were examined and no significant differences between Antarctic and related temperate species could be established. While those studies identified and quantified major toxicological pathways ${ }^{12,14}$ it remains unclear whether those result apply also to other Antarctic species.

When examining toxicological effects of PCBs in Antarctic marine ecosystems several PCB-related factors should be considered. First, Antarctica is the continent that experiences the most drastic effects of the global warming, which may place additional stress on already vulnerable local ecosystems, potentially making them more vulnerable to PCB exposure ${ }^{15-17}$. Second, comprehensive information on concentrations of PCBs and other persistent chemicals in some parts of these ecosystems is still lacking, which does not allow for a proper estimation of current exposure levels ${ }^{18,19}$. Third, the growing tourist industry and potential re-mobilization of old PCB storages may lead to increase of these levels ${ }^{3,20}$. Therefore, it is important to determine reliable indicator organisms and appropriate biomarkers that would help to provide insights on ecotoxicological risks of PCBs in Antarctica. It has been established that biochemical responses of invertebrates to exposure to PCBs may result in disrupted lipid metabolism, increased oxidative stress and induction of Aryl hydrocarbon Receptor (AhR) mediated effects ${ }^{21,22}$. However, their exact effects and related biomarkers in the Antarctic limpets ( $N$. concinna), which may be potential candidate species for environmental monitoring purposes ${ }^{23,24}$, have not been established. 
The limpet species $N$. concinna is a fairly abundant and well-studied Antarctic mollusc $c^{23,25}$. It is a grazing feeder and has a low degree of metabolic seasonality due to the maintenance of high winter metabolic rates ${ }^{23}$ which makes it suitable for toxicodynamic experiments. A recent study looked into the environmental concentrations of POPs in this species: although PCB concentrations in these animals remained low, they nevertheless may have presented a potential ecotoxicological risk ${ }^{26}$. Limpets were already proposed as bioindicators for other $\mathrm{POPs}^{24}$ and were therefore chosen as a model organism for the current study.

The main goal of the current study was to conduct an in-vivo toxicodynamic experiment by exposing Antarctic limpets $N$. concinna to different increasing concentrations of a PCB mixture with the aim of identifying potential biomarkers of exposure and effect, and establishing, whether observed concentrations in $N$. concinna are high enough to present an ecotoxicological risk.

\section{MATERIALS AND METHODS}

\section{Field Sampling}

The limpets $N$. concinna were sampled by divers around the islands of the Ryder Bay near Rothera research station $\left(67^{\circ} 35^{\prime} 8^{\prime \prime} \mathrm{S}, 68^{\circ} 7^{\prime} 59^{\prime \prime} \mathrm{W}\right)$ and the coast of the Western Antarctic Peninsula (WAP) of the British Antarctic Survey (BAS), late March of 2017. Immediately after collection the limpets were put into a temperature-controlled (ambient temperature $2^{\circ} \mathrm{C}$, water temperature around $-1^{\circ} \mathrm{C}$ ) aquarium, in which they were then transported to the UK onboard RRS Ernest Shackleton. During the voyage (12 weeks) the limpets were not fed, but the seawater exchange was performed once per day through the seawater collection system of the ship. The water exchange stopped a day before the ship entered the English Channel to avoid contamination.

\section{Experimental set-up and procedure}

From the transport aquarium the limpets were directly transferred into a tank located on BAS premises in a room permanently kept at the same temperature conditions (ambient temperature $2^{\circ} \mathrm{C}$, water temperature of $-1^{\circ} \mathrm{C}$ ). A siphon device was used to provide limpets with extra oxygen and to collect excessive mucus produced by them. The saltwater $(35 \%$ salinity) was prepared directly on site by mixing aquarium salt (D - D H2Ocean Pro $+^{\mathrm{TM}}$ by Maidenhead Aquatics (Egham, UK)) with demi-water. The seawater was exchanged twice a week. Limpets were first kept for 5 weeks under these conditions to allow acclimatization after the voyage. After the 5 weeks, the amount of mucus production decreased and the limpet mortality reached a steady state (1-2 specimens per week), after which the limpets were transferred to the experimental set-up. 
Limpets (8-10 individual specimens) were put into glass jars filled with 4 liters of saltwater, each jar representing an individual experimental unit. No sediment was included in the jars. Jars were kept slightly ajar to allow a passage of oxygen, supplied by a pump through Teflon tubes.

The experiment started by exposing limpets to a mixture of PCBs (congeners 18, 31, 28, 52, $44,101,118,149,153,138,180,170,194,209)$ dissolved in dimethyl sulfoxide (DMSO) to allow better miscibility with the water. The experiment included 4 levels of exposure with the total nominal PCB concentrations in the water in the jars (experimental units) of $1 \mathrm{ng} / \mathrm{L}$, $10 \mathrm{ng} / \mathrm{L}, 100 \mathrm{ng} / \mathrm{L}$ and $400 \mathrm{ng} / \mathrm{L}$ and control, a range of concentrations which represent environmentally relevant concentrations in the temperate areas of the world ${ }^{27-31}$. Control and exposure levels of $1 \mathrm{ng} / \mathrm{L}, 10 \mathrm{ng} / \mathrm{L}$ had 3 repetitions (i.e. 3 experimental units), while the exposure levels of $100 \mathrm{ng} / \mathrm{L}$ and $400 \mathrm{ng} / \mathrm{L}$ had 4 repetitions (i.e. 4 experimental units). PCBs dissolved in $100 \mu \mathrm{l}$ DMSO were added daily from Monday to Friday to maintain the levels of nominal concentrations (thus, the total added daily volume was $100 \mu \mathrm{l}$ ) and each Friday afternoon half of the saltwater in each jar was exchanged with fresh saltwater and the water spiked with the needed amounts of PCBs.

The experiment was terminated after 4 weeks of PCB exposure. The limpets were immediately dissected, and their hepatopancreases removed. The hepatopancreases were stored at $-80^{\circ} \mathrm{C}$ (later used for EROD and NMR), while the rest of the specimens were stored at $-20^{\circ} \mathrm{C}$ (later used for chemical analysis). Note that limpet mortality remained the same (0-1 specimens per the whole set-up per week) during the whole experiment.

\section{Chemical analysis}

All samples were analysed for the major PCB congeners in the mixture $(28,52,101,105$, $114,118,123,138,153,156,157,167,180,189)$ to allow comparison with the previously measured environmental concentrations in limpets of Rothera Bay ${ }^{26}$. The complete extraction and clean-up procedure was adapted from a previous study on PCBs in $N$. concinna and other Antarctic marine benthic species ${ }^{26}$ and is described step-by-step in Appendix 1A. For extraction $5 \mathrm{ml}$ (corresponding to $3-7 \mathrm{~g}$ dry weight) of homogenised and freeze-dried sample was transferred into $60 \mathrm{ml}$ amber glass tubes and spiked with ${ }^{13} \mathrm{C}$ PCB standards obtained from LGC Standards (Teddington, UK). Distilled water was added until the total mass of the sample was $13 \mathrm{~g}$, and the sample was shaken for 3 minutes. After this, $10 \mathrm{ml}$ ethyl acetate was added, and the mixture was vigorously shaken again in an overhead shaker for at least 10 minutes. This was followed by an addition of a mix of $2 \mathrm{~g}$ sodium chloride and $4 \mathrm{~g}$ magnesium sulphate. After mixing the samples were then centrifuged for at least 10 minutes at $350 \mathrm{~g}$. The ethyl acetate supernatant was transferred into a Turbovap tube and the procedure was repeated twice, starting from the addition of another $10 \mathrm{ml}$ ethyl 
acetate. Therefore, the total volume of the extract obtained was approximately $30 \mathrm{ml}$. The samples were concentrated in a Turbovap apparatus to $1 \mathrm{ml}$, of which $0.1 \mathrm{ml}$ was used for later lipid quantification, which was done gravimetrically. The rest of the extract was transferred quantitatively to a $60 \mathrm{ml}$ amber glass vial. Each tube was washed 3 times with $9 \mathrm{ml}$ of hexane each time, and this was combined with the extract in the $60 \mathrm{ml}$ vials. Ten $\mathrm{g}$ of $40 \%$ acidic silica were added to each sample and the sample was left overnight. After this, the hexane fraction of the sample was transferred to a new Turbovap tube, which was followed by 2 cycles of washing with $10 \mathrm{ml}$ of hexane, centrifugation for 10 minutes at $350 \mathrm{~g}$ and transferring the hexane phase to the Turbovap tube. The samples were concentrated to $1 \mathrm{ml}$ in a Turbovap and brought onto a clean-up silica column, which was packed with $1 \mathrm{~g}$ of activated silica and $8 \mathrm{~g}$ of $40 \%$ acidic silica, which were twice pre-eluted with $10 \mathrm{ml}$ and $15 \mathrm{ml}$ of hexane respectively. The sample was eluted consecutively with $18 \mathrm{ml}$ hexane and $12 \mathrm{ml}$ dichloromethane. The resulting solvent mixture was evaporated in a Turbovap to $0.5 \mathrm{ml}$, and a solvent exchange to iso-octane was performed by evaporation. The final $0.5 \mathrm{ml}$ of extract in iso-octane was stored at $-20^{\circ} \mathrm{C}$ until measurements were made.

For quality assurance (QA) and quality control (QC), a procedural blank and a sample of a certified reference material (SRM 1947 Lake Michigan fish tissue, National Institute of Standards and Technology) were analysed every 9 actual samples. Furthermore, each analysed ${ }^{12} \mathrm{C} \mathrm{PCB}$ congener had a corresponding ${ }^{13} \mathrm{C}$ congener as an internal standard for concentration correction.

Limits of quantification (LOQ) were calculated as 3 times the concentration of the compound in the extract of the corresponding blank sample. The content of extractable matter (predominantly lipid content) of each sample was determined gravimetrically. The total concentrations of PCBs were then expressed on a Toxic equivalency factor (TEF) basis, using the WHO guidelines and TEF values ${ }^{32}$. Toxic Equivalents (TEQ) were further calculated as TEQ $=\Sigma[\mathrm{Ci} \times \mathrm{TEFi}]$, where $\mathrm{Ci}$ is the concentration of the corresponding PCB congener $(\mathrm{i})^{32}$.

\section{CYP enzyme activity measurement}

The protocol for measurements of the activity of cytochrome P450 (iso)enzymes was adapted from previous studies ${ }^{47-49}$. In essence, $1.5 \mathrm{ml}$ of $0.1 \mathrm{M}$ phosphate buffer was mixed with a sample of limpet hepatopancreas (at the ratio of $\mathrm{mg}$ tissue $: \mathrm{ml}$ buffer $=1: 2$ ) and homogenized in a cooled Potter-homogenizer at moderate speed. The homogenate was transferred to an Eppendorf vial and centrifuged in a pre-cooled centrifuged at $9000 \mathrm{~g}$ for 20 minutes. Subsequently $25 \mu \mathrm{l}$ of the supernatant was transported to a 96-well plate with a flat bottom. The proper substrate (ethyl-ether-resorufin for EROD, methyl-etherresorufin for MROD, pentyl-ether-resorufin for PROD and benzyl-ether-resorufin for $\mathrm{BROD}$ ) was added to the sample, together with $\mathrm{NADPH}$ and dicumarol buffer, followed 
by an incubation at RT for 60 minutes. Dicumarol was added to prevent the breakdown of resorufin (RR) by diaphorase. Afterwards, the amount of RR was measured by fluorescence at $\lambda_{\text {excitation }}=530 \mathrm{~nm}$ and $\lambda_{\text {emission }}=590 \mathrm{~nm}$. For comparison a RR-standard curve was measured using the same method and cellular protein content was measured using the Pierce BCA method.

\section{NMR}

Nuclear magnetic resonance (NMR) was used to obtain information on the profile of lipids in the limpets. To prepare the samples for measurement, approximately $0.1 \mathrm{~g}$ of fresh hepatopancreas material was mixed with $0.5 \mathrm{ml} 50 \mathrm{mM}$ phosphate buffer $\mathrm{pH} 7.3$ in a 2.0 $\mathrm{ml}$ Eppendorf tube. The sample was ultrasonicated for 15 minutes and 800 microliter deuterated chloroform were added to the sample. The sample was hand mixed very well for 10 minutes and subsequently centrifuged at $9400 \mathrm{~g}$ for another 15 minutes. The $\mathrm{CDCl}_{3}$ bottom layer of the Eppendorf tube was carefully transferred to a $3 \mathrm{~mm}$ NMR tube (Bruker matching system).

The NMR measurement was performed on a Bruker NMR spectrometer Avance III ${ }^{\mathrm{TM}}$ (Billerica, USA) with a $600 \mathrm{MHz} / 54 \mathrm{~mm}$ UltraShield Plus magnet equipped with a CryoPlatform ${ }^{\oplus}$ cryogenic cooling system, a BCU-05 cooling unit and an ATM $^{\circledast}$ automatic tuning and matching unit. Measurements were done at the temperature of $300 \mathrm{~K}$. $1 \mathrm{D}$ nuclear Overhauser-enhancement spectroscopy (NOESY) spectra were obtained.

The intensity of the NMR resonances was corrected for amounts of hepatopancreas used for sample preparation.

\section{Statistical analyses}

Statistical significance of differences between groups was assessed by use of the Student t-test with an assumed unequal variance. Dose-response relationships between log-transformed PCB concentrations and enzyme activities were analyzed with regression analyses ${ }^{33}$. To assess the patterns of the metabolites and to related them to exposure levels, Principal Component Analyses (PCA) were used (Canoco, version 5.12 $2^{34}$ ).

\section{RESULTS AND DISCUSSION}

\section{Chemical analysis}

Bioaccumulation of PCBs associated with the water-borne exposure of the limpets to these compounds is presented in figure 1. 


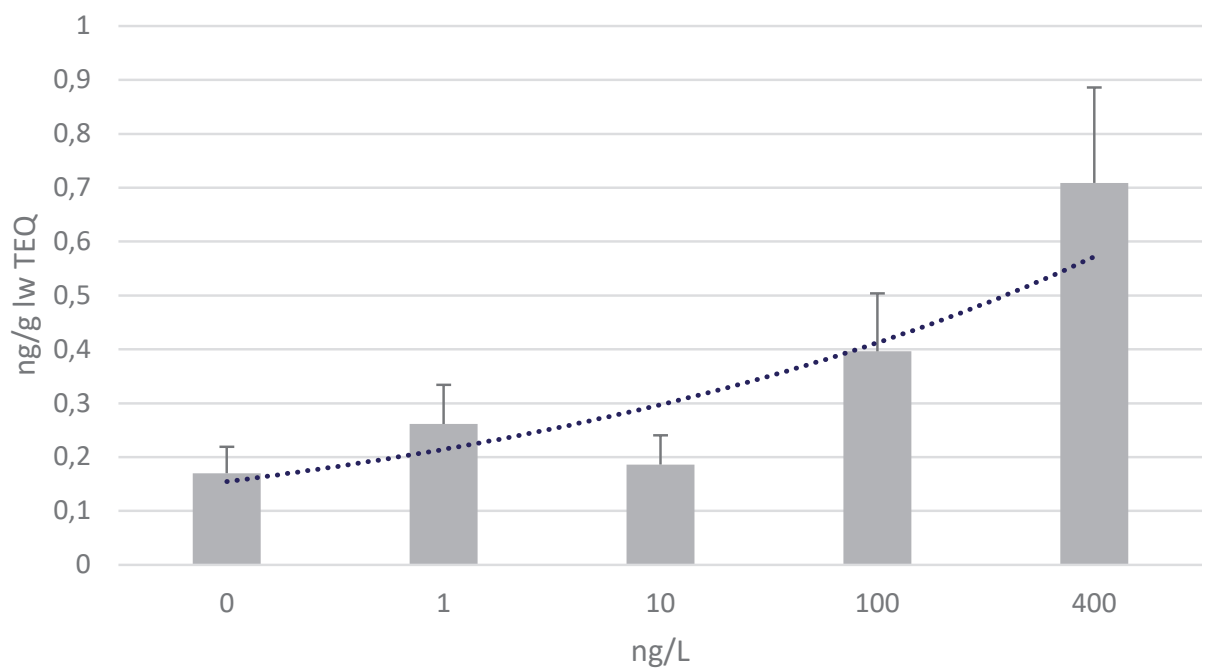

Figure 1. TEQs in limpets on $\mathrm{ng} / \mathrm{g}$ lipid weight basis at different nominal water concentrations $(\mathrm{ng} / \mathrm{L})$. The error bars represent the total standard deviations.

The detection of TEQs in the control group (Fig. 2) indicates that the limpets were likely exposed to PCBs before the actual start of the experiment, which might have happened during transport of the limpets across the Atlantic Ocean. Although concentrations of PCBs in the open Atlantic water are comparable to the ones found in Antartica ${ }^{35}$, the median concentrations in the experimental controls (0.17 TEQ ng/g lw) were 1000 times higher than previously found in the same species of Antarctic limpets from Ryder Bay in 2017 (0.0002 TEQ ng/g lw) ${ }^{26}$.

When compared to the previous studies from other parts of Antarctica, the TEQs obtained from the non-exposed animals in the current experiment were 30 times higher than found in N. concinna of the Princess Elizabeth Land in $2018^{36}$. However, they were similar to the ones in various bivalves found at the relatively non-contaminated sites near the European ${ }^{37}$ and $A \operatorname{sian}^{38}$ coasts in 2019. The TEQ concentrations did not seem to increase in the animals exposed up to $10 \mathrm{ng} / \mathrm{L}$. The concentrations showed an exposure dependent increase from $100 \mathrm{ng} / \mathrm{L}$ onwards reaching highest concentrations at $400 \mathrm{ng} / \mathrm{L}$.

\section{CYP enzyme activity}

The results of the EROD assay in connection to the tissue concentrations of PCBs in limpets are presented in figure 2, while the results of MROD, PROD and BROD shown in the Appendix. PROD and BROD had lower average $\mathrm{R} 2$ values ( 0.45 and 0.07 respectively) than EROD (0.90) and MROD (0.93), while MROD showed much more variance than EROD (Appendix). Results show relatively low induction of EROD and other CYP enzymes when compared to other studies on PCBs exposure in benthic invertebrates ${ }^{39,40}$. 


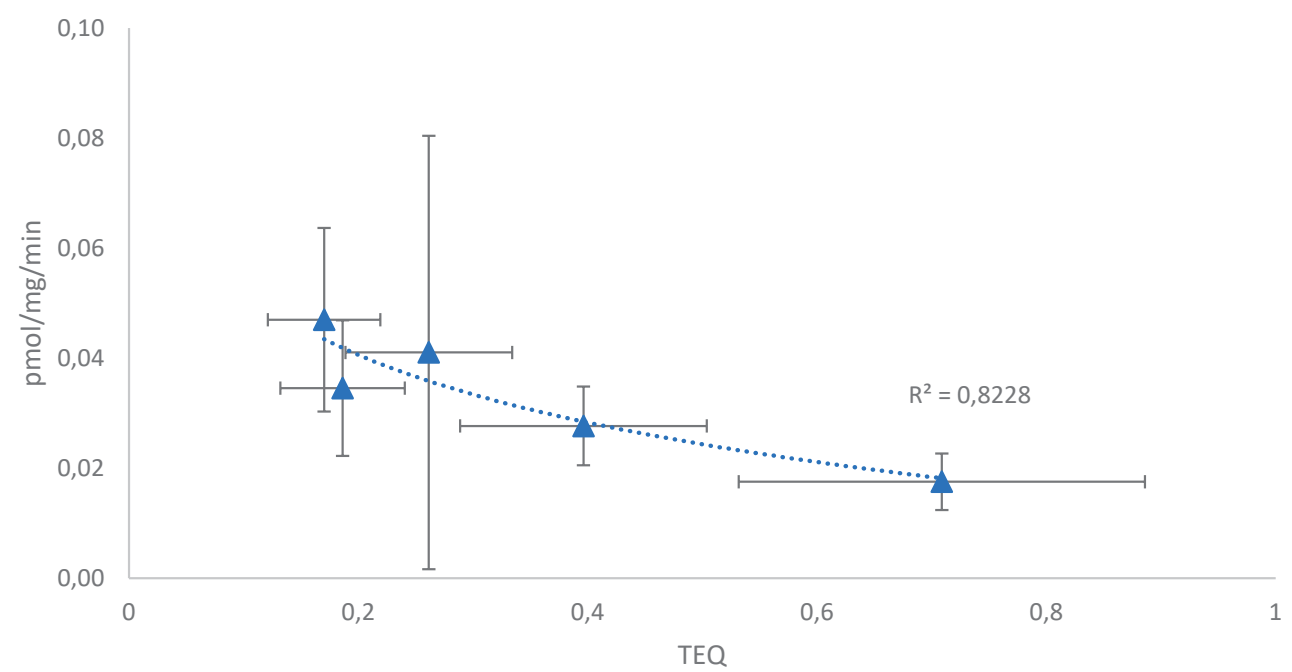

Figure 2. Measured EROD activity in $\mathrm{pmol} / \mathrm{mg} / \mathrm{min}$ with increasing internal PCB concentrations expressed in TEQs (calculated on $\mathrm{ng} / \mathrm{g}$ lw basis) corresponding to different exposure levels in the limpets.

Furthermore, EROD activities decrease with increasing TEQ concentrations. This indicates inhibition of enzyme activity with increased PCBs exposure and increased PCBs tissue concentrations. The EROD activity of the controls was 2 times higher than the one of the $100 \mathrm{ng} / \mathrm{L}$ treatment $(\mathrm{p}=0.078)$ and significantly higher than the one of $400 \mathrm{ng} / \mathrm{L}$ treatment $(\mathrm{p}=0.049)$ (fig. 2).

It is difficult to make a direct comparison between the current study and existing studies on similar temperate species due to a large number of experimental variables (e.g. duration or PCB exposure mix) involved. The 4 weeks duration of the current experiment made it possible to account for a possible delayed toxicological response in $N$. concinna, as observed for DDE in krill larvae ${ }^{11}$. A study, in which the experiment was performed under conditions most related to the current ones, was conducted on the Zebra mussel Dreissena polymorpha with an exposure to a similar mix of $\mathrm{PCBs}^{39}$. The maximum EROD activity of $3.5 \mathrm{pmol} /$ $\mathrm{mg} / \mathrm{min}$ was reached there at the tissue concentrations of $45 \mathrm{ng} / \mathrm{g}$ lw TEQ after 3 days of exposure to $100 \mathrm{ng} / \mathrm{L}$ PCBs. Exposure to PCB126 in that study induced EROD after 48 hours of exposure, after which the activity returned to the same levels as the controls. Another study ${ }^{40}$ measured EROD activity of $0.6 \mathrm{pmol} / \mathrm{mg} / \mathrm{min}$ in $D$. polymorpha with tissue concentration of approximately $1.2 \mathrm{ng} / \mathrm{g}$ lw TEQ after 5 days of exposure. Decreases in in EROD induction after exposure to PCBs have also been reported in fish species ${ }^{41,42}$, presumably due to competitive binding of PCBs to the receptor ${ }^{42}$, without inducing the enzyme activity. The mixture used in this experiment was optimized to resemble the mixture found on the Antarctic marine ecosystem, but contained very low concentrations of non-ortho or mono-ortho PCB with relatively high TEF-values. In this view, the exposure 
during transport from Antarctica to the UK may have resulted in a (low) induction of CYP enzymes, which is inhibited to a certain extent by the competitive binding of PCB congeners to the receptor ${ }^{42}$.

\section{Lipid profile}

While there was no difference in total lipid content of the hepatopancreas across different exposure levels (Appendix), NMR measurements demonstrated a correlation between TEQ-based tissue concentrations of PCBs and changes in the corresponding lipid profiles, which are shown on the figure 3 .

An increase of tissue concentrations of PCBs was associated with a decrease in occurrence of total cholesterol, polyunsaturated fatty acid (PUFA), and triglycerides and phosphatidylcholine. Previous comprehensive studies on responses of lipids in vertebrates ${ }^{43-45}$ and invertebrates ${ }^{21,22}$ to PCB exposure demonstrated complex non-linear relations between them. generally, at the beginning of an exposure, concentrations of specific lipids fractions (triglycerides, cholesterol and phospholipids) increase with the increasing PCB input ${ }^{45}$. Studies on rats ${ }^{45}$ and oysters Crassostrea virginica ${ }^{21}$ show that after some time of exposure the lipid fractions did not vary over time, which was then superseded by declines of these lipid fractions with longer PCB exposures ${ }^{22,45}$. This last part of the trend may have been particularly captured in the current study.

Generally, animals may respond to PCB exposure via induction of hepatic enzymes of lipogenesis ${ }^{46,47}$. This was shown in oysters (Crassostrea virginica), for which PCBs were theorized to inhibit production of phospholipids (e.g. phosphoglycerdes or phosphatidylcholine $)^{22}$, possibly due to interactions with their precursors - octa-and hexa-decanoic acids as shown for Whiteleg shrimp (Litopenaeus vannamei) ${ }^{48}$. Decreased phospholipids in their turn may lead to less production of cholesterol ${ }^{48-50}$, which may explain the decrease in total cholesterol at higher PCB exposure in the current study. Another mechanism was potentially responsible for the observed decline in PUFA with increasing concentrations of PCBs. Increase in concentrations of some PCBs may lead to a competition with other endogenous AhR-pathway activation ligands, such as 12-HETE. 12-KETE is a conversion component of 12-HETE and a by-product of PUFA metabolism, and thus may be a link between concentrations of PCBs and PUFA ${ }^{51}$.

All mentioned lipids play an important role in the life cycle of invertebrates: cholesterol - in molting cycle, larval development and oocyte formation ${ }^{48,50}$; PUFA - in hormone synthesis, immune function ${ }^{52-54}$ and (exceptionally important for $N$. concinna as an Antarctic species) being a source of energy during long starvation periods $s^{55}$; triglycerides - in energy control, also during starvation periods ${ }^{56}$. Previously, levels of lipids (e.g. triglycerides) were proposed as an indicator of an overall health of an ecosystem, because they represent long-term 


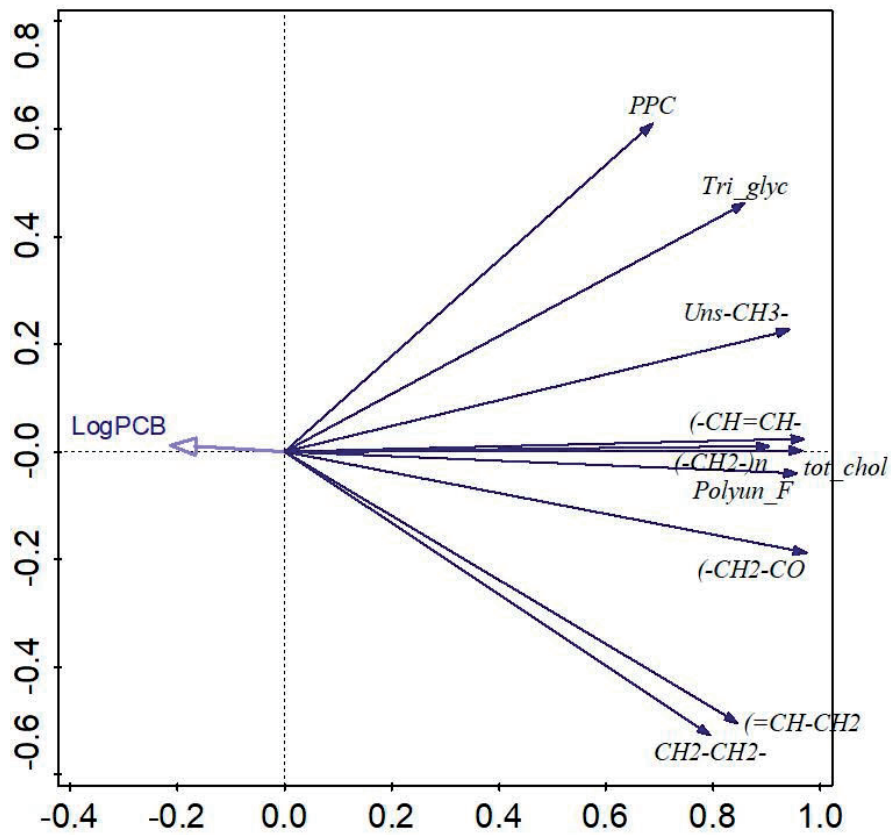

Figure 3. PCA graph showing the relationships between tissue concentrations of PCBs and various lipids, where PPC stand for phosphatidylcholine, Tri-glyc - for triglycerides, tot_chol - for total cholesterol and Polyun_F - for polyunsaturated fatty acid. Only the most relevant lipids are selected. A PCA graph with all analysed lipids can found in the appendix.

information about the fitness of the species ${ }^{57}$. It may be suggested that they would be of even bigger importance for Antarctic ecosystems due to seasonally very dynamic metabolism of the local species ${ }^{5,23,58}$ and potential disruption of their physiology by the climate change ${ }^{16,59}$.

\section{CONCLUSION}

The current data showed an ability of PCBs to accumulate in tissues of Antarctic limpets $N$. concinna. While it was not possible to establish a comprehensive relationship between EROD activation and levels of exposure to the PCB congeners used in the current study, EROD may still have a potential for usage as a biomarker of exposure in Antarctic bivalve in case of chemicals with higher induction potential. At the same time, increases in the tissue concentrations of PCBs led to changes in lipid profiles indicated by decreases of concentrations of specific lipids. However, considering the concentrations detected in environmentally exposed limpets ${ }^{26}$, it is not to be expected that current PCB levels in the benthic Antarctic marine system pose risks to this species, which is similar to DDE in krill $^{11,12}$ 


\section{REFERENCES}

1. Jones KC, de Voogt P. Persistent organic pollutants (POPs): state of the science. Environ Pollut. 1999;100(1-3):209-221. doi:10.1016/S0269-7491(99)00098-6

2. Bargagli R. Environmental contamination in Antarctic ecosystems. Sci Total Environ. 2008;400(13):212-226. doi:10.1016/j.scitotenv.2008.06.062

3. Bengtson Nash S. Persistent organic pollutants in Antarctica: current and future research priorities. J Environ Monit. 2011;13(3):497. doi:10.1039/c0em00230e

4. Peck L. Antarctic marine biodiversity: adaptations, environments and responses to change. Oceanogr Mar Biol An Annu Rev. 2018;56. http://nora.nerc.ac.uk/id/eprint/519934/. Accessed June 18, 2019.

5. Peck LS, Clark MS, Dunn NI. Morphological variation in taxonomic characters of the Antarctic starfish Odontaster validus. Polar Biol. 2018;41(10):2159-2165. doi:10.1007/s00300-018-2344-z

6. Schweitzer LE, Hose JE, Suffet IH, Bay SM. Differential toxicity of three polychlorinated biphenyl congeners in developing sea urchin embryos. Environ Toxicol Chem. 1997;16(7):1510-1514. doi:10.1002/etc.5620160726

7. Horne MT, Finley NJ, Sprenger MD. Polychlorinated biphenyl- and mercury-associated alterations on benthic invertebrate community structure in a contaminated salt marsh in southeast Georgia. Arch Environ Contam Toxicol. 1999;37(3):317-325. doi:10.1007/s002449900520

8. van Wezel AP, Traas TP, van der Weiden MEJ, Crommentuijn TH, Sijm DTHM. ENVIRONMENTAL RISK LIMITS FOR POLYCHLORINATED BIPHENYLS IN THE NETHERLANDS: DERIVATION WITH PROBABILISTIC FOOD CHAIN MODELING. Environ Toxicol Chem. 2000;19(8):2140. doi:10.1897/1551-5028(2000)019<2140:ERLFPB>2.3. $\mathrm{CO} ; 2$

9. Szczybelski AS, van den Heuvel-Greve MJ, Kampen T, Wang C, van den Brink NW, Koelmans AA. Bioaccumulation of polycyclic aromatic hydrocarbons, polychlorinated biphenyls and hexachlorobenzene by three Arctic benthic species from Kongsfjorden (Svalbard, Norway). Mar Pollut Bull. 2016;112(1-2):65-74. doi:10.1016/J.MARPOLBUL.2016.08.041

10. Renaud PE, Tessmann M, Evenset A, Christensen GN. Benthic food-web structure of an Arctic fjord (Kongsfjorden, Svalbard). Mar Biol Res. 2011;7(1):13-26. doi:10.1080/17451001003671597

11. Poulsen AH, Kawaguchi S, Kukkonen JVK, Leppänen MT, Bengtson Nash SM. Aqueous uptake

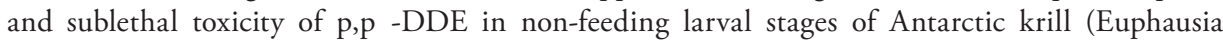
superba). Environ Pollut. 2012;160:185-191. doi:10.1016/J.ENVPOL.2011.09.022

12. Poulsen AH, Landrum PF, Kawaguchi S, Bengtson Nash SM. Dietary exposure of Antarctic krill to p,p $\bigotimes$-DDE: Uptake kinetics and toxicological sensitivity in a key polar species. Environ Pollut. 2013;175:92-99. doi:10.1016/J.ENVPOL.2012.12.026

13. Poulsen AH, Kawaguchi S, King CK, King RA, Bengtson Nash SM. Behavioural sensitivity of a key Southern Ocean species (Antarctic krill, Euphausia superba) to p,p'-DDE exposure. Ecotoxicol Environ Saf. 2012;75:163-170. doi:10.1016/J.ECOENV.2011.09.005

14. Poulsen AH, Kawaguchi S, Leppänen MT, Kukkonen JVK, Bengtson Nash SM. Altered developmental timing in early life stages of Antarctic krill (Euphausia superba) exposed to p,p'DDE. Sci Total Environ. 2011;409(24):5268-5276. doi:10.1016/J.SCITOTENV.2011.08.056

15. Clark MS, Sommer U, Sihra JK, et al. Biodiversity in marine invertebrate responses to acute warming revealed by a comparative multi-omics approach. Glob Chang Biol. 2017;23(1):318-330. doi:10.1111/gcb.13357

16. Ashton G V., Morley SA, Barnes DKA, Clark MS, Peck LS. Warming by $1^{\circ} \mathrm{C}$ Drives Species and Assemblage Level Responses in Antarctica's Marine Shallows. Curr Biol. 2017;27(17):2698-2705.e3. doi:10.1016/J.CUB.2017.07.048

17. Noyes PD, McElwee MK, Miller HD, et al. The toxicology of climate change: Environmental contaminants in a warming world. Environ Int. 2009;35(6):971-986. doi:10.1016/j.envint. 2009.02.006 
18. Bates ML, Bengtson Nash SM, Hawker DW, Shaw EC, Cropp RA. The distribution of persistent organic pollutants in a trophically complex Antarctic ecosystem model. J Mar Syst. 2017;170:103114. doi:10.1016/J.JMARSYS.2017.02.005

19. Ellis DS, Cipro CVZ, Ogletree CA, Smith KE, Aronson RB. A 50-year retrospective of persistent organic pollutants in the fat and eggs of penguins of the Southern Ocean. Environ Pollut. 2018;241:155-163. doi:10.1016/J.ENVPOL.2018.05.003

20. Enzenbacher DJ. Antarctic Tourism and Environmental Concerns. Vol 25.; 1992. https://ac.els-cdn. com/0025326X92906805/1-s2.0-0025326X92906805-main.pdf?_tid=00da902d-4706-4e1784fc-72341ca07503\&acdnat=1536584110_035ab93bf3a0003dafb2d22be0b83a7f. Accessed September 10, 2018.

21. Chu F-L., Soudant P, Cruz-Rodriguez L., Hale R. PCB uptake and accumulation by oysters (Crassostrea virginica) exposed via a contaminated algal diet. Mar Environ Res. 2000;50(1-5):217221. doi:10.1016/S0141-1136(00)00070-2

22. Chu FLE, Soudant P, Hale RC. Relationship between PCB accumulation and reproductive output in conditioned oysters Crassostrea virginica fed a contaminated algal diet. Aquat Toxicol. 2003;65(3):293-307. doi:10.1016/s0166-445x(03)00152-8

23. Fraser K, Clarke A, Peck L. Feast and famine in Antarctica: seasonal physiology in the limpet Nacella concinna. Mar Ecol Prog Ser. 2002;242:169-177. doi:10.3354/meps242169

24. Suda CNK, Vani GS, de Oliveira MF, Rodrigues E, Rodrigues E, Lavrado HP. The biology and ecology of the Antarctic limpet Nacella concinna. Polar Biol. 2015;38(12):1949-1969. doi:10.1007/ s00300-015-1789-6

25. Brêthes J-C, Ferreyra G, de la Vega S. Distribution, growth and reproduction of the limpet Nacella (Patinigera) concinna (Strebel 1908) in relation to potential food availability, in Esperanza Bay (Antarctic Peninsula). Polar Biol. 1994;14(3):161-170. doi:10.1007/BF00240521

26. Krasnobaev A, ten Dam G, Boerrigter-Eenling R, et al. Legacy and Emerging Persistent Organic Pollutants in Antarctic Benthic Invertebrates near Rothera Point, Western Antarctic Peninsula.

Environ Sci Technol. February 2020:acs.est.9b06622. doi:10.1021/acs.est.9b06622

27. Gioia R, Lohmann R, Dachs J, et al. Polychlorinated biphenyls in air and water of the North Atlantic and Arctic Ocean. J Geophys Res. 2008;113(D19):D19302. doi:10.1029/2007JD009750

28. Axelman J, Broman D, Näf C. Vertical Flux and Particulate/Water Dynamics of Polychlorinated Biphenyls (PCBs) in the Open Baltic Sea. AMBIO A J Hum Environ. 2000;29(4):210-216. doi:10.1579/0044-7447-29.4.210

29. Larsson P, Andersson A, Broman D, Nordbäck J, Lundberg E. Persistent Organic Pollutants (POPs) in Pelagic Systems. AMBIO A J Hum Environ. 2000;29(4):202-209. doi:10.1579/0044-744729.4.202

30. Sobek A, McLachlan MS, Borgå K, et al. A comparison of PCB bioaccumulation factors between an arctic and a temperate marine food web. Sci Total Environ. 2010;408(13):2753-2760. doi:10.1016/j. scitotenv.2010.03.013

31. Joiris CR, Overloop W. PCBs and organochlorine pesticides in phytoplankton and zooplankton in the Indian sector of the Southern Ocean. Antarct Sci. 1991;3(4):371-377. doi:10.1017/ S0954102091000470

32. Van den Berg M, Birnbaum LS, Denison M, et al. The 2005 World Health Organization reevaluation of human and Mammalian toxic equivalency factors for dioxins and dioxin-like compounds. Toxicol Sci. 2006;93(2):223-241. doi:10.1093/toxsci/kfl055

33. Lee PN, Lovell D. Statistics for Toxicology. In: General and Applied Toxicology. Chichester, UK: John Wiley \& Sons, Ltd; 2009. doi:10.1002/9780470744307.gat037

34. Petr Smilauer. Canoco5. 2019. http://www.canoco5.com/. Accessed February 24, 2020. 
35. Gioia R, Nizzetto L, Lohmann R, Dachs J, Temme C, Jones KC. Polychlorinated Biphenyls (PCBs) in Air and Seawater of the Atlantic Ocean: Sources, Trends and Processes. Environ Sci Technol. 2008;42(5):1416-1422. doi:10.1021/es071432d

36. Ko F-C, Pan W-L, Cheng J-O, et al. Persistent organic pollutants in Antarctic notothenioid fish and invertebrates associated with trophic levels. Hwang J-S, ed. PLoS One. 2018;13(4):e0194147. doi:10.1371/journal.pone.0194147

37. Rodil R, Villaverde-de-Sáa E, Cobas J, Quintana JB, Cela R, Carro N. Legacy and emerging pollutants in marine bivalves from the Galician coast (NW Spain). Environ Int. 2019;129:364-375. doi:10.1016/J.ENVINT.2019.05.018

38. Moon H, Kim D-H, Oh J-E. Dietary exposure to PCBs by seafood cooking method: A Korean study. Chemosphere. 2019;215:775-782. doi:10.1016/J.CHEMOSPHERE.2018.10.044

39. Binelli A, Ricciardi F, Riva C, Provini A. New evidences for old biomarkers: Effects of several xenobiotics on EROD and AChE activities in Zebra mussel (Dreissena polymorpha). Chemosphere. 2006;62(4):510-519. doi:10.1016/j.chemosphere.2005.06.033

40. Faria M, Carrasco L, Diez S, Riva MC, Bayona JM, Barata C. Multi-biomarker responses in the freshwater mussel Dreissena polymorpha exposed to polychlorobiphenyls and metals. Comp Biochem Physiol Part C Toxicol Pharmacol. 2009;149(3):281-288. doi:10.1016/J.CBPC.2008.07.012

41. Vodicnik MJ, Elcombe CR, Lech JJ. The effect of various types of inducing agents on hepatic microsomal monooxygenase activity in rainbow trout. Toxicol Appl Pharmacol. 1981;59(2):364-374. doi:10.1016/0041-008x(81)90208-8

42. Besselink HT, Denison MS, Hahn ME, et al. Low Inducibility of CYP1A Activity by Polychlorinated Biphenyls (PCBs) in Flounder (Platichthys flesus): Characterization of the Ah Receptor and the Role of CYP1A Inhibition. Toxicol Sci. 1998;43(2):161-171. doi:10.1006/TOXS.1998.2455

43. Nagaoka S, Miyazaki H, Aoyama Y, Yoshida A. Effects of dietary polychlorinated biphenyls on cholesterol catabolism in rats. Br J Nutr. 1990;64(1):161-169. doi:10.1079/bjn19900018

44. Kamal-Eldin A, Frank J, Razdan A, Tengblad S, Basu S, Vessby B. Effects of dietary phenolic compounds on tocopherol, cholesterol, and fatty acids in rats. Lipids. 2000;35(4):427-435. doi:10.1007/s11745-000-541-y

45. Boll M, Weber LWD, Stampfl A. The Response of Rat Serum Lipids to Diets of Varying Composition or Contaminated with Organochlorine Pesticides. Zeitschrift für Naturforsch C. 1996;51(1-2):91100. doi:10.1515/znc-1996-1-216

46. Mesnage R, Biserni M, Balu S, et al. Integrated transcriptomics and metabolomics reveal signatures of lipid metabolism dysregulation in HepaRG liver cells exposed to PCB 126. Arch Toxicol. 2018;92(8):2533-2547. doi:10.1007/s00204-018-2235-7

47. Deng P, Barney J, Petriello MC, Morris AJ, Wahlang B, Hennig B. Hepatic metabolomics reveals that liver injury increases PCB 126-induced oxidative stress and metabolic dysfunction. Chemosphere. 2019;217:140-149. doi:10.1016/j.chemosphere.2018.10.196

48. González-Félix ML, Lawrence AL, Gatlin DM, Perez-Velazquez M. Growth, survival and fatty acid composition of juvenile Litopenaeus vannamei fed different oils in the presence and absence of phospholipids. Aquaculture. 2002;205(3-4):325-343. doi:10.1016/S0044-8486(01)00684-6

49. Maity S, Jannasch A, Adamec J, et al. Elucidating Causes of Diporeia Decline in the Great Lakes via Metabolomics: Physiological Responses after Exposure to Different Stressors. Physiol Biochem Zool. 2013;86(2):213-223. doi:10.1086/669132

50. SANCHEZPAZ A, GARCIACARRENO F, MUHLIAALMAZAN A, PEREGRINOURIARTE A, HERNANDEZLOPEZ J, YEPIZPLASCENCIA G. Usage of energy reserves in crustaceans during starvation: Status and future directions. Insect Biochem Mol Biol. 2006;36(4):241-249. doi:10.1016/j.ibmb.2006.01.002

51. Spokas EG, Rokach J, Wong PY-K. Leukotrienes, Lipoxins, and Hydroxyeicosatetraenoic Acids. In: Eicosanoid Protocols. Vol 120. New Jersey: Humana Press; 1999:213-247. doi:10.1385/1-59259-263$5: 213$ 
52. Rees JF, Curé K, Piyatiratitivorakul S, Sorgeloos P, Menasveta P. Highly unsaturated fatty acid requirements of Penaeus monodon postlarvae: an experimental approach based on Artemia enrichment. Aquaculture. 1994;122(2-3):193-207. doi:10.1016/0044-8486(94)90510-X

53. D'Abramo LR, Sheen S-S. Polyunsaturated fatty acid nutrition in juvenile freshwater prawn Macrobrachium rosenbergii. Aquaculture. 1993;115(1-2):63-86. doi:10.1016/0044-8486(93)903597

54. KANAZAWA A, TESHIMA S, TOKIWA S. Nutritional requirements of prawn. VII. Effect of dietary lipids on growth. Nippon SUISAN GAKKAISHI. 1977;43(7):849-856. doi:10.2331/ suisan.43.849

55. Bychek EA, Dobson GA, Harwood JL, Guschina IA. Daphnia magna can tolerate short-term starvation without major changes in lipid metabolism. Lipids. 2005;40(6):599-608. doi:10.1007/ s11745-005-1421-1

56. Azeez OI, Meintjes R, Chamunorwa JP. Fat body, fat pad and adipose tissues in invertebrates and vertebrates: the nexus. Lipids Health Dis. 2014;13:71. doi:10.1186/1476-511X-13-71

57. Koop JHE, Winkelmann C, Becker J, Hellmann C, Ortmann C. Physiological indicators of fitness in benthic invertebrates: a useful measure for ecological health assessment and experimental ecology. Aquat Ecol. 2011;45(4):547-559. doi:10.1007/s10452-011-9375-7

58. Bowgen AD, Fraser KPP, Peck LS, Clarke A. Energetic cost of synthesizing proteins in Antarctic limpet, Nacella concinna (Strebel, 1908), is not temperature dependent. Am J Physiol Integr Comp Physiol. 2007;292(6):R2266-R2274. doi:10.1152/ajpregu.00350.2006

59. Clarke A, Murphy EJ, Meredith MP, et al. Climate change and the marine ecosystem of the western Antarctic Peninsula. Philos Trans R Soc Lond B Biol Sci. 2007;362(1477):149-166. doi:10.1098/ RSTB.2006.1958 


\section{SUPPLEMENTARY MATERIAL}

\section{Table of contents}

Appendix 1. Chemical analysis

Appendix 2. PCB concentrations in individual samples

Appendix 3. Results of Bioassays

Appendix 4. PCA of all analysed lipids against log concentrations of PCBs

Appendix 5. Lipid concentrations in the samples. 


\section{APPENDIX 1. CHEMICAL ANALYSIS}

\section{Appendix 1A. Complete extraction and clean-up procedure.}

1. Weigh 3 gram $\pm 1 \mathrm{mg}$ of sample in a $60 \mathrm{ml}$ glass tube.

2. Add internal standards.

3. Add as much NanoQ water as needed to reach the total volume of $13 \mathrm{ml}$ (= $13-0.8^{*}$ weight of the sample).

4. Vortex or shake vigorously to mix the water and the sample.

5. Add $10 \mathrm{ml}$ Ethyl Acetate, vortex and mix head-over-head for 10 minutes.

6. Add a homogenised mixture of 2 gram Sodium chloride and 4 gram Magnesium sulphate, and shake vigorously for at least 2 minutes. If no liquid phase is visible, add $1 \mathrm{ml}$ of methanol.

7. Centrifuge for 10 minutes at $1500 \mathrm{rpm}$.

8. Repeat steps 5-7 two times.

9. Transfer the Ethyl Acetate phase to a pre-cleaned Turbovap glass tube, evaporate in a Turbovap Evaporator at $40^{\circ} \mathrm{C}$ and $0.8 \mathrm{Bar}$ to the volume of $1 \mathrm{ml}$.

10. Take a fraction of the sample $(0.1 \mathrm{or} 0.2 \mathrm{ml})$ for lipid analysis.

11. Add $3 \mathrm{ml}$ of hexane.

12. Transfer the Hexane/Ethyl Acetate mixture to a pre-rinsed $60 \mathrm{ml}$ brown glass tube.

13. Rinse the Turbovap ${ }^{\circ}$ glass tube three more times with $9 \mathrm{ml}$ of Hexane and transfer the solvent to the $60 \mathrm{ml}$ brown glass tube.

14. Mix in a pre-rinsed Erlenmeyer flask 60 gram activated silica with 40 gram of concentrated Sulphuric acid (i.e. to get $40 \% \mathrm{H}_{2} \mathrm{SO}_{4}$ ).

15. Add 10 gram of the $40 \%$ acid silica to the $60 \mathrm{ml}$ tube and mix, repeat mixing 3 times with intervals of 10 minutes.

16. Leave the samples stand overnight.

17. Centrifuge for 10 minutes at $1500 \mathrm{rpm}$.

18. Transfer the Hexane into a pre-cleaned Turbovap tube.

19. Add $10 \mathrm{ml}$ of Hexane to the $60 \mathrm{ml}$ tube (with the solid phase of the sample in it) and mix.

20. Repeat steps $17-19$ two times.

21. Evaporate Hexane phase of the sample in the Turbovap at $40^{\circ} \mathrm{C}$ and 0.8 Bar to the volume of $1 \mathrm{ml}$.

22. Prepare a clean-up column by filling a glass column with glass wool stopper, 1 gram conditioned silica and 8 grams of $40 \%$ acid silica (prepared in the step 14).

23. Elute the column firstly with $10 \mathrm{ml}$ of Hexane, wait 5 minutes, and add another 15 $\mathrm{ml}$ of Hexane.

24. Discard these Hexane fractions. 
25. Place a clean Turbovap tube under the column and add the $1 \mathrm{ml}$ extract of the sample onto the column.

26. Rinse the initial Turbovap tube two times with $1 \mathrm{ml}$ of Hexane and add these fractions onto the column.

27. Leave the column for 15 minutes.

28. Eluate first with $18 \mathrm{ml}$ of Hexane and then with $12 \mathrm{ml}$ Dichloromethane.

29. Evaporate Hexane/Dichloromethane mix in Turbovap at $40^{\circ} \mathrm{C}$ and $0.8 \mathrm{Bar}$ to the volume of $1 \mathrm{ml}$.

30. Rinse the walls of the Turbovap tube twice carefully with $0.5 \mathrm{ml}$ of lso-Octane and thoroughly mix.

31. Evaporate again in the Turbovap at $40^{\circ} \mathrm{C}$ and $0.8 \mathrm{Bar}$ to a volume of $1 \mathrm{ml}$.

32. Store the sample in an amber glass vial at $-20^{\circ} \mathrm{C}$. 


\section{Appendix 1B. Instrumental settings for analysis of PCBs.}

The GC method for PCB analysis was adapted without changes from:

Guillaume ten Dam, Pussente I.C., Scholl G., Eppe G., Schaechtele A., van Leeuwen S. The performance of atmospheric pressure gas chromatography-tandem mass spectrometry compared to gas chromatography-high resolution mass spectrometry for the analysis of polychlorinated dioxins and polychlorinated biphenyls in food and feed samples. Journal of Chromatography A. Volume 1477, Pages 76-90. 


\section{APPENDIX 2. PCB CONCENTRATIONS IN INDIVIDUAL SAMPLES}

All tissue concentration values are given in TEF calculated on ng/g lipid weight basis.

\begin{tabular}{|l|c|c|c|c|c|c|c|c|}
\hline exposure & \multicolumn{3}{|c|}{$0 \mathrm{ng} / \mathrm{L}$} & \multicolumn{3}{c|}{$1 \mathrm{ng} / \mathrm{L}$} & \multicolumn{2}{c|}{$10 \mathrm{ng} / \mathrm{L}$} \\
\hline repetition & 1 & 2 & 3 & 1 & 2 & 3 & 1 & 2 \\
\hline PCB 123 & 0.0050 & 0.0032 & 0.0034 & 0.0037 & 0.0088 & 0.0058 & 0.0044 & 0.0031 \\
\hline PCB 118 & 0.2156 & 0.1483 & 0.1489 & 0.1793 & 0.3841 & 0.2212 & 0.1999 & 0.1296 \\
\hline PCB 114 & 0.0000 & 0.0000 & 0.0002 & 0.0002 & 0.0001 & 0.0001 & 0.0001 & 0.0000 \\
\hline PCB 105 & 0.0001 & 0.0001 & 0.0000 & 0.0002 & 0.0001 & 0.0002 & 0.0000 & 0.0001 \\
PCB 167 & 0.0006 & 0.0006 & 0.0006 & 0.0011 & 0.0016 & 0.0017 & 0.0009 & 0.0005 \\
\hline PCB 156 & 0.0001 & 0.0000 & 0.0000 & 0.0003 & 0.0000 & 0.0018 & 0.0003 & 0.0001 \\
PCB 157 & 0.0002 & 0.0002 & 0.0002 & 0.0005 & 0.0007 & 0.0005 & 0.0003 & 0.0002 \\
PCB 189 & 0.0003 & 0.0003 & 0.0003 & 0.0010 & 0.0015 & 0.0016 & 0.0008 & 0.0006 \\
PCB 28 & 0.0197 & 0.0082 & 0.0166 & 0.0133 & 0.0301 & 0.0521 & 0.0134 & 0.0184 \\
\hline PCB 52 & 0.0000 & 0.0000 & 0.0000 & 0.0000 & 0.0000 & 0.0000 & 0.0000 & 0.0000 \\
\hline PCB 101 & 0.0000 & 0.0000 & 0.0000 & 0.0000 & 0.0000 & 0.0000 & 0.0000 & 0.0000 \\
PCB 153 & 0.0000 & 0.0000 & 0.0000 & 0.0000 & 0.0000 & 0.0000 & 0.0000 & 0.0000 \\
PCB 138 & 0.0000 & 0.0000 & 0.0000 & 0.0000 & 0.0000 & 0.0000 & 0.0000 & 0.0000 \\
\hline PCB 180 & 0.0000 & 0.0000 & 0.0000 & 0.0000 & 0.0000 & 0.0000 & 0.0000 & 0.0000 \\
\hline TEQ & 0.2415 & 0.1609 & 0.1703 & 0.1996 & 0.4270 & 0.2852 & 0.2200 & 0.1525 \\
\hline
\end{tabular}

\begin{tabular}{|l|c|c|c|c|c|c|c|}
\hline exposure & \multicolumn{9}{|c|}{$100 \mathrm{ng} / \mathrm{L}$} & \multicolumn{3}{c|}{$400 \mathrm{ng} / \mathrm{L}$} \\
\hline repetition & 1 & 2 & 3 & 4 & 1 & 2 & 3 \\
\hline PCB 123 & 0.0047 & 0.0044 & 0.0278 & 0.0111 & 0.0137 & 0.0056 & 0.0231 \\
\hline PCB 118 & 0.2016 & 0.1980 & 1.1832 & 0.4516 & 0.5326 & 0.2264 & 1.0368 \\
\hline PCB 114 & 0.0000 & 0.0002 & 0.0000 & 0.0000 & 0.0000 & 0.0000 & 0.0001 \\
\hline PCB 105 & 0.0001 & 0.0001 & 0.0002 & 0.0001 & 0.0002 & 0.0001 & 0.0003 \\
\hline PCB 167 & 0.0012 & 0.0012 & 0.0068 & 0.0019 & 0.0032 & 0.0008 & 0.0055 \\
\hline PCB 156 & 0.0002 & 0.0003 & 0.0002 & 0.0000 & 0.0003 & 0.0000 & 0.0003 \\
\hline PCB 157 & 0.0006 & 0.0005 & 0.0035 & 0.0008 & 0.0017 & 0.0003 & 0.0029 \\
\hline PCB 189 & 0.0017 & 0.0017 & 0.0111 & 0.0023 & 0.0055 & 0.0008 & 0.0088 \\
PCB 28 & 0.0405 & 0.0345 & 0.2607 & 0.0739 & 0.1516 & 0.0270 & 0.2280 \\
\hline PCB 52 & 0.0000 & 0.0000 & 0.0000 & 0.0000 & 0.0000 & 0.0000 & 0.0000 \\
\hline PCB 101 & 0.0000 & 0.0000 & 0.0000 & 0.0000 & 0.0000 & 0.0000 & 0.0000 \\
\hline PCB 153 & 0.0000 & 0.0000 & 0.0000 & 0.0000 & 0.0000 & 0.0000 & 0.0000 \\
\hline PCB 138 & 0.0000 & 0.0000 & 0.0000 & 0.0000 & 0.0000 & 0.0000 & 0.0000 \\
\hline PCB 180 & 0.0000 & 0.0000 & 0.0000 & 0.0000 & 0.0000 & 0.0000 & 0.0000 \\
\hline TEQ & 0.2506 & 0.2408 & 1.4935 & 0.5418 & 0.7088 & 0.2611 & 1.3057 \\
\hline
\end{tabular}




\section{APPENDIX 3. RESULTS OF ASSAYS}

All figures show CYP enzyme activity in $\mathrm{pmol} / \mathrm{mg} / \mathrm{min}$ against corresponding average concentrations in tissues in TEQ calculated on $\mathrm{ng} / \mathrm{g}$ lipid weight basis (corresponding to 0 , 1, 10, 100 and $400 \mathrm{ng} / \mathrm{L}$ exposure respectively).

\section{MROD}

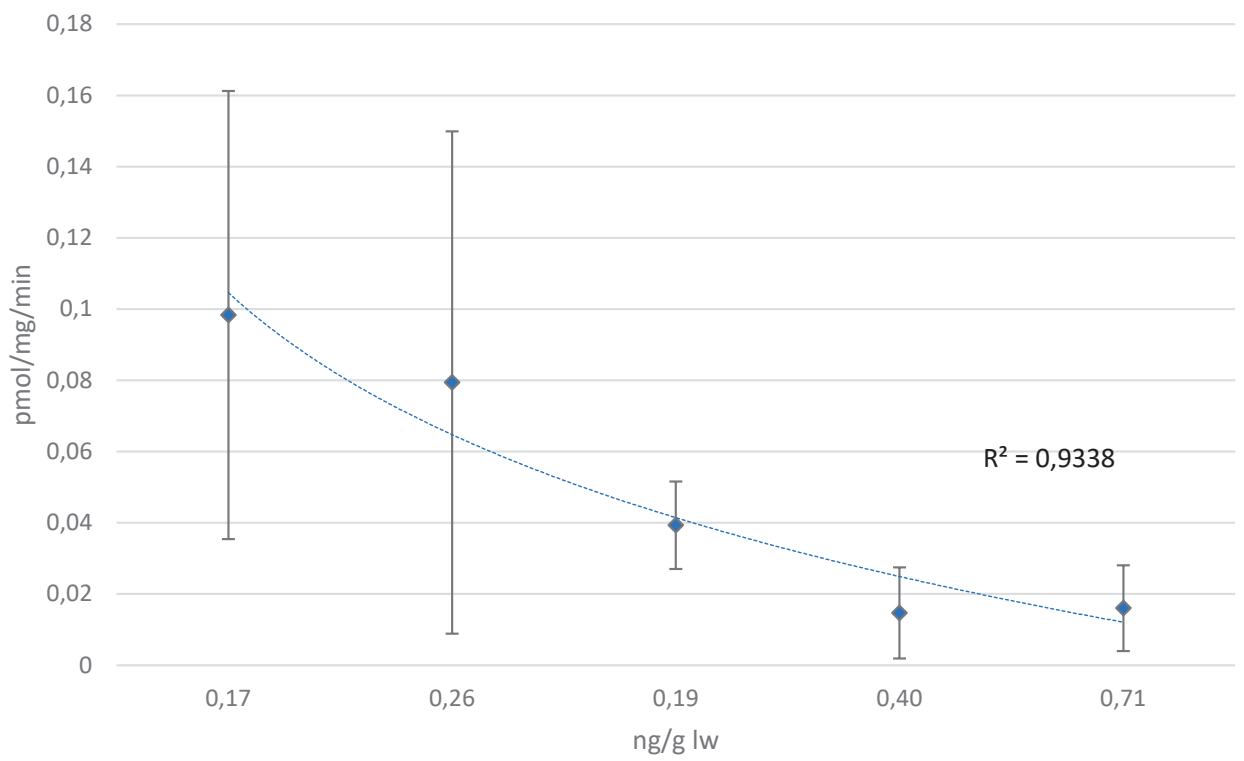

PROD

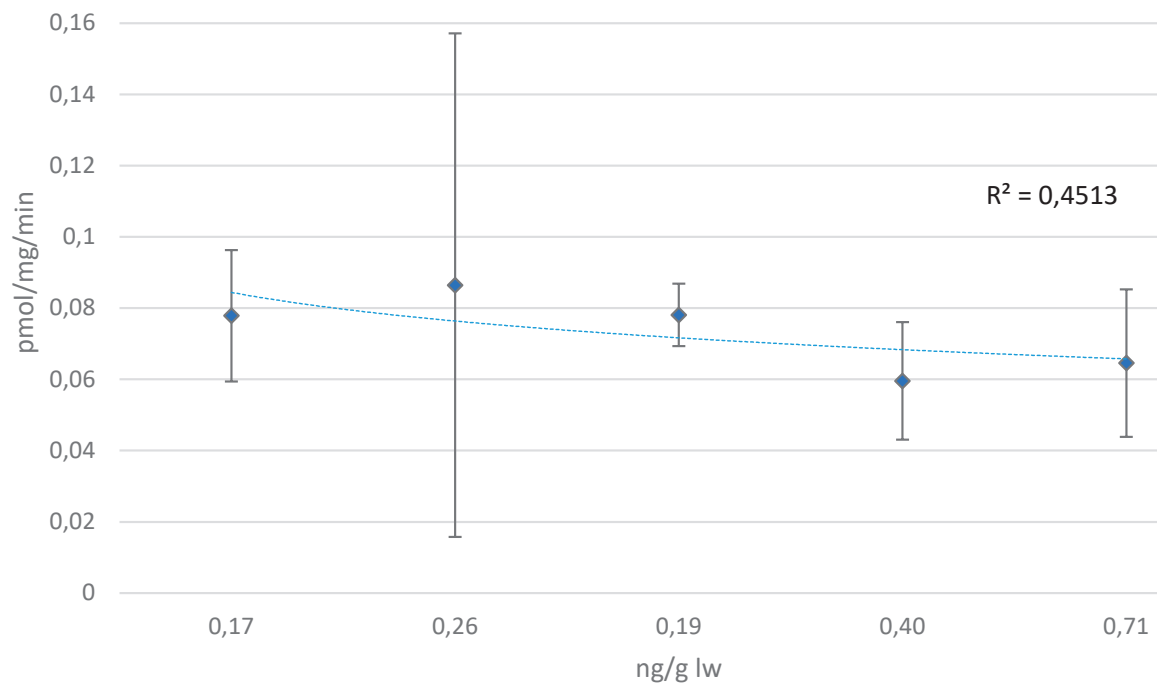




\section{BROD}

0,12

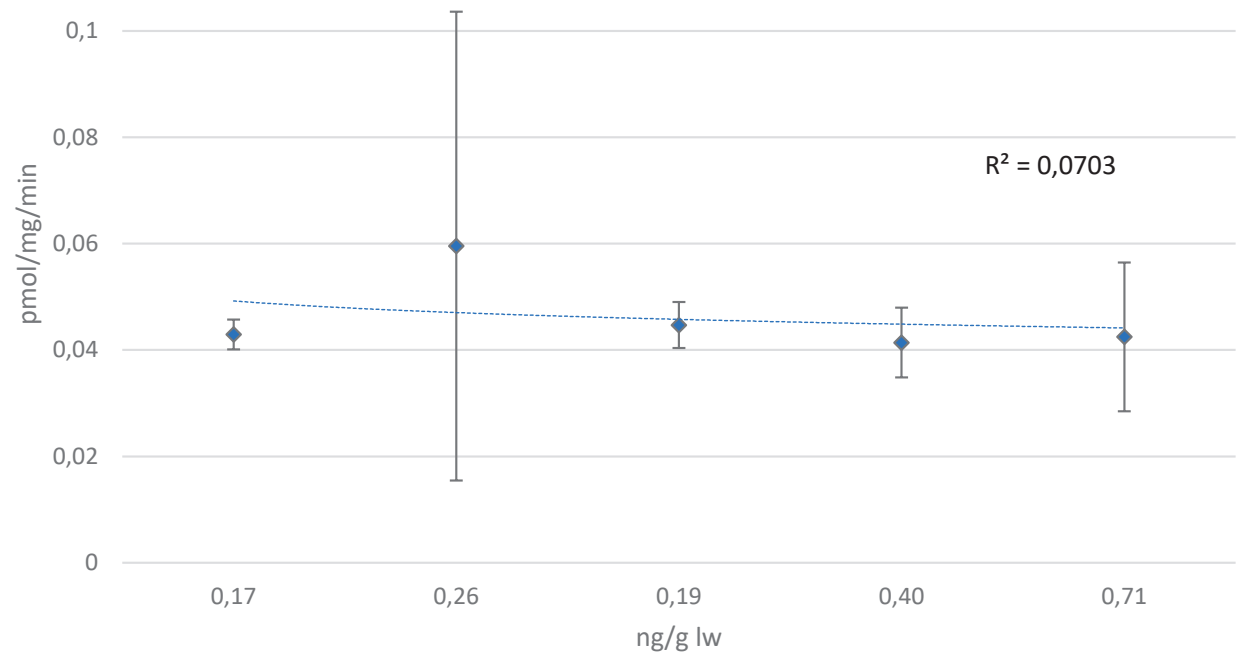




\section{APPENDIX 4. PCA OF ALL ANALYSED LIPIDS AGAINST LOG CONCENTRATIONS OF PCBS}

PCA graph showing the relationships between tissue concentrations of PCBs and all analysand lipids, where PPC stand for phosphatidylcholine, Tri-glyc - for triglycerides, tot_chol - for total cholesterol and Polyun_F - for polyunsaturated fatty acid, TMAO - for Trimethylamine $\mathrm{N}$-oxide.

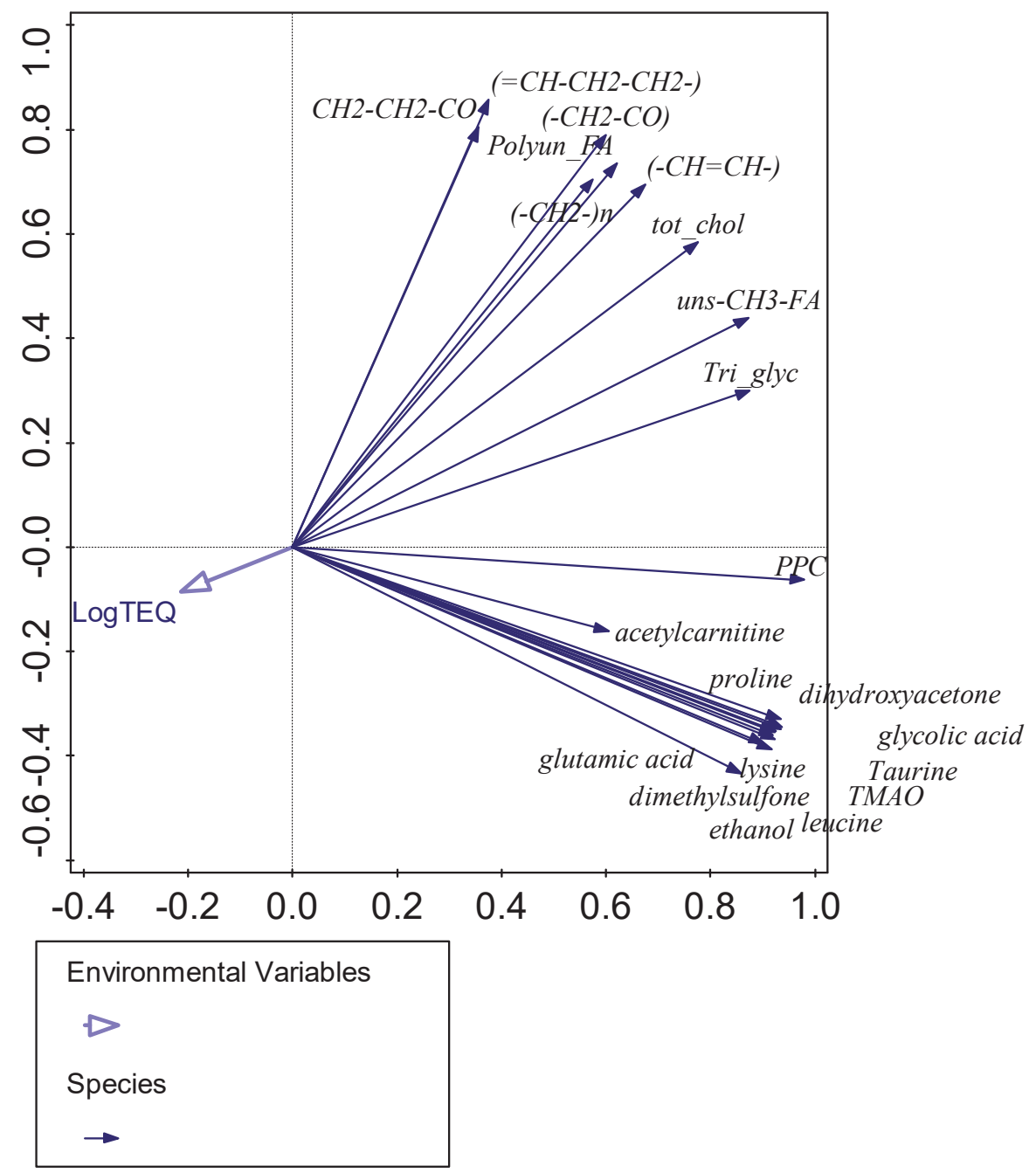




\section{APPENDIX 5. LIPID CONGENTRATIONS IN THE SAMPLES.}

\begin{tabular}{|c|c|c|c|c|c|c|c|c|c|}
\hline exposure & 0 & 0 & 0 & 1 & 1 & 1 & 10 & 10 & 10 \\
\hline repetition & 1 & 2 & 3 & 1 & 2 & 3 & 1 & 2 & 3 \\
\hline lipid content (\%) & $0.677 \%$ & $0.677 \%$ & $0.820 \%$ & $0.285 \%$ & $0.356 \%$ & $0.392 \%$ & $0.820 \%$ & $0.606 \%$ & $1.354 \%$ \\
\hline exposure & 100 & 100 & & 100 & 100 & 400 & & 400 & 400 \\
\hline repetition & 1 & 2 & & 3 & 4 & 1 & & 2 & 3 \\
\hline lipid content (\%) & $0.820 \%$ & 0.820 & & $0.392 \%$ & $0.392 \%$ & $1.105 \%$ & & $249 \%$ & $0.606 \%$ \\
\hline
\end{tabular}




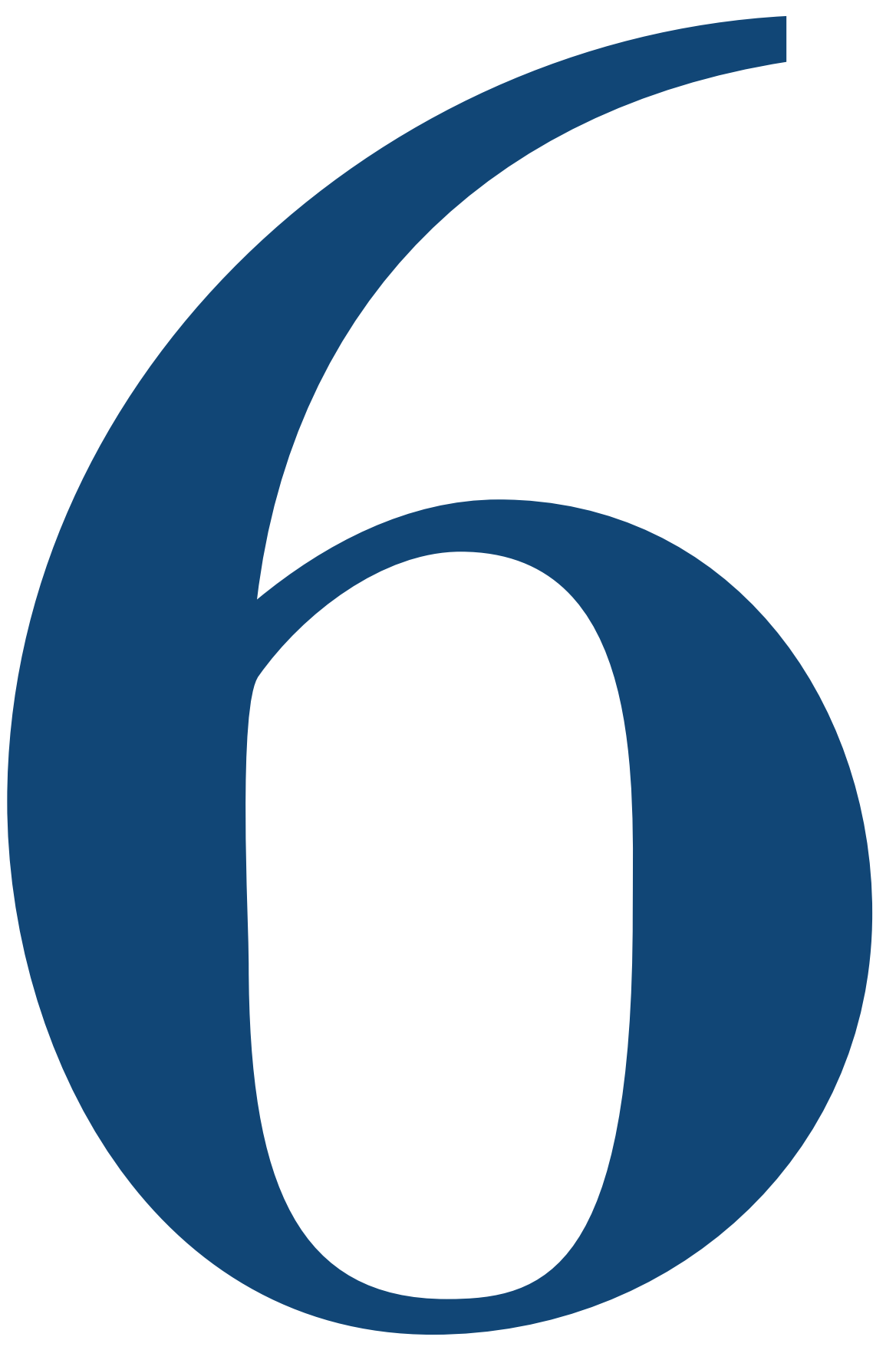




\section{Chapter 6}

General discussion 


\section{GENERAL DISCUSSION}

\section{Variability in fluxes of POPs in Antarctica}

Fluxes of POPs in the Antarctic marine ecosystems are subject to temporal variations, which make establishing their comprehensive time trends difficult. Firstly, there are long-term yearly trends influencing the fundamental characteristics of the local ecosystems ${ }^{1-3}$. Among them are, for instance, the raising ocean ${ }^{4,5}$ and atmospheric ${ }^{6,7}$ temperatures and decreasing salinity of the ocean ${ }^{8}$, which in their turn lead to alterations of biogeochemical processes at a more local scale, such as changes in the dynamics of algae blooms ${ }^{9,10}$ or possible change in species composition of ecosystems ${ }^{11}$. Such processes can have a profound effects on the fluxes of POPs ${ }^{12}$ and will be discussed further to set up a frame for the discussion.

The most important factor controlling long-term concentrations of POPs (although not happening in Antarctica itself) is the emissions of POPs in the temperate and tropical regions of the planet ${ }^{13}$. The decreasing usage (if not subjected to an outright ban) of certain legacy POPs (e.g. PCBs) has left a profound implication on their concentrations in Antarctica $^{13,14}$. At the same time, emissions of novel contaminants (e.g. PBDEs) have led and lead to increases of the concentrations in Antarctica ${ }^{15-17}$.

Secondly, the short-term (seasonal) variations of the Antarctic environmental add complexity to POPs distribution. In fact, the Antarctic marine environment might have the highest level of seasonality in the world ${ }^{18-20}$. For example, sea ice cover acting as an accumulation medium and increased inputs of organic matter during phytoplankton blooms can be responsible for rapid changes of concentrations of POPs in the upper layers of the ocean water, as examined in detail in chapter $3^{21,22}$. This can make comparisons to the previous studies unreliable and potentially lacking an appropriate depth if the sampling times and conditions are not specified.

Next to temporal variation, spatial variation of the biogeochemical processes in Antarctica is another factor to be considered. On a larger scale, atmospheric and oceanic currents may substantially impact the transport of POPs ${ }^{22,23}$, for instance the extent of long rage atmospheric transport (LRAT) inputs of POPs is dependent on the geographical position of the actual points of sampling ${ }^{24,25}$. On a smaller scale, additional local sources (e.g. research station) can skew the measurements of POP concentrations, especially if they cannot be predicted (e.g. oil spills or fires) ${ }^{26,27}$. Speculatively, specific local conditions, such as katabatic and orographic winds ${ }^{28}$, may influence flows of POPs and bias comparisons between different studies.

Last but not the least, climate change can be expected to have a profound impact on the temporal and spatial variability of POPs in Antarctica, which remains till this day largely 
unquantified $^{29}$. Nevertheless, it is evident that this global phenomenon will determine the biogeochemical processes both locally and in Antarctica as a whole ${ }^{30-32}$. While its exact ramifications will be discussed further in the light of specifics of the POP fluxes between individual environmental compartments, it is important to stress the significance this may carry for these fluxes.

\section{General hypotheses of the fluxes of POPs in the Antarctic Marine ecosystems} As stated in the introduction, the main hypothesis of this thesis is that the concentrations of POPs in the Antarctic benthic ecosystems are increasing. To prove this hypothesis, the current study was designed to determine the fluxes of POPs in the different compartments of the coastal Antarctic marine ecosystem and the biogeochemical processes controlling them. Thus, while these fluxes are, in the most general way, directed downwards from the atmosphere to the benthic ecosystems ${ }^{12,23}$, it is of importance to consider the coastal Antarctic marine ecosystem as an extremely complex inter-connected entity, where a slight change in one of its parts may lead to significant implications in the other ones.

Consequently, although the focus of the thesis was on the benthic ecosystem, local pelagic ecosystems also needed to be characterised (chapter 2) in order to establish a proper quantification of POP inputs into the benthic ones and to account for biomagnification between species. Similarly, both abiotic (chapter 3) and biotic parts (chapter 4) of the environment were considered in order to make proper estimations of bioaccumulation of POPs. Furthermore, the implications of the fluxes of POPs were also evaluated by means of an ecotoxicological study (chapter 5) in order to assess the potential effects of PCBs on local benthic species.

It can be claimed that all the inputs of POPs into the marine ecosystem of the Rothera Bay in the current study occur exclusively through the atmosphere with LRAT. Concentrations in both water and benthic animals showed no significant differences between samples collected exactly at or near the station and further away (chapters 3 and 4). Previously, it was theorised that Antarctic stations may induce an increase in concentrations of POPs at distances as far as $500 \mathrm{~m}$ away ${ }^{26}$. However, from the results presented in chapters 3 and 4 it is quite apparent that the protocols currently adopted by the British Antarctic Survey are more than adequate in minimizing direct anthropogenic releases of POPs into the local marine environment.

The deposition of POPs into the Antarctic marine system takes place either directly onto the water surface or onto the sea ice. In case of the former, POPs would in a rather straightforward manner, settle down along the water column of the ocean with the organic matter. Upon deposition onto the ice, however, their further fate in the environment is subjected to a high degree of seasonality. The POPs accumulate on top of the sea ice cover, 
and are mixed with snow - in a process known as "snow amplification"33. This would continue till the moment in spring when the sea ice cover melts, and the POPs will be released into the water column. The upper layers of the water column are not composed of actual seawater, but rather consist of a mix of salt - and freshwater, coming from the melting sea ice and snow, and potentially glaciers and icebergs. At the same time, plankton blooms may develop, which would create a surplus of organic matter in the seawater. Together, these processes would lead to a rapid increase in the concentrations of POPs in the water, superseded by a consecutive rapid decrease, as the POPs would swiftly settle down with the organic matter and (possibly) salinity gradients, therefore entering the benthic ecosystem (chapter 3).

When looking at the biotic compartments of the environment, POPs enter the Antarctic pelagic food web starting with algae, then through krill and pelagic fishes and finally through birds and marine mammals, thus undergoing the process of biomagnification ${ }^{34,35}$. While some fishes and, especially, penguins are considered important bioindicators of POPs in the Antarctic environment ${ }^{13,14,35,36}$ due to practical reasons, they remained out of scope in the current project. However, another important biomagnification endpoint of POPs, - migratory flying birds - was characterised (chapter 2). The uniqueness of this endpoint lies in the fact that because of their migrations these birds are exposed to POPs in both Antarctic and temperate (mostly South American) ecosystems. Thus, their contamination profile allows for a more profound characterization of LRAT inputs.

Upon entering the benthic ecosystem POPs start to accumulate in the local animals, including invertebrates. Chapter $\mathbf{4}$ shows that, depending on the exact species, the major intake pathway for POPs can be either food borne (sea stars) or via water exchange (squirts). Although this does influence the accumulation patterns, it can still be speculated that the overall burden is directly linked to LRAT. From here, POPs could enter sediments and thus be no longer environmentally active and participate in their global cycle ${ }^{37,38}$. Alternatively, they could (to a lesser degree) be re-released into the pelagic ecosystem either through consumption of the benthic invertebrates by benthic or pelagic fish ${ }^{39}$, or by vertical water fluxes $^{40,41}$.

Overall, the whole Antarctic marine environment acts as a complex system with bidirectional fluxes of POPs between each of its parts. However, the intensities of these fluxes are not equal: while the pelagic ecosystem functions as a transient compartment of POPs, the benthic one represents the sink compartment, representing the major endpoint for contamination of POPs in Antarctica. Therefore, temporal trends in concentrations of POPs in the benthic ecosystems have a lag in comparison to the pelagic ones. The drivers of these trends were examined through characterization of fluxes of POPs between individual compartments of the Antarctic marine ecosystem studied in the framework of the current 
project (chapters 2, 3 and 4) and linking them to an ecotoxicological study on an Antarctic benthic species (chapter $\mathbf{5}$ ).

\section{Fluxes of POPs between water and benthic invertebrates}

The concentrations of POPs in water generally displayed the most pronounced seasonality in comparison to other compartments of the Antarctic environment, as indicated by the results presented in chapter 3. The process of POPs being trapped in the snow and sea ice over winter and being released during the melt resulted in a large change (more than 10 times) in their concentrations measured at $1 \mathrm{~m}$ depth, which was in turn followed by an also rapid decline, driven by the water mixing. Further into the season it was superseded by sedimentation, whose intensity was related to the surplus organic matter coming from the phytoplankton blooms. At 20m depth the concentrations of POPs were lower throughout the season, most likely because the increased intensity of the bloom at this depth provided more organic material for the POPs to settle down with.

Although unfortunately it was not possible to obtain samples to measure concentrations of POPs during the winter months, it can be speculated that they may have remained generally constant and low, as no inputs from the atmosphere were expected.

Correspondingly to the concentrations of POPs in the upper water layers, the input fluxes of POPs to the benthic ecosystem at $20 \mathrm{~m}$ depths showed a lot of variations across the season, surging maximum in spring or early summer during the melting of the sea ice, declining (though still detectable) with the progression of the season and possibly stabilizing at the asymptotic values in winter.

Despite these general dynamics, on individual congener level, POPs demonstrated differences in the kinetics of their concentrations. The composition of PCBs in the upper water layers during the initial period of rapid concentration changes showed abundance of various congeners, both light and heavy, while later in the season only lower chlorinated congeners (predominantly PCB 28) were detected. At the same time, a variety of PBDE congeners was always present throughout the season. Most likely this discrepancy can be ascribed to the different compositions of LRAT inputs of PCBs and PBDEs, as the heavy congeners of the latter may still be legally used today or, potentially, they could be products of local environmental degradation of a single heavy BDE congener - BDE-209 ${ }^{42}$.

Similarly, while concentrations of POPs in the benthic invertebrates in chapter 4 were generally in accordance with what could have been predicted based on the physico-chemical properties of POPs and individual species traits, some elements of their accumulation pattern were rather following the patterns established by the concentrations in water from the upper layers. The filter-feeding animals (sea cucumbers and ascidians) demonstrated 
lower absolute concentrations of PCBs than the more predatory species (sea urchins and sea stars), while the PCB congener profile remained relatively the same in both species with the congeners having low Kow being the most prevalent ones. In contrast to PCBs, PBDEs showed very little interspecific differences both in terms of the absolute and relative congener concentrations. The most likely explanation for this may be that the lighter PBDE congeners, that could have accumulated in the tissues of the animals, were not present in the influx of PBDEs to the benthic ecosystems, exactly as the concentrations of PBDEs in the pelagic water suggested in chapter 3. Likewise, the OCPs predominantly found in water ( $\mathrm{HCB}$, trans-Chlordane, Aldrin, pp-DDE, heptachlor) were also the prevalent OCPs in the tissues of the studied benthic animals. A notable exception was the absence of a clear domination (although it was detected in relatively high concentrations) of $\mathrm{HCH}$ alpha in the invertebrates (chapter 4) in contrast to the concentrations in water in chapter 3. Potentially it can be explained by bacterial or photo degradation of this compound, it may act as an example of when a process controlling distribution of a POP in the Antarctic marine environment has not yet been clearly established.

In contrast to noticeable interdependencies of fluxes of POPs between different environmental compartments, the limpets in chapter $\mathbf{4}$ serve as a concurrent example of when individual traits of species overtake explicit patterns of concentrations of POPs dictated by the water concentrations. This is evident from the fact that these animals contained more POPs with higher Kow and Koa (e.g. heavy PCB congeners) than other species, although water concentrations from chapter 3 would rather suggest accumulation of POPs with lower Kow and Koa. This may be explained firstly by the grazing feeding behaviour of the limpets, as POPs with high Kow may gather in the lipophilic particles they feed on $^{20}$. Secondly, their shell may be responsible for the limited dermal exchange with the water, which may limit the uptake of POPs with lower Kow, despite them being exposed to the same water as other species.

It is noteworthy to mention that although pp-DDE and (to lesser extent) pp-DDT were detected in both water (chapter 3) and benthic invertebrates (chapter 4), there was no indication of their potential input with the melting glaciers. This can serve as an another proof $^{43}$ that the glaciers are not a significant secondary input source of POPs for the marine environment, as was previously theorised ${ }^{44}$.

To summarize, patterns in concentrations of POPs in both particulate phase of the water and benthic invertebrates were dependent on the physico-chemical properties of the POPs as well as the patterns in their concentrations in the input environmental compartment, i.e. the compartment from which the influx of POPs originates (atmosphere - for water; water, algae/food - for invertebrates). Thus, the fluxes of POPs in the Antarctic benthic ecosystems are also dependent on the biogeochemical processes in the Antarctic pelagic ecosystems and 
the atmosphere around this continent. This also suggests that, despite some species-specific differences, benthic invertebrates may be good indicators of the environmental burden in the Antarctic marine ecosystem as a whole, because concentrations of POPs are dependent on, and thus account for, all biogeochemical processes, which control the fluxes of these contaminants in other environmental compartments.

\section{Fluxes of POPs between the pelagic water and migrating birds}

While having more exposure pathways when compared to non-flying migratory birds ${ }^{14}$, flying birds of Antarctica can be good bioindicators of environmental burden of the local pelagic ecosystems $s^{45,46}$. Alike water in chapter 3 , life cycle of these birds is subject to high seasonality through their migrations. The studies in chapter 2 examined concentrations of POPs in livers, subcutaneous fat and muscles of skuas (Catharacta maccormicki) and kelp gulls (Larus dominicanus).

During the warmer periods of the austral season (normally from November till April) skuas and kelp gulls spend their time around the coast of Antarctica, where they forage, and therefore biomagnify POPs that are present in their prey. The diet of both species in Antarctica is mainly comprised of fish and invertebrates, but they can also consume carryon of other birds if given the chance. In fall the birds migrate North, where they add landfills and agricultural lands to their forage areal ${ }^{47-49}$.

The seasonal migration results in a duality in the patterns of POP accumulation in the birds. They would be exposed to legacy POPs (e.g. HCB) during their stay in Antarctica, while exposure to the emerging POPs (e.g. BDE-209) is more likely to happen in South America (chapter 2). In this light, it is advantageous to make a comparison between patterns of POP concentrations in water (transport compartment of the Antarctic environment), non-flying birds ("truly" Antarctic species) and flying, migratory birds. More volatile POPs often have lower Kow and are less likely to sediment to the benthic compartment of the marine Antarctic ecosystem, which results in their longer residence times in the pelagic system at the base of the Antarctic food chain. This can lead to their higher biomagnification and therefore burden in the migratory birds.

As mentioned before, the most abundant PCB congener in water was PCB-28 (chapter 3). In non-migrating birds this congener still remains an important one, though it loses its dominance ${ }^{50}$. However, relative concentrations of PCB-28 in both migrating bird species from chapter 2 were low when compared to other congeners. In fact, their PCB-profile was dominated by heavier hexa- and hepta-CBs, which is correspondingly not normally observed in the non-flying birds ${ }^{14,50}$. These patterns can be explained by the ability of avian species to eliminate lower chlorinated PCBs faster than the higher chlorinated ones $^{51,52}$. Thus, the concentration patterns of PCBs can serve as an example of the fact that 
individual characteristics of a species have more impact on accumulation of POPs than the concentrations in the environmental compartment, from which the influx of POPs occurs.

On the other hand, HCB (although not the most abundant OCP) was detected in water in chapter 2 and maintained its importance in the flying birds from chapter 3. Because HCB concentrations in these birds were comparable to what can also be found in the non-flying birds ${ }^{53}$, it can be speculated that an Antarctic specific biomagnification pathway of this compound is present from water to the higher trophic levels in the Antarctic ecosystems. In general, it can be concluded that despite the presence of certain specific variations, which make the interpretations of the fluxes of POPs between the Antarctic marine water and Antarctic migratory birds more challenging, the results presented in chapter 2 are essential and insightful for the estimation of overall POP burden in the Antarctic environment.

\section{Time trends of concentrations of POPs in the benthic ecosystems}

Concentrations of POPs were 10-100 times lower in the benthic invertebrates in the current study (Chapter 4) when compared to earlier reports ${ }^{54-57}$. For example, concentrations of PCBs in urchins from chapter 4 were 30 times lower than in the same species from Adélie Land in $2009^{54}$ and up to 60 lower than in the same species from Princess Elizabeth Land in $1995^{56}$. Thus, it may appear that the concentrations of POPs in the benthic ecosystems actually declined over the last decades.

However, the higher concentrations in the previous studies may be explained either by fact that they were all conducted in different parts of Antarctica (not WAP) and thus may have experienced different influences of the mentioned biogeochemical processes that control distribution of POPs, or because they overestimated the concentrations of POPs due to contamination either from a local source or during the analysis (chapter 4).

At this point it is necessary to compare the data from the current project and the historical data on concentrations of POPs in pelagic ecosystems, which were shown to be transition compartments of POPs in the Antarctic marine environment on their way to benthic ecosystems (chapters 3 and $\mathbf{4}$ ).

Although POPs in the particulate phase of water have been measured in Antarctica only in a few studies since $1983^{24,58,59}$, it can be concluded from chapter 3 that the current study indicates increased absolute and relative concentrations of PCBs and similar concentrations of OCPs when compared to those reported in previous studies. Average concentrations of PCBs in the particulate phase of water from chapter 3 from 2017 were 10 times higher than in the Indian sector of the Sothern ocean in $1991^{59}$ and 3 times higher than around WAP in $2008^{24}$. Average concentrations of OCPs in chapter 3 were either 10-100 higher $(\mathrm{HCH}-$ alpha) or comparable ( $\mathrm{HCH}$-gamma) than previously measured concentrations around 
WAP in $2006^{58}$ and $2013^{24}$. Because PBDEs in the Antarctic water were for the first time measured above detection limits in chapter 3 , it can be argued that their concentrations have increased over time ${ }^{60}$.

Similar trends can be seen in the concentrations of all the POPs in the pelagic migratory birds (chapter 2). Concentrations of POPs in these birds were comparable to the ones measured more than 20 years ago for OCPs (including HCB) ${ }^{50,51}$ and 10 years ago for PBDEs ${ }^{61}$. Moreover, the concentrations were higher than detected in the most recent studies $25,46,61-65$. For instance, comparing concentrations of POPs in skuas of chapter 2 with the historical ones in the same species from the King George Island reveals that the concentrations of PCBs in chapter 2 were 5 times higher than measured in $2016^{63}$, concentrations of HCB were 7 times higher than detected in $2013^{66}$ and concentrations of PBDEs were comparable to the ones from $2016^{63}$ respectively.

Thus, it can be concluded that the stagnating or even increasing concentrations of POPs in the Antarctic pelagic ecosystems (which can be regarded as transient compartments for the fluxes of these pollutants) may likely lead to a future increase of concentrations of POPs in the Antarctic benthic ecosystems (which are considered to be the their ultimate $\operatorname{sink}^{29}$ ), validating the main hypothesis of the thesis.

\section{Toxicological effects of PCBs on an Antaretic benthic species}

With the suggestion of potentially increasing local concentrations of POPs in the Antarctic benthic ecosystems as the ultimate sink of POPs it is of interest to assess their possible toxicological effect on the local benthic species in order to establish whether these compounds pose an actual risk to the benthic communities (chapter 5).

Current literature on this subject presents a lot of uncertainty and conflicting results, as comparable studies are quite scarce even for the temperate ecosystems $s^{67,68}$. Although it was theorised that Antarctic species could be more vulnerable to POPs ${ }^{29,69}$, recent studies on krill exposure to DDE found no evidence for such conclusion ${ }^{70-72}$.

During the experiment of chapter 5 Antarctic limpets Nacella concinna were exposed to water-borne concentrations of $\mathrm{PCBs}$ that could be found in the temperate areas of the world ${ }^{73}$, which were 100-fold higher than the concentrations found in Antarctica in chapter 3. The exposure led to accumulation of PCBs in the tissues of limpets, which, when expressed in $\mathrm{TEQ}^{74}$ resulted in levels that were more than 100 times higher than the levels detected in the limpets sampled in Antarctica from chapter 4.

The activity of EROD observed in chapter $\mathbf{5}$ was overall not significantly higher than for temperate mussels in previous studies on PCB exposure ${ }^{67,68}$ and was also not induced 
upon exposure to the PCB mixture. Therefore, current data do not support the hypothesis that the Antarctic limpets are more sensitive to PCB induced biomarkers of effect than the temperate species of mussels, which is a conclusion in line with the studies on OCPs ${ }^{71,72}$. Therefore, contrary to what was previously proposed ${ }^{29}$, Antarctic limpets do not appear to be more sensitive to PCBs than their counterparts from the temperate areas, although more research is required on this topic to make definitive conclusions. Likewise, current concentrations of PCBs in limpets in Antarctica seem to be low enough to not affect this biomarker of exposure and effect studied in chapter 5 .

At the same time, an analysis of lipid composition in the limpets revealed a negative correlation between the occurrence of different lipids and PCB exposure: more PCBs in their tissues corresponded to lower amounts of lipids. Because levels of lipids in invertebrates were proposed to be a general indicator of their general well-being ${ }^{75}$, it can be speculated that PCBs may be a stress factor to the Antarctic benthic communities, additional to the ones occurring due to climate change (e.g. increase in water temperatures).

\section{Fluxes of POPs to and in the Antaretic benthic ecosystems and global change}

The fluxes of POPs to and in the benthic ecosystem are controlled by a multitude of oceanographic and biogeochemical processes (as previously stated in this discussion) that are already heavily experiencing alterations due to climate change $e^{31,76,77}$. First and foremost, the sea ice, which acts as an accumulation compartment for POPs over winter, has experienced an unprecedented decline in both thickness and the duration during the last years ${ }^{78}$. Longer absence of the sea ice cover can not only increase the concentrations of POPs in the water during the period when POPs were trapped in the sea ice cover but would also subject the benthic ecosystems to longer periods of continual input of POPs. At the same time, this may lead to a lower amount of snow (which is composed of fresh water) accumulating on the sea ice cover during winter and therefore to a decrease in mixing processes after the melt, making the inputs of POPs into water more gradual.

Second, the escalating rate of the glacier melt in Antarctica could mean more inputs of the freshwater into the coastal marine ecosystems ${ }^{79,80}$. While it is very unlikely that this melt would directly lead to an increase in concentrations of POPs in the water through the release of some legacy compounds that might have been trapped there, it could compensate the above mentioned mixing processes to an unknown extent.

Simultaneously, it can be speculated that the glacier melt would lead to a development of more spatial variations (i.e. more variations between different regions of Antarctica) in the dynamics of POPs inputs to the benthic ecosystems ${ }^{81}$, as glaciers in the Western Antarctica (especially around WAP) melt faster than in the Eastern Antartica ${ }^{82}$. For instance, the 
Sheldon Glacier, which is located in the close vicinity of the sampling site of chapter 3, lost more than $3.5 \mathrm{~km}$ of its length in the last decades ${ }^{83}$.

Third, the changes in the phytoplankton blooms induced by the climate change may have large consequences for the influx of POPs to the benthic ecosystems ${ }^{84-87}$. Plankton blooms in Antarctica have been studied for decades, although the results are often conflicting, and some specifics remain unknown ${ }^{84-87}$. For instance, chapter 3 suggests that chlorophyll-a, as a proxy for organic carbon, is the major driver of sedimentation of POPs during most of the austral summer. Previous studies demonstrated that the year-round average amount of chlorophyll-a has significantly increased recently at the Palmer station $\left(64.77^{\circ} \mathrm{S}, 64.05^{\circ} \mathrm{W}\right)$, but significantly decreased at Rothera, which would imply more intensive downward fluxes in the former and less intensive in the latter ${ }^{87}$. Furthermore, the qualitative composition of the blooms and associated lipid profiles may change ${ }^{88}$, which could also lead to a different composition of POPs in the input fluxes of the benthic ecosystems. Overall, while it is not possible to estimate how exactly the change in plankton blooms would affect the dynamics of POPs, its importance for concentrations of POPs in the benthic is evident ${ }^{89}$.

Little information is currently available on how fluxes in POPs will develop in the Antarctic benthic ecosystems themselves due to a lack of research on the topic, although characterization of changes in these ecosystems due to climate change in general has lately become a major topic of scientific scrutiny $y^{11,90-92}$. However, it is certain that the benthic ecosystems will change both quantitively and qualitative. For instance, new areas of the sea floor become available for colonization with benthic biota due to the retreat of the melting glaciers ${ }^{90}$. At the same time, local benthic community compositions and overall biodiversity may change as different species have different tolerance to the increase in water temperatures ${ }^{91}$.

Overall, it can be theorised that the fluxes of POPs in both pelagic and benthic Antarctic marine ecosystems may likely change in the coming years. Thus, more research should be dedicated to characterization of the biogeochemical process that drive these fluxes in order to increase the understanding of the changes in spatiotemporal distributions of POPs in different compartments of the Antarctic marine ecosystem.

\section{Outlook for the future research}

While the current study comprehensively investigated POPs in different compartments of the Antarctic environment, it should be followed by further research in order to understand and safeguard this unique place, as new risks to its functioning and very existence arise, induced by the global change ${ }^{93}$. To accomplish this, it is essential to acquire large amount of data of high quality and integrity. 
As it has already been stated previously ${ }^{13,29}$ and as this discussion has proposed, establishment of reliable time trends is of crucial importance for studies of POPs in the Antarctic. For such studies to achieve their purpose successfully, the lowest possible temporal and spatial variability in data should be documented in the framework of a single study. While the former would simply require complete reporting of exact timing and environmental conditions of the moment of the sampling, the latter creates a need to conduct the research at the same sites, using the same approaches and techniques to allow for a proper integration of the data.

On the other hand, to obtain more complete and large-scale scientific insights of the environmental fate and kinetics of POPs in the Antarctic ecosystem, research must be performed and coordinated across different temporal and spatial points. As such, it is important to conduct the research across different seasons, as their certain characteristics (e.g. time of the melting of the sea ice, temperatures, etc) can vary significantly from year to year ${ }^{78,94}$. At the same time, this research should be conducted in different regions of the continent, as East Antarctica experiences the global change differently than WAP ${ }^{82}$, and thus differences in the fluxes of POPs can be expected. Possible latitudinal variations should also be explored, as suggested by a previous study ${ }^{34}$.

The complexity of fluxes of POPs has been extensively stressed in the current discussion. Thus, investigations should be carried out in various environmental compartments and monitoring of concentrations of POPs should be routinely done in both water and benthic invertebrates just as in non-migrating birds and fish, which is not performed often. Long-term inputs of POPs with LRAT should be characterized in order to get a clear quantification of the initial inputs of these contaminants. At the same time, possible rerelease or degradation of POPs in the benthic ecosystem should be assessed.

Moreover, fluxes of POPs should always be studied in the context of the biogeochemical processes that control them. On the one hand, this indicates the necessity of getting further insights on how these processes function and to what extent they actually drive fluxes of POPs. An example for that can be a precise estimation of effects of the changes in species composition in the Antarctic benthic ecosystems ${ }^{91}$ on the dynamics of POPs in the water. This also means that monitoring programmes like the RaTS at Rothera research station ${ }^{95}$, should be initiated in other parts of Antarctica.

As an intrinsic part of the current thesis, a toxicological study on the effects of PCBs on Antarctic benthic invertebrate, the Antarctic limpets Nacella concinna, demonstrated the usefulness of NMR-based omics studies. In a broader sense, studies of environmental omics have already been successfully conducted in other parts of the world for identification of toxicity pathways, mechanisms and biomarkers ${ }^{96,97}$, while such studies on species from 
Antarctica are extremely scarce ${ }^{18}$. They would allow for a better understanding and quantification of hazards that are imposed on local communities by the climate change and predict possible environmental responses to the fluxes of POPs. More studies on chronic exposure of Antarctic benthic invertebrate to pollutants should be conducted, as many of the Antarctic species are characterised by slow metabolism and thus may have a delayed response to them ${ }^{72,98}$.

The list of chemicals which can actually be considered as POPs is constantly updated, with new compounds being added on a regular basis ${ }^{99,100}$. This means that although research on legacy POPs (e.g. PCBs and OCPs) must continue, possible presence of other new substances (e.g. BDE-209, PFAs ${ }^{101}$ and chlorinated paraffins ${ }^{102}$ ) should be investigated. Furthermore, a new source of POPs in the Antarctic environment may soon arise - microplastics ${ }^{103-105}$. Only till very recently Antarctica has been free from contamination with them, although they are already considered to become a major point of concern in the near future ${ }^{105}$. In other parts of the world, microplastics are known to be responsible for increased concentrations of emerging POPs in the marine ecosystems ${ }^{106,107}$. Therefore, they may also influence time trends and toxicological effects of POPs in the benthic ecosystems of Antarctica.

Encompassing all future research directions mentioned above is a very strong need of comprehensive and rigorous reporting of the procedures of the chemical analyses, QA/QC and data analysis. Failing to do that may result in the lack of suitability of the data for the future research and establishment of the concentration time trends, for which even the data from the 1960s and 1970s is still important.

Similarly, all future research on the topic of the POPs in the Antarctic benthic ecosystems should be conducted taking the global (especially climate) changes into account. Climate change has been proven to affect benthic communities directly as well as the general functioning of the Antarctic ecosystems $s^{77,91}$.

\section{Conclusion}

The data gathered in this thesis allows to accept the hypothesis that the concentrations of POPs in the Antarctic benthic ecosystems (the ultimate sink of these pollutants) may still be increasing. This is concluded in spite of the fact that actual levels observed in the present thesis for benthic organisms were lower than in previous studies, based on the fact that levels of these pollutants in the Antarctic pelagic ecosystems, considered transient compartments for the fluxes of these pollutants to the benthic system, were higher. Seasonal fluctuations of concentrations of POPs in the pelagic ecosystems are driven by the sea ice dynamics and algal blooms, directing the effective transport of POPs to the benthic ecosystems via sedimentation with the organic material. However, more direct measurements in the Antarctic benthic ecosystems are needed to establish comprehensive 
time trends. In comparison to the temperate areas of the planet, current concentrations of POPs in Antarctica remain low. At the moment there are no indications that the Antarctic organisms should be regarded as toxicologically more sensitive to POPs than their temperate counterparts. Thus, the overall risk, which these compounds currently present to the Antarctic environment, may be low, although this may become different in the future because of the global change. 


\section{REFERENCES}

1. Convey, P. \& Peck, L. S. Antarctic environmental change and biological responses. Sci. Adv. 5, eaaz0888 (2019).

2. Rogers, A. D. et al. Antarctic Futures: An Assessment of Climate-Driven Changes in Ecosystem Structure, Function, and Service Provisioning in the Southern Ocean. Ann. Rev. Mar. Sci. 12, 87-120 (2020).

3. Turner, J. et al. Antarctic climate change and the environment: an update. Polar Rec. (Gr. Brit). 50, 237-259 (2014).

4. Etourneau, J. et al. Ocean temperature impact on ice shelf extent in the eastern Antarctic Peninsula. Nat. Commun. 10, 304 (2019).

5. Schneider, D. P. et al. Antarctic temperatures over the past two centuries from ice cores. Geophys. Res. Lett. 33, L16707 (2006).

6. Smith, R. C. \& Stammerjohn, S. E. Variations of surface air temperature and sea-ice extent in the western Antarctic Peninsula region. Ann. Glaciol. 33, 493-500 (2001).

7. Nicolas, J. P., Bromwich, D. H., Nicolas, J. P. \& Bromwich, D. H. New Reconstruction of Antarctic Near-Surface Temperatures: Multidecadal Trends and Reliability of Global Reanalyses. J. Clim. 27, 8070-8093 (2014).

8. Silvano, A. et al. Freshening by glacial meltwater enhances melting of ice shelves and reduces formation of Antarctic Bottom Water. Sci. Adv. 4, eaap9467 (2018).

9. Annett, A. L. et al. Comparative roles of upwelling and glacial iron sources in Ryder Bay, coastal western Antarctic Peninsula. Mar. Chem. 176, 21-33 (2015).

10. Biggs, T. E. G. et al. Antarctic phytoplankton community composition and size structure: importance of ice type and temperature as regulatory factors. Polar Biol. 42, 1997-2015 (2019).

11. Clark, M. S. et al. Biodiversity in marine invertebrate responses to acute warming revealed by a comparative multi-omics approach. Glob. Chang. Biol. 23, 318-330 (2017).

12. Cropp, R., Kerr, G., Bengtson-Nash, S. \& Hawker, D. A dynamic biophysical fugacity model of the movement of a persistent organic pollutant in Antarctic marine food webs. Environ. Chem. 8, 263 (2011).

13. van den Brink, N. W., Riddle, M. J., van den Heuvel-Greve, M. \& van Franeker, J. A. Contrasting time trends of organic contaminants in Antarctic pelagic and benthic food webs. Mar. Pollut. Bull. 62, 128-132 (2011).

14. Ellis, D. S., Cipro, C. V. Z., Ogletree, C. A., Smith, K. E. \& Aronson, R. B. A 50-year retrospective of persistent organic pollutants in the fat and eggs of penguins of the Southern Ocean. Environ. Pollut. 241, 155-163 (2018).

15. Li, Y.-F. et al. Decabrominated Diphenyl Ethers (BDE-209) in Chinese and Global Air: Levels, Gas/ Particle Partitioning, and Long-Range Transport: Is Long-Range Transport of BDE-209 Really Governed by the Movement of Particles? Environ. Sci. Technol. 51, 1035-1042 (2017).

16. Zheng, B. et al. Bioaccumulation characteristics of polybrominated diphenyl ethers in the marine food web of Bohai Bay. Chemosphere 150, 424-430 (2016).

17. de Wit, C. A., Herzke, D. \& Vorkamp, K. Brominated flame retardants in the Arctic environment — trends and new candidates. Sci. Total Environ. 408, 2885-2918 (2010).

18. Peck, L. Antarctic marine biodiversity: adaptations, environments and responses to change. Oceanogr. Mar. Biol. An Annu. Rev. 56, (2018).

19. S., B., A., C. \& A., C. Seasonality of feeding and nutritional status during the austral winter in the Antarctic sea urchin Sterechinus neumayeri. Mar. Biol. 139, 127-138 (2001).

20. Fraser, K., Clarke, A. \& Peck, L. Feast and famine in Antarctica: seasonal physiology in the limpet Nacella concinna. Mar. Ecol. Prog. Ser. 242, 169-177 (2002).

21. Bigot, M. et al. Spring Melt and the Redistribution of Organochlorine Pesticides in the Sea-Ice Environment: A Comparative Study between Arctic and Antarctic Regions. Environ. Sci. Technol. 51, 8944-8952 (2017). 
22. Casal, P. et al. Pivotal Role of Snow Deposition and Melting Driving Fluxes of Polycyclic Aromatic Hydrocarbons at Coastal Livingston Island (Antarctica). Environ. Sci. Technol. 52, 12327-12337 (2018).

23. Bates, M. L., Bengtson Nash, S. M., Hawker, D. W., Shaw, E. C. \& Cropp, R. A. The distribution of persistent organic pollutants in a trophically complex Antarctic ecosystem model. J. Mar. Syst. 170, 103-114 (2017).

24. Galbán-Malagón, C. J., Del Vento, S., Berrojalbiz, N., Ojeda, M.-J. \& Dachs, J. Polychlorinated Biphenyls, Hexachlorocyclohexanes and Hexachlorobenzene in Seawater and Phytoplankton from the Southern Ocean (Weddell, South Scotia, and Bellingshausen Seas). Environ. Sci. Technol. 47, 5578-5587 (2013).

25. Roscales, J. L., González-Solís, J., Zango, L., Ryan, P. G. \& Jiménez, B. Latitudinal exposure to DDTs, HCB, PCBs, PBDEs and DP in giant petrels (Macronectes spp.) across the Southern Ocean. Environ. Res. 148, 285-294 (2016).

26. Wild, S. et al. An Antarctic Research Station as a Source of Brominated and Perfluorinated Persistent Organic Pollutants to the Local Environment. Environ. Sci. Technol. 49, 103-112 (2015).

27. Gröndahl, F., Sidenmark, J. \& Thomsen1, A. Survey of waste water disposal practices at Antarctic research stations. Polar Res. 28, 298-306 (2009).

28. Grazioli, J. et al. Katabatic winds diminish precipitation contribution to the Antarctic ice mass balance. Proc. Natl. Acad. Sci. U. S. A. 114, 10858-10863 (2017).

29. Bengtson Nash, S. Persistent organic pollutants in Antarctica: current and future research priorities. J. Environ. Monit. 13, 497 (2011).

30. Cavan, E. L. et al. The importance of Antarctic krill in biogeochemical cycles. Nat. Commun. 10, 4742 (2019).

31. Shetye, S., Jena, B. \& Mohan, R. Dynamics of sea-ice biogeochemistry in the coastal Antarctica during transition from summer to winter. Geosci. Front. 8, 507-516 (2017).

32. Gutt, J. Research on climate-change impact on Southern Ocean and Antarctic ecosystems after the UN Paris climate conference- "now more than ever" or "set sail to new shores"? Polar Biol. 40, 1481-1492 (2017).

33. Casal, P. et al. Snow Amplification of Persistent Organic Pollutants at Coastal Antarctica. Environ. Sci. Technol. acs.est.9b03006 (2019). doi:10.1021/acs.est.9b03006

34. Bustnes, J. O. et al. Latitudinal Distribution of Persistent Organic Pollutants in Pelagic and Demersal Marine Fish on the Norwegian Coast. (2012). doi:10.1021/es301191t

35. Weber, K. \& Goerke, H. Persistent organic pollutants (POPs) in antarctic fish: levels, patterns, changes. Chemosphere 53, 667-678 (2003).

36. Goerke, H., Weber, K., Bornemann, H., Ramdohr, S. \& Plötz, J. Increasing levels and biomagnification of persistent organic pollutants (POPs) in Antarctic biota. Mar. Pollut. Bull. 48, 295-302 (2004).

37. Wang, P. et al. PCBs and PBDEs in environmental samples from King George Island and Ardley Island, Antarctica. RSC Adv. 2, 1350-1355 (2012).

38. Vecchiato, M. et al. Polychlorinated biphenyls (PCBs) and polybrominated diphenyl ethers (PBDEs) in Antarctic ice-free areas: Influence of local sources on lakes and soils. Microchem. J. 120, 26-33 (2015).

39. Peck, L. S., Clark, M. S. \& Dunn, N. I. Morphological variation in taxonomic characters of the Antarctic starfish Odontaster validus. Polar Biol. 41, 2159-2165 (2018).

40. Ma, Y. et al. Concentrations and Water Mass Transport of Legacy POPs in the Arctic Ocean. Geophys. Res. Lett. 45, 12,972-12,981 (2018).

41. Jordi Dachs, $\dagger, \ddagger$, Steven J. Eisenreich, ${ }^{*} \dagger$ and \& Hoff\$, R. M. Influence of Eutrophication on Air-Water Exchange, Vertical Fluxes, and Phytoplankton Concentrations of Persistent Organic Pollutants. (2000). doi:10.1021/ES990759E

42. Zeng, X. et al. Development and validation of a congener-specific photodegradation model for polybrominated diphenyl ethers. Environ. Toxicol. Chem. 27, 2427-2435 (2008). 
43. Brink, N. van den et al. Correspondence on Geisz et al. Melting Glaciers: A Probable Source of DDT to the Antarctic Marine Ecosystem. Environ. Sci. Technol. 43, 3976-3977 (2009).

44. Geisz, H. N., Dickhut, R. M., Cochran, M. A., Fraser, W. R. \& Ducklow, H. W. Melting Glaciers: A Probable Source of DDT to the Antarctic Marine Ecosystem. Environ. Sci. Technol. 42, 39583962 (2008).

45. Carravieri, A. et al. From Antarctica to the subtropics: Contrasted geographical concentrations of selenium, mercury, and persistent organic pollutants in skua chicks (Catharacta spp.). Environ. Pollut. 228, 464-473 (2017).

46. Cipro, C. V., Colabuono, F. I., Taniguchi, S. \& Carmela Montone, R. Persistent organic pollutants in bird, fish and invertebrate samples from King George Island, Antarctica. Antarct. Sci. Ltd 25, 545-552 (2013).

47. Bertellotti, M. \& Yorio, P. Spatial and Temporal Patterns in the Diet of the Kelp Gull in Patagonia. Condor 101, 790-798 (1999).

48. Reinhardt, K., Hahn, S., Peter, H. \& Wemhoff, H. A review of the diets of the Southern Hemisphere skuas. Mar. Ornithol. 28, 7-19 (1988).

49. Furness, R. W. \& Hislop, J. R. G. Diets and feeding ecology of Great skuas Catharacta skua during the. J. Zool. 195, 1-23 (2009).

50. Van den Brink, N. W. Directed transport of volatile organochlorine pollutants to polar regions: the effect on the contamination pattern of Antarctic seabirds. Sci. Total Environ. 198, 43-50 (1997).

51. Court, G. S. et al. Chlorinated hydrocarbons in the tissues of South Polar Skuas (Catharacta maccormicki) and Adélie Penguins (Pygoscelis adeliea) from Ross Sea, Antarctica. Environ. Pollut. 97, 295-301 (1997).

52. Maervoet, J. et al. Accumulation and tissue distribution of selected polychlorinated biphenyl congeners in chickens. Chemosphere 57, 61-66 (2004).

53. van den Brink, N. W., van Franeker, J. A. \& de Ruiter-Dijkman, E. M. Fluctuating concentrations of organochlorine pollutants during a breeding season in two Antarctic seabirds: Adelie penguin and southern fulmar. Environ. Toxicol. Chem. 17, 702-709 (1998).

54. Goutte, A. et al. Persistent organic pollutants in benthic and pelagic organisms off Adélie Land, Antarctica. Mar. Pollut. Bull. 77, 82-89 (2013).

55. Ko, F.-C. et al. Persistent organic pollutants in Antarctic notothenioid fish and invertebrates associated with trophic levels. PLoS One 13, e0194147 (2018).

56. Grotti, M. et al. Retrospective biomonitoring of chemical contamination in the marine coastal environment of Terra Nova Bay (Ross Sea, Antarctica) by environmental specimen banking. Chemosphere 165, 418-426 (2016).

57. Focardi, S., Bargagli, R. \& Corsolini, S. Organochlorines in Antarctic Marine Food Chain at Terranova Bay (Ross Sea). (1993).

58. Amy L. Chiuchiolo, Rebecca M. Dickhut, *, Michele A. Cochran, and \& Ducklow, H. W. Persistent Organic Pollutants at the Base of the Antarctic Marine Food Web. (2004). doi:10.1021/ES0351793

59. Joiris, C. R. \& Overloop, W. PCBs and organochlorine pesticides in phytoplankton and zooplankton in the Indian sector of the Southern Ocean. Antarct. Sci. 3, 371-377 (1991).

60. Markham, E. et al. Time Trends of Polybrominated Diphenyl Ethers (PBDEs) in Antarctic Biota. ACS omega 3, 6595-6604 (2018).

61. Yogui, G. T. \& Sericano, J. L. Levels and pattern of polybrominated diphenyl ethers in eggs of Antarctic seabirds: Endemic versus migratory species. Environ. Pollut. 157, 975-980 (2009).

62. Corsolini, S., Borghesi, N., Ademollo, N. \& Focardi, S. Chlorinated biphenyls and pesticides in migrating and resident seabirds from East and West Antarctica. Environ. Int. 37, 1329-1335 (2011).

63. Mello, F. V. et al. Relationship between legacy and emerging organic pollutants in Antarctic seabirds and their foraging ecology as shown by $\delta 13 \mathrm{C}$ and $\delta 15 \mathrm{~N}$. Sci. Total Environ. 573, 1380-1389 (2016).

64. Kim, J.-T. et al. Occurrence of Legacy and New Persistent Organic Pollutants in Avian Tissues from King George Island, Antarctica. Environ. Sci. Technol. 49, 13628-13638 (2015). 
65. Fromant, A. et al. Wide range of metallic and organic contaminants in various tissues of the Antarctic prion, a planktonophagous seabird from the Southern Ocean. Sci. Total Environ. 544, 754-764 (2016).

66. Cipro, C. V. Z., Colabuono, F. I., Taniguchi, S. \& Montone, R. C. Persistent organic pollutants in bird, fish and invertebrate samples from King George Island, Antarctica. Antarct. Sci. 25, 545-552 (2013).

67. Binelli, A., Ricciardi, F., Riva, C. \& Provini, A. New evidences for old biomarkers: Effects of several xenobiotics on EROD and AChE activities in Zebra mussel (Dreissena polymorpha). Chemosphere 62, 510-519 (2006).

68. Faria, M. et al. Multi-biomarker responses in the freshwater mussel Dreissena polymorpha exposed to polychlorobiphenyls and metals. Comp. Biochem. Physiol. Part C Toxicol. Pharmacol. 149, 281288 (2009).

69. Kumar, K. S. et al. Polychlorinated dibenzo-p-dioxins, dibenzofurans and polychlorinated biphenyls in polar bear, penguin and south polar skua. Environ. Pollut. 119, 151-161 (2002).

70. Poulsen, A. H., Kawaguchi, S., King, C. K., King, R. A. \& Bengtson Nash, S. M. Behavioural sensitivity of a key Southern Ocean species (Antarctic krill, Euphausia superba) to p,p'-DDE exposure. Ecotoxicol. Environ. Saf. 75, 163-170 (2012).

71. Poulsen, A. H., Landrum, P. F., Kawaguchi, S. \& Bengtson Nash, S. M. Dietary exposure of Antarctic krill to p,p'-DDE: Uptake kinetics and toxicological sensitivity in a key polar species. Environ. Pollut. 175, 92-99 (2013).

72. Poulsen, A. H., Kawaguchi, S., Leppänen, M. T., Kukkonen, J. V. K. \& Bengtson Nash, S. M. Altered developmental timing in early life stages of Antarctic krill (Euphausia superba) exposed to p,p'-DDE. Sci. Total Environ. 409, 5268-5276 (2011).

73. Gioia, R. et al. Polychlorinated Biphenyls (PCBs) in Air and Seawater of the Atlantic Ocean: Sources, Trends and Processes. Environ. Sci. Technol. 42, 1416-1422 (2008).

74. Van den Berg, M. et al. The 2005 World Health Organization reevaluation of human and Mammalian toxic equivalency factors for dioxins and dioxin-like compounds. Toxicol. Sci. 93, 223-41 (2006).

75. Koop, J. H. E., Winkelmann, C., Becker, J., Hellmann, C. \& Ortmann, C. Physiological indicators of fitness in benthic invertebrates: a useful measure for ecological health assessment and experimental ecology. Aquat. Ecol. 45, 547-559 (2011).

76. Fountain, A. G. et al. The Impact of a Large-Scale Climate Event on Antarctic Ecosystem Processes. Bioscience 66, 848-863 (2016).

77. Henley, S. F. et al. Variability and change in the west Antarctic Peninsula marine system: Research priorities and opportunities. Prog. Oceanogr. 173, 208-237 (2019).

78. Parkinson, C. L. A 40-y record reveals gradual Antarctic sea ice increases followed by decreases at rates far exceeding the rates seen in the Arctic. Proc. Natl. Acad. Sci. U. S. A. 116, 14414-14423 (2019).

79. Zemp, M. et al. Global glacier mass changes and their contributions to sea-level rise from 1961 to 2016. Nature 568, 382-386 (2019).

80. Marzeion, B., Jarosch, A. H. \& Hofer, M. Past and future sea-level change from the surface mass balance of glaciers. Cryosph. 6, 1295-1322 (2012).

81. Davies, B. J., Carrivick, J. L., Glasser, N. F., Hambrey, M. J. \& Smellie, J. L. Variable glacier response to atmospheric warming, northern Antarctic Peninsula, 1988-2009. Cryosph. 6, 10311048 (2012).

82. Rignot, E. et al. Four decades of Antarctic Ice Sheet mass balance from 1979-2017. Proc. Natl. Acad. Sci. U. S. A. 116, 1095-1103 (2019).

83. Cook, A. J., Fox, A. J., Vaughan, D. G. \& Ferrigno, J. G. Retreating glacier fronts on the Antarctic Peninsula over the past half-century. Science 308, 541-4 (2005).

84. Tedesco, L., Vichi, M. \& Scoccimarro, E. Sea-ice algal phenology in a warmer Arctic. Sci. Adv. 5, eaav4830 (2019). 
85. Mangoni, O. et al. Phytoplankton blooms during austral summer in the Ross Sea, Antarctica: Driving factors and trophic implications. PLoS One 12, e0176033 (2017).

86. Deppeler, S. L. \& Davidson, A. T. Southern Ocean Phytoplankton in a Changing Climate. Front. Mar. Sci. 4, 40 (2017).

87. Kim, H. et al. Inter-decadal variability of phytoplankton biomass along the coastal West Antarctic Peninsula. Philos. Trans. R. Soc. A Math. Phys. Eng. Sci. 376, 20170174 (2018).

88. Käse, L. \& Geuer, J. K. Phytoplankton Responses to Marine Climate Change $\$ An Introduction. in YOUMARES 8 - Oceans Across Boundaries: Learning from each other 55-71 (Springer International Publishing, 2018). doi:10.1007/978-3-319-93284-2_5

89. Harris, T. \& Smith, V. Do persistent organic pollutants stimulate cyanobacterial blooms? Inl. Waters 6, 124-130 (2016).

90. Barnes, D. K. A., Fleming, A., Sands, C. J., Quartino, M. L. \& Deregibus, D. Icebergs, sea ice, blue carbon and Antarctic climate feedbacks. Philos. Trans. R. Soc. A Math. Phys. Eng. Sci. 376, 20170176 (2018).

91. Ashton, G. V., Morley, S. A., Barnes, D. K. A., Clark, M. S. \& Peck, L. S. Warming by $1^{\circ} \mathrm{C}$ Drives Species and Assemblage Level Responses in Antarctica's Marine Shallows. Curr. Biol. 27, 2698 2705.e3 (2017).

92. Clarke, A. et al. Climate change and the marine ecosystem of the western Antarctic Peninsula. Philos. Trans. R. Soc. Lond. B. Biol. Sci. 362, 149-66 (2007).

93. Siegert, M. et al. The Antarctic Peninsula Under a $1.5^{\circ} \mathrm{C}$ Global Warming Scenario. Front. Environ. Sci. 7, 102 (2019).

94. Gonzalez, S. \& Fortuny, D. How robust are the temperature trends on the Antarctic Peninsula? Antarct. Sci. 30, 322-328 (2018).

95. Venables, H. A. B. P. H. M. M. Rothera Time Series - Project - British Antarctic Survey. (1997). Available at: https://www.bas.ac.uk/project/rats/\#about. (Accessed: 9th May 2019)

96. Martyniuk, C. J. \& Simmons, D. B. Spotlight on environmental omics and toxicology: a long way in a short time. Comp. Biochem. Physiol. Part D Genomics Proteomics 19, 97-101 (2016).

97. Ge, Y. et al. Environmental OMICS: Current Status and Future Directions. J. Integr. OMICS 3, (2013).

98. Koppel, D. J., Adams, M. S., King, C. K. \& Jolley, D. F. Chronic toxicity of an environmentally relevant and equitoxic ratio of five metals to two Antarctic marine microalgae shows complex mixture interactivity. Environ. Pollut. 242, 1319-1330 (2018).

99. Porta, M. \& Zumeta, E. Implementing the Stockholm Treaty on Persistent Organic Pollutants. Occup. Environ. Med. 59, 651-2 (2002).

100. Derek C. G. Muir \& Howard, P. H. Are There Other Persistent Organic Pollutants? A Challenge for Environmental Chemists†. (2006). doi:10.1021/ES061677A

101. Vento, S. Del, Halsall, C., Gioia, R., Jones, K. \& Dachs, J. Volatile per- and polyfluoroalkyl compounds in the remote atmosphere of the western Antarctic Peninsula: an indirect source of perfluoroalkyl acids to Antarctic waters? Atmos. Pollut. Res. 3, 450-455 (2012).

102. Casà, M. V., van Mourik, L. M., Weijs, L., Mueller, J. \& Nash, S. B. First detection of short-chain chlorinated paraffins (SCCPs) in humpback whales (Megaptera novaeangliae) foraging in Antarctic waters. Environ. Pollut. 250, 953-959 (2019).

103. Lacerda, A. L. d. F. et al. Plastics in sea surface waters around the Antarctic Peninsula. Sci. Rep. 9, 3977 (2019).

104. Bessa, F. et al. Microplastics in gentoo penguins from the Antarctic region. Sci. Rep. 9, 14191 (2019).

105. Waller, C. L. et al. Microplastics in the Antarctic marine system: An emerging area of research. Sci. Total Environ. 598, 220-227 (2017).

106. Gallo, F. et al. Marine litter plastics and microplastics and their toxic chemicals components: the need for urgent preventive measures. Environ. Sci. Eur. 30, 13 (2018).

107. Bakir, A., Rowland, S. J. \& Thompson, R. C. Enhanced desorption of persistent organic pollutants from microplastics under simulated physiological conditions. Environ. Pollut. 185, 16-23 (2014). 


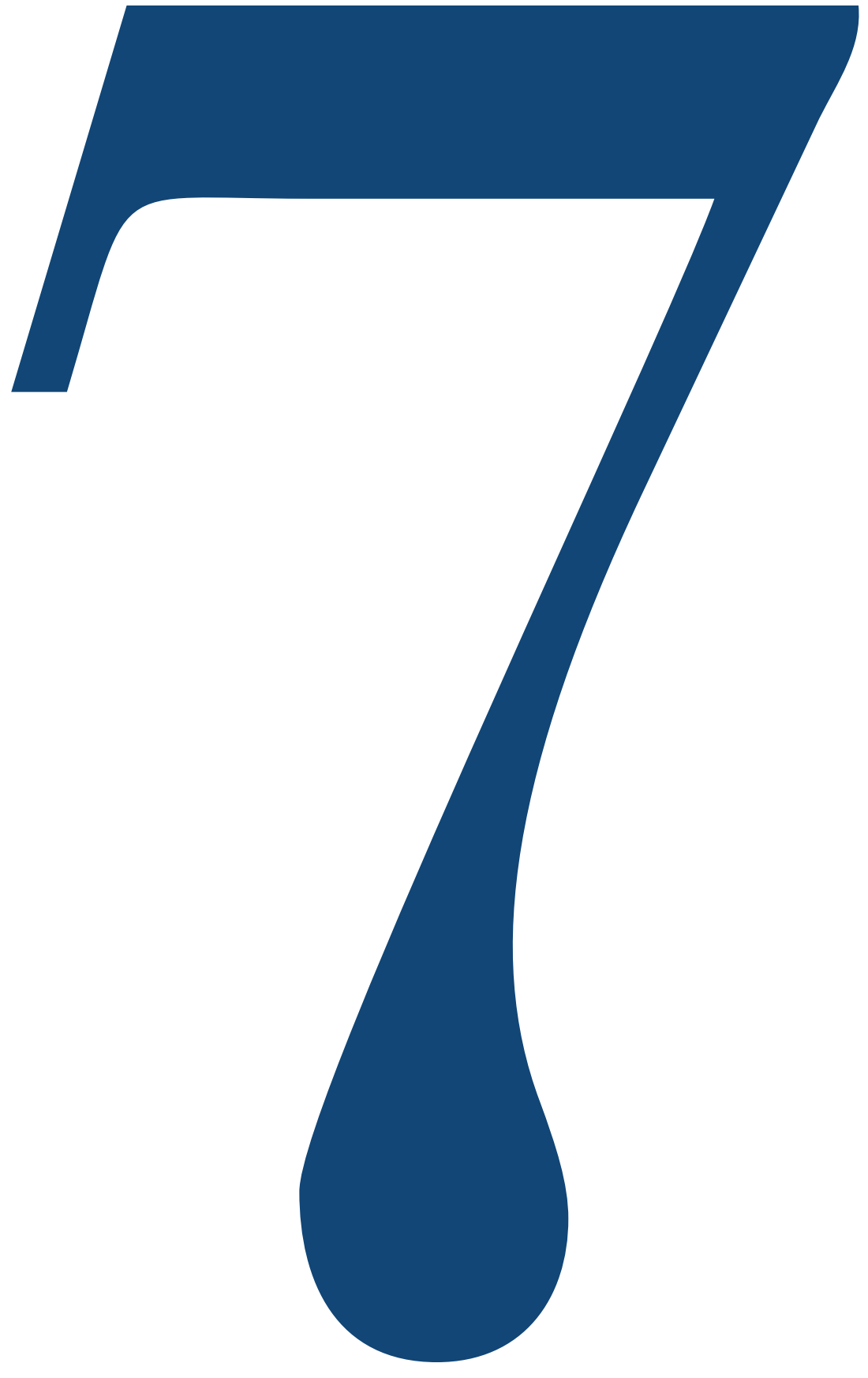




\section{Chapter 7}

Summary 


\section{SUMMARY}

Marine benthic ecosystems are considered to be the final sink of persistent organic pollutants (POPs). Antarctica is a global net receptor of POPs, therefore, quantification of fluxes of POPs to and in the Antarctic benthic ecosystems, although practically difficult, is essential to understand the overall dynamics of these contaminants on a global scale. In order to achieve that, Antarctic benthic ecosystems must be studied as an integral part of the Antarctic environment as a whole. Furthermore, robust quality assurance and reporting practices are needed to establish comprehensive time trends of these pollutants, especially due to their expected relatively low concentrations. Current thesis is one of the first attempts to assess fluxes of POPs to benthic Antarctic ecosystems.

Chapter 2 examined concentrations of POPs in two species of the pelagic flying migratory birds. While levels of some POPs (e.g. HCB) were lower than in past studies on similar species, others were within the previous range (PCBs) or even higher than previously reported (DDE, $\mathrm{HCH}$ ). Thus, these species may be still exposed to and accumulate POPs in both Antarctica and South America. Although no major interspecific differences in the absolute levels of POPs were detected, their profiles varied, being likely related to specific feeding and migration patterns of each species.

Chapter 3 was one of the very few studies on concentrations of POPs in the particulate matter of marine Antarctic water. Moreover, it was the first effort to estimate their seasonal and depth-related variations. All examined POPs reached their highest concentrations just after the melt of the sea ice cover and promptly started to decrease during the mixing of the fresh melt water and sea water. Later in the season the decrease was linked to the gradual settling down of POPs with the organic matter, which was enhanced by the plankton blooms. Total concentrations of PCBs and OCPs were comparable to the ones reported previously, while PBDEs were found in the Antarctic water for the first time. The higher chlorinated PCB congeners were detected only immediately after the sea ice melt, while later in the season PCBs were predominantly represented by lighter congeners. In contrast, no patterns in relative concentrations of PBDEs were detected, which was most likely linked to their atmospheric inputs. The most abundant OCP was $\mathrm{HCH}$-alpha, which confirmed previously detected importance of this chemical in the Antarctic marine system.

Chapter 4 was the first comprehensive study on concentrations of POPs in benthic invertebrates. Overall, the concentrations in these animals were lower than indicated in the previous studies, which may be explained by the characteristics of the measurements in the latter. The highest concentrations of POPs detected were in limpets and sea urchins, followed by sea stars, ascidians and sea cucumbers. In all the species the concentrations of these compounds could be explained by the combination of the physico-chemical characteristics 
of POPs and the specific traits of the species. At the same time, certain patterns (for example, in accumulation of PBDEs) may have been more dependent on concentrations in water from the chapter 3 than on purely benthic-related factors. Thus, the fluxes of POPs in the benthic ecosystems were also controlled by the pelagic biogeochemical processes, which underlines the complexity of these fluxes in Antarctica.

An intrinsic part of this thesis was an ecotoxicological study of the effects of PCB exposure on the Antarctic limpets (chapter 5). It was previously theorised that the Antarctic species may be more vulnerable to POPs than their counterparts from the temperate regions. However, the results of this chapter could not validate this hypothesis. Despite many uncertainties, the changes in lipid profiles of the limpets induced by the PCB exposure demonstrated similar patterns as in the species from the temperate areas and vertebrates. Because actual exposure levels of PCBs in the Antarctic benthic ecosystems were found to be much lower than the ones used in the experiment (chapter 4), it is not likely that the current concentrations of $\mathrm{PCBs}$ present a toxicological risk to the local benthic environment.

No difference between concentrations of POPs collected in the direct vicinity of the Rothera research station or further away were detected either in water (Chapter 3) or in invertebrates (Chapter 4). This means that the environmental protection measures employed by the British Antarctic Survey are more than adequate.

The major outcome of the study is the conformation of the hypothesis on potentially increasing concentrations of POPs in the benthic ecosystems. Simultaneously, the concentrations of POPs in the pelagic ecosystems may have also stopped decreasing, which was previously indicated. Nevertheless, the fluxes of POPs and, possibly, their toxicological effects on the Antarctic benthic animals will undergo considerable changes in the future due to global change, which must be researched further in detail. 


$$
\mathrm{A}
$$


Appendix 

Acknowledgment 
Writing this in early May 2020 may trigger the author to start with a full remark about how bizarre it feels to do amid a global pandemic. An ample introduction with pseudo-sinister, but ultimately optimistic overtones of how the world will be changed by this force of nature. However, it is not purely a force of nature. Just like pollution of Antarctica, the pandemic is a manifestation of complex interactions between nature and humans, at the beginning harmful only for the former, but in the end also for the letter. At the same time, just like researching Antarctic pollution could not have been possible without dedicated help from the people mentioned below, the pandemic will be stopped by everyone's consideration and empathy. And science.

I would like to thank my supervisor Nico for giving me an opportunity to work on such a fascinating topic, your approachability and constant feedback.

Thank you Ivonne for being my promotor. Although we have not had many discussions, your input has always been sharp, valuable, and fast (especially during the last stage of my work). Also thank you Jacques for the NMR measurements and your inputs.

A great thanks to my co-supervisors across the channel in Cambridge. Lloyd, Simon, Hugh - thanks for your high-quality feedback and support for all stages of my project. Lloyd, it has always been a pleasure to talk to you about matters other science. Simon, it was a great experience working with you during the limpet experiment.

I was lucky to meet many brilliant and diligent people through my work with the British Antarctic Survey in Antarctica and in Cambridge.

I must thank the whole Rothera Marine Team and, first of all, our boating officers Paul, Zach and especially Adam for their super-hard work to make our research possible despite sometimes horrendous (and it is not an understatement) sea and weather conditions. Adam, thanks for saving HNLMSS Royal Corinthian after she ran aground. Same goes for our diving officers, especially Kate and Zoë (also for your story of pigeons being a valuable source of protein). Another important group of people are the generator mechanics, who not only prevented us from freezing, but also provided and serviced the power supply of our sampling system. Saz and Ali M., many thanks for providing your support for literally every part of our filed work.

Because an Antarctic station is essentially a small city by itself, I must thank all the people keeping it alive: chefs, electricians, plumbers, station support, vehicle mechanics, general assistants, and field guides. Thanks to doctors for looking after our health, and thanks to pilots and air mechs for flying us (it was great to be a co-pilot on several flights). Thanks to the crew and the engineers of RRS Jack Clark Ross and RRS Ernest Shackleton for helping onboard. 
Thanks to other people who made my live in Antarctica a truly great experience: Emma, Gemma, Alison, Jacqueline, Maria, Stef. Joe, it was great to work with you at Fossil Bluff forward station. It was nice to see that after devolving (or evolving, matter of perspective) our conversations to grunts and comms slang we could understand each other quite well. Tom, thanks for your optimism and positive attitude.

Of course, I thank you all research assistants that worked with me in Antarctica: Melvin, David and Emily. David, I wish you best with your own PhD project. Emily, I hope your work with marine life continues to bring you joy.

Thanks to everyone who made my time in Cambridge great (again and again). Thanks to the stuff of BAS who helped with my lab experiments: Paul, Guy and especially Becs who looked after my lab animals while I was not around. Thanks to my officemates for having much fun and creating really nice atmosphere. George, please eat not only nuts. Leyre, thanks for your positive no-nonsense altitude (coming back from Rothera) and your willingness to help.

Alex, the proud master of the Boaty McBoatface, thanks for your long support and friendship, both in Antarctica and in Cambridge. I have always felt welcome when I needed crush at your house in Cambridgeshire. I have been confident that if things go tremendously south, I could count on you.

In the Netherlands, thanks to everyone from WFSR who helped me with the analytical part of my project: Stefan S., Guido, Willi, Cornelis, Edwin, Rita. You all provided invaluable inputs for the analytical procedures and GCMS measurements. Stefan, thanks for managing my work and providing constructive feedback.

Guillaume, it would literally take me a whole page to list all the things I must acknowledge you for. I shall restrain myself to mentioning your help with the development of analytical techniques, your vigorous quality assurance of all my data, and just being an absolutely greatest friend. I definitely would not have been able to finish the project without you. Thanks!!

First among the TOX people I want to thank my wonderful officemates: Chen, Mengying and Annelies. Chen, best wishes to your (new) family. Mengying, I hope that despite current uncertainties you will successfully continue your carrier in Belgium. Annelies, first, thanks for finding my laptop in Tokyo (yes, I remember that) and, second, being such a compassionate friend. Menno, you were not my officemate, but given amount of time I spent in your office it certainly felt that way. I wish you to retain your dzen and finish your $\mathrm{PhD}$. Diego, the very best for your defence, too. 
Many thanks to TOX technicians who helped with my work. Laura, thanks for your positivity. Without you half of us would be permanently burned out and the other half would be in a catatonic state. Hans, thank you for organising the logistics and EROD measurements. Sebas and Bert, thanks for your support when I often came asking for a new chemical asap. Bert, I hope you enjoy your retirement very much. Last, but not the least: Lidy, thank you for constant support and battling bureaucracy on our behalf.

Thanks to other (former and current) PhDs of TOX: Veronique, Maartje, Miaoying, Sunday, Amer, Abdul, Samantha, Jonathan, Karsten, Ixchel, Diana, Georgia, Danlei, Jing, Georgia, Biyao and everyone else.

Thanks to my friends and former colleagues from Zurich. Tobi, thanks for helping me with moving to the Netherlands in the first place - so I could actually do this project. Jana, thanks for inspiring me to do and more importantly finish a $\mathrm{PhD}$.

A great thanks to my Berlin friends, who made my every visit special and delightful. Antje, I sure you will get the Award. Julie, thanks for sharing the Berlin sky, and all the best for finishing your own $\mathrm{PhD}$. Lena, I am incredibly grateful for your mentorship of my coding skills. Without it my life would have been much sadder.

Nina, thank you for everything.

Marie-Louise and Margriet, thanks for helping me to look at my project in a different way. Katya and Glasha, thanks for making my trips back to Moscow memorable. Peter, thanks for being a good friend. I will definitely visit Pennsylvania.

As perhaps any other person, during the last years I have met (even very briefly) certain people, whom I may never see again, but who have influenced me and formed myself into who I am now. Thank you, too.

Finally, thanks to my mum, my dad and my grandparents for helping me throughout my life. 
Biography 
Artem V. Krasnobaev was born in Moscow on the $1^{\text {st }}$ of June 1990. After finishing his BSc in environmental sciences with specialization in biogeochemistry at the Moscow State University, he completed his MSc studies in Environmental Engineering at the ETH Zurich in Switzerland. After a number of internships in the field of Material science he moved to the Netherlands to pursue a PhD degree at the University of Wageningen and the British Antarctic Survey in Cambridge in the UK. During his broad career he spent a lot of time in field expeditions in remote areas of the world. 
List of publications 


\section{THIS THESIS}

Artem Krasnobaev, Guillaume ten Dam, Stefan P.J. van Leeuwen, Lloyd S. Peck, Nico W. van den Brink. Persistent Organic Pollutants in two species of migratory birds from Rothera Point, Adelaide Island, Antarctica. Mar Pollut Bull. 2018 Dec;137:113-118.

Artem Krasnobaev, Guillaume ten Dam, Rita Boerrigter-Eenling, Stefan P.J. van Leeuwen, Simon A. Morley, Lloyd S. Peck, Nico W. van den Brink. Seasonal variability in concentrations of Persistent Organic Pollutants in the particulate phase of marine water near Rothera Point, Western Antarctic Peninsula. (to be submitted).

Artem Krasnobaev, Guillaume ten Dam, Rita Boerrigter-Eenling, Fang Peng, Stefan P.J. van Leeuwen, Simon A. Morley, Lloyd S. Peck, Nico W. van den Brink. Legacy and emerging Persistent Organic Pollutants in Antarctic benthic invertebrates near Rothera Point, Western Antarctic Peninsula. Environ. Sci. Technol. 2020, 54, 5, 2763-2771.

Artem Krasnobaev, Guillaume ten Dam, Stefan P.J. van Leeuwen, Simon A. Morley, Lloyd S. Peck, Hans van den Berg, Jacques Vervoort, Nico W. van den Brink. Effects of exposure of the Antarctic limpet Nacella concinna to Polychlorinated Biphenyls (PCBs). (to be submitted)

\section{OTHER PUBLICATIONS}

Jana S. Segmehl, Tobias Keplinger, Artem Krasnobaev, John K. Berg, Christoph Willa, Ingo Burgert. Facilitated delignification in CAD deficient transgenic poplar studied by confocal Raman spectroscopy imaging. Spectrochimica Acta Part A Molecular and Biomolecular Spectroscopy. 2019, 206, 177-184 


\section{SENSE}

Netherlands Research School for the

Socio-Economic and Natural Sciences of the Environment

\section{I P L O M A}

for specialised PhD training

The Netherlands research school for the Socio-Economic and Natural Sciences of the Environment

(SENSE) declares that

\section{Artem Krasnobaev}

born on 1 June 1990 in Moscow, USSR

has successfully fulfilled all requirements of the educational PhD programme of SENSE.

Wageningen, 16 June 2020

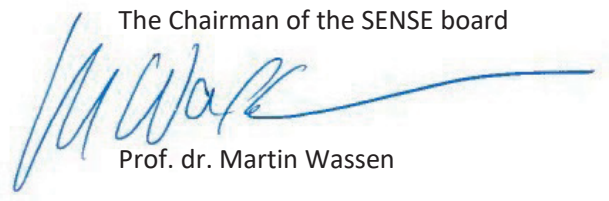

the SENSE Director of Education

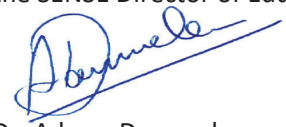

Dr. Ad van Dommelen

The SENSE Research School has been accredited by the Royal Netherlands Academy of Arts and Sciences (KNAW)

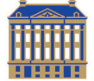

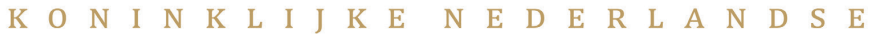

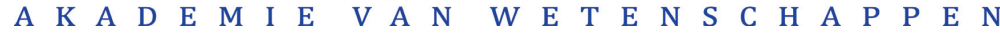




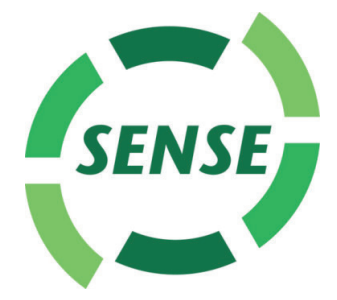

The SENSE Research School declares that Artem Krasnobaev has successfully fulfilled all requirements of the educational PhD programme of SENSE with a work load of $32.5 \mathrm{EC}$, including the following activities:

\section{SENSE PhD Courses}

- Environmental research in context (2018)

- Research in context activity: 'Organizing and participating in creativity exchange programme between art students and PhD students: Bringing Science and Art Together' (2018)

\section{Other PhD and Advanced MSc Courses}

- Hands-on Complete Gas chromatography \& Gas chromatography-mass spectrometry, Open University, United Kingdom (2015)

- Molecular Toxicology, University of Amsterdam (2016)

- Mass Spectral Interpretation, Open University, United Kingdom (2016)

- Entrepreneurship in and outside Science, Wageningen Graduate Schools (2017)

- PCDI course Employability (2017)

\section{External training at a foreign research institute}

- Preparatory courses for working in remote and offshore areas, Wageningen University and British Antarctic Survey (2015)

\section{Management and Didactic Skills Training}

o Supervising three research assistants involved in Antarctic research (2015-2017)

\section{Oral Presentations}

- Gender equality in Antarctic Research, WUR PhD Symposium, 3 May 2016, Wageningen, The Netherlands

- FluxPOPs: POPs in Western Antartica, British Antarctic Survey PhD days, 10 July 2016, Cambridge, United Kingdom

- POPs in Antartic benthic invertibrates, SETAC North America, 4-8 November 2018, Sacramento, United States of America

SENSE coordinator PhD education

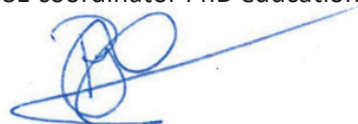

Dr. ir. Peter Vermeulen 
The research described in this thesis was financed by Netherlands Organisation for Scientific Research (NWO) (grant no. 866.14.104).

Financial support from Wageningen University for printing this thesis is gratefully acknowledged.

Cover design: Marie-Louise J. Schmidlin

Lay-out: RON Graphic Power \| www.ron.nu

Printed by: ProefschriftMaken || www.proefschriftmaken.nl 


